\title{
Summaries of FY 1996 Geosciences Research
}

December 1996
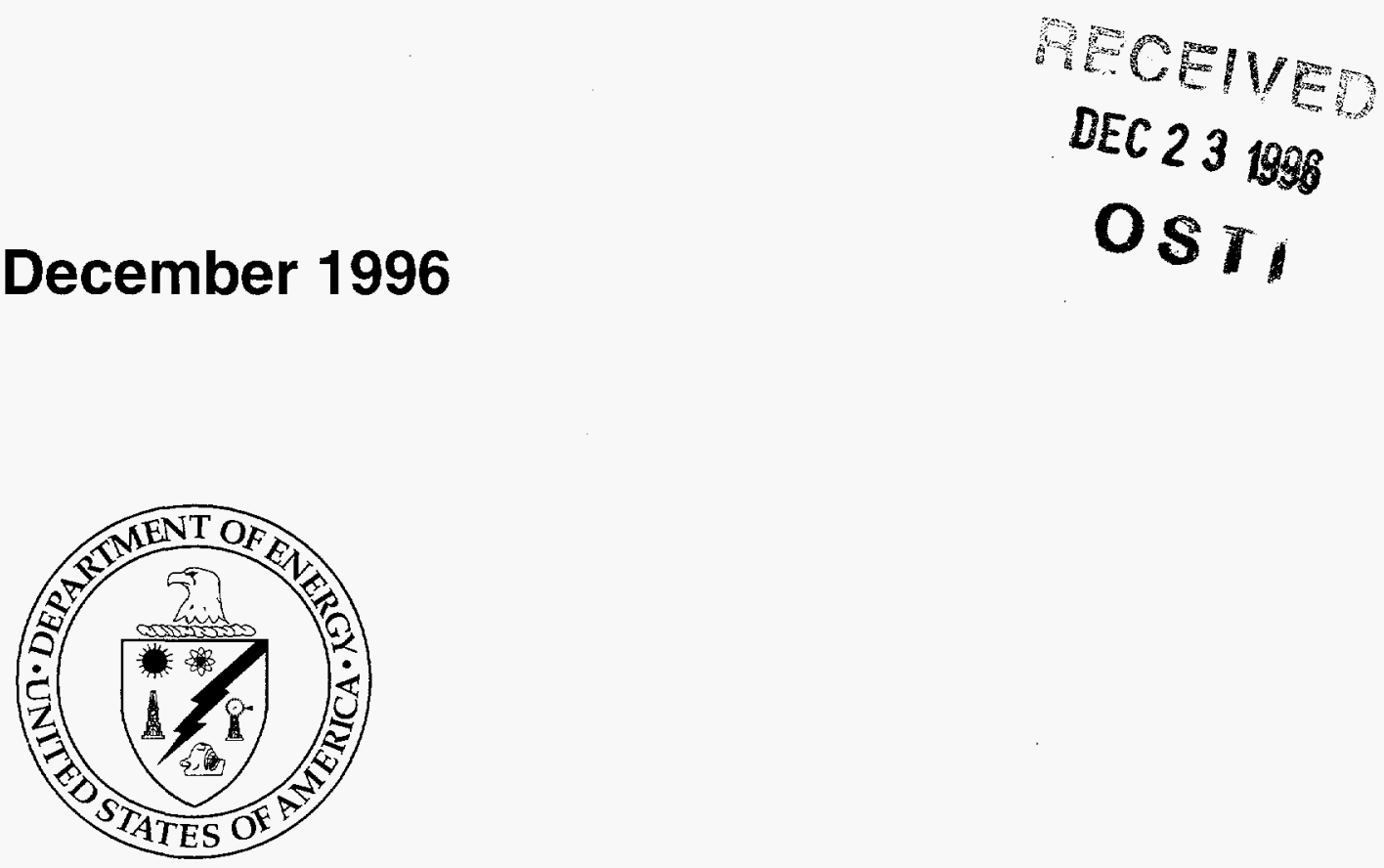

U.S. Department of Energy

Office of Energy Research Office of Basic Energy Sciences Division of Engineering and Geosciences Germantown, MD 20874 


\section{DISCLAIMER}

This report was prepared as an account of work sponsored by an agency of the United States Government. Neither the United States Government nor any agency thereof, nor any of their employees, makes any warranty, express or implied, or assumes any legal liability or responsibility for the accuracy, completeness, or usefulness of any information, apparatus, product, or process disclosed, or represents that its use would not infringe privately owned rights. Reference herein to any specific commercial product, process, or service by trade name, trademark, manufacturer, or otherwise does not necessarily constitute or imply its endorsement, recommendation, or favoring by the United States Government or any agency thereof. The views and opinions of authors expressed herein do not necessarily state or reflect those of the Untied States Government or any agency thereof.

This report has been reproduced directly from the best available copy.

Available to DOE, DOE Contractors, and the public from the U.S. Department of Energy, Office of Basic Energy Sciences, Engineering and Geosciences Division, Germantown, MD (301) 903-5822. 


\section{Summaries of FY 1996 Geosciences Research}

December 1996

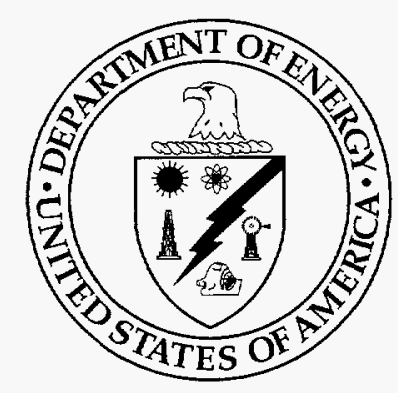

U.S. Department of Energy

Office of Energy Research

Office of Basic Energy Sciences

Division of Engineering and Geosciences Germantown, MD 20874 



\section{CONTENTS}

FOREWORD

THE GEOSCIENCES RESEARCH PROGRAM IN THE OFFICE

OF BASIC ENERGY SCIENCES

Xvi

PART 1 -- ON-SITE

ARGONNE NATIONAL LABORATORY 3

Geochemistry 3

A. Mineral-Fluid Interactions: Experimental Determination of Atomic-Scale

Processes Using Synchrotron Radiation 3

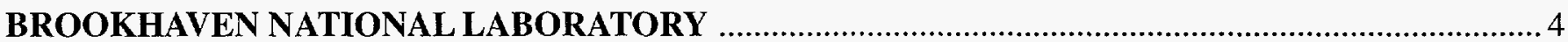

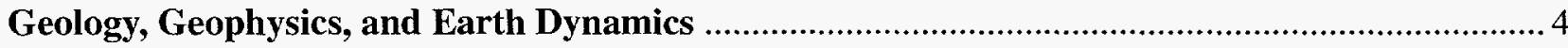

A. Measurement of Fluid Flow and Fluid-Rock Interactions

Using Synchrotron Computed Microtomography ............................................................. 4

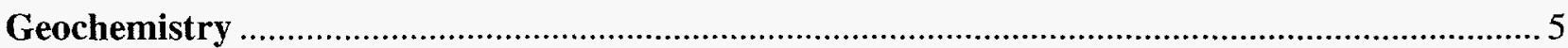

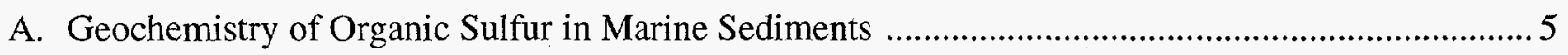

B. Sulfur Speciation in Sedimentary Macromolecular Organic

Matter by X-Ray Absorption Spectroscopy - Collaborative Project

with Woods Hole Oceanographic Institution

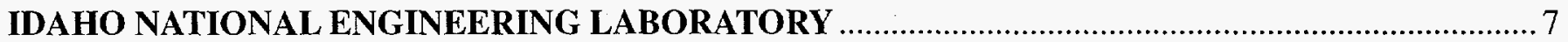

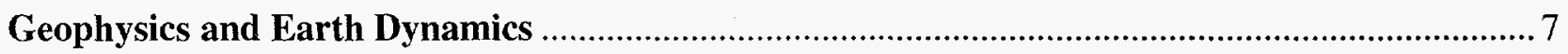

A. Frictional Process Zones in Compressive Fracture …....................................................... 7

LAWRENCE BERKELEY NATIONAL LABORATORY ….........................................................

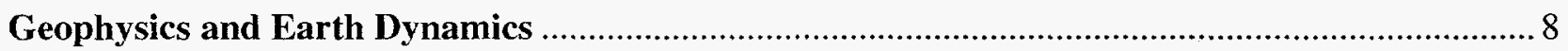

A. High-Resolution Imaging of Electrical Conductivity Using

Low-Frequency Electromagnetic Fields ............................................................. 8

B. Effects of Heterogeneity on the Mechanical Properties of Rock .................................................. 9 


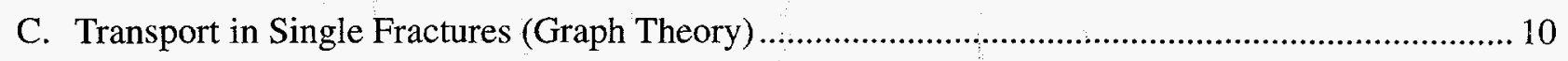

D. Energy Partitioning of Seismic Waves in Fractured Rock ...................................................... 10

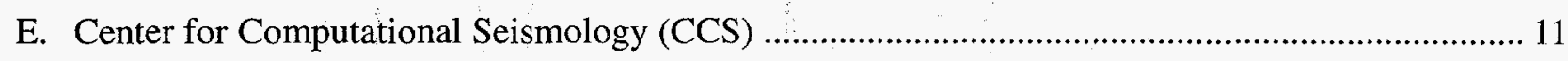

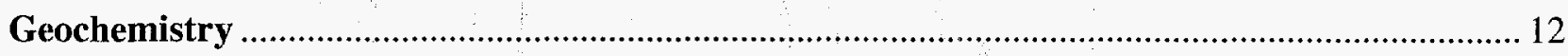

A. Integrated Isotopic Studies of Geochemical Processes ......................................................... 12

B. Calorespirometry: A New Approach to Quantify Pollutant Reactions

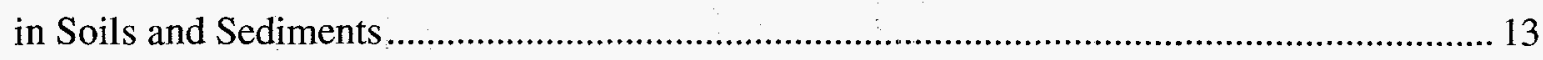

C. Isotopic and Chemical Composition of Fault Zone Fluids ..................................................... 14

D. Uses of Synchrotron X-Ray Methods in Earth Sciences Research

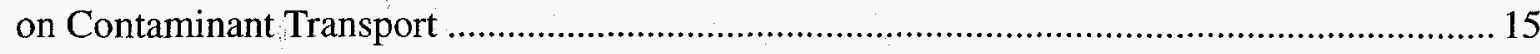

E. Thermodynamics of High Temperature Brines ...................................................................... 16

Energy Resource Recognition, Evaluation and Utilization ............................................... 16

A. Russian-American Contaminant Transport Studies …................................................... 16

B. Transport in Micro-Pore Networks (Graph Theory) ........................................................... 18

C. Development of High-Resolution EM Imaging Methodology ............................................... 18

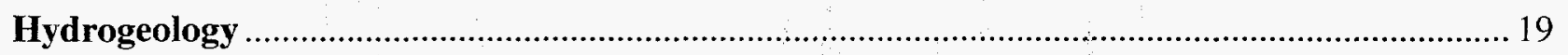

A. Three-Dimensional Hydrogeology of Fault Zones ................................................................. 19

B. Rare Gas Studies of Fluids in the San Joaquin Basin: A Basin Scale

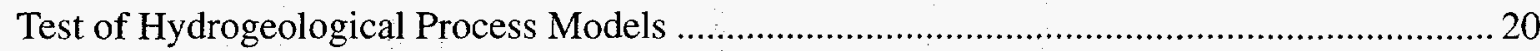

C. Investigation of Groundwater Flow Paths Through Combined Inversion

of Strontium Isotope Ratios and Hydraulic Head Data ................................................... 21

D. Unsaturated Flow and Transport In Porous and Fractured Media ......................................... 22

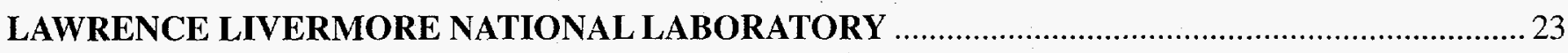

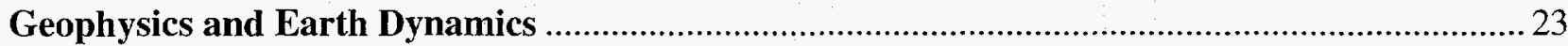

A. Effects of Heterogeneity on the Fracture of Rock ...............................................................23

B. The Role of Carbon and Temperature in Determining Electrical Conductivity

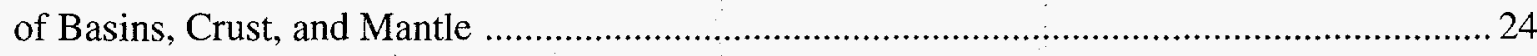

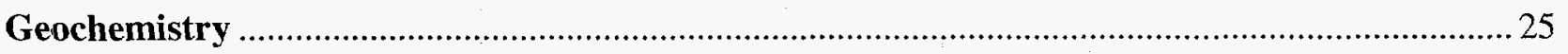

A. Thermodynamic and Transport Properties of Aqueous Geochemical Systems ..........................225 


\section{DISCLAIMIER}

Portions of this document may be illegible in electronic image products. Images are produced from the best available original document. 


\section{DISCLAIMER}

This report was prepared as an account of work sponsored by an agency of the United States Government. Neither the United States Government nor any agency thereof, nor any of their employees, makes any warranty, express or implied, or assumes any legal liability or responsibility for the accuracy, completeness, or usefulness of any information, apparatus, product, or process disclosed, or represents that its use would not infringe privately owned rights. Reference herein to any specific commercial product, process, or service by trade name, trademark, manufacturer, or otherwise does not necessarily constitute or imply its endorsement, recommendation, or favoring by the United States Government or any agency thereof. The views and opinions of authors expressed herein do not necessarily state or reflect those of the United States Government or any agency thereof. 
B. Experimental Determination of Mineralogical Controls on UThPb Redistribution:

Implications for Crust/Mantle Differentiation

C. Uranium, Thorium, Lead, and Oxygen Diffusion in Rock-Forming Minerals:

Implications for Reactive Transport

D. An Experimental Investigation of Mechanisms Controlling Glass Dissolution

E. Mineral Dissolution and Precipitation Kinetics: A Combined Atomic-Scale and Macro-Scale Investigation

Energy Resource Recognition, Evaluation, and Utilization ................................................... 29

A. Linear and Nonlinear Mechanics of Rocks.

B. Velocity Analysis, Parameter Estimation, and Constraints on Lithology for

Transversely Isotopic Sediments 30

C. Compositional Kinetic Modeling of Oil and Gas Formation

LOS ALAMOS NATIONAL LABORATORY 33

Geophysics and Earth Dynamics

A. New Methods for Modeling and Processing Seismic Data (ACTI) ........................................... 33

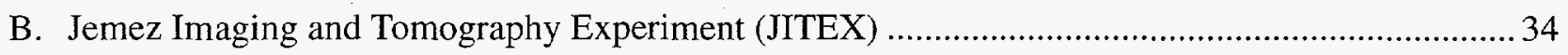

C. The Role of Carbon and Temperature in Determining Electrical Conductivity of Basins, Crust, and Mantle

D. Nonlinear Elasticity Project: Study and Application of Elastic Nonlinear Response (Hysteretic/Discrete Memory) in Earth Materials

Geochemistry

A. High Resolution Uranium-Series Geochronology and Geochemistry 36

B. Dating Young Surfaces Using Cosmogenic He and Ne

Solar-Terrestrial Physics .38

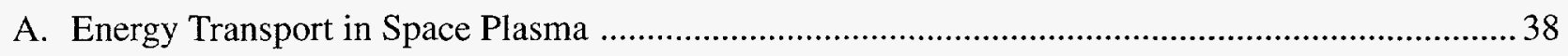

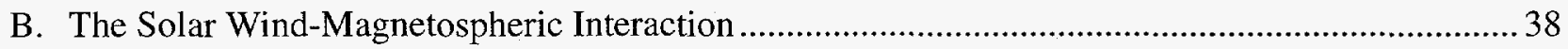

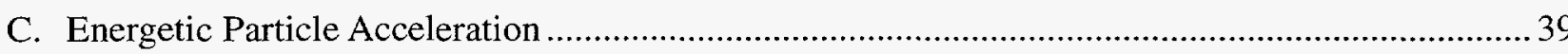


Geochemistry

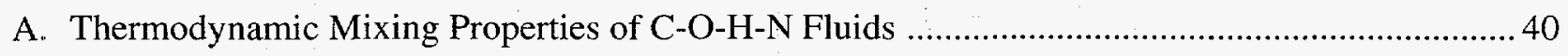

B. Fundamental Research in the Geochemistry of Geothermal Systems .........................................4 41

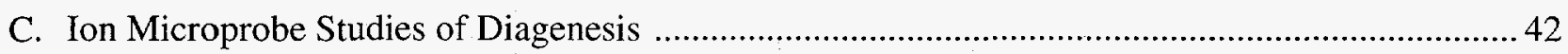

D. Experimental Studies of Fundamental Stable Isotope Exchange Reactions ................................43

E. Potentiometric Studies of Geochemical Processes ............................................................... 44

F. Mechanisms and Rates of Oxygen Isotope Exchange in Mineral-Fluid Systems .......................45

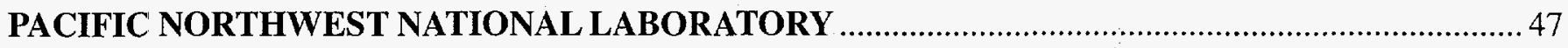

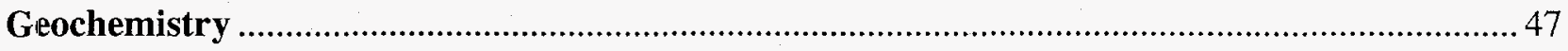

A. Surface Structure and Chemistry of Carbonate Minerals ..................................................... 47

B. Theoretical Characterization of the Physics and Chemistry of Soil Minerals .............................. 48

C. Structure and Reactivity of Ferric Oxide and Oxyhydroxide Surfaces .....................................49

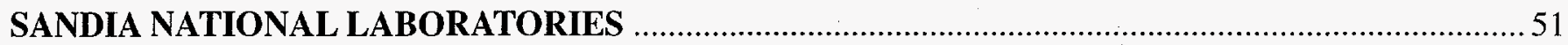

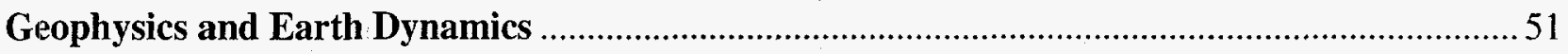

A. Micromechanics of Failure in Brittle Geomaterials ..............................................................5 51

B. Laboratory and Theoretical Analyses of Transport Paths in Single Natural Fractures ..................52

C. Shear Strain Localization and Fracture Evolution in Rocks ...................................................53

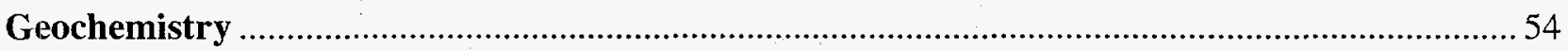

A. Cation Diffusion Rates in Selected Minerals ........................................................................... 54

B. An Investigation of Organic Anion-Mineral Surface Interactions During Diagenesis ................... 55

C. Heterogeneous Nucleation and Growth Kinetics of Clays ....................................................... 55

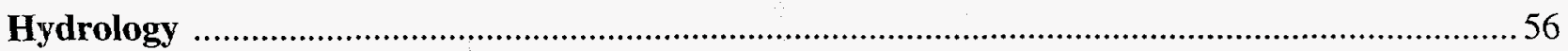

A. Laboratory Investigation of Constitutive Property Upscaling …................................................56

B. Two-Phase Immiscible Fluid Flow in Fractured Rock: The Physics of

Two-Phase Flow Processes in Single Fractures .......................................................... 57

C. Multicomponent Convection in Porous Media and Fractures .................................................. 58 


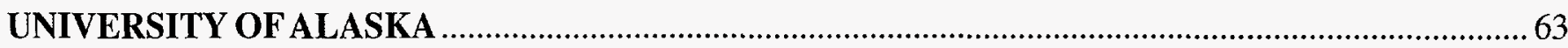

A Study of Solar Prominences and Magnetospheric Substorms ..................................................... 63

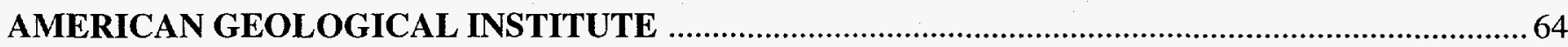

U.S.-Russian Geosciences Student Exchange Program ................................................................ 64

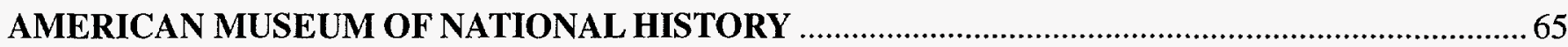

The Effect of Carbon on the Mechanical and Electrical Properties of Rocks ....................................6 65

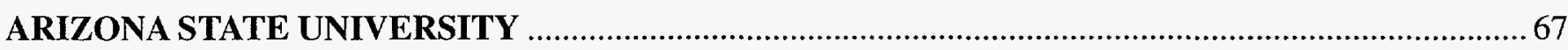

A Microanalytical (SIMS) Study of the Trace Element and Isotopic

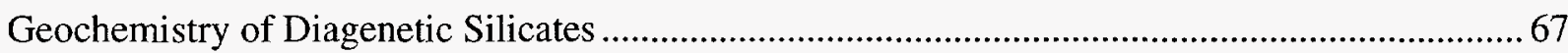

Reaction Mechanisms of Clay Minerals and Organic Diagenesis: An HRTEM/AEM Study ..............68

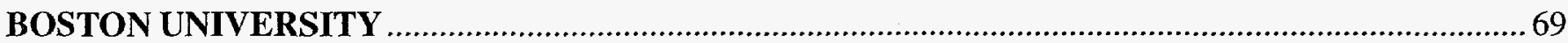

Interpretation of Geodetic Crustal Strains Using Massively Parallel

Supercomputer Simulations of Nonlinear Dynamical Models

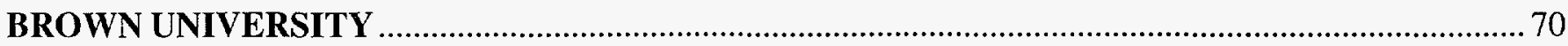

Diffusional Transport and Fluid Connectivity in Mineral Aggregates ............................................ 70

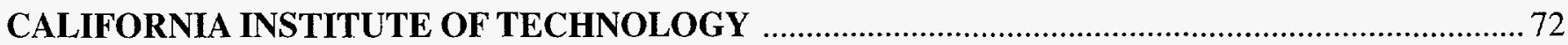

Infrared Spectroscopy and Hydrogen Isotope Geochemistry of Hydrous Silicate Glasses .................. 72

Isotope Tracer Studies of Diffusion in Silicates and of Geological

Transport Process in Aqueous Systems Using Actinide Elements .............................................. 73

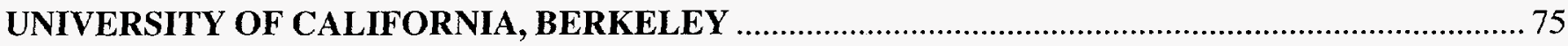

Advective-Diffusive/Dispersive Transport of Chemically Reacting Species

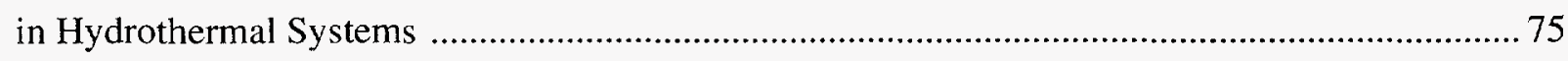

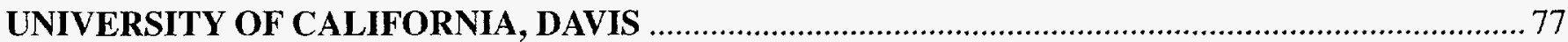

Energetics of Melts from Thermal Diffusion Studies ...................................................................... 77 
A New Method for Determining the Thermodynamic Properties of Carbonate

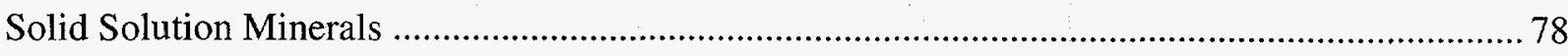

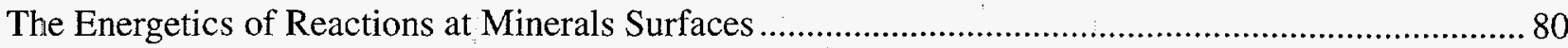

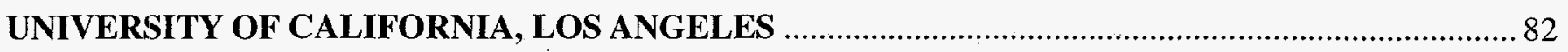

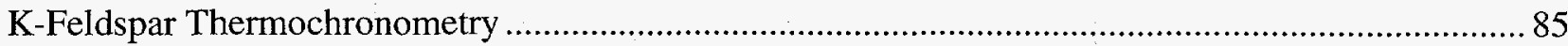

Uranium, Thorium, Lead, and Oxygen Diffusion in Rock-Forming Minerals:

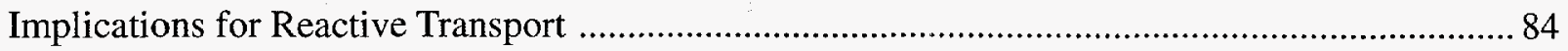

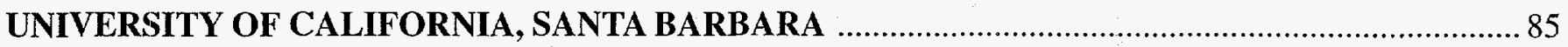

The Hydrodynamics of Geochemical Mass Transport and Clastic Diagenesis:

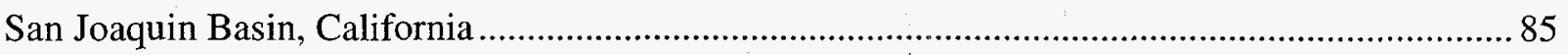

Physical and Experimental Studies of Magma Rheology, Sedimentary Basins, and Molecular Dynamics of Silicates

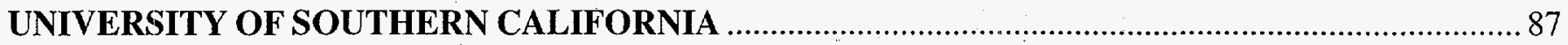

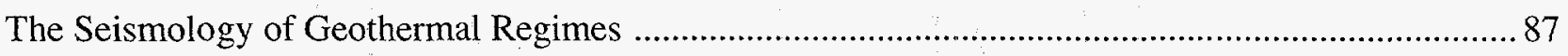

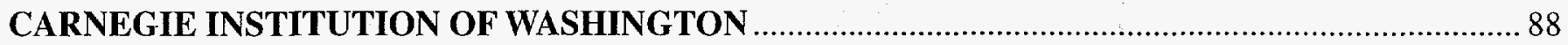

Water-Rock Interaction in the Earth's Upper Mantle: Application of Combined Stable

Isotope and Infrared Spectroscopic Analytical Techniques 88

UNIVERSITY OF CHICAGO 89

GeoCARS: A National Resource for Earth, Planetary, Soil, and Environmental

Science Research at the Advanced Photon Source

Synchrotron X-Ray Microprobe and Microspectroscopy: Technical Development for Advanced

Photon Source Research and Low Temperature Geochemistry Applications ...............................90 90

Experiments and Models for Chemical Diffusion in Silicate Melts ............................................. 91

\section{UNIVERSITY OF COLORADO}

Two-Phase Immiscible Fluid Flow in Fractured Rock: The Physics of Two-Phase

Flow Processes in Single Fractures

Interpretation of Geodetic Crustal Strains Using Massively Parallel Supercomputer

Simulations of Nonlinear Dynamical Models 
Seismic Absorption and Modulus Measurements in Porous Rocks Under Fluid and Gas Flow-Physical and Chemical Effects: A Laboratory Study

Theoretical and Experimental Studies of Hydrological Properties of Rock Fractures

During Active Deformation

COLUMBIA UNIVERSITY

The Distribution in Space and Time of Wet Events in the

Western North American Drylands 98

Energetics of Silicate Melts from Thermal Diffusion Studies

UNIVERSITY OF CONNECTICUT 100

Rare Gas Studies of Fluids in the San Joaquin Basin: A Basin Scale Test

of Hydrogeological Process Models 100

UNIVERSITY OF DELAWARE 102

Development of an Experimental Database and Theories for Prediction of

Thermodynamic Properties of Aqueous Electrolytes and Nonelectrolytes

of Geochemical Significance at Supercritical Temperatures and Pressures 102

DESERT RESEARCH INSTITUTE 104

Multicomponent Convection in Porous Media and Fractures 104

GEORGIA INSTITUTE OF TECHNOLOGY 106

Biomineralization: Organic-Directed Controls on Carbonate Growth Structures and Kinetics Determined by In Situ Atomic Force Microscopy 106

INCORPORATED RESEARCH INSTITUTIONS FOR SEISMOLOGY (IRIS) 108

Acquisition of Equipment for High Resolution Seismic Imaging 108

INDIANA UNIVERSITY 109

Mechano-Chemical Self-Organization and Nonlinear Dynamics in Sedimentary Basins. 109

THE JOHN HOPKINS UNIVERSITY 110

The Hydrodynamics of Geochemical Mass Transport and Clastic Diagenesis:

San Joaquin Basin, California ..... 110 
Predictive Single-Site Protonation and Cation Adsorption Modeling ......................................... 111

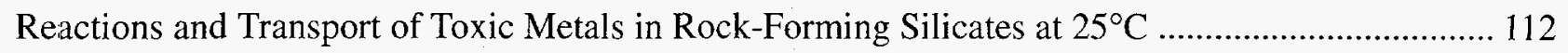

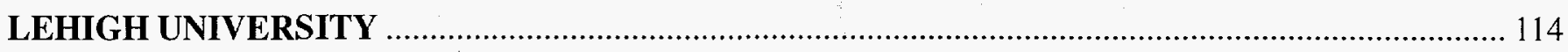

Surface and Solution-Interface Geochemistry of Lead Sulfide and Lead Selenide Minerals ............ 114

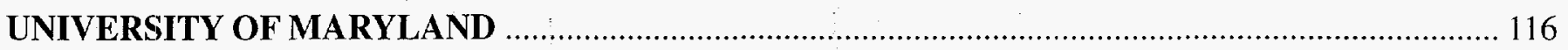

Theoretical Studies of the Adsorption of Gold Complexes and Flotation Collectors

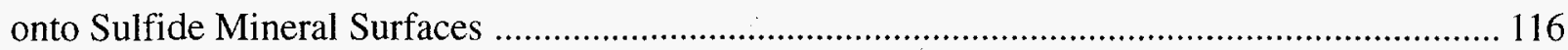

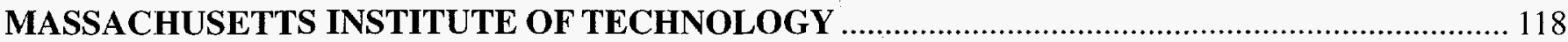

A High-Precision MT Study of the Mid and Lower Crustal San Andreas Fault Zone ..................... 118

Electroseismic Characterization of Lithology and Fluid Type in the Shallow Subsurface................ 119

In Situ Permeability Determination Using Borehole and Seismic Logging Data ........................... 120

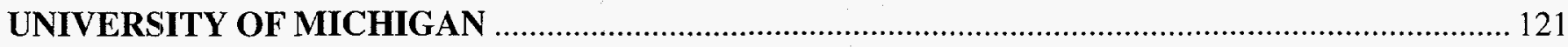

Applications of ICP Magnetic Sector Multicollector Mass Spectrometry to

Basic Energy Research

Combined Noble Gas and Stable Isotope Constraints on Nitrogen Gas Sources Within

Sedimentary Basins

UNIVERSITY OF MINNESOTA, TWIN CITIES 123

Physical and Experimental Studies of Magma Rheology, Sedimentary Basins, and Molecular Dynamics of Silicates

NATIONAL ACADEMY OF SCIENCES/NATIONAL RESEARCH COUNCIL 124

Board on Earth Sciences and Resources, Committee on Seismology,

U.S. Geodynamics Committee

UNIVERSITY OF NEW MEXICO 126

The Crystal Chemistry and Structural Analysis of Uranium Oxide Hydrates

NEW MEXICO INSTITUTE OF MINING AND TECHNOLOGY

Laboratory Investigation of Constitutive Property Upscaling 
Nonlinear Transport and Collective Processes in Heterogenous Media

STATE UNIVERSITY OF NEW YORK AT STONY BROOK

Medial Axis Analysis of Porous Media

Micromechanics of Failure in Brittle Geomaterials

High Precision Radiometric Dating of Sedimentary Materials

NORTHWESTERN UNIVERSITY

Shear Strain Localization and Fracture Evolution in Rocks

UNIVERSITY OF NOTRE DAME

Energy Partitioning of Seismic Waves in Fractured Rocks

UNIVERSITY OF OKLAHOMA

A Study of Hydrocarbon Migration Events: Development and Application of

New Methods for Constraining the Time of Migration and an Assessment of

Rock-Fluid Interactions

OREGON STATE UNIVERSITY

Multi-Station Magnetotellurics

PENNSYLVANIA STATE UNIVERSITY

Dissolution Rates and Surface Chemistry of Feldspar Glass and Crystal

Zeolite Thermodynamics and Kinetics

PRINCETON UNIVERSITY

Thermodynamics of Minerals Stable Near the Earth's Surface

\section{PURDUE UNIVERSITY}

Rupturing and Ground Deformation During the 28 June 1992

Landers, California, Earthquake

RENSSELAER POLYTECHNIC INSTITUTE

Transport Phenomena in Fluid-Bearing Rocks 
Transition Metal Catalysis in the Generation of Petroleum and Natural Gas

STANFORD UNIVERSITY

Cation Chemisorption at Oxide Surfaces and Oxide-Water Interfaces:

X-Ray Spectroscopic Studies and Modeling

Development of Fracture Networks and Clusters: Their Role in Channelized

Flow in Reservoirs and Aquifers

Experimental Investigation of Kinetics and Rheology During Diagenesis

Crosshole Seismic Attenuation Tomography and Attenuation Logging in Boreholes

Induced Seismicity

Porous Reservoir Rocks with Fluids: Acoustic and Reservoir Transport Properties

TEMPLE UNIVERSITY

The Surface Chemistry of Pyrite: An Interdisciplinary Approach

UNIVERSITY OF TENNESSEE

Development of Laser-Based Resonance Ionization Techniques for

${ }^{81} \mathrm{Kr}$ and ${ }^{85} \mathrm{Kr}$ in the Geosciences, II

TEXAS A\&M UNIVERSITY

Mechanical Properties and Modeling of Seal-Forming Lithologies

UNIVERSITY OF TEXAS

Energy Flux and Hydrogeology of Thermal Anomalies in the Gulf of Mexico

Sedimentary Basin - South Texas Example

A Robust Economic Technique for Crosswell Seismic Profiling

UNIVERSITY OF TEXAS AT DALLAS

Sedimentological and Geophysical Studies of Clastic Reservoir Analogs:

Methods, Applications, and Developments of Ground-Penetrating Radar

for Determination of Reservoir Geometries in Near-Surface Settings

U.S. DEPARTMENT OF ENERGY CORE AND SAMPLE REPOSITORY

U.S. Department of Energy, Core and Sample Repository 
Assessing the Role of Active and Ancient Geothermal Processes in Oil-Reservoir

Evolution in the Basin and Range Province

High Resolution Imaging of Electrical Conductivity Using

Low Frequency Electromagnetic Fields

UTAH STATE UNIVERSITY

Three-Dimensional Hydrogeology of Fault Zones

VIRGINIA POLYTECHNIC INSTITUTE AND STATE UNIVERSITY

Geochemical Studies of Fluid Systems

WASHINGTON UNIVERSITY

Development of an Experimental Database and Theories for Prediction of

Thermodynamic Properties of Aqueous Electrolytes and Nonelectrolytes

of Geochemical Significance at Supercritical Temperatures and Pressures

UNIVERSITY OF WASHINGTON

Two- and Three-Dimensional Magnetotelluric and Controlled

Source Electromagnetic Inversion

UNIVERSITY OF WISCONSIN

HRTEM Investigations of Interactions Between Minerals, Fluids, and Lithobiontic

Communities During Natural Weathering 174

Microanalysis of Stable Isotope Ratios in Geothermal Systems: Long Valley and Skye .................. 175

Poroelasticity of Rock

Testing the Correlation Between Seismic Stratigraphy, Diagenesis, and Physical

Rock Properties: Evaluation of Fluid Flow During Early and Late Diagenesis

WOODS HOLE OCEANOGRAPHIC INSTITUTION

Robust, Controlled Leverage Magnetotelluric Data Analysis

Geochemical Incorporation of Sulfur into Organic Matter: Role of Sulfur in the

Formation and Diagenesis of Macromolecular Organic Matter in Sediments 180

Organic Geochemistry of Outer Continental Margins and Deep Water Sediments 182 
Mineral Dissolution and Precipitation Kinetics: A Combined Atomic-Scale and Macro-Scale Investigation

YALE UNIVERSITY

A Field Experiment on Plants and Weathering

Reactive Fluid Flow and Applications to Diagenesis Mineral Deposits, and Crustal Rocks

TOPICAL INDEX

SCIENTIFIC INDEX

INDEX OF TECHNICAL CONTRIBUTORS

DOE/OBES GEOSCIENCES RESEARCH: HISTORICAL SUMMARY

(OPERATING FUNDS--THOUSANDS) 


\section{FOREWORD}

The Department of Energy supports research in the geosciences in order to provide a sound foundation of fundamental knowledge in those areas of the geosciences that are germane to the Department of Energy's many missions. The Geosciences Research Program resides within the Division of Engineering and Geosciences, as part of the Office of Basic Energy Sciences of the Office of Energy Research. The participants in this program include Department of Energy laboratories, academic institutions, and other governmental agencies. These activities are formalized by a contract or grant between the Department of Energy and the organization performing the work, providing funds for salaries, equipment, research materials, and overhead. The summaries in this document, prepared by the investigators, describe the scope of the individual programs. The Geosciences Research Program includes research in the broad areas of geophysics, geochemistry, resource evaluation, hydrogeology and solarterrestrial interactions, and their subdivisions, including earth dynamics, properties of earth materials, rock mechanics, underground imaging, rock-fluid interactions, continental scientific drilling, geochemical transport, solar/atmospheric physics, and modeling, with emphasis on the interdisciplinary areas. All such research is related either directly or indirectly to the Department of Energy's long-range technological needs. Further information on the Geosciences Research Program, including recent program activities and highlights, may be found on the World Wide Web site by accessing the URL address "http://www.er.doe.gov/production/bes/geo/geohome.html." 


\section{THE GEOSCIENCES RESEARCH PROGRAM IN THE OFFICE OF BASIC ENERGY SCIENCES}

The Geosciences Research Program is directed by the Department of Energy's (DOE's) Office of Energy Research (OER) through its Office of Basic Energy Sciences (OBES). Activities in the Geosciences Research Program are directed toward building the long-term fundamental knowledge base necessary to provide for energy technologies of the future. Future energy technologies and their individual roles in satisfying the nations energy needs cannot be easily predicted. It is clear, however, that these future energy technologies will involve consumption of energy and mineral resources and generation of technological wastes. The earth is a source for energy and mineral resources and is also the host for wastes generated by technological enterprise. Viable energy technologies for the future must contribute to a national energy enterprise that is efficient, economical, and environmentally sound. The Geosciences Research Program emphasizes research leading to fundamental knowledge of the processes that transport, modify, concentrate, and emplace (1) the energy and mineral resources of the earth and (2) the energy by-products of man.

The Geosciences Research Program is divided into five broad categories.

- Geophysics and Earth Dynamics

- Geochemistry

- Energy Resource Recognition, Evaluation, and Utilization

- Hydrogeology

- Solar-Terrestrial Interactions

The following outline of current research in these categories is intended to be illustrative. The program evolves with time and progress in these and related fields. Individual research projects supported by this program at DOE laboratories, national laboratories, academic institutions, research centers, and other federal agencies typically have components in more than one of the categories or subcategories listed. Also, it is common for research activities to involve a high level of collaboration between investigators and different institutions.

\section{GEOPHYSICS AND EARTH DYNAMICS}

A. Large-Scale Earth Dynamics. Research on the physics of lithospheric dynamics, such as plate motion, mountain building, basin development, and regional scale uplift/subsidence and its concomitant effects.

B. Evolution of Geologic Structures. Research on the physical controls and physical effects of the dynamic evolution of geologic structures (e.g., folds, faults, basins, volcanoes) on a local or regional scale.

C. Properties of Earth Materials. Research on physical properties of rocks and minerals determined in the laboratory or in the field (in situ) by direct or indirect techniques and applicable on the spatial and temporal scales of geologic processes.

D. Rock Mechanics, Fracture, and Fluid Flow. Research on the response of rock and rock units to induced stress and the role of fluid flow as a cause and/or effect. 
E. Underground Imaging. Research to characterize the layering, mineralogy, lithology, geometry, fracture density, porosity, fluid content, and composition of the lithosphere using geophysical methods.

\section{GEOCHEMISTRY}

A. Thermochemical Properties of Geologic Materials. Research on the thermodynamic and chemical properties of geologic materials and their kinetic/dynamic interactions.

B. Rock-Fluid Interactions. Research on the chemical and mechanical consequences of rock-fluid interactions and the mass and energy transport controls of such interactions.

C. Organic Geochemistry. Research on naturally occurring carbonaceous and biologically-derived substances of geologic and energy importance.

D. Geochemical Transport. Research (both experimental and theoretical) on the geochemical separation, transport, and concentration of materials in the earth's crust induced by the spatial and temporal dynamics of lithospheric processes leading to a predictive capability.

\section{ENERGY RESOURCE RECOGNITION, EVALUATION, AND UTILIZATION}

A. Resource Definition and Utilization. Research to develop new and advanced bases for the physicochemical dynamics needed for improved energy and energy-related resource exploration, definition, and use.

B. Reservoir Dynamics and Modeling. Research on the physiochemical dynamics of geothermal and hydrocarbon reservoirs in their natural and perturbed (by production, injection, or reinjection) states.

C. Properties and Dynamics of Magma. Research on the origin, migration, emplacement, and crystallization of natural silicate liquids and their heat energy.

D. Continental Scientific Drilling. Research on the scientific objectives of the OBES Geosciences Research Program, using advanced technologies in shallow, intermediate, and deep drilling for earth observation facilities. Scientific research and advanced drilling technologies development are coordinated by an Interagency Coordinating Group (DOE, the U.S. Geological Survey, and the National Science Foundation) under the aegis of the Interagency Accord on Continental Scientific Drilling.

\section{HYDROGEOLOGY}

A. Fluid Transport Dynamics and Modeling. Research on the chemical transport and energy/mechanical consequences of fluid interactions and transport, leading to a predictive capability.

B. Thermochemical Properties of Energy Materials. Research on the thermodynamic and chemical properties of materials and their kinetic/dynamic interactions in fluid-rock systems.

C. Perturbations of Fluid Flow. Research on the physicochemical dynamics and chemical transport of fluid-rock systems in response to mechanical and energy perturbations, leading to a predictive capability. 


\section{SOLAR-TERRESTRIAL INTERACTIONS}

A. Magnetospheric Physics. Research on the fundamental interactions of the solar wind with the terrestrial magnetic field and the earth's magnetosphere as a model magnetohydrodynamic generator and associated plasma physics research.

B. Upper Atmosphere Chemistry and Physics. Research on thermal, compositional, and electrical phenomena in the upper atmosphere and the interactions induced by solar radiation.

C. Solar Radiation and Solar Physics. Research on the structure and dynamics of the sun and the characteristic interactions of solar radiation with the earth, including the effects of solar radiation on the climate. 
PART I

ON-SITE 

CONTRACTOR:

CONTRACT:

CATEGORY:

PERSON IN CHARGE:
ARGONNE NATIONAL LABORATORY

Argonne, Illinois 60439

W-31-109-Eng-38

Geochemistry

N. C. Sturchio

\section{A. Mineral-Fluid Interactions: Experimental Determination of Atomic-Scale Processes Using Synchrotron Radiation (Neil C. Sturchio [630-252-3986; Fax 630-252-5498; E-mail sturchio@anl.gov] and Ronald P. Chiarello, Michael J. Bedzyk [Northwestern University], and Larry B. Sorensen [University of Washington])}

Objectives: The objective of this program is to advance the basic understanding of rock-fluid and soilfluid interactions through experimental studies of atomic-scale processes at mineral-fluid interfaces. This is crucial to establishing the relation between atomicscale processes and macroscopic geochemical transport in large-scale natural systems.

Project Description: The principal approach is to observe single-crystal mineral surfaces in situ during chemically controlled reactions with fluids, using Xray scattering and standing-wave techniques with highbrilliance synchrotron radiation. This approach applies techniques developed recently by physicists for basic studies of surface phenomena and semiconductor properties. These techniques provide high-resolution atomic-scale structural information that cannot be acquired by any other means. Experiments are being performed on common rock- and soil-forming minerals under conditions representative of geochemical environments near the earth's surface. Types of reactions being investigated include dissolution-precipitation, adsorption-desorption, and oxidation-reduction.

Results: Progress during the past year included further successful demonstrations of the ability to perform in situ X-ray reflectivity, diffraction, and stand- ing-wave studies of reacting mineral surfaces under chemically controlled conditions. During the past year, experiments were conducted to characterize the atomic structure of the calcite (104) cleavage plane in contact with water and to observe changes in this structure as a function of solution composition and time, using $\mathrm{X}$ ray reflectivity measurements. The $\mathrm{X}$-ray reflectivity data are being compared with atomic force microscopy data (obtained through a collaboration with D. Baer and Y. Liang of Pacific Northwest National Laboratory) to reconcile the two data sets in terms of the apparent atomic relaxations that occur at the calcite surface in contact with water. X-ray reflectivity and standing wave techniques were combined, for the first time, to determine the structure and amount of lead adsorbed onto calcite. It was found that lead adsorbs primarily at calcium positions in the surface atomic layer of calcite. The X-ray standing-wave technique was also used to determine that adsorbed selenite substitutes for the carbonate ion in calcite. We have initiated studies of quartz and mica surfaces. Experimental studies of clay mineral growth kinetics and mechanisms using synchrotron-based $\mathrm{X}$-ray techniques were also initiated in collaboration with K. L. Nagy (Sandia National Laboratories). 
CONTRACTOR:

CONTRACT:

CATEGORY:

PERSONS IN CHARGE:
BROOKHAVEN NATIONAL LABORATORY

Upton, Long Island, New York 11973

DE-AC02-76CH00016

Geology, Geophysics, and Earth Dynamics

K. W. Jones

\section{A. Measurement of Fluid Flow and Fluid-Rock Interactions Using Synchrotron Computed Microtomography (K. W. Jones [516-282-4588; Fax 516-282-5271; E-mail kwj@bnl.gov] and W. B. Lindquist [516-632-8361; Fax 516-632-8491; E-mail lindquis@ams.sunysb.edu])}

Objectives: The objective of this project is twofold. First, microgeometry, fluid flow and fluid-rock interactions are studied in different types of geological specimens using the nondestructive technique of synchrotron computed microtomography (CMT). The work is performed at the Brookhaven National Synchrotron Light Source. Second, attention is given to improving the CMT instrumentation to give larger tomographic volumes, higher data acquisition rates, and improved visualization facilities.

Project Description: The CMT system is used to measure the microgeometry of rocks at pore-scale dimensions. Rock properties, such as porosity, permeability, and pore connectivity, are determined from the data. Theoretical predictions for fluid flow can then be made and verified using realistic rock properties derived from the experimental results found on a microscopic scale. A true three-dimensional visualization system is used for viewing the experimental and theoretical results. This system is an invaluable tool for working with the vast amount of data produced by the synchrotron tomography apparatus. It is intended to use many aspects of this system for experiments at the Argonne Advanced Photon Source in the near future. The X-ray beams to be available there will enable new kinetic experiments and study of large samples.
Results: Extensive measurements of sandstones and seal rocks from petroleum reservoirs have been carried out in collaboration with scientists from the Mobil Research and Development Corporation. The tomographic volumes obtained have been analyzed and discussed in terms of several models. Other measurements have been done on artificial dunite, compressed sandstones, and basalts. The experimental facility has been improved in incremental ways during FY 1996. The work includes improvements in software, acquisition of a new charge-coupled device camera to produce volumes with section sizes of about $3000 \times 2000$ pixels, and incorporation of easy means for changing the system magnification. The volume visualization system came into full operation during FY 1996. It will be developed further in the future. A collaboration among groups at Brookhaven, Argonne National Laboratory, and The University of Chicago was begun to develop means for efficient use of the NSLS and APS for tomographic experiments. The system will include high-speed data links and the application of supercomputing facilities to improve data reduction methods, visualization methods, and theoretical modeling. 


\section{A. Geochemistry of Organic Sulfur in Marine Sediments (Murthy A. Vairavamurthy 1516-344-5337; Fax 516-344-5526; E-mail vmurthy@bnlarm.bnl.gov] and B. Manowitz [516-344-2458; Fax 516-344- 5526])}

Objectives: The broad objectives are to understand the geochemical mechanisms of sulfur incorporation into sedimentary organic matter, to study the changes in the abundance and forms of sulfur during early diagenesis in various organic-rich sedimentary environments, and to examine the influence of sulfur incorporation in the preservation of sedimentary organic matter.

Project Description: Sulfur is believed to be involved in preserving organic matter in sediments, in converting this organic matter to petroleum, and in controlling the timing of petroleum generation from a source rock. The fundamental geochemical issue in this matter is the mechanism of sulfur incorporation into sedimentary organic matter. Although there is compelling evidence to indicate that reactions of reduced inorganic sulfur species with organic molecules occur during the early stages of diagenesis and under very mild conditions, the molecular mechanisms are still not well understood. Previously, hydrogen sulfide has been considered to be the primary sulfur reactant for organic sulfur formation in sediments. Recently, evidence is emerging that $\mathrm{H}_{2} \mathrm{~S}$ oxidation products, especially polysulfides, are also important. The roles of elemental sulfur, sulfite, and thiosulfate in the formation of organic sulfur are still not clear. This project, which is aimed at understanding the formation and transformation of sedimentary organic sulfur during early diagenesis, has four major components: (1) studies of sulfur speciation in sediments, (2) mechanistic studies of organic sulfur formation, (3) mechanistic studies of sulfide oxidation to understand the formation of different oxidation intermediates, and (4) analytical methods development. An important goal of this project is to use synchrotron-radiation-based X-ray absorption near- edge-structure (XANES) spectroscopy for characterization and determination of sulfur species, in addition to other state-of-the-art techniques.

Results: In continuing efforts to a fuller understanding of the role of various sulfur nucleophiles in incorporating sulfur into sedimentary organic matter, the reactions of thiosulfate with different model organic compounds were studied. Thiosulfate is a major partial-oxidation product generated from the oxidation of $\mathrm{H}_{2} \mathrm{~S}$ in marine sediments. Although biological pathways of thiosulfate transformation have been recognized, chemical pathways are still not clear. Our results show that an organic thiosulfate $\left(\mathrm{R}_{-} \mathrm{S}_{2} \mathrm{O}_{3}^{-}\right)$is formed from the reaction of thiosulfate with most activated unsaturated organic molecules other than carbonyl compounds; however, with $\alpha, \beta$ unsaturated carbonyl compounds (both unsaturated aldehydes and ketones), a sulfonate and not an organic thiosulfate is generated as the end product. The formation of sulfonates represents a novel, hitherto unrecognized reaction pathway involving thiosulfate. A possible mechanism may involve the addition of thiosulfate to the $\alpha$-carbon through the outer sulfur atom, forming a cyclic intermediate first, which then dissociates with the attachment of the sulfonatesulfur to the $\beta$-carbon and the release of the outer sulfur as elemental sulfur. The reaction is highly $\mathrm{pH}$ dependent as the type of products formed and the kinetics of the reaction are changed conspicuously with varying $\mathrm{pH}$. The mechanism of this reaction is currently under study using FT-IR and NMR spectroscopic methods in addition to XANES spectroscopy. The thiosulfate carbonyls reaction could be an important geochemical pathway for forming sulfonates in marine sediments. 
We used the XANES spectroscopy for examining the speciation of sulfur in a series of humic substances of different origins, including soil and marine sediments. Organic sulfides, disulfides, polysulfides, sulfonates, and organic sulfates are the major forms of sulfur detected in all the humics we examined. The oxidized sulfonate-sulfur dominates the composition of sulfur species in soil humics, accounting for more than $60 \%$ of the total sulfur. In marine humics, although sulfonates are abundant in near surface sediments, reduced sulfur species, particularly disulfides and polysulfides, also constitute an important fraction. The distribution of sulfonate groups in humics is in agreement with our previous findings that sulfonate-sulfur is mainly associated with macromolecular organic matter rather than with low-molecular-weight organic molecules in sediments.

\section{B. Sulfur Speciation in Sedimentary Macromolecular Organic Matter by X-Ray Absorption Spectroscopy - Collaborative Project with Woods Hole Oceanographic Institution (B. Manowitz [516-344-2458; Fax 516-344-5526] and M. A. Vairavamurthy [516-344-5337; Fax 516-344-5526; E-mailvmurthy@bnlarm.bnl.gov])}

Objectives: This project focuses on the use of $\mathrm{X}$-ray absorption spectroscopy for understanding sulfur speciation in sedimentary macromolecular organic matter in a collaborative project with Woods Hole Oceanographic Institution titled "The Role of Sulfur in the Formation and Diagenesis of Macromolecular Matter in Sediments." A major objective is to quantitatively speciate sulfur forms in sediments and in the products of diagenesis to complement information obtained with other techniques, such as gas chromatography.

Project Description: In marine sediments, sulfur is intimately involved in organic matter diagenesis. Several recent studies suggest an important role for sulfur in the formation of macromolecular organic matter in sediments. The experimental and theoretical approaches used in this project are based on the premise that macromolecularly-bound sulfur can be represented by model structures that differ in such linkage type (intermolecular bridges vs intramolecular bonds), as well as the number of linkages per molecule and the number of sulfur atoms in each linkage. Studies will be conducted to understand whether the degree of sulfur cross-linking controls the molecular-size distribution in sulfur-rich organic matter. X-ray absorption spec- troscopy for sulfur will be performed in X-19A beam line at the National Synchrotron Light Source. The Kedge XANES spectra will be collected as fluorescence spectra. Quantitative analysis will be performed by computer simulation using spectra of model compounds.

Results: X-ray absorption spectroscopy was used to examine organic sulfur speciation in a series of sediment samples obtained from the size fractionation of the bulk sediment by the field-flow fractionation method. Our results showed a striking correlation between particle size and sulfur speciation. Reduced organic sulfur forms, comprising mainly organic polysulfides and sulfides, were maximally associated with the smallest sized fraction. With increasing particle size, reduced forms of sulfur decreased in abundance with concomitant increase in oxidized forms of sulfur, including sulfonates and ester sulfates. Studies are in progress towards understanding the significance of these results.

Additional description of the results is given in the Summary of the project, "The Role of Sulfur in the Formation and Diagenesis of Macromolecular Matter in Sediments," by T. Eglinton from Woods Hole Oceanographic Institution. 
CONTRACTOR:

CONTRACT:

CATEGORY:

PERSON IN CHARGE:
IDAHO NATIONAL ENGINEERING LABORATORY

Idaho Falls, Idaho 83419

SBQ040

Geophysics and Earth Dynamics

J. Epstein

\section{A. Frictional Process Zones in Compressive Fracture (J. Epstein [Experimental] [208-526-6874; Fax 208-526 0690; E-mail esj@inel.gov] and E. Steffler [Numerical] [208-526-8098; Fax 208-526-0690; E-mail steff@shed.inel.gov])}

Objectives: The objective of this project is to investigate the fracture of quasi-brittle materials that exhibit friction along their crack faces under varied degrees of shear and compression loading. Relative to the U.S. Department of Energy mission areas, these improved slip models are applicable to underground storage facilities, such as the Yucca Mountain Project, whose NRC certification requires a validated means for predicting the long-term behavior of slip planes.

Project Description: A series of homogeneous specimens have been fabricated of pure Solnhofen Limestone and bimaterial systems, consisting of Solnhofen bonded to PMMA. We are leveraging this work with the Yucca Mountain Program through the development of a four-beam phase shifted moire interferometric system to accurately quantify the $\mathrm{U}, \mathrm{V}$, and U-V (45 degree) relative slip between two contacting surfaces. The final product will be verified numerical approximations for frictional slip along crack faces that can be input into larger numerical geo-models.
Results: Our results for the past year indicate that the current complex variables elasticity theory applied to finite bodies was inadequate; this year we are utilizing finite element methods to compare against our experimental slip measurements. Uniqueness issues concerning the numerical solution still have to be resolved. We have found that our previous non-phase shifted measurements using fringe tracking created uncertainty of continuity across the sliding crack faces. This year we have begun to implement the phase shifted system developed jointly with the Yucca Mountain Project for frictional displacement measurement. The phase shifting system offers the unique advantage in that each of the 250,000 CCD pixels is focused discretely on the body tracking only its interferogram phase; this is in contrast to traditional fringe tracking where the interface shear causes the fringes to be lost across the slipping interface. 
CONTRACTOR:

CONTRACT:

CATEGORY:

PERSON IN CHARGE:
LAWRENCE BERKELEY NATIONAL LABORATORY

University of California

Berkeley, California 94720

DE-AC03-76F00098

Geophysics and Earth Dynamics

\section{A. High-Resolution Imaging of Electrical Conductivity Using Low-Frequency Electromagnetic Fields (K.H. Lee [510-486-7468; Fax 510-486-5686; E-mail khlee@lbl.gov], H.F. Morrison, and A. Becker)}

Objectives: The objective is to develop numerical and field techniques for high-resolution imaging of electrical conductivity, using magnetotelluric (MT) and controlled-source electromagnetic (CSEM) methods. Applications of high-resolution conductivity imaging include the mapping of groundwater, resource exploration and reservoir characterization, subsurface processes monitoring, and general geological mapping of the crust of the Earth.

Project description: Many fundamental questions relating to resolution, depth of exploration, required bandwidth in frequency, and spatial sampling rate remain to be answered. To resolve some of these questions, four main tasks have been selected in this project: (1) improvement of the q-domain imaging method using the wavefield transform and tomographic inversion, (2) development of an approximate analysis and imaging method using Born inversion, (3) development of a rapid and practical 3-D inversion scheme, and (4) development of a borehole time-domain EM system. Some of these tasks are driven by the pressing need to interpret an increasing amount of field data available to us. The data may be in the frequency domain but can only be interpreted properly if and when tasks 2 and 3 become successful. Also, the evident success of the q-domain tomographic imaging process strongly argues for the development of a suitable wideband borehole system (task 4).

Results: The wavefield transform method has been reformulated, using spline functions, in which the wavefield is described using spline functions instead of a collection of discrete sequential numbers. Numerical experiments show that the spline algorithm provides much more stable and robust results. Along with the numerical method development, we have successfully tested the borehole TEM transmitter at the Richmond Field Station. Based on the preliminary result of this methodology for high-resolution EM imaging, a CRADA agreement has been established between LBNL and Western Atlas Logging Services (WALS).

Further research in the Born analysis led us to develop an efficient method with a dramatic gain in computational speed. The gain in speed is realized by taking advantage of the fact that the volume integral involved is a convolution of the green's function and the scattering current in the horizontal coordinates. Evaluation of this integral can be easily accomplished in the wave number domain. Inverse Fourier transformation is then used to obtain the result in the spatial domain. The new computational method is currently being implemented in evaluating the nonlinear Born approximation.

Great progress has been made in the area of 3-D nonlinear EM inversion, using the magnetic field integral equation and new finite-element-Born-accelerating algorithm. Some of the results have been presented by (1) Lee, K.H., Xie, G., Hoverstein, G.M., and Pellerin, L., 1996, EM imaging for environmental site characterization, and (2) Xie, G., Li, J., and Lee, K.H., 1996, New 3D nonlinear electromagnetic inversion. Both papers have been accepted for publication in the book Three-Dimensional Electromagnetics to be published by the SEG. 


\section{B. Effects of Heterogeneity on the Mechanical Properties of Rock (L.R. Myer [510-486-6456; Fax 510-486-5686; E-mailmyer@lbl.gov], N. G.W.Cook, and K. T. Nihei)}

Objectives: The objective of this work is to develop a fundamental understanding of the effects of microstructural and macrostructural heterogeneity on the nonlinear, hysteretic deformation and failure of rock under compressive loading.

Project Description: This work examines the mechanical processes in rock that control how rocks deform and fracture under compressive loading and the influence of rock microstructure on these processes. Laboratory measurements on a suite of rocks are being performed to determine how microstructural heterogeneity (e.g., grain shape, size, cementation, strength, packing geometry) and macrostructural heterogeneity (e.g., inclusions, bedding) produce local stress concentrations that, in turn, produce frictional sliding, nonlinear deformation, and extensile microcracking. Laboratory work includes stress-strain, pore compressibility, and seismic properties measurements. Insight into the micromechanical processes of deformation and failure is obtained using Wood's metal impregnation. Field studies of compression-driven fracturing in sandstone are being conducted on Vancouver Island, $\mathrm{BC}$, through a combination of mapping, core testing, in situ seismic measurements, and Schmidt hammer testing.

Results: Laboratory work investigating the effects of nonlinearity and friction on the path-dependent pore compressibility of rock has continued with measurements on sandstone. These tests indicate that the measured pore compressibility for different loading states is not a simple function of the mean stress as might be expected if the rock were modeled as a linearly elastic, isotropic material. This nonfunctional dependence of the pore compressibility with mean stress is most likely due to the presence of nonlinearity and friction taking place at the grain contacts. Theoretical analysis of these measurements is currently being conducted to investigate the relative importance of intergranular friction and nonlinearity on the pore compressibility of clastic rocks.

A series of laboratory tests on synthetic glass bead samples with varying degrees of sintering were performed to examine the effects of microstructure on failure around a cylindrical opening. Compression tests performed on weakly sintered, high porosity samples were observed to fail by a fracture that initiated at the side of the borehole wall, where conventional elasticity theory predicts maximum compression; however, in direct contrast to that predicted by linear elasticity, subsequent failure was observed to propagate away from the borehole in a direction perpendicular to the applied compressive stress. Tests on well sintered, low porosity samples produced typical borehole breakout type patterns. SEM inspection of the modes of failure indicated that the high porosity samples failed by bond failure while the low porosity samples failed by grain failure. An analysis of the failure mechanism using a boundary element code revealed that denser packing creates increased dilatation of the failed grains and that this dilatation supplies a confining stress on neighboring grains, thereby preventing failure from propagating away from the borehole. The absence of this dilatation-confining micromechanism in higher porosity rocks may explain the production of wormhole-like structures that can lead to sanding problems during wellbore fluid production in clastic formations.

A field study of the fractures in a sandstone outcrop on Vancouver Island, BC, was conducted to investigate the mechanics of fracture growth at the meter scale. The site contains calcareous concretions that are slightly stiffer than the surrounding sandstone and that range in size from several centimeters to several meters in diameter. Two dominant fracture sets are present and in many instances the concretions contain multiple, closely-spaced fractures. We have found that the concretions are paleostress indicators since they act as stress concentrators that can be used to constrain the magnitudes and directions of the far-field stresses required to cause the observed fracture patterns. Detailed maps of the fractures and concretions exposed along a flat $300 \mathrm{~m}$ section of sandstone beach were made. Schmidt hammer values and seismic velocities were also measured. Analysis of the fracture spacing-to-height ratios along one part of the beach has indicated that the fractures probably formed in compression rather than tension. These measurements are being analyzed to determine the magnitudes and directions of the far-field stresses that are required to cause the observed fracture patterns. 


\section{Transport in Single Fractures (Graph Theory) (Larry Myer [510-486-6456; Fax 510-486-5686], N.G.W. Cook, and G. Yang [E-mail gemei@myer.lbl.gov for Yang])}

Objectives: This research will provide a level of understanding of multiphase flow in fractures sufficient to develop algorithms that can be used to analyze and quantitatively predict transport properties in fractures in the field.

Project Description: The mathematics of graph theory is used to characterize the topology of the fracture void space and calculate flow through it. The focus of the work is on single fractures. The general approach is to create a network that captures the important topological characteristics of apertures in a single fracture. Graph theory techniques are then used to develop highly efficient algorithms for complex connectivity, fluid flow, and phase distribution problems in a two-phase network system.

Results: The third-year studies focused on twophase distribution under different capillary pressures (imbibition and drainage processes) and hysteresis loops starting and ending at arbitrary locations on the primary drainage and secondary imbibition curves.
Given an aperture distribution for a single fracture, a graph theory model has been employed to simulate the transport properties of the fracture. In the past, only the primary imbibition-drainage loop was calculated (BES Report, 1995). The scanning loops (hysteresis inside the primary loop) can reveal much more information on the connectedness of the apertures with stochastic height distribution; however, several such attempts (Soll, Celia, and Wilson, 1993; Jerault and Salter, 1989) in the past did not produce satisfactory results that resemble the experimental observations (Morrow and Harris, 1965). Neither the imbibition curves (Soll et al.; Jerault and Salter) were smooth in non-log scale nor the residual saturations were persistent during scanning (Jerault and Salter). In our graph theory approach, the film flow model (through grooves of rough walls) is combined with the priority queue search of the imbibition/drainage fronts. The algorithm is very efficient, and the results resemble Morrow and Harris' experimental data well.

\section{Energy Partitioning of Seismic Waves in Fractured Rock (L.R. Myer 1510-486-6456; Fax 510-486-5686; E-mail myer@lbl.gov], N. G. W. Cook, and K. T. Nihei)}

Objectives: The objectives of this work are to (1) investigate the partitioning of energy between seismic body waves, guided waves, and scattered waves produced by sources of finite size and bandwidth, which are transmitted, reflected, and channeled along single and multiple fractures, (2) determine optimum source and receiver configurations for exciting and detecting these waves, (3) determine the effects of spatial variations in the fracture properties on seismic wave propagation, and (4) examine the effects of a finite-length fracture on seismic waves.

Project Description: A combination of analytic, numerical, and laboratory modeling is being conducted to determine the effects of single and multiple fractures on body waves and guided waves. Analytic work is being conducted to determine the frequency-dependent velocities and particle motions of trapped and leaky fracture-guided waves. Numerical simulations are also being performed using dynamic boundary element, finite element, and finite difference codes to analyze the generation of fracture-guided waves from a polarized, band-limited source. The predictions of the analytic and numerical modeling are being tested in the laboratory using two-dimensional (plane stress) physical models that enable measurement of both velocities and particle motions. The laboratory measurements are also being used to study the effects of finite length and variable stiffness fractures, both of which are difficult to analyze analytically and numerically.

Results: A two-dimensional, elastic finite difference code was developed for modeling seismic wave propagation in a medium with multiple fractures. The code is based on a fourth-order staggered grid scheme in which the host medium can be anisotropic. Fractures are included in the model using the effective medium approach of Coates and Schoenberg (1995). A 
series of numerical simulations have been completed for a medium composed of parallel fractures and with varying fracture spacing-to-wavelength ratios and fracture stiffnesses. These simulations show strong frequency-dependent amplitude anisotropy that is not predicted by conventional (effective medium) anisotropy theory. The simulations also show the development of guided waves that are channeled between fractures.

To understand the properties of guided waves that are channeled between fractures, we have developed a plane wave modal solution for Rayleigh fracture channel waves. The analytic expression was solved numerically to yield the phase velocities and mode shapes of the channel waves. These results demonstrate that two parallel fractures can support an infinite number of symmetric and antisymmetric Rayleigh channel wave modes. These modes are dispersive and have distinct extensional and flexural particle motions. The energy in these various modes becomes more localized between the two fractures as the stiffness is reduced. The modes degenerate to classic Rayleigh-Lamb plate modes as the stiffnesses of the fractures is reduced to zero. Laboratory experiments using a two-dimensional plane stress model are currently being assembled to study how these waves can be excited and detected with sources of finite size and bandwidth.

E. Center for Computational Seismology (CCS) (T.V. McEvilly [510-486-7316; Fax 510-486-5686; Email tvmcevilly@lbl.gov], E.L. Majer [510-486-6709; Fax 510-486-5686; E-mail elmajer@lbl.gov], and L.R. Johnson [510-486-4173; Fax 510-486-5686; E-mail lrjohnson@lbl.gov])

Objectives: The objectives of this project are to (1) maintain a state-of-the-art computing environment in support of various seismological and other geophysical research programs, (2) develop new methods in this environment for imaging the subsurface and its processes and new methods for visualizing the results, and (3) apply such methods to real research problems in U.S. Department of Energy scientific programs.

Project Description: CCS provides a core research facility for many Basic Energy Sciences programs as well as other government and private industry research ventures. A wide variety of software and hardware is developed and maintained to support high-level research. Research focuses on subsurface imaging using active and passive sources at scales ranging from meters to whole-Earth dimensions. Research activities in the previous year include tomographic inversions for threedimensional elastic properties of fluid disposal or contaminant sites, geothermal reservoirs, gas fields, Earth's mantle; processing and interpretation of vertical seismic profiles for fracture detection and fault delineation; seismic reflection imaging; and the use of microearthquake data in the study of processes in reservoirs or seismogenic fault zones. The wide range of CCS research content is contained in the listing of recent publications available through E-mail from E.L. Majer (see address in heading).
CCS resources are being converted in FY96 from the Solbourne 902 and 602 servers to a 4-cpu Sun U1tra 4000 system with 1 GByte memory. The change to the Solaris operating system will impact operations for a while as various in-house and commercial software packages are brought back on line.

The CCS "system" will still include

- multiple Sun workstations, X-terminals, and Macintosh computers for desktop use

- 9-track and 8-mm tape drives, color printer, and 36-in. black and white plotter for seismic sections

- various commercial processing packages, including DISCO, ProMAX, SierraSeis, AIMS, NAG, SAG, and CA DISSPLA

- internet access for visitors

Results: The major accomplishments of CCS come largely from the breadth of research support provided by CCS and the cross-fertilization of applications and fundamental studies. Primary strengths are in elastic wave generation and propagation, inverse methods, data processing, and tomographic imaging methods. All of these support an advanced capability in field studies that is used in many different scientific and engineering applications. Research in CCS forms the basis for several Ph.D. theses at any time. Last year there were two Ph.D.s completed in CCS. 
A. Integrated Isotopic Studies of Geochemical Processes (Donald J. DePaolo [510-486-4975;

510-643-7686; Fax 510-486-5496; E-mail depaolo@garnet.berkeley.edu or djdepaolo@lbl.gov] and

B. Mack Kennedy [510-486-6451; Fax 510-486-5496; E-mail bmkennedy@lbl.gov])

Objectives: Combine high-precision measurements of isotopic ratios in natural materials with mathematical models to understand the spatial and time scales of geochemical processes of interest for energy management.

Project Description: Current effort is concentrated on $\mathrm{Sr}, \mathrm{Ca}, \mathrm{O}, \mathrm{C}, \mathrm{He}, \mathrm{Ne}, \mathrm{Ar}, \mathrm{Xe}, \mathrm{Pb}$, and $\mathrm{Nd}$ isotopic ratios and on problems of mass transport in fluid-rock systems, interpretation of past global climatic change, crustal magmatic and tectonic processes, and Quaternary geochronological methods. A mathematical basis for the application of isotopic measurements of fluids and rocks to the field-scale parameterization of hydrological systems is a major effort of the Center for isotopic geochemistry. Modeling is accompanied by systematic measurements of relatively simple natural systems and by improved sampling and measuring techniques. Emphasis in development is on microsampling of geological materials, high-precision measurement of the small amounts of recovered material, and rapid, automated low-blank chemical separation of trace elements. Other efforts of the Center are aimed at geochemical techniques for dating and correlation of sedimentary and volcanic rocks and for understanding the time scales and mechanisms of crustal processes, such as extensional faulting, mountain building, and volcanism. All efforts are aimed at improved characterization of natural rock and fluid systems.

Results: (1) Monitoring and mapping of atmospheric noble gases, ${ }^{3} \mathrm{He}$, and ${ }^{3} \mathrm{He} / \mathrm{CO}_{2}$ ratios continued in regions of high- $\mathrm{CO}_{2}$ soil gas on the flanks of Mammoth Mountain, a Quaternary volcano on the southwest rim of Long Valley Caldera in east-central California. The high- $\mathrm{CO}_{2}$ soil gas is causing anomalous coniferous forest mortality and presently totals at least 50 ha. Soil-gas $\mathrm{CO}_{2}$ concentration in tree-kill ar- eas can exceed $90 \%$, compared to $<1 \%$ in nearby healthy forested areas, and the total $\mathrm{CO}_{2}$ flux may exceed 1200 tonnes/day. Helium isotopic compositions and ${ }^{3} \mathrm{He} / \mathrm{CO}_{2}$ ratios indicate a combined magmatic and crustal source for the soil gas $\mathrm{CO}_{2}$. An increased flux of magmatic $\mathrm{CO}_{2}$ is probably related to recent suspected intrusive activity. Large systematic and mass dependent variations in the relative abundances of atmospheric noble gases and the $\mathrm{CO}_{2}$-rich soil gas indicate gas fractionation induced by diffusion against the $\mathrm{CO}_{2}$ stream. Binary gaseous diffusion models match the observed correlation between degree of fractionation and $\mathrm{CO}_{2}$ soil-gas concentration. The relative abundances of the noble gases also show that soil-gas $\mathrm{CO}_{2}$ contents and ${ }^{3} \mathrm{He} / \mathrm{CO}_{2}$ ratios are significantly affected by infiltrating $\mathrm{CO}_{2}$-undersaturated meteoric water. By modeling the combined effects of diffusive fractionation and infiltrating meteoric water, variations in soilgas ${ }^{3} \mathrm{He} / \mathrm{CO}_{2}$ ratios can be used to monitor magmatic activity at Mammoth Mountain.

(2) Studies of calcium stable isotopic fractionation in nature were continued to explore the range of natural variations and better understand the fractionation mechanisms. Igneous rocks show a very narrow range of ${ }^{44} \mathrm{Ca}$ of 0.3 permil. There appears to be a small fractionation effect between minerals (ca. 0.2 permil) and evidence that there are slight shifts in igneous rocks due to mineral fractionation. Bone and shell material of marine organisms is systematically lower in ${ }^{44} \mathrm{Ca}$ than seawater. The smallest organisms measured, foraminifera, are ca. 0.8 permil lower than seawater, and there is evidence for a slight temperature dependence to the fractionation. The primary determinant of ${ }^{44} \mathrm{Ca}$ in the bone and shell material of higher marine organisms appears to be trophic level. Terrestrial organisms have lower ${ }^{44} \mathrm{Ca}$ values than marine organisms of approxi- 
mately similar mass and trophic level. The high ${ }^{44} \mathrm{Ca}$ of seawater appears to be a result of sedimentary sequestering of light $\mathrm{Ca}$. Measurements of older carbonate sediments suggest that there have been small shifts in the global $\mathrm{Ca}$ cycle that produced shifts in the ${ }^{44} \mathrm{Ca}$ of the paleo-oceans.

(3) Models of ${ }^{87} \mathrm{Sr} /{ }^{86} \mathrm{Sr}$ ratio evolution in groundwater systems were developed and coupled with models for radiocarbon to produce a method for determining more accurate groundwater ages from radiocarbon measurements. The models account for carbon exchange between groundwater and solid phases that does not result in changes in bicarbonate concentration in the groundwaters.

(4) Measurements of $\mathrm{Sr}$ isotope ratios were made in marine sediments of the paleo-Mediterranean area in order to better understand the paleoceanography of the Mediterranean and its relation to past climate changes. There is evidence in the isotopic record that the Mediterranean has been isolated from the Atlantic Ocean many times over the past 11 million years. This isolation may be a result of tectonic modification of the bathymetry of the channel connecting to the Atlantic or to changes in the evaporation-rainfall balance that could inhibit mixing. The $\mathrm{Sr}$ data also suggest that there may be some major problems with global biostratigraphy in the age range from 22 to $12 \mathrm{Ma}$.

(5) Stable isotope geochemistry of low-temperature clay minerals is being studied to define the effects of temperature, phase transitions, and fluid composi- tion on the hydrogen and oxygen isotopic compositions of clay minerals formed at low temperatures $\left(<150^{\circ} \mathrm{C}\right)$. Analysis of smectite samples from drill holes from the East Rift Zone of Kilauea Volcano of Hawaii indicates that the clays formed at temperatures ranging from $96^{\circ}$ to $322^{\circ} \mathrm{C}$ and demonstrates the potential use of clays for stable isotope thermometry at low temperatures. Measurements on clays from diagenetically modified marls of the Monterey Formation of California give indications of the temperature and fluid composition associated with diagenesis.

(6) Techniques for thermal ionization mass spectrometry measurements of selenium stable isotope ratios in natural samples were developed and initial measurements made. Small changes in selenium isotope ratios can be measured on samples as small as one microgram of selenium. Preliminary measurements reveal small but detectable Se isotopic differences between natural and industrial sources of Se in San Francisco Bay.

(7) Techniques for measuring stable isotope ratios of chlorine $\left({ }^{37} \mathrm{Cl} /{ }^{35} \mathrm{Cl}\right)$ have been developed. Preliminary results for analyses of standards indicate precision of better than 0.1 for samples as small as 10 mmole of $\mathrm{CH}_{3} \mathrm{Cl}$. This technique can be used for tracking degradation of chlorinated compounds in contaminated systems. Initial measurements of chlorine isotopes produced from microbial breakdown of chlorinated solvents have confirmed that there are differences between commercial products resulting from differences in the manufacturing processes.

\section{B. Calorespirometry: A New Approach to Quantify Pollutant Reactions in Soils and Sediments (Garrison Sposito [510-643-8297; Fax 510-643-5098; E-mail gsposito@nature. berkeley.edu] and Marcos A. Cheney [908-932-9094; Fax 908-932-8644; E-mail cheney@aesop. rutgers.edu])}

Objectives: The objectives of this project are to determine the mechanisms of abiotic degradation of key organic pollutants by minerals in soils or sediments and to develop a calorespirometric method, combined with spectroscopic techniques, to measure kinetic and thermodynamic parameters for degradation reactions of organic pollutants on manganese oxide surfaces.

Project Description: Abiotic transformations of organic pollutants are often neglected in remediation scenarios but nonetheless can contribute significantly to detoxification. Calorespirometric methods, particularly when coupled with spectroscopy, have great potential to become powerful tools for examining in situ reaction rates and mechanisms of abiotic transformations. Both heat and gas production can be followed continuously in simple batch experiments over a wide range of conditions. Spectroscopic methods then permit detailed mechanistic interpretations of the reaction kinetics and thermodynamics obtained by calorespirometry. 
Manganese oxide minerals are capable of degrading organic pollutants adsorbed to their surfaces by both redox and proton-promoted mechanisms. A variety of these minerals is being synthesized with varying specific surface area. The reactions of the minerals with the carcinogenic herbicides, dichlorophenoxyacetic acid $(2,4-\mathrm{D})$ and atrazine, are being investigated by calorespirometry combined with UV-visible diffuse reflectance spectroscopy, Fourier-transform infrared spectroscopy, electron spin resonance spectroscopy, gas chromatography-mass spectrometry, and liquid chromatography.

Results: Birnessite $\left(\delta-\mathrm{MnO}_{2}\right)$ catalyzes the degradation of 2,4-D to carbon dioxide $\left(\mathrm{CO}_{2}\right)$ over a 30 -hour period. Analysis of the reaction products by liquid chromatography and UV-visible absorption spectroscopy showed no stable-intermediate organic compounds were formed. Calorespirometry showed that $7.2 \mathrm{~mol}$ $\mathrm{CO}_{2}$ were produced per mole of $2,4-\mathrm{D}$ reacted. The theoretical value is $8 \mathrm{~mol} \mathrm{CO}_{2}$ per mole $2,4-\mathrm{D}$ if the herbicide were completely oxidized. Electron spin resonance spectroscopy indicated that manganous ions (Mn [II]) were produced during the degradation of 2,4-D on $\delta-\mathrm{MnO}_{2}(\mathrm{Mn}[\mathrm{IV}])$. Chloride ions also are a likely product, since no chlorinated intermediates were detected by gas or liquid chromatography analysis.

The observation that $\mathrm{Mn}$ (II) is released by the reaction (and oxygen is consumed) indicates that the reaction pathways are not simple. The carboxyl group is probably the functional group on 2,4-D that reacts with the surface Mn (IV) sites on birnessite. Because the surface is acidic, the carboxyl group $\left(\mathrm{pK}_{\mathrm{a}}=2.93\right)$ is protonated under the experimental conditions and the adsorption of 2,4-D is weak. Nevertheless, the probable first step in the reaction is partial oxidation of the 2,4-D by exchange of electrons with the mineral, probably via a carboxyl-Mn (IV) bridge. Subsequent to this reductive dissolution step, oxygen reacts with the remainder of the 2,4-D aromatic ring to produce $\mathrm{CO}_{2}$.

\section{Isotopic and Chemical Composition of Fault Zone Fluids (B. Mack Kennedy 1510-486-6451; Fax 510-486-5496; E-mail bmkennedy@lbl.gov])}

Objectives: The San Andreas Fault (SAF) is weak in an absolute and relative sense compared to adjacent plate interiors. Models relate the low strength to high pore fluid pressures within the fault zone. Critical factors discriminating between the fault weakening models are the origin of fault zone fluids and the hydraulic connectivity between the fault zone, country rocks, and underlying basement or mantle. To address these questions, helium isotopes are being measured in fault zone fluids associated with the San Andreas and companion faults.

Project Description: The San Andreas Fault is weak. Weakness in an absolute sense is suggested by the absence of a heat flow anomaly across the fault implying that failure occurs under much smaller shear stress than inferred from laboratory friction measurements of fault zone materials. Weakness in a relative sense is indicated by a mechanically stronger adjoining crust despite the high angle that the maximum horizontal stress makes with the trace of the fault.
To explain fault weakness, several models propose that permanent high pore fluid pressures exist within the fault zone, but only near hydrostatic pressures are present within the adjoining country rock. Although the models are mechanically identical, they rely on different mechanisms to maintain the high pressure differential between the fault zone and country rock, and, as a consequence, the discriminating factor between the models is the origin of the fault zone fluids. In one case, fluids derived locally from the brittle upper crust or from infiltrating meteoric water are drawn into the fault zone during fault initiation, trapped by chemical reactions sealing the fault, and pressurized by compaction during subsequent shearing. In both cases, the brittle-ductile transition is treated as an impermeable boundary. An alternative model has fluids supplied from a region near the ductile root of the fault zone by a mantle-fed fluid source at or near lithostatic pressures.

The fault zone fluids in these three models would be expected to have very different chemical and isoto- 
pic signatures. For instance, from a noble gas perspective, fault zone fluids derived from the brittle crust would be enriched in radiogenic ${ }^{4} \mathrm{He}$, whereas fault zone fluids derived from the mantle would be enriched in ${ }^{3} \mathrm{He}$.

Results: Nearly all of the fluids sampled from the San Andreas and companion faults were found to be strongly enriched in total helium relative to the concentration in air saturated water or seawater. The isotopic composition ranged from 0.12 to $4.0 \mathrm{Ra}$, indicating a ${ }^{3} \mathrm{He}$ enrichment relative to radiogenic production and suggesting a mantle component pervades the fault zones. There is a spatial association between high ${ }^{3} \mathrm{He} /{ }^{4} \mathrm{He}$ ratios and the main strike of the San
Andreas. The highest ratios along the SAF (2.0 Ra) are found in the creeping Parkfield segment, whereas the lower ratios are found in the locked Mojave and Bear Canyon sections. Unfortunately, the relevance of this apparent correlation is limited by a lack of data. Assuming 8.0 Ra for the mantle source, a radiogenic ${ }^{4} \mathrm{He}$ addition rate equivalent to local production, and a vertical transport distance of $\sim 30 \mathrm{~km}$ (combined thickness of the brittle and ductile crust), the Parkfield sample and a steady state one-dimensional advective flow model yield a maximum upward flow rate of 2-4 mm/yr, consistent with preferred modeled flow rates necessary to maintain fault-weakening high faultzone fluid pressures.

\section{Uses of Synchrotron X-Ray Methods in Earth Sciences Research on Contaminant Transport (T.K. Tokunaga [510-486-7176; Fax 510-486-5686; E-mail tktokunaga@lbl.gov])}

Objectives: Applications of the synchrotron Xray microprobe and micro-XANES in studies of contaminant transport in soil and rock are being investigated. Spatially- and temporally-resolved chemical speciation provided with these methods is being directed toward better understanding of trace element partitioning in soil, sediment, and rock systems. This second year's research has continued to focus on diffusion and reduction of selenium and chromium at boundaries between sediments and ponded waters. In addition, feasibility studies of solute transport associated with water film flow on rock surfaces have utilized X-ray microprobe determinations of water film thickness and movement.

Project Description: Predicting transport of trace elements between various environmental compartments is currently often unsuccessful, partly due to lack of relevant information at compartment boundaries and omission of some basic transport mechanisms. Without in situ, spatially- and temporally-resolved chemical information, transport between compartments can only be described with system-specific, nonmechanistic, mass transfer models. Boundaries between surface waters and underlying sediments are important zones for transport and reaction in aquatic environments. A much less investigated but potentially very important process is that of solute transport in water films in unsaturated, fractured rock. Mechanistic understanding of solute transport in these two very different environments requires spatially- and temporallyresolved information. The present study employs micro-XANES for tracking $\mathrm{Se}$ and $\mathrm{Cr}$ diffusion and reduction at ponded water-sediment boundaries and $\mathrm{X}$ ray microprobe for tracking the thickness and advance of water films.

Results: Activities during FY 1996 (conducted primarily at NSLS) include (1) micro-XANES experiments for tracking selenium diffusion and reduction at pond-sediment boundaries, (2) similar $\mathrm{Cr}$ microXANES experiments in ponded sediment, and (3) film flow studies supplemented with X-ray microprobe experiments. Analyses of the micro-XANES on Se transport and reduction at pond-sediment boundaries have been completed. Reduction of Se(VI) to Se(IV), and ultimately to $\mathrm{Se}(0)$ (and possibly organo-Se species), within specific depths in the sediments is consistent with diffusion-limited Se depletion from pool waters. Chrome(VI) diffusion and reduction to immobile $\mathrm{Cr}$ (III) in sediment were investigated in a similar microXANES experiment. Diffusivities, distribution coefficients, and apparent first-order reduction rates obtained directly from these experiments are in reasonable agree- 
ment with values from the literature. Upcoming micro-XANES experiments on reactive transport from fracture surfaces into rock are based on experience gained from the Se and $\mathrm{Cr}$ studies.

The conditions under which solutes are transported in thin films flowing along rock surfaces are being investigated in several ways. Modifications of conven- tional soil physics methods have permitted macroscopic determination of average film thicknesses and average film velocities on a tuff fracture surface. Methods for using the X-ray microprobe (in white beam and monochromatic modes) for tracking solute movement in water films on rock surfaces are being developed.

\section{E. Thermodynamics of High Temperature Brines (K. S. Pitzer [510-486-5456; Fax 510-642-6911; \\ E-mailkspitzer@lbl.gov])}

Objectives: This project covers theoretical and experimental studies concerning the thermodynamic properties of aqueous electrolytes and other systems at high temperatures. The components important in natural waters and other geochemical fluids are emphasized. The resulting data are important in understanding various geological processes, in exploiting geothermal and other natural resources, and in fission-product waste disposal. Moreover, this information has a wide range of applicability, since similar fluids arise in many industrial processes and in high pressure steam power plants.

Project Description: The project includes both experimental and theoretical programs. The experimental program involves measuring heats of mixing or dilution of solutions at temperatures extending above $350^{\circ} \mathrm{C}$ and pressures to 1 kbar. The new calorimeter has been tested. Measurements have been made for the mixing of $\mathrm{NaCl}(\mathrm{aq})$ with $\mathrm{CaCl}_{2}(\mathrm{aq})$ and will proceed for $\mathrm{NaCl}$ (aq) with $\mathrm{MgCl}_{2}(\mathrm{aq})$.

Results: The heat of mixing results for $\mathrm{CaCl}_{2}-$ $\mathrm{NaCl}-\mathrm{H}_{2} \mathrm{O}$ will be incorporated in a general equation of state for that system. Recent theoretical results include an equation of state for $\mathrm{CaCl}_{2}-\mathrm{H}_{2} \mathrm{O}$ for temperatures above $250^{\circ} \mathrm{C}$. This equation represents phase equilibria and volumetric properties. Its structure involves theoretically calculated properties of quadrupole-dipole mixtures with moments appropriate for $\mathrm{CaCl}_{2}$ and $\mathrm{H}_{2} \mathrm{O}$, respectively, together with a few empirical terms fitted to all available experimental data. The development of this equation received support also from the Chemical Sciences Division of BES, DOE.

\section{CATEGORY:} PERSON IN CHARGE:

\section{Energy Resource Recognition, Evaluation, and Utilization}

\section{A. Russian-American Contaminant Transport Studies (Chin-Fu Tsang [510-486-5782; Fax 510-486-5686; E-mail chinfu@lbl.gov])}

Objectives: The overall goal of this project is to carry out scientific interactions and cooperative research among Russian and American scientists on the understanding of various processes in the release and trans- port of radionuclides and hazardous waste in the subsurface.

Project Description: In order to better the communication and information exchange, a visiting Rus- 
sian scientist program was established at the LBNL Russian-American Center for Contaminant Transport Studies to allow extended in-depth interaction among Russian and American researchers. The Center annually invites two to five selected Russian scientists to work at the Berkeley Laboratory as Center Fellows for a period of one to three months. During their stay in the U.S., they are to interact with U.S. scientists, give seminars, and prepare reports in English. Nominations of these scientists come from the Russian Academy of Sciences, Russian Ministry of Atomic Energy (MINATOM), Moscow State University, and U.S. national laboratories. In addition to this, the Center also receives short-term visiting scientists for a duration of a few days to one or two weeks. Through these visits and interactions, joint scientific discussions and cooperative research were carried out.

Results: In FY 1996, four Russian geoscientists were invited to LBNL as Center Fellows to share their expert knowledge on their research experience and interact with LBNL scientists. Some of the discussions centered on field investigation at the Chelyabinsk site. The Chelyabinsk site, situated in the south of the Ural Mountains, is the most radioactively contaminated site in the world due to deliberate release of radioactive wastes into rivers and lakes. (Just Lake Karachai alone in the area contains more than twice the total radioactivity released from the much publicized Chernobyl accident!)

In FY 1996, a series of 19 reports were published, among which about half have been submitted to U.S. scientific journals or books. The reports by these Russian scientists represent a wide range of disciplines (characterization studies, theoretical calculations, geochemical analyses, etc.) in the contaminate transport studies. The following is a list of these published reports: (1) Drozhko, E. G., Glagolenko, Y. U., Mokrov, Y. G., et al., Joint Russian-American hydrogeological-geochemical studies on the Karachaisystem, south Urals, LBL-38261, RAC-16. Submitted to Journal of Environmental Geology. (2) Frangos, W. and Ter-Saakian, S. A., Resistivity and induced polarization survey at a Russian nuclear waste site. LBL38188, RAC-17. Submitted to Geophysics, January 1996. (3) Solodov, I.N., Zotov, A. V., Khoteev, A. D., et al., Geochemistry of natural and contaminated sub- surface waters in fissured bed rocks of the Lake Karachai area, southern Urals, Russia. To be submitted to Journal of Applied Geochemistry, February 1996. (4) Velichkin, V.I., Asadulin, A. A., Tarasov, N. N., Poluektov, V. V., et al., Geology and geochemical features of the "Mayak" area bedrock (Chelyabinsk, S. Urals, Russia). (5) Novikov, A. P., Pavlotskaya, F. I., Korobova, E. M., et al., Distribution, speciation and computational migration model of selected radioactive nuclides in some ecosystems from the Mayak region. (6) Petrov, A. V., Samsonova, L. M., Vasil'kova, N. A., et al., Numerical modeling of the groundwater contaminant transport for the Lake Karachai area: the methodological approach and the basic two-dimensional regional model, LBL-38262, RAC-11, UC-600. (7) Samsonova, L. M. and Drozhko, E., Migration of high-density industrial waste solutions through fresh groundwaters, RAC-18. (8) Dorogokupets, P., Development of thermodynamic data bases for geochemical models, with potentional application to contaminant transport. (9) Mironenko, V. A., Flow and tracer tests at sites for underground storage of liquid waste, RAC19. (10) Rybal'chenko, A. I., Pimenov, M. K., and Munaev, E. N., Application of accumulated experience of deep-well injection of radioactive waste in hazardous and industrial waste management, RAC-20. (11) Rybal'chenko, A. I., Kurochki, V. M., Kostin, P. P., and Pavlov, P. N., Basic principles of safety assessment and system control during deep-well injection of radioactive wastes, RAC-21. (12) Rybal'chenko, A. I., Pimenov, M. K., and Kurochki, V. M., Scientific and practical results of the deep-injection disposal of liquid radioactive wastes in Russia, RAC-22. (13) Zakharova, E. V., Kaimin, E. P., Mikerin, E. I., et al., Behavior of radionuclides in geologic formations used for underground disposal of liquid nuclear wastes, RAC-23. (14) Malkovsky, V.I., Pek, A.A., Velichkin, V. I., et al., Safe geological disposal of liquid wastes: criteria for site selection in sedimentary basins. (15) Solodov, I.N., Velichkin, V.I., and Laverov, N. P., Safe geological disposal of liquid wastes: isolating geochemical properties of the injection zone rocks. (16) Pozdniakov, S.P., and Shestakov, V. M., A model of salt/fresh groundwater flow in the layered aquifer, LBL-36774. (17) Pozdniakov, S.P., Tsang, C.-F., and Korneev, V. A., Flow and tracer transport of a doublet 
well system in an aquifer with a circular inclusion, LBL38260, RAC-9, UC-600. (18) Myasoedov, B. F., The development of radiochemical procedures for determination of uranium, neptunium, plutonium, americium, strontium-90 and cesium-137 in selected samples from Mayak region. (19) Drozhko, E. G., Mokrov, Yu. G., Glagolenko, Yu. V., and Samsonova, L. M., Determination of hydrodynamic parameters of cleaved rock mass according to regime examination data in the Lake Karachai area.
Among the above, the first six papers cover scientific data and information from the Chelyabinsk (Mayak) region; papers (10)-(13) cover the subject of deep injection disposal of radioactive liquid waste, and the rest represent fundamental studies or general exploratory considerations. Papers (1)-(3) and (17) are coauthored by Russian and American scientists, though all the rest included significant review comments and suggestions from LBNL staff.

\section{B. Transport in Micro-Pore Networks (Graph Theory) (Larry Myer [510-486-6456; Fax 510-486- 5686; E-mail gemei@myer.lbl.gov for Yang], N.G.W. Cook, and G. Yang)}

Objectives: This research will provide a level of understanding of multiphase flow in microscale pores sufficient to develop algorithms that can be used to analyze and quantitatively predict transport properties in porous media at the lab scale.

Project Description: The mathematics of graph theory is used to characterize the topology of the pore structure and calculate flow. The focus of the work is on microscale pore network. The general approach is to generate a random ball-stick model that captures the important topological characteristics of pore networks. Graph theory techniques are then used to develop highly efficient algorithms for complex connectivity, fluid flow, and phase distribution problems in a two-phase network system.

Results: The first-year studies focused on twophase distribution under different capillary pressures (imbibition and drainage processes) and hysteresis loops starting and ending at arbitrary locations on the primary drainage and secondary imbibition curves. Given a pore diameter distribution in a three-dimen- sional grid, a graph theory model has been employed to simulate the transport properties of the porous media. The scanning loops (hysteresis inside the primary loop) can reveal much more information on the connectivity of the pores with stochastic diameter distribution; however, several such attempts (Soll, Celia and Wilson, 1993; Jerault and Salter, 1989) in the past did not produce satisfactory results that resemble the experimental observations (Morrow and Harris, 1965). Neither the imbibition curves (Soll et al.; Jerault and Salter) were smooth in non-log scale nor the residual saturations were persistent during scanning (Jerault and Salter). In our graph theory approach, the film flow model (through grooves of rough walls) is combined with the priority queue search of the imbibition/drainage fronts. The algorithm is very efficient and the results resemble Morrow and Harris' experimental data well. Relative permeability curves for non-wetting phase have also been produced, which capture the major features of experimental curves.

\section{Development of High-Resolution EM Imaging Methodology (Ki Ha Lee [510-486-7468; Fax 510- 486-5686; E-mail khlee@lbl.gov])}

Objectives: Lawrence Berkeley National Laboratory (LBNL) and Western Atlas Logging Services (WALS) entered a CRADA agreement in June 1996 to work together to identify and develop subsurface imaging techniques that will lead to a new dimension of electromagnetic (EM) imaging methodology with great 
potential for increased productivity. The specific objective of the CRADA project is to develop new highresolution time-domain EM (TEM) imaging technology primarily for improved reservoir evaluation, which will directly lead to increased productivity at thewell head. This will be accomplished by a joint effort between WALS, who will conduct a TEM model studies and will ultimately develop the final commercial system, and LBNL, who will provide theoretical algorithms for the high-resolution EM imaging and the prototype system and will prepare system design and specifications of the commercial system. As a background objective, with no less importance, the same technology can be applied to analyzing groundwater and groundwater contamination problems of environmental concern.

Project Description: LBNL will complete the theoretical development of wavefield transform (q-domain) and tomographic imaging methodology, verify theoretical work with scale models, prepare detailed system specifications and system design for WALS, and construct jointly with WALS a prototype borehole TEM system. WALS will provide LBNL with $2 \mathrm{D}$ and $3 \mathrm{D}$ synthetic data obtained from TEM numerical model- ing, field test the prototype borehole TEM system, and finally develop the commercial system. In addition, WALS will examine the wavefield transform technique applied to electric field data.

Results: We have identified two phases of the proposed project over a total period of four years. A prototype system will be developed in the first two years (Phase I) to demonstrate the concept of the methodology. The prototype system will be specifically for the cross-hole environment. Based on the prototype system, WALS will develop the final field system for commercial applications, including potential applications in a surface-to-borehole and single-hole acquisition environment, over the next two-year period (Phase II). There is no Phase II funding planned for LBNL at this time. Therefore, the LBNL portion of research in Phase II can only be activated if the proper level of funding becomes available at the end of Phase I. Following the Phase I schedule, LBNL is in the process of transferring imaging algorithms to WALS. A preliminary field test of the LBNL constructed prototype transmitter is scheduled for November 1996 at a site that will be jointly selected.
CATEGORY:

PERSON IN CHARGE:

\section{Hydrogeology}

\author{
S. M. Benson
}

\section{A. Three-Dimensional Hydrogeology of Fault Zones (Jane C. S. Long and Janet Jacobsen [Lawrence Berkeley National Laboratory], Kevin Hestir [Utah. State University, Department of Mathematics and Statistics] [801-797-2826; Fax 801-797-1822], James P. Evans [Utah State University], Stephen Martel [University of Hawaii, Honolulu, HI 96844])}

Objectives: The project is designed to examine the three-dimensional hydrogeologic structure of fault zones by field mapping, mechanical modeling, and probabilistic modeling. The results of these efforts will be used in developing inverse techniques for determining fault zone hydrologic behavior from well test data.

Project Description: We are examining the threedimensional permeability structure of faults in crystalline rocks and integrating these results into fluid flow models, developing mechanical models for the nucleation and growth of faults in three dimensions, and using these mechanical models in developing and testing the numerical models of fluid flow. Goals of the project are to

(1) Establish the geometry and permeability structure of small faults by geologic mapping and examinations of both hydrothermal mineral deposits and hydrothermally altered rock along the faults. 
(2) Develop a three-dimensional, numerical-mechanical technique to model fracture growth. The results of the model will be compared to the natural faults we investigate. We also will conduct parameter studies to help predict how different states of stress and different material properties affect the distribution and linkage (i.e., organization) of permeable and impermeable features along faults.

(3) Develop stochastic models, based on field data and our mechanical models, for fault development. These models will represent how permeable features and impermeable features are likely to be organized along faults. This work will form the foundation of a stochastic model for examining the hydrology of faults.

(4) Compare the long-term permeability structure of faults, as revealed by geologic evidence, with the short-term permeability structure revealed by well tests.

(5) Implement and develop software for visualizing in three-dimensions both field data on fault structure and hydrologic models of fracture flow systems.

This research integrates field work with deterministic and stochastic modeling to gain insight into how the three-dimensional permeability structure of a fault develops through time. This work will lead to an increased understanding of fault zones from geologic, geomechanical, and hydrologic points of view and to the development of a methodology for building physically realistic stochastic models for fault zone hydrology.

Results: Detailed maps of the fault zone in the Bear Creek region of the Sierra Nevada, California, have been made and visualized in three-dimensions. Thin sections have been prepared from nearly all of the rock samples collected last summer in the Bear Creek region. Nearly all the samples collected for the purpose of dating the fault zones show significant amounts of fracture-bound white mica; this indicates that the samples can yield dates for the timing of fracturing and faulting. The thin sections collected for mineralogical and geochemical analyses have also been examined; they indicate episodic precipitation of hydrothermal minerals in the faults.

One stage of two-dimensional analytical modeling has nearly been completed that bears on the mechanics of fracturing near the ends of the faults. The results so far mark a distinct improvement in our ability to account for the orientation of fault-related fractures as observed in the field, appear to place constraints on forthcoming three-dimensional mechanical modeling, and also suggest how the most essential aspects of fracturing might be accounted for in a simple but realistic manner in the stochastic modeling.

A manuscript describing a two-dimensional stochastic fracture hydrology model is awaiting final comments from the coauthors and will be submitted this fall to the Journal of Geophysical Research. Two preliminary three-dimensional stochastic models for fault zones have been constructed. These models incorporate fault zone structures suggested by the mechanical and field results of the project. The first stochastic model will be used with field maps to estimate the likely size and density of fracture components in the mapped fault zone. The second model will be used to study the hydrology of fault zones, including an inverse modeling with pressure data from a similar fault zone at the Finnsjon site in Sweden.

\section{B. Rare Gas Studies of Fluids in the San Joaquin Basin: A Basin Scale Test of Hydrogeological Process Models (B. Mack Kennedy [510-486-6451; Fax 510-486-5496; E-mail bmkennedy@lbl.gov] and T. Torgersen [University of Connecticut; 860-445-3441; Fax 860-445-3484])}

Objectives: This research project (with the University of Connecticut) will use isotopes of rare gases and their concentrations as in situ process tracers to investigate the source regions, release mechanisms, and time scales for fluid flow in the San Joaquin Basin. Specifically, this project will investigate the Elk Hills and Cymric oil fields west of Bakersfield, CA.
Project Description: The processes and time scales of fluid flow in sedimentary basins represent a fundamental question in the earth sciences with direct application to exploration and exploitation strategies for energy and mineral resources. Published studies on basin evolution and cementation history of the San Joaquin Basin suggest a simple (first cycle) sediment 
accumulation history and an episodic fluid flow history with currently extant fluids from three distinct sources: (1) meteoric waters, (2) diagenetically altered waters that have apparently undergone little transport in the system, and (3) significant cross-formation fluid flow from deeper in the system but of unknown specific origin.

This project will use noble gas isotope measurements and chemical analysis of fluids obtained from oil wells and water wells in the San Joaquin Basin to define end member sources for these fluids and use the dynamics of helium transport in the system to generate "helium model ages" (residence times) that have the capability of dating fluids on the geologic time and space scales. This study will provide first order constraints on the parameterization of fluid flow controlling the evolution of gas/oil in this system. Such refinements provide a critical test of basin models and improvements in exploration/exploitation strategies.

Results: The separate field collection efforts coordinated with three different operators have produced a suite of approximately 25 samples, including waters, oils, and gases from the lower Miocene Carneros sandstone through the upper Miocene Etchegoin Formation. An additional set of gas samples has been obtained from the Pliocene Mya member of the San Joaquin Formation. These samples cover a depth range from -3100 $\mathrm{m}$ to $60 \mathrm{~m}$ and spread over $13 \mathrm{~km}$ covering several pools.

Water samples are being analyzed for $\mathrm{Na}, \mathrm{K}, \mathrm{Ba}$, $\mathrm{Sr}, \mathrm{Ca}, \mathrm{Mg}$, and a suite of heavy metals, using plasma emission spectroscopy, and for $\mathrm{Cl}, \mathrm{Br}, \mathrm{F}$, and $\mathrm{SO}_{4}$ using ion chromatography. Preliminary examination of the analysis to date suggests that most water samples are a mixture of a deep-sourced brine with variable degrees of mixing with a less concentrated fluid. Subgroups are distinguished by reaction end members.

Oil samples were analyzed by gas chromatography/mass spectrometry and selected biomarker parameters, including C27:C28:C29 stearane ratios, C27:C28:C29 ring $\mathrm{C}$ monoaromatic stearane ratios, pristane:phytane, and phytane:C18 ratios. The results suggest a common depositional environment (in agreement with the geologic setting) for all the oils with some differences in maturity evident. Some of the shallow oils show differing degrees of biodegradation with some being highly degraded.

Gas samples are being analyzed for noble gas abundances and isotopic compositions in the RARGA laboratory at Lawrence Berkeley National Laboratory. Co-variations between the ${ }^{4} \mathrm{He} /{ }^{36} \mathrm{Ar},{ }^{132} \mathrm{Xe} /{ }^{36} \mathrm{Ar}$, and ${ }^{3} \mathrm{He} /$ ${ }^{4} \mathrm{He}$ ratios indicate mixing of two components. One is ${ }^{4} \mathrm{He}$ - and ${ }^{132} \mathrm{Xe}$-rich $\left({ }^{4} \mathrm{He} /{ }^{36} \mathrm{Ar}>4500\right.$ times the air ratio and ${ }^{132} \mathrm{Xe}^{136} \mathrm{Ar}>35$ times the air ratio) and a ${ }^{3} \mathrm{He} /{ }^{4} \mathrm{He}$ ratio $<0.02 \mathrm{Ra}$. The other component is most evident in the deeper and older formations and may have a ${ }^{3} \mathrm{He} /$ ${ }^{4} \mathrm{He}$ ratio as high as $\sim 1 \mathrm{Ra}$, but the ${ }^{4} \mathrm{He} /{ }^{36} \mathrm{Ar}$ and ${ }^{132} \mathrm{Xe} /$ ${ }^{36} \mathrm{Ar}$ ratios are low $(<1000$ and $<3.5$ times the air ratios). As the high ${ }^{3} \mathrm{He} /{ }^{4} \mathrm{He}$ ratio of the second component cannot be explained by atmospheric contamination, there is a mantle He component in the deeper portions of the Cymric and Elk Hills Fields.

\section{Investigation of Groundwater Flow Paths Through Combined Inversion of Strontium Isotope Ratios and Hydraulic Head Data (Thomas Johnson [510-486-4975; Fax 510-486-5686; E-mail tmjohnson@lbl.gov])}

This project focuses on finding zones of preferential groundwater flow using innovative geochemical and hydrologic methods. The ${ }^{87} \mathrm{Sr} /{ }^{86} \mathrm{Sr}$ ratio of the dissolved $\mathrm{Sr}$ in groundwater often evolves toward that of the $\mathrm{Sr}$ acquired from chemical reaction with the host rock and thus gives a relative indication of water-rock contact time. Preferential flow zones or "fast paths" in which residence times are much shorter than other areas may thus be observed as zones of unusually high or low ${ }^{87} \mathrm{Sr} /{ }^{86} \mathrm{Sr}$; exploitation of this effect is a major goal of this study. Additional geochemical data will be used to separate reaction effects from the effects of mixing between contrasting water masses and also to complement the ${ }^{87} \mathrm{Sr} /{ }^{86} \mathrm{Sr}$ analysis.

The geochemical part of the study is complemented by a second component that concentrates on the physical hydrology. A state-of-the-art technique that processes fields of hydraulic head data to identify zones 
of unusually high or low permeability will be applied. This inverse method incorporates fractal geometry, which facilitates a search for both the complex structure and parameters of heterogeneous permeability distributions, using only a few unknown parameters.
Work has begun toward applying these techniques to INEL and surrounding areas in the Snake River Plain Aquifer. Water samples have been acquired; ${ }^{87} \mathrm{Sr} /{ }^{86} \mathrm{Sr}$ ratio analyses and other geochemical measurements will soon be under way. Acquisition of data for the hydraulic head inversion is also in progress.

\section{Unsaturated Flow and Transport in Porous and Fractured Media (Jiamin Wan [510-486-6004; Fax 510-486-5686; E-mail jwan@csa2.lbl.gov])}

Objectives: The objective of this research is to obtain insights into some previously unrecognized processes and mechanisms influencing flow and transport in subsurface unsaturated porous and fractured media. Progress has been made at three different aspects.

Project Description/Results: (1) As background work for this project, a new method for constructing glass micromodels has been developed that permits direct visualization and quantification of flow and transport phenomena in fractured porous media. The improved micromodel method provides a unique tool for exploring some of the previously unrecognized flow and transport processes in fractured porous media. This method is directed at providing microscale explanations to some currently unresolved flow and transport issues important in predicting the larger-scale flow processes. An article, "Improved glass micromodel methods for studies of flow and transport in fractured porous media," has been published in Water Resources Research, July 1996.

(2) As another background effort for this project, a new method was developed to fabricate rock fracture casts with glass. The glass casts provide accurate reproduction of aperture structure and fine-scale surface roughness of natural fractures, good optical clarity, and representative wettabilities of mineral surfaces. The glass fracture casts will be useful tools for visually and quantitatively studying various of physical, chemical, and microbial processes occurring in rock fractures. A manuscript, "Glass casts of rock fractures: A new tool for studying flow and transport," has been submitted to Water Resources Research, May 1996.

(3) Colloid-enhanced transport in subsurface environments has become recognized as an important process. A better understanding of basic colloid transport mechanisms is needed in addressing concerns for transport of radionuclides, metals, organic contaminants, and microbes. Good progress has been made on "Colloid straining in unsaturated porous media." The outcome of this study will provide the first physically realistic conceptual model on colloid straining during unsaturated transport, along with experimental support. 
CONTRACTOR:

CONTRACT:

CATEGORY:

PERSON IN CHARGE:
LAWRENCE LIVERMORE NATIONAL LABORATORY

University of California

Livermore, California 94550

W-6405-ENG-48

Geophysics and Earth Dynamics

A. Effects of Heterogeneity on the Fracture of Rock (S. C. Blair 1510-422-6467; Fax 510-423-1057; E-mail blair5@llnl.gov], joint research with L.R. Myer [Lawrence Berkeley Laboratory; 510-486-6456])

Objectives: The objectives of this research are to understand how microscale (or grain scale) heterogeneity affects macroscopic mechanical behavior of rocks, study the process of progressive fracture of rock in compression, and evaluate the role of crack interaction in rock deformation and fracture. Moreover, this work also aims to investigate the relationship of static to dynamic moduli (in collaboration with LBL) and to characterize the role of heterogeneity at a variety of scales in fracture and the scaling properties of rocks.

Project Description: This project is concerned with simulation of rock deformation and fracture at grain and larger scales. During the initial phase of the project, a 2-D field-theory model for rock fracture was developed and then used to determine how heterogeneity in different microscale parameters affects behavior in the simulated compression tests and how macroscopic stress strain behavior is related to the formation of cracks. During the past year, a new 3-D model for deformation and fracture has been developed. This is a lattice-spring model in which elastic properties of individual volume elements (voxels) in a material are assigned separately. Stresses are transmitted by linear springs that connect the nodes surrounding each voxel.
Results: Results from the 2-D simulations show that the model exhibits an implicit size effect (inverse power law) that closely matches laboratory and field data for the dependence of sample strength on sample size and that local heterogeneity in geometry and strength may lead to crack interactions along macroscopic surfaces that are similar to those caused by shear localization and that are often observed in real experiments. The model was also used to relate macroscopic stress strain behavior in compression to the formation of microcracks and to strain energy due to cracks. Two patterns of cracking were found, including spatially uncorrelated, noninteracting cracks that have little effect on macroscopic deformation and spatially correlated interacting cracks associated with extension or linking of cracks and fractures. These cause strain softening and large changes in crack strain energy. The 3-D model has been used with images of bone microstructure obtained from X-ray tomography to estimate deformation and determine likely models of failure. Results indicate that this technique can be used to efficiently calculate the elastic properties of heterogeneous materials, incorporating on the order of 106-107 occupied voxels. 


\section{B. The Role of Carbon and Temperature in Determining Electrical Conductivity of Basins, Crust, and Mantle (A. G. Duba [LLNL; 510-422-7306; Fax 510-423-1057; E-mail alduba@llnl.gov] joint research with T. J. Shankland [505-667-4907; Fax 505-667-8487; E-mail shankland@lanl.gov], and E.A. Mathez [American Museum of Natural History; 212-769-5379; Fax 212-769-5339; E-mail mathez@amnh.org7)}

Objectives: The intent of this work is to comprehend the electrical conduction mechanisms in carbonbearing rocks and in mantle minerals for the purpose of relating electrical conductivity (s) measured in the field to formation conditions and existing state of crustal rocks and to temperatures in the mantle.

Project Description: Electrical conductivity depends strongly on temperature $(\mathrm{T})$ and on the presence of other phases, such as carbon, fluids, or ore minerals at the lower temperatures of the crust and basins. Thus, one research approach is to measure $\sigma$ of mantle minerals as functions of temperature, orientation, oxygen fugacity $\left(\mathrm{fO}_{2}\right)$, and iron content. These data supply the best models for "electrogeotherms" yet available. Another approach is to document textures of carbon in crustal rocks from basins and metamorphic zones and relate them to rock conductivity. In this case texture of carbon distribution is mapped with electron microscopy in the same samples used for conductivity measurement.

Results: We have documented that the electrical conductivity of a water-saturated schist, collected from a surface outcrop near the Denali Fault Zone in the Yukon-Tanana terrane of south-central Alaska, increases slightly with pressure to about $200 \mathrm{MPa}$. Thus, the accepted hypothesis that electrical conductivity of saturated crustal rocks decreases with pressure is not necessarily true. Detailed petrographic examination of one sample, a quartz-mica-garnet-schist, revealed the presence of a stringer of carbonaceous material generally less than $10 \mu \mathrm{m}$ thick within one of the muscovite layers. The stringer extends for about $2 \mathrm{~cm}$ along the foliation and is probably responsible for the anomalous conductivity change with pressure. The carbon- aceous stringer together with its host muscovite layer is deformed and broken around a rotated garnet porphyroclast. We interpret this to indicate that the carbonaceous material formed by fluid deposition in a fracture formed within the muscovite layer, possibly during the main phase of metamorphism and deformation. The mica and carbon stringer were then deformed by a non-coaxial deformation responsible for rotation of the garnet porphyroclasts. The deformation was accommodated by plastic deformation of quartz, indicating that it occurred in the ductile regime under conditions at least equivalent greenschist facies metamorphism. This result demonstrates that the carbonaceous stringer was present at depth. Brittle deformation on the microscopic scale is observed in the rock and interpreted to have been caused by subsequent unloading due to uplift. The brittle deformation broke the connectivity of the carbon stringer, explaining in part why the rock does not exhibit anomalously high conductivity at $0.1 \mathrm{MPa}(1 \mathrm{~atm})$ pressure. The observations indicate that carbonaceous material may exert a primary control on crustal electrical conductivity because it may be present as interconnected arrays in grain boundaries or microfractures or in megascopic, throughgoing fractures. We are currently pursuing laboratory measurements on the effect of carbon deposition on the electrical conductivity of rocks during dilatancy associated with fracture. Preliminary indications are that there is an increase in conductivity as carbon is precipitated on newly formed crack surfaces as a rock fails in the laboratory. In addition, we have documented a small effect of intracrystalline hydrogen on the electrical conductivity of olivine. 


\section{CATEGORY:}

PERSON IN CHARGE:

\section{Geochemistry}

\section{A. Thermodynamic and Transport Properties of Aqueous Geochemical Systems (Joseph A. Rard [510-422-6872; Fax 510-422-0208; E-mail rard1@llnl.gov] and Donald G. Miller [510-422-8074; Fax 510-422-6363; E-maildmiller@llnl.gov])}

Objectives: The objectives are to (1) measure precise and accurate osmotic/activity coefficients, solubilities, densities, and mutual (Fick's law) diffusion coefficients for aqueous brine salts and their mixtures and osmotic/activity coefficients for acidic sulfate mixtures, (2) develop reliable methods to estimate such properties for multicomponent solutions from binary solution properties, and (3) calculate generalized transport coefficients.

Project Description: The general techniques of classical thermodynamics and of linear irreversible thermodynamics are used to understand and model equilibrium and transport processes in brines and other aqueous electrolyte mixtures relevant to energy programs. Properties being measured are osmotic/activity coefficients and solubilities by the isopiestic method, densities by pycnometry and vibrating densimetry, and diffusion coefficients by Rayleigh and Gouy interferometry. One goal is to measure highly accurate data for systems involving geochemical brines, radioactive waste isolation, and chemical pollutants. A second goal is to develop estimation methods for accurate predictions of these properties for aqueous electrolyte mixtures of arbitrary complexity, using the accurate new data as test systems. Transport data are being analyzed as Onsager transport coefficients and osmotic/activity coefficients are being analyzed using extended Pitzer's equations.

Results: Diffusion experiments were performed previously at two different solute ratios of mixtures of $\mathrm{NaCl}$ and $\mathrm{Na}_{2} \mathrm{SO}_{4}$ at $0.5 \mathrm{~mol} / \mathrm{dm}^{3}$ and $25^{\circ} \mathrm{C}$ using Gouy interferometry. Two additional solute ratios were studied as were the limiting binary solutions $\mathrm{NaCl}$ and $\mathrm{Na}_{2} \mathrm{SO}_{4}$, all at $0.5 \mathrm{~mol} / \mathrm{dm}^{3}$, using Rayleigh interferometry. The Rayleigh experiments were done with the Gosting diffusiometer, which is now automated for "real time" data acquisition using a computer-controlled photodiode array. Similar experiments are planned at 1.0 $\mathrm{mol} / \mathrm{dm}^{3}$. Isopiestic experiments were performed for aqueous $\mathrm{H}_{2} \mathrm{SO}_{4}+\mathrm{MgSO}_{4}$ mixtures at $25^{\circ} \mathrm{C}$ and are now complete for the acid-rich half of this system at three molality fractions $\mathrm{z}$ of $\mathrm{H}_{2} \mathrm{SO}_{4}$. A total of 195 data points have been measured, covering the total molality (sum of the molalities of $\mathrm{H}_{2} \mathrm{SO}_{4}$ and $\mathrm{MgSO}_{4}$ ) and water activity ranges of $0.12548 \leq \mathrm{m}_{\mathrm{T}} \leq 12.050 \mathrm{~mol} / \mathrm{kg}$ and $0.9958 \leq \mathrm{a}_{\mathrm{w}} \leq 0.2758$ at $\mathrm{z} \approx 6 / 7$, of $0.13563 \leq \mathrm{m}_{\mathrm{T}} \leq 11.011$ $\mathrm{mol} / \mathrm{kg}$ and $0.9958 \leq \mathrm{a}_{\mathrm{w}} \leq 0.3312$ at $\mathrm{z} \approx 5 / 7$, and of $0.14741 \leq \mathrm{m}_{\mathrm{T}} \leq 7.2060 \mathrm{~mol} / \mathrm{kg}$ and $0.9958 \leq \mathrm{a}_{\mathrm{w}} \leq 0.5582$ at $z \approx 4 / 7$. The highest molalities for all three $z$ values extend well into the supersaturated region. Stock solutions of $\mathrm{H}_{2} \mathrm{SO}_{4}+\mathrm{MgSO}_{4}$ mixtures were prepared with $z \approx 3 / 7,2 / 7$, and $1 / 7$, and one series of experiments was started. Another of our isopiestic chambers is being prepared for a second series at these composition fractions. Once the experiments have been performed for the $\mathrm{MgSO}_{4}$-rich region, the results will be modeled with extended versions of Pitzer's equations and will yield reliable parameters for the interaction of $\mathrm{Mg}^{2+}$ with $\mathrm{HSO}_{4}^{-}$.

During this period three journal articles were published and three more submitted. One published paper reported isopiestic results for aqueous $\mathrm{H}_{2} \mathrm{SO}_{4}$ solutions at low molalities where literature data were discrepant. The other two analyzed various possible mixing rules for estimating ternary solution densities and electrical conductances based on the properties of their constituent binary solutions. Papers submitted for publication include $\mathrm{NaCl}+\mathrm{Na}_{2} \mathrm{SO}_{4}$ diffusion coefficients at $0.5 \mathrm{~mol} / \mathrm{dm}^{3}$, the effect of different-sized concentration differences on the diffusion coefficients of $\mathrm{NaCl}+\mathrm{KCl}$, and isopiestic results for acid-rich $\mathrm{H}_{2} \mathrm{SO}_{4}+\mathrm{MgSO}_{4}$ mixtures. 


\section{B. Experimental Determination of Mineralogical Controls on UThPb Redistribution: Implications for Crust/Mantle Differentiation (H.F. Shaw 1510-423-4645; Fax 510-423-1057; E-mail shaw4@llnl.gov] and F.J. Ryerson [510-422-6170; Fax 510-422-1002; E-mail ryerson@s91.es.llnl.gov])}

Objectives: The objective of this work is to determine mineral/aqueous fluid and mineral/silicate liquid partition coefficients for a suite of trace elements ( $U$, $\mathrm{Th}, \mathrm{Hf}, \mathrm{Zr}, \mathrm{Nb}$, Ta, Sr, Ba, Rb, and $\mathrm{Pb}$ ) under conditions relevant to fluid metasomatism and partial melting in the upper mantle. The results of the project will provide important constraints on the petrogenetic interpretation of trace element, $\mathrm{U}, \mathrm{Th}, \mathrm{Pb}$, and $\mathrm{U}$-series disequilibrium data obtained on igneous rocks, particularly those formed in subduction-zone environments.

Project Description: Along with the formation of the Earth's core, the differentiation of the crust and mantle represents the major chemical fractionation process occurring on the Earth. The nature of this process has been constrained by a wide variety of trace element and isotopic analyses of crust- and mantle-derived samples. Effective utilization of these data requires a quantitative understanding of the fractionation of the elements of interest between minerals and both silicate melts and aqueous fluids. For many elements, however, the relevant mineral/melt partition coefficients are poorly known and there is an almost complete lack of data for the partitioning of trace elements between minerals and aqueous fluids. The experimental data generated in this project will provide quantitative information of the partitioning of trace elements of geologic interest between minerals and melts and aqueous fluids, with emphasis on the partitioning of $\mathrm{U}, \mathrm{Th}, \mathrm{Pb}$, and the high field strength elements ( $\mathrm{Zr}, \mathrm{Hf}, \mathrm{Nb}, \mathrm{Ta})$. Partition coefficients for elements of interest are being obtained as a function of $\mathrm{O}_{2}, \mathrm{~T}, \mathrm{P}$, and fluid or melt composition. Experimental charges are produced using standard and newly developed techniques that utilize one-atmosphere gas-mixing furnaces and high-pressure piston-cylinder devices. The trace element composition of the charges is being measured primarily by quantitative ion microprobe techniques, supplemented by electron microprobe analyses and solid-source mass spectrometry.

Results: The partitioning of $\mathrm{U}, \mathrm{Th}, \mathrm{Pb}, \mathrm{Ba}, \mathrm{Sr}, \mathrm{Nb}$, and Ta between aqueous fluids (with and without added $\mathrm{Cl}^{-}$and $\mathrm{CO}_{3}^{2-}$ ) and rutile, clinopyroxene, orthopyroxene, pyrope, olivine, and pargasitic amphibole under upper mantle conditions has been studied. Using these data, together with literature data for $\mathrm{Sr}$ and $\mathrm{Pb}$ isotopic compositions of Pacific island arc basalts (IABs), the calculated composition of a fluid in equilibrium with the average $\mathrm{Pacific}$ IAB source is ${ }^{87} \mathrm{Sr} /{ }^{86} \mathrm{Sr}=0.7036,{ }^{207} \mathrm{~Pb} /$ ${ }^{204} \mathrm{~Pb}=15.57, \mathrm{Sr} \sim 500 \mathrm{ppm}$ and $\mathrm{Pb} \sim 30 \mathrm{ppm}$. The Subarc fluid composition is consistent with a mixture of fluids from both altered MORB ( 96wt $\%)$ and sediment $(\sim 4 \mathrm{wt} \%)$, with $\sim 96 \%$ of the Sr from the former and $\sim 70 \%$ of the $\mathrm{Pb}$ from the latter. Although the mass fraction of sediment-derived fluid in the Subarc fluid may be minor, sedimentary input for $\mathrm{Ba}(0-50 \%)$, Th (53$88 \%), \mathrm{U}(61-83 \%)$, in addition to $\mathrm{Pb}$, can be significant. Our results are consistent with, and provide additional support for models of, slab input to IAB sources. Preliminary results indicate that metasomatism by water-rich fluids and silicate melts will produce similar but distinguishable trace element signatures in IABs. Experiments were conducted to determine partition coefficients for $\mathrm{Ti}, \mathrm{Rb}, \mathrm{Ba}, \mathrm{Sr}, \mathrm{Zr}, \mathrm{Nb}, \mathrm{Ta}, \mathrm{Hf}, \mathrm{Pb}, \mathrm{U}$, and Th between pargasitic amphibole and a synthetic hydrous silicate liquid. $\mathrm{Rb}, \mathrm{Ba}, \mathrm{Nb}$, and $\mathrm{Ta}$ are dramatically less compatible in pyroxene than in amphibole, while other elements, such as $\mathrm{Th}, \mathrm{U}, \mathrm{Hf}$, and $\mathrm{Zr}$, have similar compatibilities. Because of these differences, liquids produced by small degrees of partial melting of amphibole-bearing mantle sources, or by high-level fractionation of amphibole, should have distinctively lower Th-normalized $\mathrm{Rb}, \mathrm{Ba}, \mathrm{Nb}$, and $\mathrm{Ta}$ concentrations than melts from amphibole-free systems. Using mineral-melt partition coefficients determined in this project, the isotopic evolution of the uranium-series nuclides ${ }^{238} \mathrm{U},{ }^{230} \mathrm{Th},{ }^{226} \mathrm{Ra}$, and ${ }^{231} \mathrm{~Pa}$ during partial melting in an ascending column of mantle was modeled. The observed $\left[{ }^{230} \mathrm{Th}\right]$ and $\left[{ }^{231} \mathrm{~Pa}\right]$ excesses in e-MORB and $n-M O R B$ can be generated by initiating melting in the garnet stability field at varying depths, and these excesses can be preserved during equilibrium transport of the melt at geologically reasonable rates through the overlying spinel herzolite. The mineral/melt partition- 
ing of $\mathrm{Li}, \mathrm{Be}$, and $\mathrm{B}$ between olivine, orthopyroxene, clinopyroxene, amphibole, and synthetic basaltic melt has been determined at 1 atmosphere and $15 \mathrm{~kb}$. Calculations using these data indicate that the $\mathrm{B} / \mathrm{Li}$ and $\mathrm{Be} /$ $\mathrm{Li}$ ratios in mantle-derived melts will be fractionated with respect to their source but that the $\mathrm{B} / \mathrm{Be}$ ratio in the melt will faithfully record the value in the source throughout melting. This implies that the systematic variation in the $\mathrm{B} / \mathrm{Be}$ ratio of arc basalts as a function of distance from the trench is a primary feature of the mantle source region and not a result of the melting process.

\section{Uranium, Thorium, Lead, and Oxygen Diffusion in Rock-Forming Minerals: Implications for Reactive Transport (F.J. Ryerson [510-422-6170; Fax 510-422-1002; E-mail ryerson@s91.es.llnl.gov] and K.D. McKeegan [University of California at Los Angeles; 310-825-3580; Fax 310-825-2779; E-mail kdm@argon.ess.ucla.eduJ)}

Objectives: The spatial distributions of isotopes of elements, such as uranium, thorium, lead, and oxygen, observed on a microscale can be utilized to constrain thermal histories of crustal rocks and the extent of their interactions with fluids. There are two requirements necessary for application of this idea to real geologic systems: first, microanalytical techniques must be employed to quantitatively measure the isotopic or elemental heterogeneities, and, second, fundamental diffusion data must be experimentally determined in order to know the rates at which equilibrium between fluid (either melts or aqueous fluids) and host rocks can be approached as a function of various external conditions.

Project Description: The diffusion coefficients for uranium, thorium, lead, and oxygen will be determined in a number of different minerals under a variety of external conditions. The experimental diffusion runs are performed at the Lawrence Livermore National Laboratory and the analytical phase of the work is done at UCLA, using the Cameca ims 1270 ion microprobe. Techniques for the in situ measurement of either experimentally induced or naturally occurring variations of isotopic and elemental concentrations are being developed for the UCLA ion microprobe.

Results: Silicon and oxygen diffusion have been measured in a grossular, spessartine, and pyrope almandine garnets at $800^{\circ} \mathrm{C}, 1 \mathrm{GPa}$, and oxygen diffusion measured at $800^{\circ} \mathrm{C}, 1 \mathrm{~atm}$. The $1 \mathrm{GPa}$ runs employ an overgrowth technique in which a single crystal of garnet is annealed in an $\mathrm{H}_{2}{ }^{18} \mathrm{O}$ fluid-containing powdered ${ }^{30} \mathrm{SiO}_{2} ; 1$ atm runs employ an ${ }^{18} \mathrm{O}$-enriched gas reservoir. The garnet overgrowth formed in the $1 \mathrm{GPa}$ runs (typically $300 \mathrm{~nm}$ thick) decreases the tendency for surface dissolution under hydrothermal conditions, and our experiments yield well-behaved diffusion profiles. "Water" concentrations were determined by IR and ranged from $0 \mathrm{ppm}$ (Tanzania pyrope-almandine) to $2800 \mathrm{ppm}$ (Jeffrey Mine grossular). At $800^{\circ} \mathrm{C}$, $1 \mathrm{~atm}$ (air and NNO), the garnets showed no loss of water when annealed up to $120 \mathrm{hr}$. At $1 \mathrm{~atm}$, oxygen diffusion in all of the studied garnets is $\sim 10-24 \mathrm{~m}^{2} \mathrm{~s}^{-1}$, independent of both water content and bulk composition. Oxygen diffusion in grossular and spessartine both increases to $\sim 10-21 \mathrm{~m}^{2} \mathrm{~s}^{-1}$ at $1 \mathrm{GPa}$ under hydrous conditions; unfortunately, the short diffusion profiles preclude IR analysis for water in the diffused region. Oxygen diffusion is inversely correlated with silicon concentration (approximated from the sum of ${ }^{28} \mathrm{Si}$ and ${ }^{30} \mathrm{Si}$ intensities) and suggests that the decreased rates of oxygen diffusion are related to a decrease in the hydro-garnet component through the exchange of $\mathrm{SiO}_{4}^{4-}$ $=\mathrm{O}_{4} \mathrm{H}_{4}{ }^{4-}$. At $1.0 \mathrm{GPa}$, silicon diffusion coefficients are equal to oxygen diffusion coefficients for both grossular and spessartine. Closure temperatures for oxygen diffusion in a $1 \mathrm{~mm}$ diameter garnet are always in excess of $1000^{\circ} \mathrm{C}$ for geologically reasonable cooling rates. Sluggish oxygen diffusion in garnet confirms that oxygen isotopic compositions recorded during the growth will be faithfully retained. 


\section{An Experimental Investigation of Mechanisms Controlling Glass Dissolution (Susan A. Carroll [510 423-5694; Fax 510-422-0208; E-mail carroll6@llnl.gov] and William L. Bourcier [510-423-3745; Fax 510-422-0208; E-mail billb@llnl.gov])}

Objectives: The objective of this project is to identify the underlying molecular mechanisms responsible for dissolution of glass and to utilize this understanding in the development of quantitative models for predicting glass dissolution rates in nature.

Project Description: This project uses a combination of conventional glass dissolution experiments, potentiometric surface titrations, and NMR characterization of glass and its solution interface to determine the mechanisms controlling glass dissolution. The dissolution behaviors of three simple glass compositions $\left(\mathrm{SiO}_{2}, \mathrm{Na}_{2} \mathrm{O}_{4} \cdot \mathrm{SiO}_{2}\right.$, and $\left.\mathrm{NaAlSi}_{3} \mathrm{O}_{8}\right)$ will be used to develop a mechanistic model based on three principal observations: (1) the $\mathrm{pH}$ dependence of dissolution rates, (2) the saturation effect, and (3) the effect of absorbed alkali cations on dissolution rates. The results will be relevant to a number of problems, including the stability of radioactive waste glasses, weathering of volcanic glasses, and obsidian hydration age dating, among others.

Results: In this first year of the project, we are focusing on the mechanisms controlling simple $\mathrm{SiO}_{2}$ glass dissolution as a function of solution $\mathrm{pH}, \mathrm{Al}, \mathrm{Si}$, $\mathrm{Na}$, and C's concentrations. We have completed the experimental measurements of silica glass dissolution rates at $25^{\circ}$ and $70^{\circ} \mathrm{C}$ in $\mathrm{pH} 2,4,6,8,10$, and 12 solutions and in similar buffer solutions at $\mathrm{pH} 4$ and 10 doped with $\mathrm{NaCl}$ and $\mathrm{CsCl}$. We have also reacted high surface area $\left(270 \mathrm{~m}^{2} / \mathrm{g}\right)$ silica gels in constant $\mathrm{pH} 4$ and 10 solutions ( $\mathrm{pH}$-stat experiments) also doped with either $\mathrm{CsCl}$ or $\mathrm{NaCl}$. These samples are to be used in NMR studies of $\mathrm{Si}, \mathrm{Cs}$, and $\mathrm{Na}$. Their high surface areas are optimum for enabling the NMR probe to detect adsorbed alkali cations on the silica surface. We have made $\mathrm{NaAlSi}_{3} \mathrm{O}_{8}$ (albite) glass for our next set of dissolution experiments that are currently in progress. Samples of the reacted glass and silica gels are currently being analyzed at the NMR lab at UC Davis. A sample probe suitable for making measurements on the reacted glass samples has been installed and tested. The NMR work is in progress. Our results show that the dissolution rate of silica glass as a function of $\mathrm{pH}$ is independent of $\mathrm{pH}$ below $\mathrm{pH} 8$ but increases with increasing $\mathrm{pH}$ above 8 . This trend is similar to that observed for quartz; however, the dissolution rate for silica glass is higher than for quartz, as expected. At $25^{\circ} \mathrm{C}$, silica glass dissolves about two times faster with each ten-fold increase in $\mathrm{Na}$ concentration at $\mathrm{pH} 10$. Under the same conditions, Cs does not affect silica glass dissolution rates. This difference in behavior of the two ions of quite different sizes is the focus of the NMR work. We anticipate that the NMR will be able to determine how $\mathrm{Na}$ and $\mathrm{Cs}$ are coordinated at the glasssolution interface, and this information we anticipate will help to explain the different effects the two cations have on glass dissolution.

\section{E. Mineral Dissolution and Precipitation Kinetics: A Combined Atomic-Scale and Macro-Scale Investigation (Kevin G. Knauss [510-422-1372; Fax 510-422-0209; E-mail knauss@s19.es.llnl.gov] and Carrick M. Eggleston [307-766-6769; Fax 307-766-6679; E-mail carrick @uwyo.edu])}

Objectives: Our objectives are to build and test a contact atomic force microscope (AFM) capable of operation at up to $150^{\circ} \mathrm{C}$ and 6 atm pressure, to apply this AFM to direct, in situ, and real-time observations of step dynamics during dissolution and growth of oxide and silicate minerals at elevated temperature and pressure, and to use rate and stoichiometric data from parallel macroscopic dissolution and growth experi- ments to interpret mineral rates, using a combined microscopic Burton-Cabrera-Frank and macroscopic surface-complexation model.

Project Description: This project combines atomic-scale and macro-scale approaches to the study of mineral-fluid interaction in order to significantly improve our understanding of, and ability to predict the course of, mineral dissolution and precipitation pro- 
cesses. We are building a high temperature flowthrough fluid cell for the AFM. This will allow atomicscale kinetic experiments under geologically relevant conditions for important oxide and aluminosilicate minerals. Identical conditions will be investigated, using macroscopic wet-chemical rate experiments, including conditions both near and far from equilibrium. We will measure rates of dissolution and precipitation, determine activation energies, measure rates of step motion across surfaces (including anisotropy), and investigate step-step interactions that affect rate. We will then be able to address many still-open questions concerning the exact forms for rate laws near and far from equilibrium, the microscopic interpretation of these rate laws in terms of dissolution and precipitation mechanisms operating under various conditions, and the question of what exactly the "active area of interaction" and "active sites" are on mineral surfaces.

Results: This project was only recently initiated. We are still in the design stages for the proposed high temperature and pressure AFM. Several important design modifications have been made so that we can use existing commercial control electronics, software, and, in some cases, hardware.

\section{CATEGORY:}

\section{Energy Resource Recognition, Evaluation, and Utilization}

\section{PERSON IN CHARGE:}

\section{F. J. Ryerson}

A. Linear and Nonlinear Mechanics of Rocks (J. G. Berryman [510-423-2905; Fax 510-422-1002; E-mail berryman@s123.es.llnl.gov], P. A. Berge [510-423-4829; Fax 510-423-1057; E-mail berge@s44.es.llnl.gov], and D. Elata [510-423-8281; Fax 510-422-1002; E-mail elata@llnl.gov])

Objectives: Our major objective is to understand factors affecting physical properties of rocks in order to improve our ability to predict rock behavior from knowledge of rock components. One new tool developed to accomplish this objective is the recent discovery of exact results in poroelasticity and thermoelasticity for two component composite rocks. This project exploits these as well as other new results, with the expectation that new insight into the linear and nonlinear mechanics of rocks will result. Such insight may prove important for understanding earthquake source mechanisms and for oil field engineering practices related to drilling and pumping. Also, such information is important for interpretation of both seismic and electrical field data.

Project Description: Modeling of idealized twomineral component rocks has been one of the main thrusts of the effort. Recent advances show that it is possible to compute all the compressibilities (jacketed, unjacketed, jacketed pore, and unjacketed pore) exactly for certain models. Although very general results on effective-stress rules for various physical properties of rocks have already been published, more explicit applications to examples of well consolidated and poorly consolidated rocks have now been studied and will soon be reported. The new approach based on exact results offers promise of analytical and/or numerical modeling capability from linear to semilinear to fully nonlinear deformation of rocks, including rocks containing cracks, within the same basic theoretical framework. These types of results are of interest in the oil and gas industry, as they play a significant role in interpretation of AVO (amplitude versus offset) data used as direct hydrocarbon indicators. The same basic framework can also be employed to treat reservoir characterization problems, especially regarding the effects of changing stress on matrix and fracture permeability in double-porosity models used for reservoir pumpdown studies. In addition to linear and nonlinear elastic materials, mixtures of viscoelastic materials have also been studied. 
Results: We have developed a unified approach for deriving effective medium theories and demonstrated the range of applicability and relationships between implicit and explicit schemes. A paper on this work was recently published in the journal Mechanics of Materials. A new theory of the elastic behavior of granular materials and/or cracked materials under uniaxial stress has been developed and its implications continue to be explored. In collaboration with Stanford researchers, we have developed a new approximate analytical solution describing the pressure dependence of contact stiffnesses for coated spheres, which can be used to describe the elastic behavior of cemented sandstones. These results have also been submitted for publication in the journal Mechanics of Materials. We also show that theoretical models for granular rocks must be modified to avoid violating thermodynamic constraints. A paper on these results has been submitted to the ASME Journal of Applied Mechanics. In collaboration with Professor Graeme Milton of the University of Utah, we have developed a method for obtaining rigorous bounds on the shear modulus of viscoelastic composites, such as rocks that contain mixtures of two viscoelastic constituents (for example, quarts and a viscous fluid, or quartz and clay). This work extends and completes the previous work of Gibiansky (Princeton) and Milton on the bounds for the bulk modulus of viscoelastic composites and furthermore shows how well various realizable theoretical models produce results consistent with the bounds. A paper describing this work has been submitted for publication to the Proceedings of the Royal Society of London. In collaboration with researchers at the University of Wisconsin, we have developed methods to determine and in some cases drastically reduce the number of elastic coefficients required to describe the behavior of a double-porosity system in the presence of changing pore pressure for applications to reservoir pumpdown. The first part of this work has been accepted for publication in the Journal of Geophysical Research. This work continues both at the theoretical level and also at the level of developing new computer simulation techniques to make use of our results for reservoir engineering and resource management.

\section{B. Velocity Analysis, Parameter Estimation, and Constraints on Lithology for Transversely Isotropic Sediments (P.A. Berge [510-423-4829; Fax 510-423-1057; E-mail berge@s44.es.llnl.gov], J. G. Berryman [510-423-2905; Fax 510-422-1002; E-mail berryman@s123.es.llnl.gov], D. Elata [510-423-8281; Fax 510-422-1002; E-mail elata@llnl.gov], I. Tsvankin [Colorado School of Mines] [303-273-3060; Fax 303-273-3478; E-mail ilya@dix.mines.edu], K. Larner [Colorado School of Mines] [303-273-3428; Fax 303-273-3478; E-mail klarner@dix.mines.edu], F. Muir [Stanford University] [415-723-9390; Fax 415-723-1188; E-mail francis@pangea.stanford.edu])}

Objectives: Our major objective is to obtain constraints on lithology, using the anisotropy parameters recovered from seismic data, in order to improve analysis of seismic reflection data collected in areas where the geology is complicated by anisotropy and heterogeneity.

Project Description: The influence of anisotropy leads to significant distortions in seismic reflection data processing and errors in interpretation that can result in drilling in the wrong place or to the wrong depth and errors in data analysis that may turn a play into a non-play or vice versa. Theoretical constraints on the elastic stiffnesses in a transversely isotropic medium and algorithms newly-developed at the Colorado School of Mines for processing seismic reflection data exhibiting transverse isotropy are being combined with rock physics analysis to determine how constraints on anisotropy translate into constraints on lithology and improved interpretation of seismic reflection data. Expected benefits of this project are improved processing and interpretation of seismic reflection data in the oil exploration industry and increased understanding of the connections between seismic properties and other physical properties of rocks and sediments exhibiting anisotropy. 
Results: Investigators from the Colorado School of Mines have developed new algorithms and codes for processing seismic reflection data in vertically inhomogeneous, transversely isotropic media and have applied these codes to a Chevron data set to produce estimates of some of the anisotropy parameters. These results have been published in Geophysics and in The Leading Edge and were presented at the 7th International Workshop on Seismic Anisotropy. Colorado School of Mines researchers have also developed algorithms for processing seismic reflection data that exhibit transverse isotropy with a nonvertical symmetry axis. These results have been submitted to Geophysical Prospecting, to the EAGE 58th Annual Meeting, and to the 1996 annual meeting of the Society of Exploration Geophysicists. Results from research at Stanford include the development of a set of mathematical tools for describing the elastic constants of anisotropic materials using a minimum number of parameters, where these parameters have lithologic significance. These results were presented at the 7 th In- ternational Workshop on Seismic Anisotropy. LLNL investigators have found some links between constraints on anisotropy parameters in certain models of anisotropic media and constraints on lithology. These results were presented at the 7th International Workshop on Seismic Anisotropy. LLNL researchers collaborating with Schlumberger researchers have also developed models to describe stress-induced anisotropy in granular media. Some of these results have been presented at the 7th International Workshop on Seismic Anisotropy and submitted for publication in Phys. Rev. E. LLNL and Stanford researchers are currently developing and analyzing additional theoretical models of rocks to determine how anisotropy parameters are related to rock properties, especially for rocks containing fluids, and how these relationships constrain both lithology and fluid content. The Stanford/LLNL group is also determining what information from seismic reflection data is necessary and sufficient for correlating anisotropy parameters and lithology. Work on fluid substitution in anisotropic sediments is in progress.

\section{Compositional Kinetic Modeling of Oil and Gas Formation (Alan K. Burnham [510-443-8779; 510-423-7914; E-mail burnham1@llnl.gov])}

Objectives: This work develops and tests models of petroleum generation, migration, and thermal stability. These models are used to reduce petroleum exploration risk and costs through integrated basin analysis, which combines many aspects of geology, geophysics, geochemistry, and hydrology to determine where and when oil is generated, migrates, and accumulates.

Project Description: Oil and gas generation kinetics and oil destruction kinetics have been measured by a variety of techniques, including isothermal hydrous pyrolysis, temperature-programmed pyrolysis using various detectors, and sealed capillary tube pyrolysis, and kinetic models are developed to predict oil and gas generation and composition and their expulsion from the source rock. The final remaining experiments are directed towards understanding the kinetics of oil cracking to better understand the floor for oil survival and formation mechanisms of natural gas.
Results: During the past year, four papers were published on earlier work on a new kinetic model for well-preserved algal kerogens, a test of the conventional parallel reaction model for marine and terrestrial kerogens using hydrous pyrolysis residues, experiments and a kinetic model for high-pressure cracking of hexadecane, and a basin analysis study of the Maracaibo basin. New experimental work expanded our use of isotopically labeled hydrocarbons to study the cracking of hydrocarbons in crude oil, including hexadecane cracking at $310^{\circ} \mathrm{C}$, the fate of alkene intermediates, and the rate of dealkylation of benzene and cyclohexane. The experiments are now essentially complete, but since data analysis is currently in progress, there are only a few conclusions that can be given at this time. Earlier results indicated that both the rate and mechanism of alkane cracking are different in pure alkanes and in crude oils. Cracking of oils doped with $1,2-{ }^{13} \mathrm{C}$-labeled dodecene indicated that alkanes are readily saturated 
and much less likely to undergo addition reactions in crude oils as compared to alkane mixtures. This supports the idea that there are sufficient hydrogen donors in crude oils to quench free radical chain reactions and slow the overall cracking rate of alkanes. Of the alkyl radicals and alkenes that are not saturated by hydrogen donors, ${ }^{13} \mathrm{C}$ NMR measurements show that addition to aromatic rings rather than alkylation of alkenes is the predominant pathway. The cracking rate of $1,2-{ }^{13} \mathrm{C}$ labeled hexadecane doped in a North Sea crude oil was measured at $310^{\circ} \mathrm{C}$ over nine months in order to more accurately extrapolate to geologic time frames. No cracking products were observed, which means that the rate must be at least 150 times slower than at 350, which indicates an activation energy of $90 \mathrm{kcal} / \mathrm{mol}$. This suggests that all free-radical propagation reactions have been quenched and the effective activation energy approaches that of initiation reactions. If thermal cracking were the only destruction mechanism, petroleum could survive for nearly a million years at $250^{\circ} \mathrm{C}$ and more than a billion years at $200^{\circ} \mathrm{C}$, in agreement with some recent geological observations. 
LOS ALAMOS NATIONAL LABORATORY

University of California

Los Alamos, New Mexico 87545

CONTRACT:

W-7405-ENG-36

CATEGORY:

Geophysics and Earth Dynamics

PERSON IN CHARGE:

M. Fehler

A. New Methods for Modeling and Processing Seismic Data (ACTI) (M. Fehler [505-667-1925; Fax

505-667-8487; E-mail fehler@seismo5.lanl.gov], Ru-Shan Wu [U.C. Santa Cruz], N. Bleistein

[Colorado School of Mines], M.N. Toksoz [Massachusetts Institute of Technology])

Objectives: Objectives are to develop and test new methods for modeling and processing seismic data of importance to the oil and gas industry.

Project Description: As new oil and gas reserves become more difficult to find and expensive to drill for, there is increased interest in obtaining ever better images of the earth beneath increasingly complicated structures. The demand for processing large seismic data sets to obtain high-quality images has thus become of critical importance. This project consists of three parts, each addressing a significant issue in analysis of seismic data that is relevant to petroleum exploration. The three parts are (1) Fast 3D Modeling and Prestack Depth Migration Using Multi-Screen Wave Propagator. We are developing and testing the use of a multi-screen (phase-screen for acoustic waves, complex-screen for elastic waves) algorithm as a backpropagator for $3 \mathrm{D}$ pre-stack migration in laterally inhomogeneous media. The method is a wide-angle one-way elastic wave propagator that neglects reverberations and adopts a fast dual-domain (space and wave number) implementation. (2) Statics Estimation for Complex Media Using Prestack Migration. Development and testing of a method for estimating statics in complex terrain by iterative use of migration. (3) True Amplitude Dip Moveout. An investigation of amplitude effects of nonplanar interfaces on DMO by high-frequency asymptotic analysis of the application of a DMO formalism to Kirchhoff-approximate data for a single reflector.
Results: Improvements have been made to the elastic multi-screen modeling methods to allow wide-angle scattering and single backscattering effects to be included. An algorithm for 3D prestack depth migration was developed for the acoustic phase-screen one-way propagator. Both the original phase screen and the wideangle approximation methods have been tested on synthetic models. An initial computer code was implemented on the Cray T3D that demonstrates the phasescreen migration algorithm parallelizes well by having multiple processors each working on separate subsets of wavefield frequencies.

Further theoretical tests on the wide-angle complexscreen forward modeling method revealed an instability for critical-angle incident waves. The instability is removed by allowing slowness to be complex to avoid the singularity. Numerical comparisons with finite difference and ray methods showed that the modified (complex slowness) wide-angle approximation gives the greatest accuracy of all screen methods for models, including steep interfaces and velocity contrasts typical for salt domes.

A complete analysis of that effect of the curvature on the DMZ/TZO operator for the case of constant background velocity and a single line of common offset data has been made. The curvature factor of the finite offset observed data is transformed into the curvature factor of zero offset data. 


\section{B. Jemez Imaging and Tomography Experiment (JITEX) (M. Fehler [505-667-1925; Fax 505-667-8487; E-mail fehler@seismo5.lanl.gov] and W. S. Baldridge)}

Objectives: To obtain insight into volcanic and crustal forming processes by constructing a model of the crust and upper mantle beneath the Valles Caldera that incorporates data from as many geophysical and geological disciplines as possible.

Project Description: The project is focused on obtaining an improved understanding of the origin, evolution, and modern thermal regime of a major intraplate magmatic system. Insight into how crustalforming processes occur in mid-continental volcanic systems will also be obtained. Geophysical data will be used to test models for the geometry of the caldera structure and fill, geometry and internal structure of the composite pluton underlying the caldera, and the structure and composition of the middle to lower crust beneath the pluton. A majority of the effort will involve collecting and interpreting seismic data to be used in imaging the subsurface structure beneath the caldera. Active seismic data will be collected along three lines, each about $170 \mathrm{~km}$ in length. Seismic sources include vibroseis explosions along each line. The reflection, wide-angle reflection, and refraction data from these six lines will be interpreted to obtain a detailed irnage of the crust beneath the Jemez volcanic field. In addition, two passive seismic arrays, consisting of up to 50 seismic instruments, will be set up to record teleseisms. The teleseismic data will be used to constrain the mid-crustal and upper-mantle seismic structure. Part of the teleseismic array will consist of one or more sub-arrays, with instrument spacing of as little as $1 \mathrm{~km}$. Converted phases recorded on these sub-arrays will be analyzed to obtain more constraints on locations of velocity anomalies in the crust. The existing gravity data set will be supplemented with new data. Gravity and magnetotelluric data will be analyzed along with the seismic data.

Results: Using data from the second passive seismic experiment, we have now developed a 3D tomo- gram for the crust and upper mantle beneath the Jemez Volcanic Field. The low-velocity anomalies at 8- to $12-\mathrm{km}$ depth and near the crust-mantle boundary that were seen in the previous 2D tomogram are clearly resolved in the 3D tomograms. Comparing the amount of velocity reduction observed in the mid-crustal lowvelocity zone with properties of rocks appropriate for this region leads us to conclude that the low velocity zone must contain some fraction of molten rock.

The second phase of the active seismic experiment was successfully completed. Seismometers were successively deployed along two lines crossing the caldera and in a 2D geometry within the caldera. Explosions were detonated near the middle and ends of the lines and vibroseis was used along the central portions of the lines. We are currently evaluating the quality of the data collected.

Travel-time studies of explosion data at large offset and vibroseis data at short offset have been conducted to make preliminary models of the mid-crustal (explosion data) and shallow-crustal (vibroseis data) regions. Clear vibroseis signals were obtained by stacking out to distances of $50 \mathrm{~km}$. The derived models are currently being evaluated.

Analysis of the passive data from the first experiment using a travel-time tomographic technique has indicated the existence of a low-velocity body beneath the center of the caldera at a depth of between $8 \mathrm{~km}$ and $12 \mathrm{~km}$. This anomaly is substantially smaller than but better resolved than the one found from previous studies using fewer instruments. The existence of this anomaly is consistent with the data collected during the first active phase of the project. Analyses completed to date on the active data do not give a good constraint on the horizontal location of the anomaly. An anomaly located near the crust-mantle boundary is also consistent with both active and passive data sets. This lowvelocity anomaly was unexpected. 


\section{The Role of Carbon and Temperature in Determining Electrical Conductivity of Basins, Crust, and Mantle (T. J. Shankland [505-667-4907; Fax 505-667-8487; E-mail shankland@lanl.gov], joint research with A. G. Duba [LLNL; 510-422-7306; Fax 510-423-1057; E-mail alduba@llnl.gov] and E. A. Mathez [American Museum of Natural History; 212-769-5379; Fax 212-769-5339; E-mail mathez@amnh.org])}

Objectives: The intent of this work is to comprehend the electrical conduction mechanisms in carbonbearing rocks and in mantle minerals for the purpose of relating electrical conductivity $(\sigma)$ measured in the field to formation conditions and existing state of crustal rocks and to temperatures in the mantle.

Project Description: Electrical conductivity depends strongly on temperature $(\mathrm{T})$ and on the presence of other phases, such as carbon, fluids, or ore minerals at the lower temperatures of the crust and basins. Thus, one research approach is to measure $\sigma$ of mantle minerals as functions of temperature, orientation, oxygen fugacity $\mathrm{fO}_{2}$, and iron content. These data supply the best models for "electrogeotherms" yet available. Another approach is to document textures of carbon in crustal rocks from basins and metamorphic zones and relate them to rock conductivity. In this case texture of carbon distribution is mapped with electron microscopy in the same samples used for conductivity measurement.

Results: Experiments on ceramic materials in the presence of iron oxides have shown that carbon-rich atmospheres lead to corrosion, fracture, and failure at high temperatures. We have conducted experiments to observe whether such phenomena occur in rocks. We are investigating the hypothesis that as fractures open in the time leading up to rock failure, carbon is deposited as a continuous film on the new, reactive crack surfaces, and electrical conductivity increases. Subsequent changes in electrical conductivity should occur as the connectivity of the initial fracture network is altered by continued deformation.

We developed an experimental technique to fracture rocks in a controlled $\mathrm{C}-\mathrm{O}-\mathrm{H}$ atmosphere at $\mathrm{P} \AA$ 1000 bars and $\mathrm{T} \AA 400^{\circ} \mathrm{C}$ and to simultaneously monitor sample resistance. The first experiments were conducted on a carbon-free sandstone containing small quantities of $\mathrm{Fe}$-oxide in the cement in an atmosphere of $5 \% \mathrm{CO}-95 \% \mathrm{CO}_{2}$. Decreases in resistance were observed to occur during micro-fracture events, as monitored by small changes in the load, and, at failure, large decreases in resistance occurred. Samples from several of the first experiments have been examined by $\mathrm{X}$-ray photoelectron spectroscopy (XPS), which provides information on carbon concentration in several monolayers of the analytical surface. It has been found that samples run in CO-bearing atmospheres contain more carbon on the surfaces exposed by fracture than control samples run in Ar. At face value, the experiments support the hypothesis above and indicate that making and breaking of carbon film interconnections could be involved in electrical effects associated with failure on seismic faults.

\section{Nonlinear Elasticity Project: Study and Application of Elastic Nonlinear Response (Hysteretic/ Discrete Memory) in Earth Materials (P. A. Johnson [505-667-8936; Fax 505-667-8487; E-mail johnson@cuzco.lanl.gov], R. A. Guyer [413-545 3673; Fax 413-545 1691; E-mail rag@cmp.phast.umass.edu], and T. J. Shankland, [505-667-4907; Fax 505-667-8487; E-mailshankland@lanl.gov])}

Objectives: Research objectives are to investigate the physical manifestations of nonlinear elasticity, including those indicating reservoir/repository characteristics and those affecting seismic observations, and to characterize nonlinear properties of rocks. Of primary importance are developing and applying a holistic model describing the nonlinear response of rock over broad stress-strain-frequency ranges so that practical applications can proceed.

Project Description: Rocks display unique elastic behavior. They are extremely nonlinear, being hysteretic and possessing discrete memory (memory of 
strain). Such behavior plays a central role in new methods with which to characterize rock properties, for instance, interrogating the entire elastic microstructure of rock. Nonlinear attributes of rock have important consequences on processes in the earth, such as earthquake slip, reservoir subsidence, seismic wave propagation and attenuation, stress fatigue damage, and hydraulic fracturing.

The central component of this work is a new approach to describe the nonlinear response (including hysteresis and discrete memory) of rock. This approach, different enough to be termed a new paradigm, has already had unprecedented successes in explaining some static-dynamic measurements. It involves developing a comprehensive theoretical and experimental framework that (1) employs static and dynamic laboratory investigation of rocks to provide a macroscopic and microscopic description of the elastic state and (2) provides for turning the microscopic description into a prescription for rock properties that can be used to predict change in stress state, both static and dynamic.

Results: Experiments illustrate that nonlinear response manifests itself in several manners, depending on the type of experiment applied. In acoustic resonance experiments, nonlinear response can manifest itself as a resonant peak shift downward in frequency (modulus softening). The resonant acceleration response as a function of drive frequency has been compared for a linear material (polyvinyl chloride, PVC) and a rock (Lavoux limestone). Driving the samples at various drive amplitude levels clearly demonstrates that the rock exhibits a nonlinear response when compared to PVC, especially as drive amplitude is increased.

For other types of experiments, other manifestations of the nonlinear response are observed. In pulsemode experiments, as nonlinear waves propagate, harmonics are generated coherently, so that harmonic amplitudes build up as a function of distance. In the case of a broad-band source, each frequency creates harmonics, and all frequencies in the wave multiply with all other frequencies, so that spectral energy is shifted upward and downward in frequency, causing the spectrum to flatten with frequency. This phenomenon was observed by us and has been verified by field observations. The observation has ramifications for source mechanics and strong motion studies.

Our work is now focused on explaining all of the above manifestations of nonlinear response with a single model: the Priesach Model. The model treats the compliance of the rock as a large group of individual hysteretic elastic units placed in a continuum model. The model provides us the ability to interrogate the entire elastic structure of the material and to predict the behaviors from waves. We are currently studying the fundamental cause of the nonlinear response: the contained liquid and flat, compliant features in the rock. These will be placed in the model this year. Of special additional importance are nonlinear slow dynamics that were noted this past year and seem to be controlled by contained fluids.

\section{CATEGORY:}

PERSON IN CHARGE:

\section{Geochemistry}

\section{Janecky}

\section{A. High Resolution Uranium-Series Geochronology and Geochemistry (M.T. Murrell [505-667-4299; Fax 505-665-4955; E-mail mmurrell@lanl.gov] and S.J. Goldstein [505-665-4793])}

Objectives: The goal of this project is to use improved capabilities for Quaternary dating to provide unique information on the behavior of U-series members in the environment.
Project Description: Previously, we have developed mass spectrometric methods for measuring ${ }^{230} \mathrm{Th} /$ ${ }^{238} \mathrm{U},{ }^{226} \mathrm{Ra} /{ }^{230} \mathrm{Th},{ }^{228} \mathrm{Ra} /{ }^{232} \mathrm{Th}$, and ${ }^{231} \mathrm{~Pa} /{ }^{235} \mathrm{U}$ disequilibria, which have significant advantages over decay 
counting methods. Current emphasis is on using these techniques to better understand the systematics of Useries geochronology for carbonates. Because ${ }^{230} \mathrm{Th}$ (half-life $=75.4 \mathrm{ky}$ ) studies suffer from uncertainty about possible open system behavior, it is desirable to have another chronometer to test for age concordancy. The ${ }^{231} \mathrm{~Pa}$ (half-life $=32.8 \mathrm{ky}$ ) method is perhaps the only possibility, but with decay counting techniques this method does not yield the required precision. Consequently, we measured ${ }^{231} \mathrm{~Pa}$ using mass spectrometric techniques originally developed at Los Alamos. This work was done in close collaboration with $\mathrm{H}$. Cheng and R. L. Edwards from the University of Minnesota.

Results: We analyzed reef-building corals for which ${ }^{230} \mathrm{Th}$ ages had already been determined. Typical $2 \mathrm{~F}_{\mathrm{m}}$ errors in ${ }^{231} \mathrm{~Pa}$ age are $\pm 5-10$ years for 100 -yearold corals, $\pm 1 \%$ at $1-100 \mathrm{ky}$, and $\pm 8 \%$ at $200 \mathrm{ky}$. Corals that passed screening for diagenesis typically give concordant ${ }^{231} \mathrm{~Pa}$ and ${ }^{230} \mathrm{Th}$ ages. Corals known to be altered because of elevated ${ }^{234} \mathrm{U} /{ }^{238} \mathrm{U}$ yield grossly discordant ages, demonstrating the power of this method in identifying open system behavior. Concordancy ob- served in young corals (e.g., ${ }^{231} \mathrm{~Pa}$ age $=140 \pm 5 \mathrm{y},{ }^{230} \mathrm{Th}$ age $=138 \pm 6$ y for one) indicates that initial ${ }^{231} \mathrm{~Pa}$ is less than the equivalent of $10 \mathrm{y}$ of radiogenic ingrowth. We have also studied very young deep- sea corals with $D$. Lea from UCSB in which U-series and ${ }^{14} \mathrm{C}$ ages are combined to yield ventilation ages for the deep ocean. Preliminary results also indicate little initial ${ }^{231} \mathrm{~Pa}$ or ${ }^{230} \mathrm{Th}$, concordant ${ }^{231} \mathrm{~Pa}$ and ${ }^{230} \mathrm{Th}$ ages, and a modern deep-sea ventilation age for the Southern ocean of 500800 years. We also analyzed two Devils Hole calcite samples. The $16 \mathrm{~mm}$ sample from $\mathrm{DH}-11$ gives a ${ }^{231} \mathrm{~Pa}$ age $=82.5 \pm 1.4 \mathrm{ky}$, indistinguishable from ${ }^{230} \mathrm{Th}$ dates reported by Ludwig et al. (Science, 1992). The result of the $188 \mathrm{~mm}$ sample was within error $( \pm 0.25 \%)$ of the secular equilibrium value, consistent with its reported ${ }^{230} \mathrm{Th}$ age of $350 \mathrm{ky}$. The concordance of these samples provides support for the accuracy of the Devils Hole chronology. Overall, this work has validated the major assumptions of the ${ }^{231} \mathrm{~Pa}$ dating approach for carbonates and has been used to confirm key aspects of the Quaternary climate record.

\section{B. Dating Young Surfaces Using Cosmogenic He and Ne (Jane Poths [505-665-2636; Fax 505-665- 6637; E-mail jpoths@lanl.gov])}

Objectives: The objective is to understand quantitatively the processes affecting use of cosmogenic noble gases as chronometers for dating young $(<0.5$ Ma) surfaces.

Project Description: Geomorphic surfaces start accumulating cosmogenic $\mathrm{He}$ and $\mathrm{Ne}$ once they are created (e.g., by flood or volcanic eruption). The concentrations of minerals separated from these surfaces by ultrasensitive mass spectrometry. Through investigating the ages of a set of carefully selected surfaces, we are both tackling specific geomorphic problems and testing the assumptions inherent in this new technique. These tests are being performed on surfaces of lava flows, stone pavements, and paleo-shorelines in the arid southwestern U.S. and Mexico. Our approach includes (1) comparison with dates from other experimental techniques, (2) determining reproducibility for multiple samples from a single surface, and (3) use of $\mathrm{He} / \mathrm{Ne}$ ratios to identify additional components and check for gas loss. The results provide the eruption history of volcanic fields, insight into the mechanism for formation of stone pavements, and timing of climatic events recorded by lake high stands.

Results: One thrust of this year's work has been to determine the timing of volcanism for the ten volcanic centers of the San Quintin volcanic field in Baja California, Mexico. The surface exposure ages fall in two groups; most centers erupted between 84 and $165 \mathrm{ka}$. After a hiatus, three centers cluster at $25 \mathrm{ka}$ and are suggestive of structural control on timing and location of volcanism. Encouragingly, several Ar-Ar ages and surface exposure ages agree within uncertainties. Another thrust has been to investigate stone pavement formation. Surface exposure ages were determined on pavement clasts and their source lava flows for five flows in two volcanic fields. For each 
flow, several individual clasts and the parent flow yield identical ages. This strongly suggests that stone pavements are created and maintained at the surface. This is true even for clasts that have exposure ages of 260 $\mathrm{ka}$, implying that stone pavements are some of the oldest and best preserved surfaces in the desert landscape.
A third thrust has been to investigate the use of plagioclase as a phase for surface exposure dating. In two out of three cases, ${ }^{21} \mathrm{Ne}$ dates for plagioclase are significantly younger than those for coexisting olivine, implying that the plagioclase is not suitable for surface exposure dating.

\section{CATEGORY: $\quad$ Solar-Terrestrial Physics}

\section{PERSON IN CHARGE: $\quad$ S. Peter Gary}

A. Energy Transport in Space Plasma (S. P. Gary [505-667-3807; Fax 505-665-3332; E-mail pgary@lanl.gov])

Objectives: The long-term goal of this research is to understand the flow of plasma energy in the nearEarth space environment from a small-scale point of view. The objective of this research is to use plasma theory, simulations, and data analysis to express the consequences of plasma microinstabilities as concise relationships that may be used in large-scale models of space plasmas that describe the solar-terrestrial interaction.

Project Description: Particle distribution functions and parameters observed by Los Alamos plasma instruments on scientific spacecraft as well as computer simulations are used to carry out fundamental studies of plasma instabilities and associated transport in and near the solar wind, the Earth's bow shock, and the terrestrial magnetosphere.

Results: The most important accomplishment of this program was the development of a prediction for the temperatures of anisotropic warm protons observed near 10 electron volts $(\mathrm{eV})$ in the outer magnetosphere. Under the assumptions that hot $(\mathrm{keV})$ protons drive the electromagnetic proton cyclotron instability and that this mode is the heating source for the warm protons, one-dimensional hybrid computer simulations were used to determine the nonlinear consequences of instability growth on initially cool protons. From an ensemble of such simulations, a scaling law for the warm proton temperature as a function of the hot proton properties has been developed. Comparison against observations from Los Alamos plasma instruments on a geosynchronous satellite has shown that the simulation results provide a good description of warm proton temperatures measured in the outer magnetosphere. This scaling relation may be able to describe the heating of cool ionospheric protons in large-scale computer models of plasmaspheric refilling and, if so, may significantly improve the predictive accuracy of such models.

B. The Solar Wind-Magnetospheric Interaction (J. Birn [505-667-9232; Fax 505-665-3332; E-mail jbirn@lanl.gov])

Objectives: The goal of this research is to further the understanding of the Earth's magnetosphere, coupled to the fast-flowing solar wind plasma on the one hand and to the ionosphere on the other.
Project Description: The focus of this research is the large-scale structure and dynamics of the Earth's magnetosphere, using theory, numerical modeling, and correlative studies of data from multiple sites within 
and near the magnetosphere (including the Earth itself as well as scientific satellites).

Results: Major achievements concerned the role of plasma anisotropies and their reduction through a microscopic instability in the dynamics of the magnetotail. Anisotropic magnetofluid simulations were used to investigate the influence of several models of anisotropy reduction on the dynamic evolution of the magnetotail, concerning both the substorm growth phase and the substorm expansive phase. The plasma models included one that is fully isotropic, the double adiabatic model in which pressures parallel and perpendicular to the background magnetic field are completely uncoupled, and a model in which smallscale instabilities impose an upper bound on the anisotropy. In the last model, anisotropies that exceed this bound are reduced on a short Alfvenic time scale. The major effects of the growth phase, resulting from an external applied electric field, are a localized increase in current density and a reduction in the magnitude of the magnetic field strength in the near-Earth neutral sheet; both of these effects are more pronounced for the more isotropic plasma models. For the expansive phase magnetotail model, the development of a generalized tearing instability occurs faster and the substorm wedge currents grow stronger when the plasma model is closer to isotropy. During both phases the plasma anisotropy model strongly influences the spatial variation of the magnetic field in the neutral sheet and hence the location where reconnection occurs and a neutral line forms. Both the driven and the unstable anisotropic models develop mirror-type anisotropies in the boundary regions of the plasma sheet and the adjacent lobes, while the center region of the plasma/current sheet remains close to isotropy.

\section{Energetic Particle Acceleration (G. D. Reeves 1505-665-3877; Fax 505-665-4414; E-mail reeves@lanl.gov])}

Objectives: The goal of this research is to develop a better understanding of the Earth's energetic particle environment near geosynchronous orbit.

Project Description: This effort concerns the analysis of data from a series of geosynchronous spacecraft that carry Los Alamos energetic particle detectors. The energies measured range from tens of $\mathrm{keV}$ to hundreds of $\mathrm{MeV}$. The lower end of this range lies somewhat above the thermal plasma energies and is therefore sensitive to local acceleration processes such as magnetospheric substorms. The higher end of the energy range is in the realm of cosmic rays and is therefore well suited to the study of energetic particles that can penetrate the Earth's magnetic field, such as galactic cosmic rays and particles produced in solar flares.

Results: We continued our study of the magnetic connectivity between the ionosphere and the magnetosphere. We compared particle spectra obtained at geosynchronous orbit (20,000 km altitude, equatorial orbit) and with the DMSP satellites $(800 \mathrm{~km}$, polar orbit). We identified 102 conjunctions with good spectral matches and compared the resulting mapping with six widelyused magnetic field models. Surprisingly, we found that no single magnetic field model emerged as a clear "winner." Systematic overstretching of the magnetic field was found in all models, and, while none of the models had enough dynamic range to account for all measurements, all models predicted a clear magnetic relationship between magnetospheric substorm activity and auroral processes.

We also investigated the energization of relativistic electrons in corotating high-speed solar wind streams from coronal holes and studied the relationship between magnetic storms and substorms. One interesting result showed distinct differences between energetic particle injections observed during storms and those observed during substorms. Storm-related injections seem to be more global, more periodic, and more efficient at accelerating ions to energies above $1 \mathrm{MeV}$ than substorms. This calls into question the commonly held view that a magnetic storm is simply the summed effect of a series of substorms. 
CONTRACTOR:

CONTRACT:

CATEGORY:

PERSON IN CHARGE:
OAK RIDGE NATIONAL LABORATORY

Lockheed-Martin Energy Research Corporation

Oak Ridge, Tennessee 37831

DE-AC05-96OR22464

Geochemistry

B. R. Appleton

\section{A. Thermodynamic Mixing Properties of C-O-H-N Fluids (J.G. Blencoe [423-574-7041;} Fax 423-574-4961; E-mail jblencoe@coe.chem.ornl.gov], J.C. Seitz, and L.M. Anovitz)

Objectives: Thermochemical data for $\mathrm{C}-\mathrm{O}-\mathrm{H}-\mathrm{N}$ fluids are insufficient in quantity and quality to permit formulation of accurate equations of state for natural, deep-seated fluids in the Earth's crust-hydrothermal waters, natural gas, etc.-that are composed predominantly of $\mathrm{H}_{2} \mathrm{O}, \mathrm{CO}_{2}, \mathrm{H}_{4}$, and $\mathrm{N}_{2}$. Such equations would have numerous applications in geochemistry, including geothermal and hydrocarbon reservoir hydrodynamics modeling, thermochemical calculations of the stabilities of hydrocarbons and alteration minerals, predicting permeability changes in reservoirs, quantifying contaminant transport, and characterizing global cycling of greenhouse gases.

Project Description: Experiments are performed with $\mathrm{H}_{2} \mathrm{O}, \mathrm{CO}_{2}, \mathrm{CH}_{4}, \mathrm{~N}_{2}$, and mixtures of these fluid species at temperature-pressure conditions similar to those encountered in deep aquifers, sedimentary basins, and geothermal fields. The pressure-volume-temperature relations of pure $\mathrm{C}-\mathrm{O}-\mathrm{H}-\mathrm{N}$ fluids and their mixtures are determined with high precision and accuracy using a unique vibrating-tube densimeter designed for operation in the range $50^{\circ}-450^{\circ} \mathrm{C}$ and 100-2000 bars. The pressure-temperature-composition relations of aqueous $\mathrm{C}-\mathrm{O}-\mathrm{H}-\mathrm{N}$ mixtures are studied in another unique facility: a hydrogen-service internally heated pressure vessel capable of operation at high hydrogen fugacities, with an overall operating range up to 10 kilobars at $100^{\circ}$ to $1200^{\circ} \mathrm{C}$. Finally, novel Raman spectroscopic studies of C-O-H-N fluid mixtures, performed in collaboration with scientists at Washington University and the U.S. Geological Sur- vey, complement our volumetric and phase equilibrium studies. Data obtained in these various research activities are combined with literature data to develop empirical and semiempirical equations of state.

Results: Densities for pure $\mathrm{CO}_{2}$, pure $\mathrm{CH}_{4}$, and $\mathrm{CO}_{2}-\mathrm{CH}_{4}, \mathrm{CO}_{2}-\mathrm{N}_{2}$, and $\mathrm{CH}_{4}-\mathrm{N}_{2}$ mixtures (at 10 mole percent intervals) were measured at $400^{\circ} \mathrm{C}$ and 200 , $300,400,600,800$, and 1000 bars. This is the first time that volumetric data for binary $\mathrm{CO}_{2}-\mathrm{CH}_{4}-\mathrm{N}_{2}$ fluids have been obtained at temperatures above $300^{\circ} \mathrm{C}$. Recently, we started measuring the densities of aqueous $\mathrm{C}-\mathrm{O}-\mathrm{H}-$ $\mathrm{N}$ fluids, with initial attention being given to $\mathrm{H}_{2} \mathrm{O}-\mathrm{CO}_{2}$ mixtures. To date, density data have been obtained at $400^{\circ} \mathrm{C}$ and $100,200,250,300,350,400,600,800$, and 1000 bars. Results obtained at pressures above 250 bars are of unprecedented precision and accuracy. There are now sufficient volumetric data available for $\mathrm{H}_{2} \mathrm{O}$ $\mathrm{CO}_{2}$ fluids to permit rigorous thermodynamic modeling.

Good progress was also made in efforts to determine the activity/composition $(\mathrm{a} / \mathrm{X})$ relations of $\mathrm{H}_{2} \mathrm{O}$ $\mathrm{N}_{2}$ and $\mathrm{H}_{2} \mathrm{O}-\mathrm{CO}_{2}$ fluids. More than 90 measurements were made at $500^{\circ} \mathrm{C}$ and 500 bars to complement and supplement the density data for aqueous C-O-H-N fluids described above. The new $\mathrm{a} / \mathrm{X}$ data are highly precise and accurate and fill an important gap in our knowledge of these fluids because (1) there are few $\mathrm{a} / \mathrm{X}$ data for $\mathrm{H}_{2} \mathrm{O}-\mathrm{N}_{2}$ mixtures available in the literature and (2) the results for $\mathrm{H}_{2} \mathrm{O}-\mathrm{CO}_{2}$ mixtures indicate large, continuously positive deviations from Raoultian behavior in marked contrast to the predictions of two 
widely applied semiempirical thermodynamic models for $\mathrm{H}_{2} \mathrm{O}-\mathrm{CO}_{2}$ fluids (Holloway, 1977; Kerrick and Jacobs, 1981), which suggests that $\mathrm{H}_{2} \mathrm{O}-\mathrm{CO}_{2}$ mixtures are essentially ideal solutions at $500^{\circ} \mathrm{C}$ and 500 bars.

Finally, using Raman spectroscopic data obtained from $\mathrm{CO}_{2}-\mathrm{CH}_{4}$ mixtures loaded into a high-pressure cell, a method was developed to simultaneously determine fluid composition and pressure (or density) in fluid inclusions from a single Raman spectrum. The technique was applied to fluid inclusions in quartz in graphite-bearing rocks from the Crystal Graphite Mine, located at the southwestern end of the Ruby Range in Montana. It was found that fluid compositions and densities measured by microthermometry and values obtained from the new spectroscopic method are in excellent agreement.

\section{B. Fundamental Research in the Geochemistry of Geothermal Systems (D. J. Wesolowski [423-574-6903; Fax 423-574-4961; E-mail dqw@ornl.gov], J. Horita, D.R. Cole, and P. Benezeth)}

Objectives: The objective of this project is to provide fundamental information on geochemical reactions that play pivotal roles in a wide range of geological processes but that specifically impact reservoir dynamics, corrosion, and heat extraction in active geothermal systems. The speciation of elements in aqueous solutions, mineral solubilities, kinetic and equilibrium partitioning of stable C-O-H-S isotopes, and other fluid-solid interactions are primary subject areas for this research.

Project Description: At Oak Ridge National Laboratory, a long-term basic research program in experimental hydrothermal geochemistry, stable isotope geochemistry, and igneous petrology has led to the development of unique methodologies for extracting rigorous and unambiguous information on a wide range of geochemical processes. This capability permits the efficient and definitive examination of specific problems hampering the ability to quantitatively model fluid-rock interaction processes related to the discovery and exploitation of geothermal resources. Research topics in this project are selected in close cooperation with geothermal industry representatives and are frequently augmented by parallel research on more applied aspects of the same problems funded by the U.S. Department of Energy's Geothermal Technology Development Program.

Results: Current topics include the aqueous geochemistry of aluminum, which affects permeability development and includes scaling in geothermal systems, and the effects of dissolved salts on the partitioning of the stable isotopes of hydrogen and oxygen between geothermal brines and other phases, which is central to the use of stable isotopes in elucidating fluid sources and fluxes and reservoir temperatures and dynamics.

Studies of the solubility of boehmite, $\mathrm{AlOOH}$, were conducted in 0.03 to 1.0 molal $\mathrm{NaCl}$ brines at temperatures of $101^{\circ}-290^{\circ} \mathrm{C}$ at $\mathrm{pHs}$ of 2.5 to 10 , using our unique hydrogen electrode concentration cell (HECC) that was specifically designed to permit long-term studies of the solubility of minerals with continuous and highly accurate $\mathrm{pH}$ monitoring. The $\mathrm{pH}$ of the solution can be determined with an accuracy of $0.01 \mathrm{log}$ units and resolution of 0.001 units, and samples can be periodically withdrawn for chemical analyses. For the reaction $\mathrm{AlOOH}_{(\mathrm{cr})}+(3-n) \mathrm{H}^{+} \Leftrightarrow \mathrm{Al}(\mathrm{OH})_{n}^{3-n}+(2-n) \mathrm{H}_{2} \mathrm{O}$, $n=0-4$, which controls the solubility of boehmite and defines the dominant aluminum aqueous species, monitoring the change in $\mathrm{pH}$ as a function of time after addition of acidic or basic titrant gives a very sensitive indicator of the rate of dissolution or precipitation and the attainment of equilibrium. The solubility of this solid has been reversed with an accuracy of $1 \%$ by conducting $\mathrm{pH}$-increasing and $\mathrm{pH}$-decreasing experiments during the same run over periods up to one month. When equilibrium is attained, a sample is then withdrawn for total aluminum analysis ( $\left.\sum \mathrm{Al}\right)$ by ion chromatography and/or atomic absorption. The shape and position of the solubility curve $\left(\log \sum \mathrm{Al}\right)$ as a function of $\mathrm{pH}$ is then analyzed to extract the stability boundaries between the $\mathrm{Al}(\mathrm{OH})_{n}{ }^{3-n}$ species as a function of temperature and ionic strength. These aluminum aqueous species determine the solubility of all aluminumbearing minerals, including the feldspars, micas, clays 
and other alteration minerals, the precipitation or dissolution of which greatly influences reservoir hydrodynamics and scaling in producing geothermal fields.

The effect of dissolved $\mathrm{KCl}(0-4$ molal) on the partitioning of the naturally occurring, stable isotopes of hydrogen $(\mathrm{D} / \mathrm{H})$ and oxygen $\left({ }^{18} \mathrm{O} /{ }^{16} \mathrm{O}\right)$ between geothermal brines and steam has been extended to temperatures of $130^{\circ} \mathrm{C}$. The hydrogen isotope salt effect increases linearly with $\mathrm{KCl}$ molality and the slope decreases gradually from 2 permil per molal at room temperature to 1.1 permil per molal at $130^{\circ} \mathrm{C}$. At $130^{\circ} \mathrm{C}$, $\mathrm{KCl}$ has essentially no effect on the partitioning of oxygen isotopes between brine and steam, as compared with small but measurable effect at room temperature. The effect of dissolved $\mathrm{NaCl}(0-5$ molal $)$ and $\mathrm{MgCl}_{2}$
(0-3 molal) on the partitioning of hydrogen isotopes between brines and the mineral brucite $-\mathrm{Mg}(\mathrm{OH})^{2}$ has been studied at $400^{\circ}-500^{\circ} \mathrm{C}$ and $500-800$ bars. Pure water-brucite fractionations obtained are in excellent agreement with the literature. Dissolved $\mathrm{NaCl}$ increases the brucite/water $\mathrm{D} / \mathrm{H}$ fractionation factor up to 8 per mil. The effect of equivalent concentrations of $\mathrm{MgCl}_{2}$ is two to three times greater than the $\mathrm{NaCl}$ effect. These results clearly demonstrate that salt effects on the partitioning of isotopes between brines and other phases is a general phenomenon, not limited to the brine-steam equilibrium previously studied in this program, and that the effects persist well above the critical point of pure water.

\section{Ion Microprobe Studies of Diagenesis (L.R. Riciputi [423-576-4839; Fax 423-576-8559; E-mail riciputilr@ornl.gov], D.R. Cole, and R.L.Ripperdan)}

Objectives: The principal objective of this research is to use elemental and isotopic compositions and mineralogical relationships to quantify the mass transfer processes influencing porosity, permeability, and fluid chemistry during diagenesis of carbonates and clastics. Development of ion probe methodologies for elemental and isotopic analyses of geological materials has been a secondary objective.

Project Description: In this project, the micronscale spatial resolution, elemental and isotopic imaging, and quantitative trace element and isotope ratio capabilities of ORNL's Cameca $4 \mathrm{f}$ ion microprobe are being developed and used in studies of fluid-rock interactions in sedimentary basins. The probe studies are augmented by information obtained from a variety of other geochemical techniques, including conventional gas-source isotope ratio mass spectrometry, electron microprobe, scanning electron microscopy, neutron activation, and fluid inclusion microthermometry. These techniques are currently being applied to (1) investigations of sulfate reduction and sedimentary sulfide formation in hydrocarbon reservoir rocks and their relationship to hydrocarbon migration, (2) the formation of diagenetic iron oxides associated with largescale fluid migration events in and near sedimentary basins, and (3) the use of ion probes to obtain precise measurements of the ${ }^{18} \mathrm{O} /{ }^{16} \mathrm{O}$ and ${ }^{34} \mathrm{~S} /{ }^{32} \mathrm{~S}$ ratios in clastic, primary precipitated, and diagenetic minerals in sedimentary rocks and to study low to moderate temperature fluid-rock interaction.

Results: In our ongoing studies of biogenic and thermogenic sulfate reduction processes in the Western Canada Sedimentary Basin (Alberta), we have found additional complex sulfide textures that previously had been undetected. In particular, we have identified complex pyrite-marcasite intergrowths that may reflect fluctuating $\mathrm{pH}$ conditions during growth of the sulfides. These pyrite-marcasite clusters display a substantial degree of isotopic variability, often exceeding $30 \%$. The cause of this variability is presently uncertain but may be reflecting processes that create this mineral texture.

In samples from both the central and western flank of the North Sea oil and gas province (in collaboration with scientists at Exxon Production Research, Queens University in Belfast, and the Scottish Universities Research Reactor Center), we have found distinct sulfur isotopic zoning patterns in sulfide minerals. Overall variations in $\delta^{34} \mathrm{~S}$ values from individual thin sections can exceed $100 \%$ and $50 \%$ ranges are relatively com- 
mon. In many samples, both from sandstones and shales, isotopic paragenesis suggests a trend from relatively heavy ( $+30 \%$ to $+50 \%$ ) $\delta^{34} S$ values to lighter values with progressive diagenesis. This trend is the opposite of that which has been observed in sulfides from other sedimentary basins and cannot be explained by either Rayleigh fractionation or a shift from biogenic to thermogenic sulfate reduction with increasing temperature. We are currently continuing our investigation to try and understand how such extreme isotopic variations can develop and the cause of the "reverse" isotopic zoning that may persist throughout the basin.

Fe-oxide samples suitable for ion microprobe analyses have been identified from the Belden Formation (Colorado) and the Viola Formation (Oklahoma). Geothite from the Viola Formation occurs in late-stage crosscutting calcite veins that are related to large-scale basinal fluid movements. Our preliminary results suggest that, using the geothite calcite oxygen fractionation factor proposed by Yapp, the goethite is in equilibrium with the calcite at temperatures indicated by fluid inclusions $\left(50^{\circ} \pm 6^{\circ} \mathrm{C}\right)$. These results may also provide a natural calibration of the fractionation factor, since the temperatures of formation are well constrained by fluid inclusions.

In our technique development work, we have demonstrated that the instrumental mass bias (or instrumental fractionation) measured using the high mass resolution technique can vary by over $8 \%$ from one thin section to another, requiring that a standard be mounted in every thin section analyzed to achieve the most accurate results; however, the extreme energy filtering technique does not suffer from the same problem, instrumental mass bias varied by less than $0.2 \% 0$ $\delta^{34} \mathrm{~S}$ for the same set of samples previously analyzed using high mass resolution. We have also developed an empirical method of predicting oxygen isotope instrumental mass bias in chemically zoned samples, which allows us to conduct precise and accurate analyses of compositionally variable materials with only a few standards.

\section{Experimental Studies of Fundamental Stable Isotope Exchange Reactions (D.R. Cole [423-574-5473; Fax 423-574-4961; E-mail me@cole.chem.ornl.gov], J. Horita, and D. J. Wesolowski)}

Objectives: The objective of this project is to obtain reliable information on the partitioning of the stable isotopes of oxygen, carbon, and hydrogen among minerals and fluids of critical importance in defining fluidrock interaction parameters, such as fluid sources and fluxes, temperatures, and duration of fluid-rock interaction, in a variety of settings, including oil, gas, and geothermal reservoirs, sedimentary basins, and waste repositories.

Project Description: This project is currently focussed on (1) the oxygen isotope partitioning among aqueous fluids and the minerals hematite, $\mathrm{Fe}_{2} \mathrm{O}_{3}$, and magnetite, $\mathrm{Fe}_{3} \mathrm{O}_{4}$, in the $60^{\circ}-500^{\circ} \mathrm{C}$ range and (2) the exchange rates and equilibrium fractionations of hydrogen and carbon isotopes among gaseous species in the system $\mathrm{H}_{2} \mathrm{O}-\mathrm{CO}_{2}-\mathrm{CH}_{4}-\mathrm{H}_{2}$. Multiple novel experimental methods are used to promote recrystallization and/or synthesis of the iron oxide minerals. Synthetic catalysts and natural minerals, including magnetite and hematite, are investigated for isotopic exchange among the C-O-H gases.

Results: Oxygen isotope fractionations among magnetite, $\mathrm{Fe}_{3} \mathrm{O}_{4}$, and water have been studied over a wide range of temperatures from $60^{\circ}$ to $600^{\circ} \mathrm{C}$. At high temperatures $\left(300^{\circ}-600^{\circ} \mathrm{C}\right)$, three different reaction schemes were selected: (1) recrystallization of finegrained $(<1 \mu \mathrm{m})$ magnetite in dilute acetic acid or $\mathrm{NaCl}$ solutions, (2) reductive dissolution of hematite and recrystallization of magnetite in pure water, dilute acetic acid, or $\mathrm{NaCl}$, and (3) oxidation of fine-grained $(<1 \mu \mathrm{m})$ $\mathrm{Fe}$ metal powder to magnetite in pure water of dilute $\mathrm{NaCl}$. The mineralogic and isotopic results indicate that reaction pathway (2) provided the most consistent results of the various pathways. Results indicate that fractionation factors for $450^{\circ} \mathrm{C}$ and above agree very well with those cited in the literature. From $450^{\circ}$ to $300^{\circ} \mathrm{C}$, an apparent minimum in the fractionation factors (about -8.5 per mil) was observed. A similar minimum was 
reported in quasitheoretical studies but at temperatures between $200^{\circ}$ and $300^{\circ} \mathrm{C}$. Magnetite was synthesized by titrating an oxygen-free $\mathrm{KNO}_{3}$ and $\mathrm{KOH}$ solution into an $\mathrm{FeSO}_{4}$ or $\mathrm{FeC}_{12}$ solution at $60^{\circ}, 70^{\circ}, 80^{\circ}$, and $90^{\circ} \mathrm{C}$. Preliminary oxygen isotope results at $90^{\circ} \mathrm{C}$ show that an empirical curve in the literature overestimates the observed magnetite-water fractionation factor by 2-3 per mil. Oxygen isotope fractionation during magnetite precipitation facilitated by novel thermophilic bacteria (anaerobic growth up to $75^{\circ} \mathrm{C}$ and in salinity twice the seawater) from deep subsurface formations was studied at $50^{\circ}, 60^{\circ}$, and $70^{\circ} \mathrm{C}$. The dominant phase formed at all temperatures was magnetite, with lesser amounts of maghemite $\left(\gamma \mathrm{Fe}_{2} \mathrm{O}_{3}\right)$. The fractionation values for oxide-water from the enrichment cultures are negative but become less so with decreasing temperature. The most interesting aspect of these results is the fact that the data fall on the extrapolation of high temperature data to the low temperature fractionation value derived from natural magnetite and the water in which it formed.

Preliminary measurements of the oxygen isotope fractionation factors for the system hematite-water at $150^{\circ}, 300^{\circ}$, and $350^{\circ} \mathrm{C}$ suggest that recent quasitheoretical calculations underestimate the value of the fractionation by $1-2$ per mil at all temperatures.

Employing a recently identified $\mathrm{Ni}$ catalyst for carbon isotope exchange between $\mathrm{CO}_{2}$ and $\mathrm{CH}_{4}$, a series of experiments was conducted at $200^{\circ}$ to $500^{\circ} \mathrm{C}$. The run products were predominantly $\mathrm{CH}_{4}, \mathrm{CO}_{2}$, and $\mathrm{H}_{2} \mathrm{O}$ with varying proportions reflecting changing equilibrium constants among $\mathrm{C}-\mathrm{O}-\mathrm{H}$ gases. Isotopic reversal experiments (initial differences in ${ }^{13} \mathrm{C} /{ }^{12} \mathrm{C}$ ratios between $\mathrm{CO}_{2}$ and $\mathrm{CH}_{4}$ higher and lower than expected equilibrium values) yielded indistinguishable values of $\mathrm{CO}_{2}^{-}$ $\mathrm{CH}_{4}$ carbon isotope fractionation factors at all of the temperatures studied, demonstrating for the first time that carbon isotopic equilibrium was reached between the two gases. Experiments of the carbon isotope exchange with the three different starting materials: (1) $\mathrm{CO}_{2}$ and $\mathrm{CH}_{4}$, (2) $\mathrm{CH}_{4}$ and $\mathrm{H}_{2} \mathrm{O}$, and (3) oxalic acid all yielded reproducible results at $400^{\circ} \mathrm{C}$. Experimental values of the carbon isotope fractionation factor between $\mathrm{CO}_{2}$ and $\mathrm{CH}_{4}$ agree well with statistical-mechanical calculations at $200^{\circ}-250^{\circ} \mathrm{C}$; however, with increasing temperature to $500^{\circ} \mathrm{C}$, the values of the fractionation factor gradually deviate from the calculations to more positive values. It is possible that this slight but progressive deviation is due to retrograde isotope exchange during quench of the runs. Alternatively, the deviation is real, suggesting systematic errors in the calculations in the literature.

The potential catalytic activities of common Febearing minerals (magnetite, hematite) were examined at $500^{\circ} \mathrm{C}$. After a duration of 27 days, carbon isotope exchange between $\mathrm{CO}_{2}$ and $\mathrm{CH}_{4}$ appears to have proceeded about $70 \%$ to an equilibrium, suggesting that iron oxides can catalyze the carbon isotope exchange in natural environments.

\section{E. Potentiometric Studies of Geochemical Processes (D. J. Wesolowski [423-574-6903; Fax 423-574-4961; E-mail dqw@ornl.gov], R.E. Mesmer, and P. Benezeth)}

Objectives: The objective of this project is to utilize ORNL's unique, high temperature, hydrogen-electrode, potentiometric cells to study aqueous reactions that involve exchange of hydrogen ions (i.e., changes in $\mathrm{pH})$.

Project Description: The $\mathrm{pH}$ is considered the master variable in aqueous systems, controlling the nature of dissolved species, the rates of homogeneous and heterogenous reactions, the solubility and absorbtivity of rock minerals, the transport and deposition of contaminants and ore components, and the volatility of mineral and organic acids. In this program we develop and use unique experimental facilities to directly measure the $\mathrm{pH}$ of aqueous solutions over broad ranges of temperature, salinity, and $\mathrm{pH}$ and to use these measurements to quantify the dissociation constants of mineral and organic acids and bases, the hydrolysis and complexation of metal ions in solution, and the solubilities and surface properties of minerals.

Results: All three acid dissociation constants of citric acid were determined in $0-1$ molal $\mathrm{NaCl}$ solutions from $5^{\circ}$ to $150^{\circ} \mathrm{C}$. This acid is present in natural 
systems, such as soils and sedimentary basin brines, and is a very common component of DOE mixed wastes. It has also been proposed for use in a variety of radioactive waste remediation schemes. Now that the dissociation constants of the acid have been firmly established, metal complexation and surface sorption studies of the chelating acid anions can commence. Studies of complexing agents and metal transport in sedimentary basin systems were extended to include measurements of the association constants of aluminum with malonic acid anions in $0-1$ molal $\mathrm{NaCl}$ brines from $5^{\circ}-75^{\circ} \mathrm{C}$ and with oxalic acid anions in 0.1 to 0.6 molal $\mathrm{NaCl}$ brines from $5^{\circ}$ to $150^{\circ} \mathrm{C}$. The complexes of aluminum with these dicarboxylic acids, reported from oil field brines and soil waters, are exceedingly stable, and this type of chelation may play a role in the transport of metals and permeability changes in these environments.

Studies of the complexation of aluminum by sulfate in acidic solutions continued during this period. We have now completed a detailed series of potentiometric titrations in $0-1$ molal $\mathrm{NaCl}$ brines from $5^{\circ}$ to $125^{\circ} \mathrm{C}$, which substantiates our preliminary findings that the formation constants of $\mathrm{Al}\left(\mathrm{SO}_{4}\right)_{\mathrm{n}}{ }^{3-2 \mathrm{n}}, \mathrm{n}=1$ to 2, increase with decreasing temperature by one to two orders of magnitude from $50^{\circ}$ to $5^{\circ} \mathrm{C}$. This controversial result is in sharp disagreement with published work in the $15^{\circ}-55^{\circ} \mathrm{C}$ range, including both potentiometric and calorimetric studies; however, our results have been partially substantiated by studies of the dissolution rates of gibbsite $-\mathrm{Al}(\mathrm{OH})_{3}$ - in $\mathrm{NaCl}+\mathrm{H}_{2} \mathrm{SO}_{4}$ solutions, which are found to be ten times faster at $5^{\circ} \mathrm{C}$ than the rates in $\mathrm{NaCl}+\mathrm{HCl}$ solutions at identical $\mathrm{pH}(2.0)$, ionic strength
( $0.1 \mathrm{molal})$, and solid/solution ratio. We also obtained an extensive suite of equilibrium solubility measurements of gibbsite in $\mathrm{NaCl}+\mathrm{H}_{2} \mathrm{SO}_{4}$ solutions at $50^{\circ} \mathrm{C}$, 0.1 molal ionic strength, and $\mathrm{pH} 3.5-4.0$, which is in quantitative agreement with our new aluminum sulfate complexation data, coupled with our previous studies of gibbsite solubility and the dissociation constants of sulfuric acid in $\mathrm{NaCl}$ brines. We are currently conducting Raman spectroscopic and calorimetric titration studies in order to provide two lines of independent proof for these controversial results. The implications are profound for modeling the effects of acid rain and acid mine drainage on ecosystems (where aluminum has been identified as a major toxicant) and on weathering rates in high altitude and high latitude environments.

Studies of the sorption of $\mathrm{H}^{+}$on the surface of rutile, $\mathrm{TiO}_{2}$, at elevated temperatures by potentiometric titrations (a unique ORNL capability) were extended to include titrations in tetramethylammonium chloride brines, in order to test our capacitance model for the double layer structure and surface speciation on the mineral surface. We have initiated studies of the surface charge and sorptive characteristics of zincite, $\mathrm{ZnO}$, in order to establish techniques for studying minerals that dissolve significantly and reach equilibrium rapidly in our potentiometric cells. Finally, we have successfully obtained equilibrium solubilities of magnetite, $\mathrm{Fe}_{3} \mathrm{O}_{4}$, an exceedingly abundant and redox-controlling phase in sedimentary basins and geothermal systems, in 0.1 molal $\mathrm{NaCl}$ and sodium trifluoromethanesulfonate brines from $100^{\circ}$ to $250^{\circ} \mathrm{C}$.

\section{F. Mechanisms and Rates of Oxygen Isotope Exchange in Mineral-Fluid Systems (D. R. Cole [423-574-5473; Fax 423-574-4961; E-mail me@cole.chem.ornl.gov], and L. R. Riciputi)}

Objective: The major objective of this research is to measure the rates of isotope exchange between minerals and fluids controlled by one of two mechanisms: surface reactions leading to mineral growth or volume diffusion.

Project Description: There are many documented case histories of natural fluid-rock interaction systems that indicate (1) isotope disequilibrium may be more widespread than previously realized, (2) isotope disequilibrium can occur at high as well as low temperatures, (3) different minerals exhibit varying susceptibilities to retrograde exchange, and (4) the mechanisms of chemical and isotope exchange are varied and depend on the prevailing conditions (tempera- 
ture, fluid chemistry, etc.). This research is focused primarily on the experimental determination of rates of isotope exchange and mineral growth in the carbonate-quartz-feldspar-fluid system at temperatures of $300^{\circ}$ to $700^{\circ} \mathrm{C}$ and pressures up to 3 kilobars. These results will allow extrapolation to lower temperatures appropriate for studies of fluid-rock interactions in sedimentary basins, geothermal systems, waste repositories, etc.

Results: Variations in the extent of oxygen isotope exchange have been measured in the system calcite$\mathrm{H}_{2} \mathrm{O}-\mathrm{NaCl}$ as a function of temperature and concentration of $\mathrm{NaCl}$. The conditions of these hydrothermal experiments are $\mathrm{T}=300^{\circ}-700^{\circ} \mathrm{C}, \mathrm{P}=1 \mathrm{kbar}, \mathrm{NaCl}=$ $0,1,3$, and 5 molal, fluid/solid mass ratio $>>4$, and run durations $=26-857 \mathrm{hrs}$. There is a pronounced increase in the degree of exchange toward equilibrium with increasing temperature, salinity, and degree of grain rounding and regrowth. The rate of change in the degree of exchange is initially steep but tends to flatten out with either increasing salinity (to $1 \mathrm{~m}$ ) or time ( $20 \%-30 \%$ of total run duration). Our new results confirm those obtained previously, wherein the natural $\log$ of the clegree of oxygen isotope exchange increases linearly with the ratio of the mean "new" grain diameter to the initial grain diameter and the calcite growth rate follow's the cube root of time.

In a related study, we have conducted oxygen isotope exchange experiments between a series of either metal carbonates or layered silicates and pure water in order to test our empirical model relating exchange rates with lattice energies. $\mathrm{Sr}, \mathrm{Ba}, \mathrm{Ca}$, and $\mathrm{Mg}$ carbonates were reacted at $300^{\circ} \mathrm{C}$ with pure water at a fluid to solid oxygen mole ratio of about 8 for durations of 271 , 695 , and $1390 \mathrm{hrs}$. We observe an increase in the rate of oxygen isotope exchange with decreasing electrostatic lattice energy in the order: $\mathrm{Mg}-\mathrm{Ca}-\mathrm{Sr}-\mathrm{Ba}$. Pre- liminary results of a similar nature have been obtained for exchange between chlorite, biotite, and muscovite reacted with pure water at temperatures between $300^{\circ}$ and $600^{\circ} \mathrm{C}$ and $0.3-1 \mathrm{kbar}$. Isotope exchange rates increase with decreasing lattice energy in the order: muscovite, biotite, chlorite. This order is consistent with our model and reflects an increase in the iron content for this particular group of silicates.

A number of diffusion experiments have been completed that focused on the rate of isotope exchange in calcite and the sheet silicates, brucite and chlorite. Isotope-tracer diffusion profiles were measured using the $4 \mathrm{f}$ Cameca ion microprobe. In one series of experiments, 1-3 millimeter chips of Iceland spar calcite were reacted at $400^{\circ}, 600^{\circ}$, or $800^{\circ} \mathrm{C}$ and various fluid compositions (pure water, pure $\mathrm{CO}_{2}, \sim 4 \mathrm{~mol} \% \mathrm{CO}_{2}$ ) at pressures between 1 and 2.5 kbar. From our preliminary results it is clear that the diffusivities of oxygen are faster in the water-rich system compared to pure $\mathrm{CO}_{2}$. There is a linear dependence of increasing diffusivity and increasing water fugacity. Additionally, oxygen diffusion is faster than carbon diffusion regardless of whether water is present, suggesting that some kind of decoupling must occur between oxygen and carbon in terms of the dominant transport species. We also explored the use of the ion probe to quantify the transport rates of hydrogen and oxygen in hydrous phases. Coarse chips (1-3 mm) of brucite and chlorite were reacted with pure water enriched in either ${ }^{18} \mathrm{O}(98 \%)$ or $\mathrm{D}\left(98 \% \mathrm{D}_{2} \mathrm{O}\right)$ at $500^{\circ} \mathrm{C}$ and 1.5 or $2.5 \mathrm{kbar}$. The hydrogen diffusivities are between one and two orders of magnitude faster than the oxygen, again suggesting a decoupling of the mechanism of hydrogen transport compared to oxygen. As with the calcite, we observed an increase in diffusion rate for both hydrogen and oxygen with increasing pressure. 
CONTRACTOR:

CONTRACT:

CATEGORY:

PERSON IN CHARGE:
PACIFIC NORTHWEST NATIONAL LABORATORY

MS K2-25

Richland, Washington 99352
D-AC06-76RLO-1830

Geochemistry

A.R. Felmy

\section{A. Surface Structure and Chemistry of Carbonate Minerals (D. R. Baer [509-375-2375; Fax 509-375-5965; E-mail dr_baer@pnl.gov], J. E. Amonette [509-372-6125; Fax 509-372-6328; E-mail je_amonette@pnl.gov], and J. P. LaFemina [509-375-6895; Fax 509-375-4486; E-mail jp_lafemina@pnl.gov])}

Objectives: The purpose of this program is to develop a fundamental, microscopic understanding of the structure and chemistry of carbonate surfaces, including the interactions between adsorbates and mineral surfaces.

Project Description: This project involves an interdisciplinary theoretical and experimental effort designed to gain a fundamental, molecular level understanding of carbonate mineral surface structure and chemistry. Carbonate minerals are particularly important in the global $\mathrm{CO}_{2}$ cycle and in subsurface contaminant migration processes. The availability of large single-crystals allows fundamental measurements to be made on well-defined surfaces. By linking experimental studies of geochemical reactions on single-crystal surfaces with first-principles quantummechanical model calculations to describe the surface and interfacial structure and chemistry, a systematic study of the factors controlling the surface chemistry of carbonate minerals can be made. In particular, the effects of substitutional impurities and other point chemical defects on the structure and geochemical reactivity of carbonate mineral surfaces and interfaces can be isolated and quantified. Moreover, this improved microscopic understanding will eventually provide insights into the behavior of these materials in natural systems.

The approach to meeting program goals involves three interdependent areas of effort: development of ab initio and kinetic Monte Carlo (KMC) models for the structure and chemistry of the calcite cleavage surface, vacuum studies of the structure and chemistry of the cleavage surface, and comparison of surfaces in vacuum with those in model geochemical environments.

Results: High resolution atomic force microscopy (AFM) measurements of the $\mathrm{CaCO}_{3}$ (101-4) surface in different aqueous solutions indicate a slight relaxation of the uppermost surface carbonate oxygen atoms (Liang et al., 1996a). These measurements imply that the surface maintains a $1 \times 1$ structure in which the carbonate group within the surface unit cell slightly reorients itself. In previous studies some evidence of a $2 \times 1$ reconstruction had been reported (Stipp et al., 1994). A series of ab initio density-functional computations has been completed that shows no evidence for a $2 \times 1$ reconstruction and suggests only a slight $(0.1)$ relaxation of the outermost oxygen atoms and a small reorientation of outer carbonate groups. These calculations found no evidence (cleaved or water-exposed surfaces) of an asymmetrical relaxation as observed by the AFM in aqueous solutions.

AFM observations of the motion of steps during dissolution (Liang et al., 1996b) have been extended to more geologically relevant conditions that include impurities, as well as various solutions with different degrees of saturation. These measurements show that increasing amounts of $\mathrm{Mn}$ in solution decrease dissolution and minimize the anisotropy in step velocities 
observed in more pure conditions. As might be expected, increasing levels of bicarbonate in solution slow step velocities during dissolution. In addition, the anisotropy of step velocity is changed such that the steps that dissolve the fastest in "pure" conditions nearly stop while the "slow" moving steps are relatively unaffected. The effects are also sufficiently anisotropic so that the shape of pits changes from being rhombohedral to being partially rounded.

In earlier work, a KMC model of dissolution was developed that, after parameterizing to AFM results, was able to reproduce quantitatively all of the available AFM data on shallow pit growth. Fitting to experiment in this way allowed individual elementary microscopic rates involved in the dissolution to be determined for the five types of step edge sites. It also allowed pit growth to be simulated for very small pits in the early stage of growth, a regime that is extremely difficult to observe experimentally. More recent work has clarified the relationship existing between the terrace-ledge-kink (TLK) and KMC models of dissolution. Despite its simplicity, the TLK model provides a description of the dissolution of calcite that is semiquantitatively correct when tested against the more sophisticated KMC model. This indicates that the dominant microscopic processes occurring during dissolution in the real system, as incorporated into the TLK model, have been correctly identified.

The KMC model is now expanded to study the surface reactivity when closer to equilibrium. In this case, as well as dissolution, growth from solution also occurs and produces observable changes in pit morphology. Again, matching the KMC behavior to AFM data is being used to provide quantitative atomistic information. This approach is also being adopted to study how the elementary rates are affected by the presence of impurities.

\section{References:}

Liang. Y., A. S. Lea, D. R Baer, M. H. Engelhard, Surface Science 351, 172 (1996a).

Liang, Y., D. R. Baer, J. M. McCoy, J. P. LaFemina, Journal of Vacuum Science and Technology A14, 1368 (1996b).

\section{B. Theoretical Characterization of the Physics and Chemistry of Soil Minerals (Anthony C. Hess [509-375-2052; Fax 509-375-6631; E-mail ac_hess@pnl.gov] and Maureen I. McCarthy)}

Objectives: This program develops and uses solid state quantum mechanical and classical mechanical methods to investigate the atomic scale properties of aqueous mineral interfaces that affect the transport and speciation of geochemically important systems.

Project Description: This research program investigates the microscopic properties of minerals and mineral interfaces that affect the macroscopic transport of contaminants through the subsurface. Our principal focus is on the mineral/water interface with the goal of identifying critical or controlling aspects of atomic scale phenomena that influence the behavior of complex geochemical systems on longer length and time scales. Our strategy is based on an integrated theoretical approach that combines methods from ab initio quantum mechanics and classical mechanics. Ab initio and first principle quantum mechanical methods implemented on massively parallel computer architectures are used to investigate such phenomena as adsorption, dissocia- tive chemisorption, diffusion and desorption on the internal and external surfaces of oxide, metal oxide, and aluminosilicate minerals. Molecular dynamics and molecular mechanics techniques are employed in conjunction with the quantum mechanical calculations to study interfacial dynamics and ensemble effects.

This research program is jointly supported by OBES/Geosciences and OBES/Chemical Sciences.

Results: Our recent work has focused on completing the implementation of a new periodic first principles Gaussian basis density function program (GAPSS) and in using molecular dynamics potentials, developed from our previous quantum mechanical studies using periodic Hartree-Fock theory to investigate mineral water interfaces.

The new program, GAPSS, as implemented on large-scale parallel computer systems, can now study significantly larger systems to higher degrees of accuracy than could previously be achieved. To establish 
the accuracy and reliability of this new approach, we have tested its predictions against the available theoretical and experimental data for a variety of bulk oxides and semiconductors, including selected external surfaces of these materials. In addition, studies involving the physisorption of several molecular species $\left(\mathrm{H}_{2} \mathrm{O}\right.$, $\mathrm{CO}, \mathrm{HCl}$, etc.) on the surface of $\mathrm{MgO}, \mathrm{a}-\mathrm{Al}_{2} \mathrm{O}_{3}$, and $\mathrm{ZnO}$ have been completed and compared to our previous quantum mechanical calculations of these systems. Having successfully completed the initial validation phase, GAPSS is currently being used to investigate the interaction of molecular water with complex defect structures on $\mathrm{MgO}$ and $\mathrm{a}-\mathrm{Al}_{2} \mathrm{O}_{3}$.

Studies have also been completed using molecular dynamics methods that are increasing our understanding of the solvation and near surface geometric structure of ionic species at the water/MgO(001) interface. Comparisons of experimental and theoretical XAFS spectra are currently being used to understand the geometric structure of this aqueous mineral interface.

\section{Structure and Reactivity of Ferric Oxide and Oxyhydroxide Surfaces (James R. Rustad [509-372-6313; Fax 509-372-6328; E-mail jr_rustad@pnl.gov] and Andrew R. Felmy [509-372-6296; Fax 509-372-6328; E-mail ar_felmy@pnl.gov])}

Objectives: The objectives of this program are to (1) develop the capability to develop large-scale molecular models of hydroxylated ferric oxide and oxyhydroxide surfaces, (2) use these models to better understand the relationship between surface structure and reactivity for this class of minerals, and (3) use this knowledge to advance the predictive capability of thermodynamic models for adsorption.

Project Description: Ferric oxides have high specific surface areas and high affinities for oxyanions and heavy metals and actively respond to changes in redox conditions in natural environments. These minerals are therefore important in a variety of low-temperature geochemical processes, particularly those in which adsorption and dissolution couple with fluctuations in redox potential. For many solutes, measurement of sorption density versus aqueous concentration suggests the presence of a heterogeneous array of surface sites having a range of affinities for the probing solute. Crystallographic differences in the arrangement of surface oxide sites are a fundamental aspect of this heterogeniety. In this project, the effects of crystallographic heterogeneity on adsorption are evaluated using large-scale computational molecular models. These results are then used to produce a more robust thermodynamic description of adsorption at the mineral-water interface.

Results: During FY 1996: (1) We have performed molecular-dynamics simulations of the goethite-water interface in an effort to assess the role of solvent in controlling surface speciation. Water molecules (125) were placed in a thin film between two goethite (110) surfaces. The hydroxyls associated with the dissociatively-adsorbed water remained bound to the $\mathrm{FeOH}_{2}$ groups. Thus, the reaction mechanism for the uptake of protons by the goethite surface appears to be $\mathrm{FeOH}_{2}-\mathrm{OH}+\mathrm{H}^{+} \rightarrow \mathrm{FeOH}_{2}^{+}+\mathrm{H}_{2} \mathrm{O}$. (2) The infrared spectrum of hydroxylated goethite was computed and shown to be in reasonable agreement with the experimental results. In particular, it was shown that several surface species were not infrared active. The results explain the existence of only two peaks in the surface vibrational spectrum, despite the presence of five distinct surface species. (3) Studies of nonhydroxylated hematite (001) and (012) surfaces were undertaken to provide a benchmark of our classical simulation methods with quantum mechanical calculations. Our results are in excellent agreement with available LDA, HartreeFock, and tight-binding calculations. (4) Hydroxylation of the hematite surface strongly affected the manner of surface relaxation through surface hydrogen bonding. The coordination of the surface iron ions was strongly distorted for surfaces in which the face-sharing octahedra are exposed. (5) The shape of the surface charge vs solution $\mathrm{pH}$ curve for goethite was well-represented in the dilute region by the model derived from the molecular statics methods; however, prediction of surface titration data at higher background electrolyte calculation required introduction of specific pair formation constants between the background electrolyte ions and the surface. 


\section{References:}

Rustad, J. R., A. R. Felmy, and B. P. Hay, Molecular statics calculations of proton binding to goethite surfaces: A new approach to estimation of stability constants for multisite surface complexation models, Geochim. et Cosmochim. Acta, 60, 1563-1576, 1996.
Rustad, J. R., A. R. Felmy, and B. P. Hay, Molecular statics calculations for iron oxide and oxyhydroxide minerals: Toward a flexible model of the reactive mineral-water interface, Geochim. et Cosmochim. Acta, 60 , 1553-1562, 1996. 
CONTRACTOR:

CONTRACT:

CATEGORY:

PERSON IN CHARGE:
SANDIA NATIONAL LABORATORIES

Lockheed Martin

Albuquerque, New Mexico 87185

DE-AC04-94AL85000

Geophysics and Earth Dynamics

A. Micromechanics of Failure in Brittle Geomaterials (Joanne T. Fredrich [505-844-2096; Fax 505844-7354; E-mail fredrich@ sandia.gov] and Teng-fong Wong [State University of New York at Stony Brook])

Objectives: The objective of this project is to provide a fundamental understanding of the effects of grain boundary structure and cementation, damage state, and load path on the deformation and failure mode of brittle porous and nonporous geologic materials by measurement of mechanical behavior under high pressure and deviatoric stress, quantitative microstructural characterization of pristine and deformed samples, and theoretical analysis.

Project Description: Knowledge of the failure behavior of rocks is important for several energy-related applications, including oil and gas exploration and production, underground disposal of nuclear waste, and drilling technology. The experimental investigation will provide a detailed understanding of the micromechanical processes associated with the brittle failure of geomaterials and includes triaxial tests following various load paths that are defined by the ratio $\mathrm{K}$ of the change in the radial confining (horizontal) stress to the change in the axial (overburden) stress. Tests are conducted to various stages of failure and include measurement of strain and acoustic emission. The micromechanical failure process is further elucidated and characterized quantitatively using light microscopy, laser scanning confocal microscopy (LSCM), and scanning electron microscopy. Work focuses on porous carbonate and siliciclastic rocks, although related experiments are also being performed on low-porosity crystalline rocks in order to study completely the ef- fect of certain parameters. The results of the laboratory tests and microstructural studies are used to guide analyses using fracture mechanics and continuum plasticity theories.

Results: Application of a high resolution threedimensional imaging technique developed previously under this project to various engineering materials was demonstrated. Thermal Protection System (TPS) materials possess a complicated, porous microstructure that directly influences their thermal, mechanical, and chemical properties. This is especially true of rigid, fibrous insulations, such as the LI, FRCI, and AETB families of TPS tile insulations used on the Space Shuttle. Conventional imaging techniques, such as optical microscopy or scanning electron microscopy, cannot be used to quantify the microstructures of these porous materials $(\phi \sim 80 \%)$, which is crucial for TPS modeling, development, and optimization. We determined that the LSCM technique can be used to image the microstructure of these fibrous insulations and also to quantify various aspects of the microgeometry of both the solid matrix and void space. As a result of the successful preliminary results, Fredrich is now conducting a collaborative project with Dr. J. Marschall of NASA Ames Research Center with funding from NASA Ames Research Center. In a second application, the LSCM technique was applied to image growth defects in SiC crystals. The growth defects are of interest since they are detrimental to the performance of 
semiconductor devices fabricated from SiC. The LSCM technique was used to reveal the three-dimensional structure of superscrew dislocations that can be used to constrain theories of their development. This work was conducted in collaboration with Dr. W. M. Vetter and Prof. M. Dudley of SUNY Stony Brook. Preliminary results were reported in MRS Symp. Proc. V. 406.

Analysis of the experimental test series conducted on Westerly granite with differing initial damage states was conducted. The experimental data suggest two regimes of crack growth in brittle geomaterials subjected to all-compressive loading: a low pressure regime $(<25 \mathrm{MPa})$, where the failure process is sensitive to the preexisting crack population, and a higher pressure regime, where microcrack growth leading to brittle failure is unrelated to the preexisting microcracks. We are applying Gupta and coworkers' analysis of stress singularities at grain triple junctions due to elastic anisotropy to interpret the experimental results.

A triaxial test series to investigate the effect of ductile grain-boundary-lining second phases on brittle failure in compression was conducted. The experimental data reveal a transition in crack propagation behavior at elevated pressures where shear localization is inhibited. The data suggest that the second phase enhances the damage tolerance of the material by causing grainboundary delamination with no loss in load-bearing capacity. Detailed microscopy studies and micromechanical analyses of crack propagation at an interface are underway.

\section{B. Laboratory and Theoretical Analyses of Transport Paths in Single Natural Fractures (S. $R$. Brown [505-844-0774; Fax 505-844-7354; E-mail srbrown@sandia.gov], N. G. W. Cook, L. R. Myer, and $G$. Yang (University of California at Berkeley and Lawrence Berkeley National Laboratory])}

Objectives: Fluid flow in fractured rock is an important phenomenon to understand in connection with energy production and containment or disposal of wastes. The objective of this project is to address several outstanding questions of the effects of void topology on flow and transport in single fractures by quantitative, visual observations and measurements of single- and two-phase flow.

Project Description: We have developed a method for obtaining precise replicas of real fracture surfaces using transparent epoxy resins. These replicas are being used to examine flow in the fracture void space using digitized optical imaging and nuclear magnetic resonance imaging (NMRI). In parallel work, we are examining single- and two-phase flow in irregular fracture aperture distributions using graph theory, effective medium theory, and percolation theory to analyze the topology of the conducting network of void space. This work emphasizes that the topology of the network is of at least as much importance as the conductance of the individual elements in determining fluid flow. The topological characteristics of the preferred paths at different scales will be analyzed to study the effects of scale on flow and dispersion in fractures. Numerical predictions based on graph theory will be compared with experimental observations of multiphase flow.

Results: Field specimens of several natural rock joints were collected. Two samples were chosen for detailed study. Matched two-dimensional images of the surface topography of each fracture surface were measured using laser profilometry, allowing computation of the aperture distribution. Silicon rubber molds were used to construct epoxy replicas of both specimens. Clear and dyed fluids were injected into the fracture pore space. The Lambert-Beer Law for light attenuation of dyes was used to determine the aperture distribution of the replicas. Dye was injected into clear fluid to observe flow channels. NMRI was used for quantitative measurements of flow velocity. Both NMRI and video imaging techniques show distinct and strong channeling of fluid flow at the sub-millimeter to centimeter scale. Both replicas have one large dominant flow channel. The aperture distributions derived from NMRI and video imaging are very similar; however, the correlation between direct aperture measures and those reconstructed from surface profilometry was poor. The single large channel does not appear in the reconstructed aperture. Differences between actual and reconstructed 
sample assembly and differences in the scale of the measurements are likely reasons for this discrepancy.

A new effective medium theory (EMT) was developed and documented in collaboration with J. B. Walsh (MIT). This model departs from standard theories in that it includes short-range spatial correlations in aperture size. Adding aperture correlation to EMT improves substantially on the accuracy of flow predictions from statistical aperture data as compared to most earlier methods.

In collaboration with R. L. Bruhn (U. of Utah), a model has been developed and documented for the for- mation of voids and veins along geologic faults. This model includes progressive dilation of the fault during multiple slip events and the elastic deformation of the surfaces normal to the fault plane (closure) as new void space develops. The model predicts vein geometries that are qualitatively similar to those observed in faultcontrolled mineral deposits. The model shows that new void space opened by slip along a typical rough fault cannot easily be closed by elastic processes due to $10 \mathrm{~km}$ burial. This emphasizes the high capacity of faults to transmit fluids at depth.

\section{Shear Strain Localization and Fracture Evolution in Rocks (W. R. Wawersik 1505-844-4342; Fax 505-844-7354; E-mail wrwawer@sandia.gov], D. J. Holcomb, and W. A. Olsson)}

Objectives: This research seeks an improved understanding of the mechanism of the formation of faults and fractures in rock and the prediction of their causative stresses, location, orientation, thickness, and spacing. Specifically, the research examines the applicability of a theory by Rudnicki and Rice that describes faulting as a constitutive instability leading to a localization of shear deformation from a homogeneous pattern of deformation.

Project Description: An experimental program is undertaken that entails four parts: (1) A systematic evaluation of the Rudnicki-Rice constitutive parameters under axisymmetric and truly multiaxial stress states. Several rock types are used to cover a range of porosities, including low-porosity Tennessee marble and intermediate porosity Gosford sandstone. (2) Experiments to measure and compare the actual and predicted development of strain localization in axisymmetric and plane-strain compression. (3) Multiaxial stress tests on pressurized thin-walled cylinders with superimposed torsion to investigate special phenomena leading to strain localization at relatively small deformations. (4) Post test petrographic observations concerning the details of shear banding and the potentially accelerating effects of imperfections in experimental boundary conditions. The foregoing research is integrated with a parallel theoretical study by Rudnicki.

Results: Previous work had shown that a vertex forms at the load point on the yield surface for Tennes- see marble. To investigate this phenomenon for a porous rock, a zigzag stress history was applied to both Gosford and Berea sandstones. Initial data analysis indicates that vertices also form on the yield surface for these rocks, suggesting that strain localization can occur earlier than smooth-yield-surface predictions. A collaboration was begun with a computational group at Sandia with the goal of incorporating the constitutive properties measured in this project into codes suitable for modeling large-scale geological structures. There is increasing interest in the petroleum industry in developing this capability. In addition to incorporating general criteria for localization, realistic modeling requires the inclusion of nonnormality, hardening, and pressure dependence; both the form and the values of these quantities were measured for the rocks studied under the current project.

A larger, true triaxial apparatus was brought into operation during the year, capable of deforming samples as large as 10 by 10 by $20 \mathrm{~cm}$. Initial applications of the apparatus to Gosford sandstone showed the effects of stress state clearly. At the same mean stress, plane strain deformation resulted in failure with dilation, while conventional triaxial testing led to failure with compaction. The associated fault angles differed by 10 degrees in accord with theory. The apparatus' ability to apply stress states that are not axially symmetric is crucial to testing theories of localization. 
CATEGORY:

PERSON IN CHARGE:
Geochemistry

M. C. Walck

\section{A. Cation Diffusion Rates in Selected Minerals (Diana K. Fisler, Randall T. Cygan [505-844-7216; Fax 505-844-7216; E-mail rtcygan@sandia.gov], and H.R. Westrich)}

Objectives: Determine experimental cation diffusion coefficients for enstatite and carbonate minerals at temperatures less than $1000^{\circ} \mathrm{C}$ for evaluating disequilibrium behavior in geological, nuclear waste, energy, and materials concerns.

Project Description: Evaluation and modeling of geochemical processes related to nuclear waste, energy, and materials problems will require the accurate determination of cation diffusion data in silicate minerals and carbonates. A new technique for the preparation of diffusion couples using thin film technology was developed in an effort to evaluate the relatively slow diffusion of $\mathrm{Mg}^{2+}$ and $\mathrm{Ca}^{2+}$ in phases such as pyroxene and calcite, where diffusion rates are on the order of $10^{-22}$ to $10^{-16} \mathrm{~m}^{2} / \mathrm{s}$ in the temperature range of $700^{\circ}$ to $1000^{\circ} \mathrm{C}$. Resistive evaporation of enriched stable isotopes onto polished mineral surfaces is used to create a thin film-mineral diffusion couple. Diffusion couples are annealed in a controlled oxygen fugacity furnace for periods up to three months in order to provide a diffusive penetration depth of approximately 0.2 microns. Depth profiles of the tracer isotope are obtained using an ion microprobe and are then fit to appropriate diffusion models to obtain precise and reproducible diffusion coefficients.

Results: Work has been completed on the enstatite phase of this project. Samples of enstatite with compositions ranging from $\mathrm{Mg}_{0.99} \mathrm{Fe}_{0.01} \mathrm{SiO}_{3}$ to $\mathrm{Mg}_{0.83} \mathrm{Fe}_{0.17} \mathrm{SiO}_{3}$ show no dependence on iron content within the resolution of this technique. Samples of the composition $\mathrm{Mg}_{0.91} \mathrm{Fe}_{0.09} \mathrm{SiO}_{3}$ and $\mathrm{Mg}_{0.99} \mathrm{Fe}_{0.01} \mathrm{SiO}_{3}$ were annealed at oxygen fugacities ranging from the quartzfayalite-magnetite to the iron-wustite buffers for determining the oxygen-fugacity dependence of the diffusion coefficient and show small or no dependence on oxygen fugacity in contrast to assumptions based on comparisons to the diffusion of cations in olivine. In addition, extensive transmission electron microscopy on the enstatite/oxide interface reveals the character and thickness $(400 \AA)$ of the thin film. Ten to 15 samples each of calcite, dolomite, rhodochrosite, and magnesite were obtained and prepared to provide surfaces parallel to cleavage and coated with ${ }^{25} \mathrm{Mg}$-enriched oxide. Five samples each of calcite and dolomite were prepared and coated with ${ }^{44} \mathrm{Ca}$-enriched oxide. Preliminary experiments on the diffusion of ${ }^{25} \mathrm{Mg}$ in calcite suggest that diffusion coefficients are on the order of $10^{-23} \mathrm{~m}^{2} / \mathrm{s}$ for anneals performed at $500^{\circ} \mathrm{C}$ and $600^{\circ} \mathrm{C}$. An ion microprobe profile analysis for a ${ }^{44} \mathrm{Ca}$ diffusion experiment is shown in the accompanying figure. These results suggest a similar value of $10^{-23} \mathrm{~m}^{2} / \mathrm{s}$ for the ${ }^{44} \mathrm{Ca}$ self-diffusion coefficient for an anneal completed at $650^{\circ} \mathrm{C}$. Further experiments are in progress to confirm the results for $\mathrm{Mg}$ and $\mathrm{Ca}$ diffusion in calcite and to extend the measurements to lower temperatures.

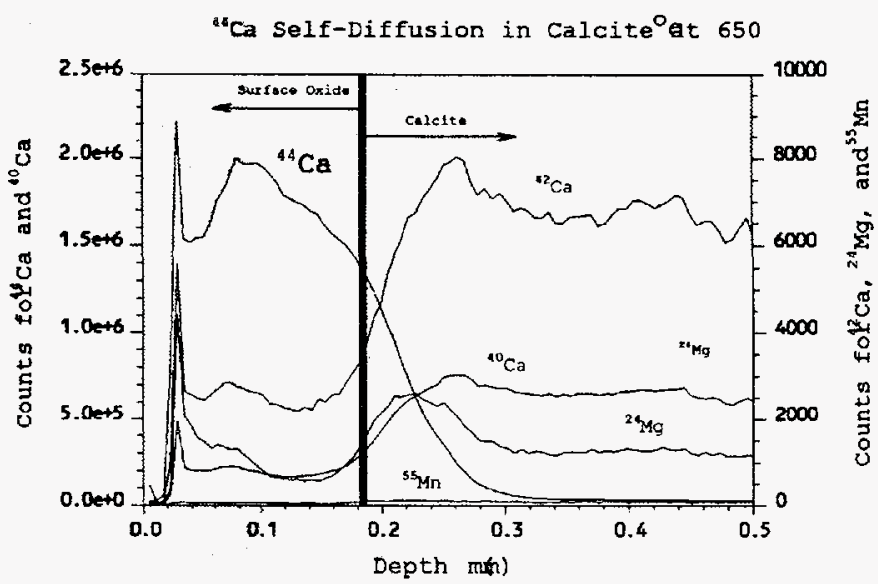




\section{B. An Investigation of Organic Anion-Mineral Surface Interactions During Diagenesis (Patrick $V$. Brady [505-844-7146; Fax 505-844-7354; E-mail pvbrady@sandia.gov], Randall T. Cygan, and Henry R. Westrich)}

Objectives: Mineral surface-organic acid interactions affect organic anion budgets and often control the dissolution and growth of aluminosilicate minerals during soil formation and diagenesis. Determination of temperature-dependent adsorption of oxalate, benzoate, and salicylate onto enstatite, albite, aluminum oxide, and kaolinite as functions of organic anion type and concentration will lead to improved understanding of soil weathering characteristics and diagenetic porosity evolution.

Project Description: The adsorption of organic anions to mineral surfaces in soils and deep basins can be understood if temperature-dependent adsorption isotherms of carboxylate and phenolate groups onto aluminosilicate surfaces are first known. Moreover, the catalytic role of adsorbed organic anions on mineral dissolution and porosity evolution in soils and during diagenesis may be reliably estimated if the mechanistic link between anion adsorption and reaction rate is quantitatively established. These hypotheses are being examined by wet-chemical measurements of the temperature-dependent adsorption of oxalate, salicylate, and benzoate onto quartz $\left(\mathrm{SiO}_{2}\right)$, corundum $\left(\mathrm{Al}_{2} \mathrm{O}_{3}\right)$, enstatite $\left(\mathrm{MgSiO}_{3}\right)$, albite $\left(\mathrm{NaAlSi}_{3} \mathrm{O}_{8}\right)$, and kaolinite $\left(\mathrm{Al}_{2} \mathrm{Si}_{2} \mathrm{O}_{5}[\mathrm{OH}]_{4}\right)$. To complement this experimental program, a variety of computer-based techniques are being used to examine the molecular interactions at the mineral-solution interface, including ionic modeling, Monte Carlo docking and molecular dynamic simulations. Linking observed anion-surface interactions with an atomistic evaluation of reaction mechanisms and pathways will lead to a set of general rules for predicting the extent of organically mediated phase changes during diagenesis. At the same time, field measurements of soil weathering in the presence and absence of organic acids are being used to determine linkages among soil biota, the silicate-carbonate cycle, and global climate.

Results: (1) Mineral dissolution at $\mathrm{pH} 3$, enstatite dissolution at $25^{\circ}$ and $60^{\circ} \mathrm{C}$ varies from $10^{-14.7}$ to $10^{-14.0}$ moles $/ \mathrm{cm}^{2} \mathrm{~s}$, respectively. At similar temperatures and near neutral $\mathrm{pH}$, dissolution rates range from $10^{-15.5}$ to $10^{-14.9}$ moles $/ \mathrm{cm}^{2} \mathrm{~s}$. At $25^{\circ} \mathrm{C}$ albite dissolution from $\mathrm{pH}$ 3 to 5 is approximately $10^{-16.5} \mathrm{moles} / \mathrm{cm}^{2} \mathrm{~s}$. Oxalate at $100 \mu$ mol levels depresses the dissolution of both enstatite and albite at $25^{\circ} \mathrm{C}$.

(2) Temperature-dependent sorption albite at $25^{\circ} \mathrm{C}$ and kaolinite at $60^{\circ} \mathrm{C}$ both strongly sorb salicylate under acidic conditions $(\mathrm{pH}<3)$. Only mild sorption of benzoate occurs on albite, $\mathrm{Al}_{2} \mathrm{O}_{3}$, and kaolinite at $25^{\circ}$ and $60^{\circ} \mathrm{C}$.

(3) Digital imaging of field weathering: We have completed digital imaging of abiotic and lichen-controlled weathering of plagioclase and olivine as a function of temperature and precipitation on Hualalai Volcano in Hawaii. The activation energies for abiotic weathering are very close to those measured in the lab. The lichen-controlled activation energy for plagioclase dissolution is $13 \mathrm{kcal} / \mathrm{mol}$. Precipitation effects on runoff are fit with a power law and are found to be much greater for lichen-controlled weathering.

\section{Heterogeneous Nucleation and Growth Kinetics of Clays (Kathryn L. Nagy 1505-844-5337; Fax 505-855-7354; E-mail klnagy@sandia.gov] and Randall T. Cygan)}

Objectives: Clay nucleation and growth often occur heterogeneously and/or epitaxially on detrital minerals. Kinetics of these processes and role of nucleating substrates are unknown. The goal is to quantify clay mineral growth by examining the reaction at the surface, assess reactive surface area, and provide kinetic data for accurate modeling of weathering and diagenesis.

Project Description: Experiments are performed in which the growth surface (single crystal or organic substrates) is characterized before and after reaction 
by various techniques used by the surface physics community to investigate thin films. These include atomic force microscopy (AFM), ion beam analyses (Rutherford backscattering and elastic recoil detection), rotating anode and synchrotron X-ray reflectivity, and X-ray diffraction (XRD). Comparison is made with results from standard powder experiments in which rates are quantified from solution chemistry changes. Clay growth occurs under controlled solution composition and temperature conditions that mimic nature. Nucleation site densities and nucleated crystal morphologies are monitored to acquire information on reactive surface areas, a parameter considered typically by bulk measurements such as gas adsorption. Molecular modeling of the bonding interactions between substrate and overgrowth as well as overgrowth morphology provides a fundamental basis for interpreting the experimental results.

Results: In the first year, an AFM was acquired and set up for application to measurement of clay growth. Initial batch and flow-through experiments on brucite growth on muscovite were conducted at $80^{\circ} \mathrm{C}$, in $\mathrm{pH} 9$ solutions. Growth was characterized by Tapping Mode ${ }^{\mathrm{TM}} \mathrm{AFM}$, ion beam analyses, and rotating anode XRD. Results from the ion beam and low-angle $\mathrm{X}$-ray reflectivity analyses show that a layer 100$300 \AA$ thick forms at supersaturations seven times higher than the equilibrium ion activity product at 1 to 5 days. Tapping Mode ${ }^{\mathrm{TM}}$ AFM images show a distinction in morphology and growth mechanism of the brucite islands as a function of saturation state. At a supersaturation of 7 , islands are spaced about $0.5 \mu \mathrm{m}$ apart, have trigonal outlines with convex edges 0.3 $0.5 \mu \mathrm{m}$ in length, and are one unit cell high. In contrast, at a supersaturation of 15 , islands are spaced every $0.05-0.1 \mu \mathrm{m}$, exhibit no obvious shape, and are 4-5 unit cells high. At lower supersaturation, monolayers appear to form sequentially perpendicular to the basal plane, while, at higher supersaturation, individual islands grow upwards before spreading laterally. Calculated rates based on the brucite film thickness are similar in magnitude to published dissolution rates at comparable temperatures and in comparable solutions. Brucite dissolves seven orders of magnitude faster than other sheet-structured minerals, including gibbsite, kaolinite, and muscovite. Therefore, it is promising to obtain growth rates that to first order match dissolution rates.

\section{CATEGORY:}

PERSON IN CHARGE:

\section{Hydrology}

M. C. Walck

\section{A. Laboratory Investigation of Constitutive Property Upscaling (Vincent C. Tidwell [505-848-0574; Fax 505-848-0558; E-mail vctidwe@sandia.gov], John L. Wilson [New Mexico Institute of Mining and Technology])}

Objective: The basic objective of this research program is to enhance fundamental understanding of the processes and media characteristics that govern permeability upscaling. Specifically, we will address the following questions:

- Does permeability upscale in a predictable and quantifiable manner?

- What characteristics of the geologic medium influence upscaling behavior?
- What are the appropriate measures of permeability upscaling (i.e., first two statistical moments, fractal dimension, other)?

Project Description: Laboratory investigation of permeability upscaling is accomplished through the use of a specially adapted mini-permeameter that we have termed the multi-support permeameter (MSP). The MSP allows rapid, precise, nondestructive measurement of gas permeability over a range of discrete sample 
supports (i.e., sample volumes). Measurements are made at different sample supports by simply varying the size of the permeameter tip seal. In this way, measurements spanning five orders of magnitude on a per volume basis are made subject to consistent boundary conditions and flow geometry. Experiments progress by collecting thousands of measurements on multiple faces of meter-scale blocks of rock with each of five different tip seals $(0.31,0.62,1.27,2.54$, and $5.08 \mathrm{~cm}$ inner diameter[ID]) plus a single large-scale $(15.24 \mathrm{~cm}$ ID) measurement designed to integrate over the entire sampling domain. This process is repeated on multiple rock samples each of which is carefully selected according to its depositional and diagenetic history. The acquired data is used to evaluate the performance of theoretical upscaling models, to bound their application with respect to limiting assumptions, and to explore alternative measures and models of upscaling behavior.

Results: In this project's first year, efforts have focused on evaluation of the MSP. Modifications to tip seal design have been made to achieve improved control over tip seal geometry under compression. Evaluation of seal quality as a function of compression time and pressure has also been accomplished. In addition, effects of gas slippage, head loss, nonsteady- state flow, and non-Darcy flow on permeability calculations have been assessed. A series of experiments were then performed on synthetic, "homogeneous" plaster and mortar blocks to demonstrate that measurements made at different sample supports are free from bias induced by the measurement technique. A suite of exhaustive measurements was also collected from natural rock samples to demonstrate that measurement error is low and consistent across the different tip seals.

Upon completion of the system evaluation, extensive upscaling data were collected from two fluvial sandstones, a 0.3 by 0.3 by $0.3 \mathrm{~m}$ block of Berea Sandstone (14,000 permeability measurements) and a 1.0 by 1.0 by $1.0 \mathrm{~m}$ block of Massillon Sandstone (75,000 permeability measurements). It should be noted that such 3-D, spatially exhaustive, multi-support data sets do not exist elsewhere. Reduction of this data has revealed strong trends in the mean, variance, and correlation length scale as a function of sample support. Considering the care that has been taken to insure consistency in the multi-support measurements, we are convinced that the measured trends are not simply artifacts of the sampling program but are diagnostic of permeability upscaling. Analysis of this data and comparison to theoretical upscaling models are ongoing.

\section{B. Two-Phase Immiscible Fluid Flow in Fractured Rock: The Physics of Two-Phase Flow Processes in Single Fractures (Robert J. Glass [505-848 0556; Fax 505-848-0558; E-mail rjglass@nwer.sandia.gov], Harihar Rajaram [University of Colorado, Boulder], Michael J. Nicholl [Oklahoma State University])}

Objectives: The objective is to develop a quantitative understanding of the critical processes controlling two-phase flow and transport in fractures based on detailed physical experiments and high resolution numerical simulations. This understanding may subsequently be abstracted for use in conceptual models applied at large-scale to applied problems in petroleum extraction and the isolation of hazardous or radioactive waste.

Project Description: Under two-phase, immiscible fluid-flow conditions, phase geometry within the fracture (i.e., the geometry saturated with each phase) ultimately controls the permeability to each phase, fluid pressure/saturation relations, and solute dispersion within each phase. Phase geometry is a function of both the aperture field and the two-phase flow processes themselves. Capillary, gravitational, and viscous forces in combination with boundary and initial conditions have all been demonstrated to play roles in the formation of fracture phase-geometry. Phase "fingering," separate from the single phase concept of flow channelization, occurs where any of these forces are dominant (capillary fingering, gravity-driven fingering, viscous fingering), emphasizing the importance of understanding the two-phase displacement processes themselves. 
In this collaborative project between Sandia National Laboratories and the University of Colorado, systematic physical experimentation is coupled with concurrent numerical simulation to explore the interplay among capillary, gravitational, and viscous forces in the control of phase structure and, thus, flow and transport in rough-walled fractures. Understanding of capillary, viscous, and gravity fingering is explored in order to identify mechanisms that may be used to damp or enhance fingered flow. In addition, a conceptual understanding is developed for the phase invasion processes controlling replacement of a fully entrapped, immobile phase as it dissolves into the flowing phase.

Results: Experimental study of two-phase flow in fractures has been limited by the inability to measure fracture aperture fields, phase occupancy geometry, and solute concentration fields within a given experiment at sufficient resolution. At Sandia National Laboratories, high resolution (time, space, concentration, aperture) full-field light transmission techniques to make such measurements in transparent fractures constructed out of analog materials have been developed and evaluated. Aperture and solute concentration fields measured in a series of fractures that increase roughness systematically are being used to test and develop capabilities for large-scale modeling of single phase flow, solute transport (diffusive to advective dominated), and phase dissolution in fractures containing entrapped phase structures (see University of Colorado contribution for this project).

A modified invasion percolation (MIP) model has been developed to simulate slow-flow phase invasion processes; MIP incorporates both gravity and capillary forces in the absence of viscous forces (i.e., applicable to small capillary number flows). Capillary forces are modeled by the Laplace-Young equation that relates pressure drops across fluid/fluid interfaces to its curvature and surface tension. Interfacial curvature includes both curvature between the rough walls (determined by the local aperture, contact angle, and local plane convergence/divergence angle) and "inplane" curvature as one would see looking normal to the plane of the fracture. When only aperture-derived curvature is included, the model does not predict the experimental results; however, inclusion of in-plane curvature allows good simulation of past experimental results for gas dissolution, gravity-driven fingers, horizontal invasion, and gravity stabilized rises and drains. A series of simulations using measured aperture fields (0.01 $\mathrm{mm}$ resolution) form an analog rough-walled fracture (isotropic, correlation length $0.7 \mathrm{~mm}$ ) is being conducted to define the set of physical experiments required for a full test of the MIP model.

\section{Multicomponent Convection in Porous Media and Fractures (Robert J. Glass [505-848-0556; Fax 505-848-0558; E-mail rjglass@nwer.sandia.gov], Harlan W. Stockman, and Scott W. Tyler [Desert Research Institute, Reno, Nevada])}

Objectives: Objectives are to understand the physical processes controlling multicomponent convection in natural porous and fractured media and to develop quantitative relationships between system parameters (permeability, porosity, and solute concentrations) and the magnitude of convective mass transport in subsurface hydrologic environments.

Project Description: Multicomponent convection is a transport phenomenon that can occur in fluid bodies and fluid-filled porous media that contain two or more components (heat, solutes, etc.) that influence the local fluid density. If two or more of the components individually influence local fluid density, differ in dif- fusivity, and have opposing individual density gradients, then the globally stable system can develop local buoyancy-driven instabilities in the form of thin fingers or larger convection cells. These instabilities may in turn drive larger scale motion within the porous media or fluid body. Multicomponent (double-diffusive for two component systems) convection may contribute significantly to mass and heat transport in porous and fractured systems; leading to fluxes in excess of two orders-of-magnitude higher than would be predicted in an equivalent, density-stable system.

In this collaborative project between Sandia National Laboratories and the Desert Research Institute, 
we combine systematic physical experimentation with concurrent numerical simulation to explore multicomponent convection in porous media and fractures. Sandia National Laboratories' high resolution, full-field energy transmission techniques are used to study the onset and development of multicomponent convection in simulated porous media (Hele-Shaw cells), sands, and fracture analogs. Boundary and initial conditions, as well as the permeability field are varied to evaluate the conditions under which multicomponent convection occurs in natural systems. Numerical modeling efforts focus on application of lattice gas automata techniques to consider two- and three-component systems.

Results: This project was initiated in February 1996. We have analyzed 13 experiments that investigate the factors controlling the transition from stable diffusive transport to unstable multicomponent convection. Each experiment began by layering a sucrose solution over a sodium chloride solution in a Hele-Shaw cell such that the fluid was density stable, although double-diffusively unstable. The concentration of the sucrose solution was systematically varied between experiments to test the analytical theory predicting the stability boundary. Using light transmission techniques, the sodium chloride concentration field was tracked using a nonreactive dye. Analysis of images taken throughout an experiment show mass conservation better than $2 \%$, in spite of the evolution of highly contorted concentration fields.

Experiments conducted to date suggest that, for sufficiently large component Rayleigh numbers, system stability can be predicted without detailed knowledge of variability within the permeability or solute concentration field. If found to hold, this will be an important result, as uncertainty with respect to the permeability and solute concentration fields is often extreme within the subsurface environments. The experiments also demonstrate that solute fluxes can be quantitatively determined and that these fluxes are well in excess of that predicted if the solutes are transported by diffusion alone. 


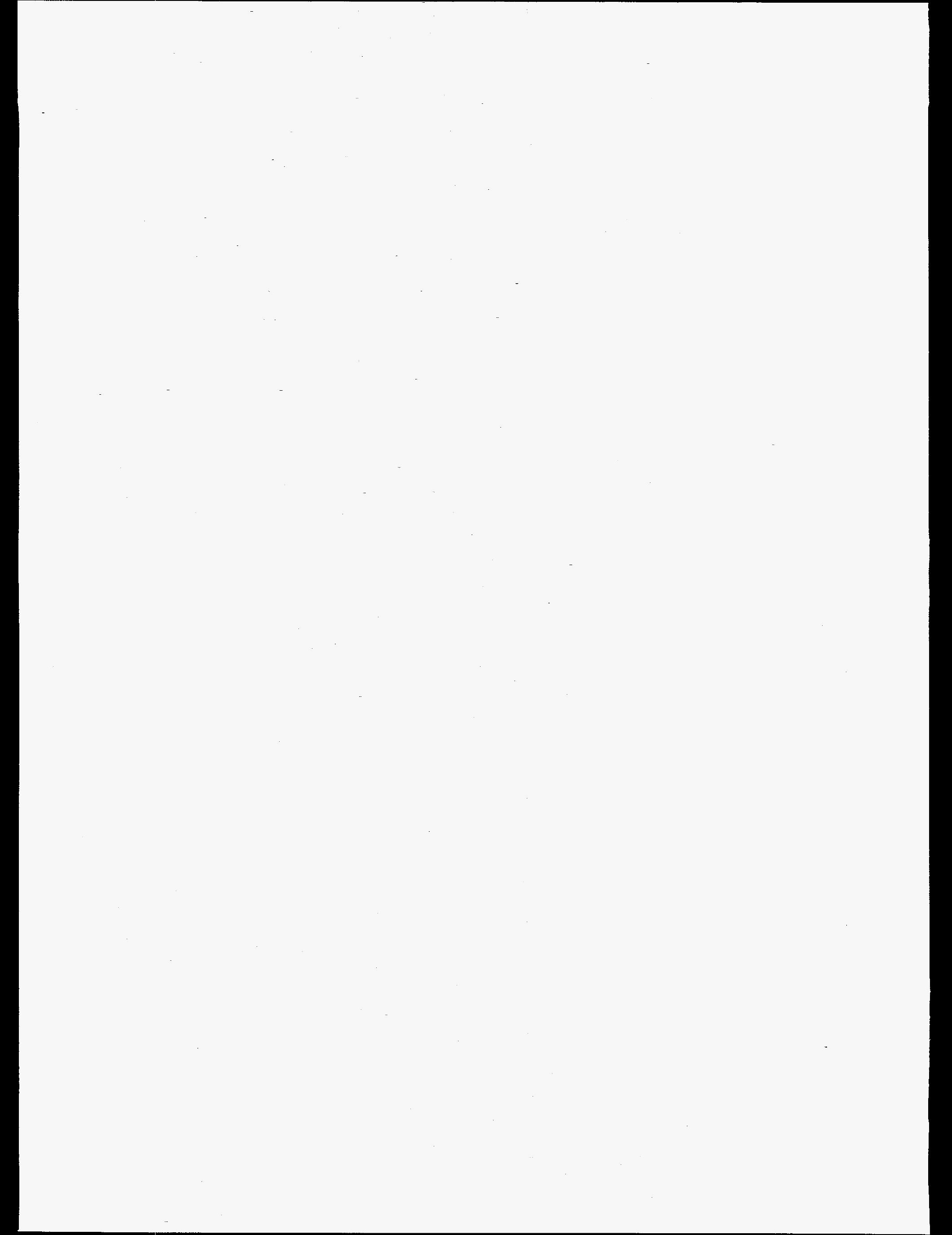


PART TWO

OFF-SITE 

GRANTEE:

GRANT:

TITLE:

PERSONS IN CHARGE:
UNIVERSITY OF ALASKA

Geophysical Institute

Fairbanks, Alaska 99775-7320
DE-FG06-86ER13530

A Study of Solar Prominences and Magnetospheric Substorms

L. C. Lee (907-474-7410; Fax 907-474-7290; E-mail

lclee@geewiz.gi.alaska.edu) and S. I. Akasofu
Objectives: The objectives are to examine and understand the (1) development of preconditions for solar flares, (2) role of magnetic reconnection in the solar eruptive processes, and (3) formation of a very thin current sheet during the substorm growth phase.

Project Description: This project deals with the formation of a thin current sheet and magnetic reconnection in the solar corona and in the geomagnetotail. These problems have relevance to formation and eruption of solar prominences and magnetospheric substorms. The methodology of this study encompasses mathematical analysis and computer simulations. Specifically, the following topics are addressed: (1) formation of a current layer in a solar magnetic arcade under foot-point shearing, (2) magnetic reconnection and subsequent change of field line topology in a magnetic arcade system, (3) stretching of the near-earth tail due to nonuniform convection, and (4) thinning of the near-earth tail current sheet due to entropy anti-diffusion instability.

Results: In the ideal MHD evolution of a magnetic arcade, no instability or nonequilibrium is found for any amount of shear, but a current layer is found to develop and become longer and thinner in the later stage. Thus, it is inferred that a fully open field is an asymptotic state for an infinite shear. When resistivity is applied to a sheared arcade, magnetic reconnection can take place only above a critical amount of shear.
The reconnection characteristics in magnetic arcades are found to depend on spatial resistivity patterns. A fast reconnection with small shock angles can be achieved only when the resistivity is confined to a small volume. In this case, high speed reconnection outflows can tear the magnetic island into a pair. The fast-moving island system creates a fast shock or a steepened fast mode structure that resembles an observed CME frontal loop. In a nonuniform magnetospheric convection, the electrostatic field in the ionosphere causes advection of the entropy function in the flux function space. The consequential stretching of the near-earth magnetotail induces a dusk-dawn electric field across the plasma sheet, which compensates for the dawn-dusk electrostatic field there. This can explain why no appreciable electric field is observed in the near-earth plasma sheet in the substorm growth phase. In the earth's magnetotail, the plasma pressure and the entropy per flux tube have opposite slopes in the flux function space. Thus, particle diffusion across the field line implies antidiffusion of the entropy function. This results in an increase of the slope of both the pressure and the entropy, which leads to a self-accelerating process of current sheet thinning. This "entropy anti-diffusion instability" is proposed to explain the dipolarization of magnetic fields and the onset of magnetic reconnection in the near-earth tail. 
GRANTEE:

GRANT:

TITLE:

PERSON IN CHARGE:
AMERICAN GEOLOGICAL INSTITUTE

4220 King Street

Alexandria, Virginia 22302-1502

DE-FG05-94 ER 75979

U.S.-Russian Geoscience Student Exchange Program

Edward M. Davin (703-379-2480; Fax 703-379-7563)
Objectives: The objective is to support administration and operation of the U.S.- Russian Geoscience Student Exchange Program.

Results: On August 10, 1996, seven Russian students will complete their one-year training program and return to Moscow where they will enter careers in petroleum exploration and development with U.S. international oil companies or their Russian counterparts. This is the third class to complete the program, bringing the total to 22 students.

On August 18th, seven new Russian students are scheduled to arrive in Houston to begin their one-year training program. This group of students was selected from applicants who had completed the five-year course in geoscience at Russian universities and who planned to make a career in petroleum exploration and development. Each student scored 500 or better on TOEFL (Test of English as a Foreign Language). Final selection was based on results of personal interviews with U.S. faculty advisors from the two participating uni- versities: Texas A\&M University and the University of Texas-Austin.

In Houston, the students will receive a technical orientation program in the offices of the oil company sponsors (i.e., one day each at Amoco, at Exxon, at Conoco, and at Texaco). Scheduling does not permit travel to the DOE/BDM facility in Bartlesville, OK. The program covers the range of knowledge and skills required to evaluate oil/gas prospects and consists of lectures and laboratory demonstrations. Each company emphasizes that geoscience skills are basic to building models of risk analysis. This orientation was requested by the faculty advisors to guide the students in their course selections. On August 23, the students will arrive at their assigned university for two semesters of academic training. The last phase of the program is a ten-week internship in the offices of the oil company sponsors, Houston, and at DOE/BDM, Bartlesville, where they have hands-on experience with teams of geoscientists working on oil prospects in Russia. 
GRANTEE:

GRANT:

TITLE:

PERSONS IN CHARGE:
AMERICAN MUSEUM OF NATURAL HISTORY

Department of Earth and Planetary Sciences

New York, New York 10024

\title{
DE-FG02-92ER14265
}

\section{The Effect of Carbon on the Mechanical and Electrical Properties of Rocks}

\author{
E. A. Mathez (212-769-5379; Fax 212-769-5339; E-mail \\ mathez@amnh.org), A. G. Duba (Lawrence Livermore National \\ Laboratory), and T. J. Shankland (Los Alamos National Laboratory)
}

Objectives: Objectives are to understand how carbon films form on crack surfaces in rocks, determine how these films influence electrical conductivity, and explore the effect of growth of carbon in rocks on fracture propagation.

Project Description: Experiments will be conducted to test two hypotheses. (1) As fractures open in the time leading up to failure along a fault, carbon is deposited as a continuous film on the new mineral surfaces and electrical conductivity increases. Subsequent changes in electrical conductivity occur as the connectivity of the initial fracture network is altered by continued deformation. (2) The rate of crack growth may be enhanced by the catalytic growth of carbons. Two sets of experiments will be conducted. In the first set we shall determine if carbon is deposited on new crack surfaces during rock deformation and its effect on electrical conductivity. The latter will be monitored as a rock approaches failure in the presence of a $\mathrm{CO}-\mathrm{CO}_{2}-$ $\mathrm{CH}_{4}$ gas mixture. In the second set of experiments acoustic emission will be monitored as the rocks are loaded to failure in an inert carbon-free atmosphere of $\mathrm{N}_{2}$, and then identical experiments will be conducted in $\mathrm{CO}-\mathrm{CO}_{2}-\mathrm{CH}_{4}$ gas mixtures.

Results: The experimental technique to fracture rocks in a controlled $\mathrm{C}-\mathrm{O}-\mathrm{H}$ atmosphere at $\mathrm{P}=100 \mathrm{MPa}$ and $\mathrm{T}=400^{\circ} \mathrm{C}$ and to simultaneously monitor resistance has been developed. The first experiments have been conducted on a carbon-free sandstone containing small quantities of Fe-oxide in the cement in an atmo- sphere of $5 \% \mathrm{CO}--95 \% \mathrm{CO}_{2}$. Resistance exhibits a progressive increase with time and increased load. Sudden decreases in resistance are associated with micro-fracture events, as monitored by small changes in the load, and at failure large decreases in resistance are observed. Samples from several of the first experiments have been examined by X-ray photoelectron spectroscopy, which provides information on carbon concentration within several monolayers of the analytical surface. It has been found that samples run in CO-bearing atmospheres contain more carbon on the surfaces exposed by fracture than control samples run in Ar. At face value, the experiments support the first hypothesis listed above.

The relations among electrical conductivity and graphite content, metamorphic grade, and fluid:rock interaction have been investigated for a suite of regionally metamorphosed graphitic carbonate rocks from the Waits River formation, Vermont. Graphitization was complete by the lowest grade of metamorphism $\left(450^{\circ} \mathrm{C}\right.$, $450 \mathrm{MPa}$ ). Low- and medium-grade rocks contain 4400 and $2800 \mathrm{ppm}$ of reduced carbon, respectively, but graphite does not form interconnected networks. Highgrade rocks are almost completely devoid of graphite. The $\delta^{13} \mathrm{C}$ and $\delta^{18} \mathrm{O}$ values for carbonate and graphite are $4 \%$ o lower in the high-grade compared to lowergrade rocks. The shift in isotope composition and graphite depletion of the high-grade rocks was caused by influxes of large quantities of magmatic water. Laboratory measurements of electrical conductivity of fluid- 
saturated rocks containing $>7000 \mathrm{ppm}$ carbon are almost an order of magnitude higher than expected from their fluid content alone. Graphite does not form an interconnected network in these rocks, yet it combines with the saline fluids to significantly increase electrical conductivities. 
GRANTEE:

GRANT:

TITLE:

PERSONS IN CHARGE:
ARIZONA STATE UNIVERSITY

Center for Solid State Science

Box 871704

Tempe, Arizona 85287-1704
DE-FG03-94ER14414

\section{A Microanalytical (SIMS) Study of the Trace Element and Isotopic Geochemistry of Diagenetic Silicates}

Objectives: Microanalyses of oxygen and boron isotopes in authigenic silicates are being obtained to determine their variation in hydrocarbon-producing sedimentary basins. These analyses can be used to constrain mass transport processes occurring during diagenesis and hydrocarbon migration.

Project Description: The primary goals of the investigation are to determine whether quartz overgrowths or other authigenic minerals are zoned with respect to their $\mathrm{O}$ isotopes and discover the relation between the isotopic composition of sandstone minerals and provenance and burial diagenesis. The $\mathrm{O}$-isotope microanalyses obtained guide the interpretation of the timing (during burial) of reservoir cementation and help shape models to explain the volumes and chemistry of paleofluids that influenced the reservoirs' burial history. Understanding the sources of mineral components and mass transfer processes will aid the understanding of fluid flow and hydrocarbon migration in sedimentary basins. This technique, combined with B-isotope and conventional SIMS trace element microanalyses, has been applied to diagenetic minerals in oil-producing wells from the Western Canadian Sedimentary Basin (WCSB), the Texas Gulf of Mexico Sedimentary Basin (GMSB), and the North Sea Sedimentary Basin (NSSB).
Results: The oxygen isotope microanalyses of hundreds of quartz grains from these three reservoirs (and new boron isotope analyses of clays) are summarized below: Provenance. In the WCSB and GMSB, detrital quartz varied only slightly from one value. The NSSB samples showed a bimodal variation suggesting metamorphic $\left(\delta^{18} \mathrm{O} \sim 16\right.$ per mil $)$ and igneous $\left(\delta^{18} \mathrm{O} \sim\right.$ 12 per mil) sources. Variability of authigenic quartz. Authigenic quartz is not mono-isotopic. The range of values was similar in all basins $(\sim 15 \%)$, but they show different absolute values in $\delta^{18} \mathrm{O}$; WCSB: $20-34 \%$ per mil, GCSB: $22-35 \%$ per mil, NSSB: $13-28 \%$ oper mil. This suggests that all basins experience quartz precipitation over a similar temperature range while the evolution of pore fluid $\delta^{18} \mathrm{O}$ varies. Temperatures of precipitation. In all basins, high values of $\delta^{18} \mathrm{O}$ were observed on texturally-defined "early" quartz, indicating initial precipitation temperatures $\leq 40^{\circ} \mathrm{C}$. In these basins, the sediments reside at such temperatures for more than 100 million years, so it may not be surprising to observe precipitation occurring at low temperature. Boron isotopes. Study of natural and synthetic clay minerals suggests that B-isotopes change by $<2$ per mil during the conversion of smectite to illite. Thus, authigenic clays record fluid conditions similar to those at the time of their initial formation. 
GRANTEE:

TITLE:

PERSONS IN CHARGE:
ARIZONA STATE UNIVERSITY

Departments of Geology and Chemistry/Biochemistry

Box 871404

Tempe, Arizona 85287-1404
GRANT: $\quad$ DE-FG03-95ER14533

Reaction Mechanisms of Clay Minerals and Organic Diagenesis: An HRTEM/AEM Study

Peter R. Buseck (602-965-3945; Fax 602-965-8102;

E-mail pbuseck@ asu.edu) and Huifang Xu
Objectives: Objectives are to gain an improved understanding of the microstructures and reaction mechanisms in the following reaction processes during diagenesis: (1) berthierine-to-chamosite reaction and polytype transformation in chamosite, (2) smectite illitization and mechanism for the formation of periodically interstratified illite/smectite (ISS), and (3) textural and structural evolution of the organic matter vitrinite.

Project Description: We will study clay and detrital minerals as well as organic matter in sequences of Upper Cretaceous and Lower Tertiary clastic rocks from the southern Rocky Mountains using a range of analytical and structural techniques. We are especially interested in (1) the berthierine-to-chamosite reaction, (2) smectite illitization, and (3) organic diagenesis.

This research will lead to an improved understanding of the states of I/S, C/B, organic matter, and detrital minerals in diagenetic environments. The results will provide important information for determinations of reaction mechanisms and establishment of kinetic models that permit one to predict the extent to which the formation of certain clay minerals occurs at certain depths, temperatures, and times. Such fundamental data will help with evaluations of basinal diagenetic patterns in hydrocarbon exploration.
Results: The mechanisms for the formation of interstratified I/S and the smectite-to-illite reaction have been controversial, and many results are ambiguous because standard XRD and chemical analyses of clay fractions only provide average characteristics. We recently developed a method for characterizing illite and smectite layers in ambient air at room temperature by using scanning force microscopy (SFM). Our preliminary results show this method can be used to distinguish illite and smectite layers based on steps that show their 10 - and 15 - $\AA$ basal thicknesses. Since the SFM images provide three-dimensional information, they also show I/S morphology and hexagonal pits (similar to etch pits) on some surfaces. Also, the orientation relationship between the layers with hexagonal pits can be identified. TEM results of the I/S minerals show the same morphology as is revealed by SFM. We believe SFM is a potentially powerful method for studying interstratified $\mathrm{U} / \mathrm{S}$ crystals since it can give three-dimensional information. The method avoids artifacts from dehydration of smectite layers in I/S samples.

We also investigated clay-like minerals in intergranular pores and oölitic grains in sandstones. TEM images show they are coherently intergrown along (001) and consist of dominant chamosite $(14 \AA)$ and lesser berthierine $(7 \AA)$. Based on their chemical and textural features, we hypothesize that they are precipitation products of pore fluids. 


\section{GRANTEE:}

GRANT:

TITLE:

PERSONS IN CHARGE:
BOSTON UNIVERSITY

Center for Computational Science and Department of Physics

Cambridge, Massachusetts
DE-FG02-95ER14498

Interpretation of Geodetic Crustal Strains Using Massively Parallel Supercomputer Simulations of Nonlinear Dynamical Models

William Klein (617-353-2188; Fax 617-353-9393; E-mail klein@buphyc.bu.edu) and J. B. Rundle (CIRES and Department of Geosciences, University of Colorado)

Objectives: The underlying objective of this basic research is to understand the fundamental physical processes giving rise to the hazards and risks a variety of critical energy facilities face from several kinds of tectonic instabilities, notably earthquakes, volcanic eruptions, and landslides, in concert with the International Decade of Natural Disaster Reduction.

Project Description: A variety of nonlinear dynamical processes operate within the complex earth system and are observed to display the signatures of many of the same phenomena as, for example, neural networks, driven foams, and magnetic depinning in high temperature superconductors. In particular, scaling (fractal distributions), nonlinear thresholds, and spatial interactions are all features possessed by these systems. Signatures of these processes include the appearance of scaling (geometric and dynamical fractal distributions), global and local self-organization, intermittency (transitions from "laminar" to "turbulent" behavior), chaos, and the emergence of coherent spacetime structures. The geodynamical effects observed in earthquake systems, particularly crustal straining, dynamical segmentation, and intermittent seismicity, are being modeled in massively parallel simulations in an effort to clarify the origins of these phenomena. Simulations and theoretical investigations are particularly aimed at quantifying the limits of predictability for disasters that occur within the earth system. We are currently developing both the simulation methods for earthquake models and the statistical mechanical analy- sis techniques needed to understand and interpret the results. From these simulations, we will then predict geodetic and other deformations associated with impending earthquakes to be tested against global positioning system, synthetic aperature radar, and other field data.

Results: During this second year of the project, we have been led by physical considerations to examine mean field models for the dynamics of driven systems with thresholds. Such systems have been used to successfully model earthquakes, neural networks, driven foams, and magnetic depinning transitions in superconductors. In a variety of results, we found that (1) these systems have Boltzmann energy fluctuations, (2) a spatial-temporal coarse graining procedure can be defined that leads to a well-defined Ito-Langevin equation for the mean field dynamics, and (3) a new class of models called "Traveling Density Wave" models can be constructed that have a Lyapunov functional and are governed by the same kind of Ito-Langevin equations. The significance of this work is that these scientifically and technologically important classes of systems can be understood using statistical field theoretic tools developed over the past few decades for analyzing equilibrium systems. Thus we have shown that meanfield threshold systems can be mapped into systems that have appealing and elegantly simple symmetries, scaling properties, and dynamical patterns. These systems are also subject to both first and second order "phase" transitions in the dynamical variables. 
GRANTEE:

GRANT:

TITLE:

PERSONS IN CHARGE:

\section{BROWN UNIVERSITY}

Department of Geological Sciences

Providence, Rhode Island 02912
DE-FG02-90ER14144

\section{Diffusional Transport and Fluid Connectivity in Mineral Aggregates}

\author{
R. A. Yund and J. R. Farver (401-863-1931; Fax 401-863-2058; \\ E-mail ray@gech031.geo.brown.edu)
}

Objectives: The objective of this study is to experimentally determine bulk diffusional transport rates of oxygen (as molecular water) and selected geologically and environmentally important ion species in natural and hot-pressed single and polyphase aggregates of common mineralogies over a range of temperatures, pressures, and coexisting fluid compositions. In addition, the connectivity of coexisting fluids in these aggregates is evaluated from the bulk diffusivity measurements. The results provide much needed data on the nature of grain boundaries in rocks and the rates of transport of chemical components through rocks. Applications of these data include evaluating the retentiveness of different geological media for the isolation and confinement of nuclear and chemical waste, modeling the migration of hydrocarbons through different rock types to refine exploration and development strategies for more efficient oil and natural gas recovery, and determining patterns of circulation of hydrothermal meteoric water and associated ore-body deposition and geothermal energy systems.

Project Description: Bulk diffusional transport rates are determined in natural and hot-pressed aggregates of common mineralogies either "as is" or after textural equilibration with fluids common to natural environments ( $\mathrm{H}_{2} \mathrm{O} \pm \mathrm{CO}_{2} \pm \mathrm{NaCl}$ fluids). The transport rates are determined from profiles of chemical or isotopic tracers measured using an ion microprobe (SIMS). The bulk diffusivities are correlated with the physical nature of the grain boundaries and sample textures that are characterized using transmission and scanning electron microscopy (TEM) and (SEM).
Results: Previous workers have suggested that diffusional transport rates are significantly greater in rocks containing micas or other sheet silicates. To test this idea, a series of experiments has been initiated to determine diffusional transport rates of oxygen and several important cations $(\mathrm{K}, \mathrm{Sr}$, and $\mathrm{Ba}$ ) in a natural ultramylonite sample. The sample is fine-grained $(<10$ $\mathrm{mm}$ ) and is composed of $\sim 15 \%$ biotite, $\sim 25 \%$ quartz, $\sim 60 \%$ feldspars, plus minor oxides. The mica grains define a strong foliation. The experimental charges were prepared using sawn and polished pieces of ultramylonite oriented relative to the foliation. Samples were weld-sealed in a thick-walled Au tube along with a weld-sealed thin-walled $\mathrm{Pt}$ tube containing ${ }^{18} \mathrm{O}$-enriched water $\pm^{41} \mathrm{~K}$ and ${ }^{134} \mathrm{Ba}$. Diffusion experiments were run at $350^{\circ}-550^{\circ} \mathrm{C}$ and $100 \mathrm{MPa}$ pressure under hydrothermal conditions. The samples were pre-annealed at the temperature and pressure of the diffusion anneals for at least one week in order to allow any microcracks that may have formed during run-up to heal and to equilibrate the grain boundaries. The tracer(s) was then introduced by slowly decreasing the pressure, at constant temperature, until the $\mathrm{Pt}$ tube ruptured (typically to $\sim 60 \mathrm{MPa}$ ). TEM examination of samples before and after the diffusion experiments shows no apparent change in the microstructures.

The complex mineralogy of the ultramylonite sample greatly complicates the determination of diffusion rates for the cations; however, the bulk diffusion rates obtained for oxygen are similar to those obtained in monomineralic quartz aggregates pre-annealed in $6 \mathrm{M}$ $\mathrm{NaCl}$ to produce an interconnected fluid distribution. 
The rates are 4-6 orders of magnitude greater than oxygen grain boundary diffusion in quartz and feldspar aggregates with unconnected fluid distributions, and the activation energy obtained is similar to water selfdiffusion in water $(25-30 \mathrm{~kJ} / \mathrm{mol})$ and significantly lower than activation energies for oxygen grain boundary diffusion in quartz and feldspar aggregates (80-110 $\mathrm{kJ} / \mathrm{mol}$ ). The rapid oxygen bulk diffusional transport rates measured in the ultramylonite indicate the presence of an interconnected fluid. The TEM observations show no evidence for interconnected grain-edge channels (as were seen in the monomineralic quartz aggregates pre-annealed in $6 \mathrm{M} \mathrm{NaCl}$ ), suggesting that the fluid is distributed along mica-mica and/or mica-second phase boundaries. If aqueous fluids wet mica boundaries, bulk diffusional transport rates would be greatly increased in mica-bearing lithologies.

In addition, oxygen grain boundary diffusion rates have been determined in natural (Solnhofen limestone) and hot-pressed calcite aggregates. The experiments were done at $350^{\circ}-500^{\circ} \mathrm{C}$ and $100 \mathrm{MPa}$ pressure under hydrothermal conditions. There is no difference in the measured oxygen grain boundary diffusion rates between the natural sample and the hot-pressed aggregates. The D' $\delta$ values are similar to oxygen grain boundary diffusion rates measured in feldspar aggregates with unconnected fluid distributions and yield a similar activation energy of $\sim 110 \mathrm{~kJ} / \mathrm{mol}$. Consistent with the measured $D^{\prime} \delta$ values, TEM observations show no evidence for an interconnected fluid distribution in these calcite samples. 
GRANTEE:

GRANT:

TITLE:

PERSONS IN CHARGE:

\author{
CALIFORNIA INSTITUTE OF TECHNOLOGY \\ Division of Geological and Planetary Sciences \\ Pasadena, California 91125
}

DE-FG03-89ER13445

\section{Infrared Spectroscopy and Hydrogen Isotope Geochemistry of Hydrous Silicate Glasses}

Objectives: The focus of the proposed project is the application of experimental petrology, infrared spectroscopy, and stable isotope geochemistry to problems in petrology and geochemistry, with particular emphasis on the behavior of volatile components in magmatic systems.

Project Description: This project integrates (1) a laboratory component directed toward the development of analytical techniques and a solid understanding of the physical chemistry of volatile components in melts and glasses through carefully controlled experiments and syntheses and (2) a field-oriented component in which these techniques and chemical principles are applied to specific petrological and volcanological problems. A key feature of this project is the combination of methodologies from stable isotope geochemistry with those from experimental petrology and mineralogy. A unique aspect of the project is the explicit focus on the roles played by different species of dissolved water and carbon dioxide in silicate melts and glasses (e.g., molecules of $\mathrm{H}_{2} \mathrm{O}$ and hydroxyl groups; molecules of $\mathrm{CO}_{2}$ and carbonate ion complexes). Many seemingly complex behaviors of volatiles in liquids, glasses, and magmas can be simply and quantitatively explained if the speciation is understood and taken into account.

Results: (1) The partitioning of oxygen isotopes among $\mathrm{CO}_{2}$ vapor and rhyolitic glass and melt, albitic glass, melt, and crystals, and silica glass was measured. This work contributes to the data base necessary for quantitative interpretation of the distributions of oxygen isotopes in nature and in particular during igneous processes. (2) The fractionation of ${ }^{13} \mathrm{C}$ and ${ }^{12} \mathrm{C}$ be- tween $\mathrm{CO}_{2}$ vapor and $\mathrm{CO}_{2}$ dissolved in rhyolitic melt and glass was measured. These measurements are essential for understanding the significance of measured ${ }^{13} \mathrm{C} /{ }^{12} \mathrm{C}$ ratios of magmatic gases and volcanic glasses. (3) The kinetics of oxygen isotopic exchange between $\mathrm{CO}_{2}$ vapor and silicate glasses and melts were measured. Mobility of small amounts of molecular $\mathrm{H}_{2} \mathrm{O}$ and/or $\mathrm{CO}_{2}$ control diffusive exchange of oxygen isotopes in most silicate materials under most natural conditions. (4) The kinetics of reactions between water molecules and anhydrous silicate structural units to form hydroxyl groups in silicate glasses were studied. This is of practical value in that it can be used as a cooling rate indicator and geothermometer for hydrous volcanic glasses. (5) The $\mathrm{C}, \mathrm{O}$, and $\mathrm{H}$ isotopic compositions of natural apatites, a widespread mineral, have been measured. (6) In connection with the Hawaii Scientific Drilling Project, oxygen isotope ratios in olivine phenocrysts from several Hawaiian volcanoes were used to demonstrate for the first time significant correlations between oxygen and radiogenic isotope ratios. (7) A survey of the oxygen isotope ratios of olivine phenocrysts from ocean island basalts spanning the full range of distinct mantle reservoirs was conducted and provided evidence for variable oxygen reservoirs in the mantle. (8) Explosive volcanic eruptions were simulated experimentally by rapidly depressurizing $\mathrm{CO}_{2}-$ saturated water and using high speed photography to follow the bubble growth and motion, the acceleration of the fluid, and the "fragmentation" of the material. This work has led to several insights into explosive volcanic eruptions. 


\section{GRANTEE:}

GRANT:

TITLE:

PERSON IN CHARGE:
CALIFORNIA INSTITUTE OF TECHNOLOGY

Division of Geological and Planetary Sciences

Pasadena, California 91125

\title{
DE-FG03-88ER13851
}

\section{Isotope Tracer Studies of Diffusion in Silicates and of Geological Transport Process in Aqueous Systems Using Actinide Elements}

\author{
G. J. Wasserburg (818-395-6139; Fax 818-796-9823; \\ E-mail isotopes@gps.caltech.edu)
}

Objectives: The research program was directed to three principal objectives: (1) the determination of Ir at ultra-low levels, (2) the nature of $U$ transport on colloids in natural waters, and (3) the effects of oxygen fugacity on the diffusion of $U$ and $T h$ in silicate melts.

Project Description: We are carrying out studies of the transport of actinide and platinum group elements in rivers, bogs, estuarine environments, and oceans. This involves development of advanced laboratory analytical procedures and improved field filtering techniques. These have been applied to both oxic and anoxic environments and establish clear relationships for element transport in natural conditions. The analytical techniques involve high sensitivity mass spectrometry (TIMS and NTIMS), ICPMS, and very low blank-level chemical procedures. The diffusion in silicate melts and glasses is carried out using separated tracers and synthetic glasses. Diffusion couples are produced that permit very high quality diffusion profiles. Measurements are made with an ion probe. This approach is now shown to be applicable to both silicate melts and glasses. The results obtained appear precise and highly reliable. They are basic to understanding the mechanisms and rates of diffusion of elements in glasses.

Results: We have completed the development of Ir analytical procedures for measuring concentrations down to 108 atoms per $\mathrm{kg}$. This was applied to studying the concentrations of Ir in rivers in pristine and industrial areas, and the subsequent transport into the Baltic estuarine environment and the deep sea. This constitutes the first data set on Ir in waters and shows that the Ir riverine input is stripped $\sim 70 \%$ in the estua- rine environment. The remainder supplies the oceans with the dominant inventory of Ir with a residence time of $2 \times 10^{3}$ to $2 \times 10^{4}$ years. The report is in press in Science.

${ }^{238} \mathrm{U}$ and ${ }^{234} \mathrm{U}$ were separated from groundwaters, anoxic mire waters, river waters, and oxic/suboxic brackish waters, using ultrafiltration techniques, and were measured by mass spectrometry. The dominant riverine $\mathrm{U}$ is carried by $>10 \mathrm{k}$ dalton colloids. Within the Baltic Sea, $U$ is removed by sedimentation of colloids. There is a continuing association of $\mathrm{U}$ with colloids at higher salinities $(>6 \%$ ) . Anoxic mires strongly concentrate $U$ but are not the source of high ${ }^{234} \mathrm{U} /{ }^{238} \mathrm{U}$, which comes from $\mathrm{U}$ in bedrock waters. This work was presented at the 1996 V. M. Goldschmidt Conference in Heidelberg, Germany.

Self-diffusion in silicate melts was measured using chemically identical but isotopically labeled glasses. Diffusion coefficients for eight elements were measured in the same experiment with a reproducibility of $\pm 15 \%$. Our results show that self-diffusion in melts is controlled dominantly by melt viscosity but with some effects of ionic radius and charge. There is no effect of the oxidation state on diffusion except for Eu and $\mathrm{U}$ where there is a small shift. Activation energies for all elements are similar and approximately equal to the activation energy for viscosity indicating that network modifier diffusion is dominated by the same mechanisms that control viscosity. One paper has been published and another submitted.

Publications: (1) Anbar, Wasserburg, Papanastassiou, and Andersson, Science (1996). (2) 
Porcelli, Andersson, Wasserburg, Ingri, and Baskaran, V. M. Goldschmidt Conference, J. Conf. Abstracts 1, 482 (1996). (3) Andersson, Porcelli, and Wasserburg, V. M. Goldschmidt Conference, J. Conf. Abstracts 1, 16 (1996). (4) Porcelli, Andersson, Wasserburg, Ingri, and Baskaran, Geochim. Cosmochim. Acta, in preparation. (5) LaTourrette, Fahey, and Wasserburg, Geochim. Cosmochim. Acta 60, 1329-1340 (1996). (6) LaTourrette and Wasserburg, Geochim. Cosmochim. Acta, in press (1996). 
GRANTEE:

GRANT:

TITLE:

PERSON IN CHARGE:
UNIVERSITY OF CALIFORNIA, BERKELEY

Department of Geology and Geophysics

Berkeley, California 94720

DE-FG03-85ER13419

\section{Advective-Diffusive/Dispersive Transport of Chemically Reacting Species in Hydrothermal Systems}

Harold C. Helgeson (510-642-1251; Fax 510-643-9980; E-mail

brogie@garnet.berkeley.edu)

Objectives: The overall research objective of this project is to explore the consequences of oxidation/ reduction processes on the generation and maturation of petroleum in sedimentary basins in an effort to facilitate detection and development of energy resources in hydrocarbon source rocks and reservoirs.

Project Description: The major scientific and technical issues of concern in this project are:

1. What are the thermodynamic properties of organic molecules at elevated temperatures and pressures in sedimentary basins?

2. How prevalent are metastable equilibrium states involving these molecules and the minerals and waters in source rocks and reservoirs?

3. What is the role of oxygen fugacity relative to temperature and pressure in the degradation of kerogen to bitumen and the maturation of petroleum in source rocks?

4. What are the congruent and incongruent solubilities of detrital minerals in oil-field waters, and what diagenetic role do organic species in petroleum play at the oil-water interface in determining these solubilities and generating secondary porosity resulting from mineral dissolution?

5. What is the role of water and hyperthermobarophilic microbes in the generation and maturation of petroleum in sedimentary basin?

Results: During the past year, research efforts have continued to be concerned primarily with generating equations of state parameters and standard molal thermodynamic properties of organic solids, liquids, gases, and aqueous species at elevated temperatures and pressures. The species considered include normal alkanes $\left(\mathrm{CnH}_{2(n+1)}\right)$ with carbon numbers ( $n$, which is equal to the number of moles of carbon atoms in one mole of the species) ranging from 2 to 100 , and 23 amino acids (unless indicated otherwise, all amino acid designations refer to the L-alpha form), including glycine, alanine, valine, leucine, isoleucine, aspartic acid, glutamic acid, ß-asparagine, glutamine, proline, phenylalanine, tryptophan, methionine, serine, threonine, cysteine, tyrosine, lysine, lysine:HC1, D, L-arginine, arginine:HC1, histidine, and histidine:HC1. The values for the latter compounds permit calculation of the standard molal thermodynamic properties of protein unfolding in biogeochemical processes. The other organic species considered consist of 2- and 3-methylalkanes $\left(\mathrm{C}_{n} \mathrm{H}_{2(n+1)}\right)$, for $4 \leq n \leq 20$ and $6 \leq n \leq 20$, respectively, 2,3 dimethylpentane, 4-methylheptane, cycloalkanes $\left(\mathrm{C}_{n} \mathrm{H}_{2 n}\right)$ for $3 \leq n \leq 8$, alkylcycloalkanes $\left(\mathrm{C}_{n} \mathrm{H}_{2(n+1)}\right)$ for $6 \leq n \leq 20$, methylated benzenes $\left(\mathrm{C}_{n} \mathrm{H}_{2(n-3)}\right)$ for $7 \leq n \leq$ 12 , normal alkylbenzenes $\left(\mathrm{C}_{n} \mathrm{H}_{2(n-3)}\right)$ for $6 \leq n \leq 20$, normal 1-alkanols $\left(\mathrm{C}_{n} \mathrm{H}_{2(n+1)} \mathrm{O}\right)$ for $1 \leq n \leq 20$, ethylene glycol $\left(\mathrm{C}_{2} \mathrm{H}_{6} \mathrm{O}_{2}\right)$, glycerol $\left(\mathrm{C}_{3} \mathrm{H}_{8} \mathrm{O}_{3}\right)$, normal 1 alkanethiols $\left(\mathrm{C}_{n} \mathrm{H}_{2(n+1)} \mathrm{S}\right)$ for $1 \leq n \leq 20$, normal amides $\left(\mathrm{C}_{n} \mathrm{H}_{2 n+1} \mathrm{NO}\right)$ for $6 \leq n \leq 20$ and amines $\left(\mathrm{C}_{n} \mathrm{H}_{2 n+3} \mathrm{~N}\right)$ for $1 \leq n \leq 20$, normal carboxylic acids $\left(\mathrm{C}_{n} \mathrm{H}_{2 n} \mathrm{O}_{2}\right)$ for $2 \leq n$ $\leq 20$, and 9 miscellaneous sulfur-, nitrogen-, or oxygen-bearing species. In a continuing effort to supplement the relatively sparse set of calorimetric data available for the multitude of high molecular weight organic compounds of geologic interest, group addi- 
tivity algorithms were used to generate corresponding coefficients and properties for a myriad of high molecular weight compounds in hydrocarbon source rocks.
Research plans call for using these equations of state coefficients and thermodynamic properties to minimize the Gibbs functions for these systems. 
GRANTEE:
GRANT:

TITLE:

PERSON IN CHARGE:
UNIVERSITY OF CALIFORNIA, DAVIS

Department of Geology

Davis, California 95616
DE-FG03-92ER14240

\section{Energetics of Melts from Thermal Diffusion Studies}

\author{
C. E. Lesher (916-752-9779; Fax 916-752-0951; E-mail \\ lesher@.geology.ucdavis.edu)
}

Objectives: This research program characterizes mass transport by diffusion in geological fluids in response to thermal, solubility, and/or chemical gradients to obtain quantitative information on the thermodynamic and kinetic properties of multicomponent systems.

Project Description: Thermal diffusion is the phenomenon of chemical migration in response to heat flow along a thermal gradient. The details of this response are conditioned by the thermochemical properties and constitution of the substance. Silicate liquids undergo substantial thermal diffusion (Soret) differentiation, while the response in sulfide, carbonate, and aqueous fluids to an imposed temperature gradient is varied. The experimental observations of this differentiation are used to evaluate the form and quantitative values of solution parameters and to quantify ordinary diffusion coefficients, heats of transport, and activation energies of multicomponent liquids. The diffusion, solution, and element partition coefficients determined for these geological fluids form a data base for understanding magmatic crystallization behavior and for evaluating geothermal, ore deposit, and nuclear waste isolation potentials. Thermal and isothermal diffusion experiments are conducted using the one atmosphere gas mixing apparatus, rapid-quench cold seal apparatus up to $0.3 \mathrm{GPa}$, piston cylinder device at pressures between $0.7-3.5 \mathrm{GPa}$, and a simplified multianvil device above $3.5 \mathrm{GPa}$. The electron and ion microprobes, and the infrared spectrometer are used in the characterization of experimental run products.
Results: Current experimental capabilities include two 1-atm gas mixing furnaces, a rapid-quench cold seal apparatus using TZM and HZM vessels, three piston cylinder devices, and a Walker-style multianvil device driven by a 1000 -ton Clifton press equipped with a computer-controlled hydraulic system. Automated pressure regulation systems are now also available for the piston cylinder devices. Among the research activities of the last year, we conducted thermal diffusion experiments at very high pressure on magmatic silicate liquids in an attempt to use the recovered heats of transport and chemical potentials as monitors of changing speciation with pressure. We continue to study the influence of water and carbonate species on the Soret diffusion properties naturally occurring silicate liquids. We are expanding our study of network self-diffusion to include highly polymerized melts, and we are continuing our quantitative treatment of chemical diffusion based on Darken's theory of ion mobility for $\mathrm{Pb}$, $\mathrm{U}$, and Th. We have also initiated a comprehensive study of thermal, self, and chemical diffusion of multicomponent liquids of the system $\mathrm{CaO}-\mathrm{MgO}-\mathrm{SiO}_{2}$. New collaborations with colleagues in material science are exploiting our capabilities for high pressure generation to examine the sintering behavior at elevated $\mathrm{T}$ and $\mathrm{P}$ of nano-alumina, nano-titanium, and amorphous silicon carbide and various nanocrystalline composites. Densified nanocrystalline alumina-diamond composites are shown to possess improved mechanical properties and superplasticity. 
GRANTEE:

GRANT:

TITLE:

PERSONS IN CHARGE:
UNIVERSITY OF CALIFORNIA, DAVIS

Department of Land, Air and Water Resources and

Department of Chemistry

Davis, California 95616

DE-FG03-92ER14307

\title{
A New Method for Determining the Thermodynamic Properties of Carbonate Solid-Solution Minerals
}

\author{
William H. Casey (916-752-3211; Fax 916-752-1552; E-mail \\ whcasey@ucdavis.edu) and Peter A. Rock (916-754-8918; \\ Fax 916-754-9057; E-mail rock@miles.ucdavis.edu)
}

Objectives: We are measuring thermodynamic properties for some carbonate solid-solution minerals that are important in soils and aquifers.

Project Description: Our new method is an electrochemical double cell without liquid junction. Such a cell for cadmium-carbonate minerals is (Rock et al., 1994, Geochim. Cosmochim. Acta 58, 4281-4291):

$$
\begin{gathered}
\mathrm{Cd}(\mathrm{Hg}, 2-\text { phase })\left|\mathrm{CdCO}_{3}(\mathrm{~s})\right| \mathrm{CaCO}_{3} \text { (s) } \\
\left|\mathrm{CaCl}_{2}(\mathrm{aq})\right| \mathrm{Hg}_{2} \mathrm{Cl}_{2}(\mathrm{~s}) \mid \mathrm{Hg}(1)- \\
-\mathrm{Hg}(1) \mid \mathrm{Hg}_{2} \mathrm{Cl}_{2} \text { (s) } \mid \mathrm{CaCl}_{2}(\mathrm{aq}), \mathrm{CdCl}_{2} \text { (aq) } \\
\left.\mid \mathrm{Cd}_{\mathrm{x}} \mathrm{Ca}_{1-\mathrm{x}} \mathrm{CO}_{3} \text { (s)|CdCO}{ }_{3} \text { (s)|Cd( } \mathrm{Hg}, 2 \text {-phase }\right)
\end{gathered}
$$

yielding a net cell reaction of

$$
\begin{gathered}
\left(\mathrm{CaCO}_{3}\right)^{\text {calcite }}+(1-\mathrm{x}) \mathrm{CdCl}_{2}(\mathrm{aq})= \\
\left(\mathrm{Ca}_{\mathrm{x}} \mathrm{Cd}_{1-\mathrm{x}} \mathrm{CO}_{3}\right)^{\mathrm{Cd-calcit}}+(1-\mathrm{x}) \mathrm{CaCl}_{2}(\mathrm{aq})
\end{gathered}
$$

Values of $\mathrm{G}_{f}$ for the solid solution relative to the end members are obtained from the cell voltage and known activities of the electrolytes. With these $\mathrm{G}_{f}^{\circ}$ values, we estimate excess Gibbs energies of mixing $\left(G^{e x}\right)$ and the partitioning of metals into the solid solutions at equilibrium. The $\mathrm{G}^{\mathrm{ex}}$ values are compared with enthalpies of mixing $\left(\mathrm{H}^{\mathrm{mix}}\right)$ that we determined via hightemperature drop-solution calorimetry.

Results: Electrochemical studies of mixing in the $\mathrm{CaCO}_{3}-\mathrm{MnCO}_{3}$ binary system are complete and the results are in draft manuscript form. Electrochemical measurements on a series of high magnesian calcite samples supplied by Hank Westrich, as well as dolomite, have been completed. New electrochemical cells were developed for the study of hydrocarbonates and used successfully to determine Gibbs energies of formation of hydrocerussite and hydrozincite. The results have been prepared for publication (Mercy et al.) and will be submitted to American Mineral.

The electrochemical method provides a means of estimating thermodynamic properties at the low temperatures that are characteristic of most soils and aquifers. At these conditions, acid-solution calorimetry is inaccurate for determining enthalpies of reaction because $\mathrm{CO}_{2}$ degasses slowly from an aqueous solution. Solubility experiments are likewise difficult because secondary minerals typically precipitate in a dissolution experiment, thereby complicating interpretation of the data. Metastable equilibrium is much easier to achieve with the electrochemical cells that we employ because the voltage measurements do not dramatically perturb the system, unlike dissolution experiments where a significant fraction of the solid must be dissolved to receive information. Thermodynamic data are also derived from the electrochemical cell data directly, without a complicated model for solute speciation. Equilibrium in the cell can be demonstrated through (1) Nernstian response of the potential to changes in solute activities, (2) the absence of hyster- 
esis in voltage-current plots for the cell, and (3) the rapid and reversible response of the cell voltage to temperature cycling. The method is also demonstrably accurate; our estimated value of $\mathrm{G}^{\circ}$ for otavite $\left(\mathrm{CdCO}_{3}\right)$ and calcite $\left(\mathrm{CaCO}_{3}\right)$ is within $2 \mathrm{~kJ} \cdot \mathrm{mol}^{-1}$ of the NBS values reported in Wagman et al., 1982 (J. Phys. Chem. Ref. Data 11 [Suppl. 2] 1-392).

In order to complement the electrochemical measurements, we are comparing the $\mathrm{G}^{\mathrm{ex}}$ values at $298 \mathrm{~K}$ with $\mathrm{H}^{\text {mix }}$ values (also at $298 \mathrm{~K}$ ) determined via hightemperature drop-solution calorimetry. The calorimetry is conducted using the laboratory of A. Navrotsky at Princeton University. Results for $\mathrm{Ca}_{\mathrm{x}} \mathrm{Sr}_{1-\mathrm{x}} \mathrm{CO}_{3}$ solids have been published (Casey et al., 1996, Geochim. Cosmochim. Acta 60, 933-940).

In order to develop a general theory for predicting Gibbs excess energies for metal carbonate solid solutions, it is necessary to first examine pure metal carbonates that form via the following reaction:

$$
\mathrm{M}^{2+}(\mathrm{g})+\mathrm{CO}_{3}{ }^{2-}(\mathrm{g}) \rightarrow \mathrm{MCO}_{3}(\mathrm{~s})
$$

To date, $U_{\text {electrostatic }}$ and $U_{\text {polarization }}$ for the above reaction ( $\mathrm{M}=\mathrm{Ca}, \mathrm{Cd}, \mathrm{Fe}, \mathrm{Mg}, \mathrm{Mn}$ ) have been theoretically determined as functions of $\mathrm{Q}_{\mathrm{oxy}}$ and $\mathrm{Q}_{\mathrm{oxy}}$ that respectively represent the charge on oxygen in $\mathrm{MCO}_{3}(\mathrm{~s})$ and the oxygen charge for $\mathrm{CO}_{3}{ }^{2-}(\mathrm{g})$. The calculation of $\mathrm{U}_{\text {electrostatic }}$ was achieved via a point charge pairwise interaction approach carried out by means of a Fortran program. The quantity $U_{\text {polarization }}$ was determined by a two-step process. First, the oxygen polarizabilities of the pure metal carbonates under consideration were determined from the crystal refractive indices by employing the Lorentz local field model. These calculations were modelled from Lawless and DeVries (1964, J. Phys. Chem. Solids 25, 1119) and also extended well beyond the nearest neighbor approach they utilized.
Next, a self-consistent method was employed to determine the oxygen dipole moment in both $\mathrm{MCO}_{3}(\mathrm{~s})$ and $\mathrm{CO}_{3}{ }^{2-}(\mathrm{g})$. With this information $\mathrm{U}_{\text {polarization }}$ was easily computed.

The calculation of $U_{\text {repulsive }}$ was performed by way of the following Slater repulsive potential:

$$
\mathrm{U}_{\text {repulsive }}=\mathrm{AR}^{-9}
$$

(Slater, 1939, Introduction to Chemical Physics, McGraw-Hill Book Co., Inc., p. 389). The quantity A is a constart, while $R$ represents the distance of closest approach between $\mathrm{M}^{2+}$ and $\mathrm{CO}_{3}{ }^{2-}$ in $\mathrm{MCO}_{3}(\mathrm{~s})$. By utilizing the following equilibrium condition:

$$
\mathrm{d} / \mathrm{dR}\left[\mathrm{U}_{\text {electrostatic }}+\mathrm{U}_{\text {polarization }}+\mathrm{U}_{\text {repulsive }}\right]=0
$$

the value of the constant A was determined; however, this constant is valid for only one particular value of $\mathrm{Q}_{\text {oxy }}$, namely the correct one. Because of this limitation, an accurate graph of lattice energy vs. oxygen charge is not constructable at this time. In order to achieve this important goal, a new method for determining $\mathrm{U}_{\text {repulsive }}$ has been devised and is in the process of being implemented. It involves Gaussian ' 94 energy calculations on metal carbonate clusters. By subtracting out the electrostatic and polarization energy of these clusters, it is possible to determine $U_{\text {repulsive }}$ as a function of $\mathrm{Q}_{\mathrm{oxy}}$. With this information at hand, graphs of metal carbonate lattice energy vs. $Q_{\text {oxy }}$ can be constructed. By locating the minimum on these figures, theoretical predictions of $Q_{o x y}$ and lattice energy will become possible. At this point, the method will be extended to solid solutions in order to predict excess energies. Comparisons can then be made to existing experimental data obtained from the electrochemical studies. 


\section{GRANTEE:}

GRANT:

TITLE:

PERSONS IN CHARGE:
UNIVERSITY OF CALIFORNIA, DAVIS

Department of Land, Air and Water Resources

Davis, California 95616
DE-FG03-96ER14629

The Energetics of Reactions at Mineral Surfaces
Objective: Metal exchanges between a mineral surface and an adjacent aqueous solution control a wide range of geochemical processes and are manifested as organized motion of monoatomic steps on mineral surfaces. We find evidence ${ }^{1-5}$ that water exchanges are key elementary steps in these reactions and we are establishing the reactivity trends via dynamic NMR measurements on dissolved metal-ligand complexes. This information is used to establish a linear-free-energy correlation for predicting rate coefficients for surface processes.

Project Description: The metal-oxygen bonds to water molecules in dissolved metal-ligand complexes can act as a proxy for metal-oxygen bonds at the surface of an oxide or silicate mineral in an aqueous solution. Similar metal-oxygen bonds are commonly dissociated in ligand-exchange reactions affecting both the dissolved and adsorbed complexes. We propose to predict rate coefficients for ligand-promoted dissolution through knowledge of the rates of exchange of water molecules in simpler dissolved analogues. ${ }^{4,9} \mathrm{We}$ expect ligand-promoted dissolution of oxide minerals by adsorbates to correlate with rates of water exchange in dissolved metal-ligand complexes in cases where structural similarity exists between the surface and dissolved complexes.

Although evidence suggests that they are similar, ligand-exchange reactions at mineral surfaces need not be mechanistically identical to those in solution for success in this approach. Rates of water motion around dissolved metals, for example, correlate with the rates of exchange of nonaqueous solvents around those same metals and range over a factor of $10^{15}$. Establishing reactivity trends using well-established methods on analogous, albeit simplified, complexes is the most efficient means of developing predictive understanding of the surface chemistry in geochemical settings with a much wider range of ligands and metals, and the chemistry is usually poorly characterized.

Results: This project has just begun, and we start by determining rates of water exchange between bulk and inner-coordination-sphere waters in dissolved $\mathrm{Al}\left(\mathrm{H}_{2}{ }^{17} \mathrm{O}\right)_{6-x} \mathrm{~F}_{x}{ }^{3-x}(\mathrm{aq})[0<\mathrm{x}<4]$ and $\mathrm{Al}\left(\mathrm{C}_{2} \mathrm{O}_{4}\right)_{x}\left(\mathrm{H}_{2}{ }^{17} \mathrm{O}\right)_{6-2 x}{ }^{2-2 x}(\mathrm{aq})[0<\mathrm{x}<2]$ complexes as a function of $x$. These complexes have coordination chemistries comparable to the fluoro- and oxalato-complexes supposed to be present at the surface of $\alpha-\mathrm{Al}_{2} \mathrm{O}_{3}$, a well-studied solid. ${ }^{6-7}$ We have already successfully determined rates of water exchange between the bulk solution and the inner-coordination sphere of $\mathrm{Al}\left(\mathrm{H}_{2}{ }^{17} \mathrm{O}\right){ }_{6}^{3+}(\mathrm{aq})$ [Fig. 1], indicating that our methodology is sound.

The $\mathrm{T}_{2}$ values [Fig. 1] are the transverse (spin-spin) relaxation times of the ${ }^{17} \mathrm{O}$ nuclei determined from the width of the absorption peak. The relaxation rates $\left(\mathrm{T}_{2}-\right.$ 1) have two contributions in this system: (1) chemical exchange of waters between the inner-coordination sphere of the complex and bulk waters and (2) interactions of the ${ }^{17} \mathrm{O}$-nuclear-quadrupole moments with fluctuating electric field gradients arising from molecular 
motions in and around the complex. The net sum of these two components varies nonlinearly with temperature such that chemical exchange can be isolated and a rate coefficient for the elementary exchange reaction determined at $298 \mathrm{~K}$. The rate coefficient for water exchange around $\mathrm{Al}(\mathrm{III})$ in our experiments is determined to be $3 \mathrm{~s}^{-1}$ [Fig. 1], which compares well with the accepted value $\left(1-4 \mathrm{~s}^{-1}\right)$. We are now conducting a similar set of measurements on the model complexes.

References: ${ }^{1}$ Casey, W. H. (1991) On the relative dissolution rates of some oxide and orthosilicate minerals. 146: J. Coll. Interf. Sci. 586-589. ${ }^{2}$ Casey, W. H. and Ludwig, C. (1996) The mechanism of dissolution of oxide minerals. Nature 381:506-508. ${ }^{3}$ Casey, W. H and Westrich, H. R. (1992) Control of dissolution rates of orthosilicate minerals by divalent metal-oxygen bonds. Nature 355:157-159. ${ }^{4}$ Ludwig C., Casey W.H., Rock, P.A. (1995) Prediction of ligand-promoted dissolution rates from the reactivities of aqueous complexes. Nature 375:44-47. ${ }^{5}$ Duke, C. V. A., Miller, J.

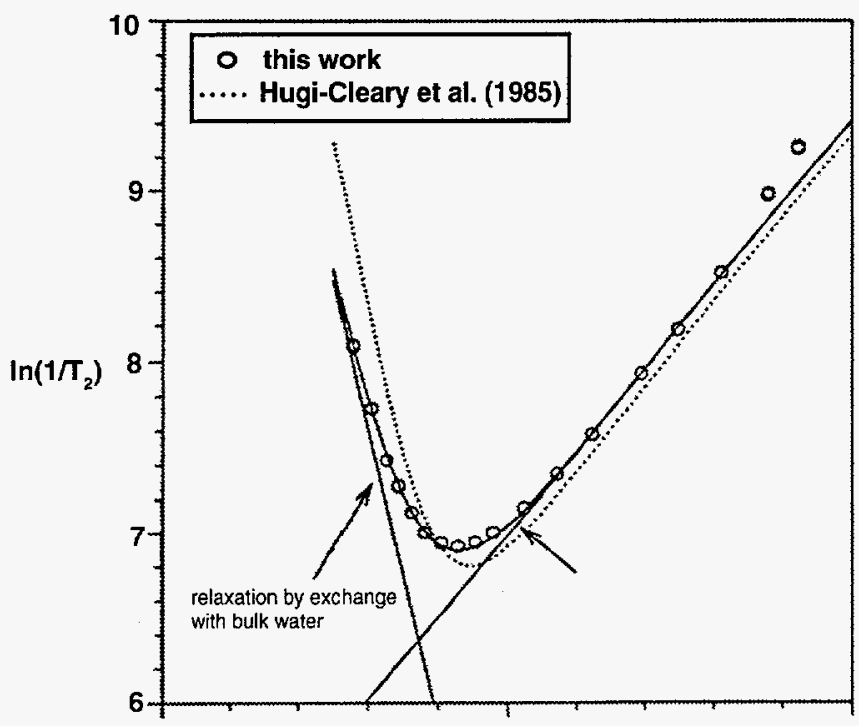

$1000 \pi$
M., Clark, J. H. and Kybett, A. P. (1990) ${ }^{19}$ F MAS NMR and FTIR analysis of the adsorption of alkali metal fluorides onto alumina. J. Molec. Catalysis 62, 233-242. ${ }^{6}$ Pulfer, K., Schindler, P. W., Westall, J. C. and Grauer, R. (1984) Kinetics and mechanism of dissolution of bayerite $\left(\gamma-\mathrm{Al}(\mathrm{OH})_{3}\right)$ in $\mathrm{HNO}_{3}-\mathrm{HF}$ solutions at 298.2 K. J. Coll. Interface Sci. 101, 554-564. ${ }^{7}$ Matwiyoff, N. A. and Wageman, W. E. (1970) Nuclear magnetic resonance studies of aluminum(III) fluoride ion complexes in aqueous solutions. Inorg. Chem. 9, 1031-1036. ${ }^{8}$ Plankey, B. J, and Patterson, H. H. (1986) Kinetics of aluminum fluoride complexation in acidic waters. Environ. Sci. Tech. 20, 160-165. ' Ludwig C., Devidal J-L and Casey W.H. (1995b) The effect of different functional groups on the ligand-promoted dissolution of $\mathrm{NiO}(\mathrm{s})$ and other oxide minerals. Geochim. Cosmochim. Acta 60, 213-235. ${ }^{10}$ Hugi-Cleary, D., Helm, L. and Merbach, A. E. (1985) Variable temperature and variable pressure ${ }^{17} \mathrm{O}$ NMR study of water exchange of hexaquaaluminum(III). Helv. Chim. Acta 68, 545-554.

Fig.1: ${ }^{17} \mathrm{O}$ NMR transverse relaxation rates $\left(\mathrm{T}_{2}{ }^{-1}\right)$, as determined by ${ }^{17} \mathrm{O}-\mathrm{NMR}$-line broadening, vary nonlinearly with temperature but directly yield the rate constant for water exchange between the inner-coordination-sphere of a metal complex and bulk solvent. Here the filled circles represent our new data on a solution containing $0.44 \mathrm{~m} \mathrm{AlCl}_{3}\left(\mathrm{H}_{2} \mathrm{O}\right)_{6}, 0.50 \mathrm{~m} \mathrm{HCl}$ and $0.4 \mathrm{~m}$ $\mathrm{MnCl}_{4}\left(\mathrm{H}_{2} \mathrm{O}\right)_{4}$. The data are compared with previous results from perchlorate solutions ${ }^{10}$. The rate coefficient for water exchange at $298 \mathrm{~K}$ using our data in chloride solutions is: $\mathrm{k}_{\mathrm{ex}}=3.0 \mathrm{~s}^{-1}$; the value from Hugi-Cleary, et al., (1985) in perchlorate solutions in $\mathrm{k}_{\mathrm{ex}}-1.29 \mathrm{~s}^{-1}$. 
GRANTEE:

GRANT:

TITLE:

PERSON IN CHARGE:

\author{
UNIVERSITY OF CALIFORNIA, LOS ANGELES \\ Department of Earth and Space Sciences \\ Los Angeles, California 90024
}

DE-FG03-89ER14049

K-Feldspar Thermochronometry

T.M. Harrison (310-825-7970; Fax 310-825-4396; E-mail tmh@argon.ess.ucla.edu)
Objectives: The ${ }^{40} \mathrm{Ar} /{ }^{39} \mathrm{Ar}$ method can furnish information about both the internal distribution of ${ }^{40} \mathrm{Ar}^{*}$ and Ar diffusion parameters. The multi-diffusion domain (MDD) model shows considerable promise in application to energy-related problems. The objective of this research is to develop K-feldspar ${ }^{40} \mathrm{Ar} /{ }^{39} \mathrm{Ar}$ thermochronometry into a robust tool for assessing upper-crustal thermal histories.

Project Description: In our formulation of the MDD model, the form of the Arrhenius plot and age spectrum is a function of the diffusion parameters for each discrete domain (activation energy, E, and frequency factor, $D_{0}$ ), the domain distribution parameters (domain size, $\rho$, and volume fraction, $\phi$ ), and the thermal history. Since the diffusion parameters may be obtained directly from the Arrhenius plot and we have two independent measures of $\rho$ and $\phi$ (the Arrhenius plot and age spectrum), we have sufficient information to obtain a solution for the thermal history. The underlying assumptions and general predictions of the theory are being tested through laboratory investigations and study of argon isotopic variations in natural K-feldspars.

Results: We have conducted a comprehensive survey of the Ar diffusion properties of over $150 \mathrm{~K}$-feldspar samples analyzed in ${ }^{40} \mathrm{Ar} /{ }^{39} \mathrm{Ar}$ step-heating experiments in order to systematically address fundamental issues underlying the MDD hypothesis. A significant outcome of this endeavor was the statistical analysis of the Arrhenius $\left(\mathrm{E}\right.$ and $\left.\mathrm{D}_{0} / \mathrm{r}^{2}\right)$ and domain distribution parameters that revealed highly systematic behavior. The development of routines to automatically calculate the Arrhenius and distribution parameters eliminates the human bias introduced into the manual modeling and allow us to process a very large data set in a systematic fashion. This analysis resolved issues, such as confidence estimates of the kinetic parameters of the laboratory data and their effect on the reconstruction of thermal histories. We have developed statistical methods, based on the correlation theorem, to determine the extent to which the age and $\log \left(\mathrm{r} / \mathrm{r}_{\mathrm{o}}\right)$ plots exhibit the sympathetic behavior predicted by the MDD model. Correlated behavior is expected only if Ar diffusion takes place by the same mechanisms and uses the same diffusion boundaries in nature as it does during laboratory heating. The MDD model predicts that the age spectrum and $\log \left(\mathrm{r} / \mathrm{r}_{\mathrm{o}}\right)$ plots will be highly correlated when all domains experience uniformly fast or slow cooling, with some degradation observed from the effect of more complicated thermal histories. $90 \%$ of the analyzed samples yielded normalized correlation values above 0.9 (1.0 is a perfect correlation), which agrees well with the model prediction. Samples highly contaminated with excess Ar have poorly correlated age and Arrhenius data until the age spectra are corrected for $\mathrm{Cl}$-correlated ${ }^{40} \mathrm{Ar}_{\mathrm{E}}$, which dramatically increases the correlation to predicted values.

An automated code for modeling K-feldspar thermal history based on use of Chebyshev polynomials was implemented that permits histories involving reheating. Through a variational process, the program is able to determine an optimum solution that fits the age spectrum to the desired accuracy. The method we employ finds these solutions by starting several iterative processes from different initial thermal histories that end when the laboratory age spectrum and the model 
agree to the desired accuracy. Thus, multiple running of the variational iterative method, using a set of random initial thermal histories, produces the whole spectrum of solutions. Contour plots of the probability density calculated from these solutions indicate the full range of T-t constraints afforded by the K-feldspar age and kinetic results. This is a significant improvement over Monte Carlo routines that simply calculate age spectra from random T-t histories. We have applied these routines to $\mathrm{K}$-feldspar results from the Gangdese Thrust and Renbu-Zedong Thrust systems, southern Tibet, and have been able to constrain the magnitude and timing of reheating of footwall rocks and thus infer the initiation age of thrusting. 
GRANTEE:

GRANT:

TITLE:

PERSONS IN CHARGE:
UNIVERSITY OF CALIFORNIA, LOS ANGELES

Department of Earth and Space Sciences

Los Angeles, California 90024

DE-FG03-91ER14222
Uranium, Thorium, Lead, and Oxygen Diffusion in
Rock-Forming Minerals: Implications for Reactive Transport

K. D. McKeegan (310-825-3580; Fax 310-825-2779; E-mail

kdm@argon.ess.ucla.edu) and F. J. Ryerson (510-422-6170;

Fax 510-422-1002; E-mail ryerson@s91.es.llnl.gov)
Objectives: The spatial distributions of isotopes of elements, such as uranium, thorium, lead, and oxygen, observed on a microscale can be utilized to constrain thermal histories of crustal rocks and the extent of their interactions with fluids. There are two requirements necessary for application of this idea to real geologic systems: first, microanalytical techniques must be employed to quantitatively measure the isotopic or elemental heterogeneities, and, second, fundamental diffusion data must be experimentally determined in order to know the rates at which equilibrium between fluid (either melts or aqueous fluids) and host rocks can be approached as a function of various external conditions.

Project Description: The diffusion coefficients for uranium, thorium, lead, and oxygen will be determined in a number of different minerals under a variety of external conditions. The experimental diffusion runs are performed at the Lawrence Livermore National Laboratory, and the analytical phase of the work is done at UCLA, using the Cameca ims 1270 ion microprobe. Techniques for the in situ measurement of either experimentally induced or naturally occurring variations of isotopic and elemental concentrations are being developed for the UCLA ion microprobe.

Results: Silicon and oxygen diffusion have been measured in grossular, spessartine, and pyrope almandine garnets at $800^{\circ} \mathrm{C}, 1 \mathrm{GPa}$, and oxygen diffusion measured at $800^{\circ} \mathrm{C}, 1 \mathrm{~atm} .1 \mathrm{GPa}$ runs employ an overgrowth technique in which a single crystal of garnet is annealed in an $\mathrm{H}_{2}{ }^{18} \mathrm{O}$ fluid containing powdered ${ }^{30} \mathrm{SiO}_{2}$; $1 \mathrm{~atm}$ runs employ an ${ }^{18} \mathrm{O}$-enriched gas reservoir. The garnet overgrowth formed in the $1 \mathrm{GPa}$ runs (typically $300 \mathrm{~nm}$ thick) decreases the tendency for surface dissolution under hydrothermal conditions, and our experiments yield well-behaved diffusion profiles. "Water" concentrations were determined by IR and ranged from $0 \mathrm{ppm}$ (Tanzania pyrope-almandine) to $2800 \mathrm{ppm}$ (Jeffrey Mine grossular). At $800^{\circ} \mathrm{C}, 1 \mathrm{~atm}$ (air and NNO), the garnets showed no loss of water when annealed up to $120 \mathrm{hr}$. At $1 \mathrm{~atm}$, oxygen diffusion in all of the studied garnets is $\sim 10^{-24} \mathrm{~m}^{2} \mathrm{~s}^{-1}$, independent of both water content and bulk composition. Oxygen diffusion in both grossular and spessartine increases to $\sim 10^{-21} \mathrm{~m}^{2} \mathrm{~s}^{-1}$ at $1 \mathrm{GPa}$ under hydrous conditions; unfortunately, the short diffusion profiles preclude IR analysis for water in the diffused region. Oxygen diffusion is inversely correlated with silicon concentration (approximated from the sum of ${ }^{28} \mathrm{Si}$ and ${ }^{30} \mathrm{Si}$ intensities) and suggests that the decreased rates of oxygen diffusion are related to a decrease in the hydrogarnet component through the exchange of $\mathrm{SiO}_{4}{ }^{4}$ with $\mathrm{O}_{4} \mathrm{H}_{4}{ }^{4}$. At $1.0 \mathrm{GPa}$, silicon diffusion coefficients are equal to oxygen diffusion coefficients for both grossular and spessartine. Closure temperatures for oxygen diffusion in a $1 \mathrm{~mm}$ diameter garnet are always in excess of $1000^{\circ} \mathrm{C}$ for geologically reasonable cooling rates. Sluggish oxygen diffusion in garnet confirms that oxygen isotopic compositions recorded during the growth will be faithfully retained. 
GRANTEE:

GRANT:

TITLE:

PERSONS IN CHARGE:
UNIVERSITY OF CALIFORNIA, SANTA BARBARA

Department of Geological Sciences

Santa Barbara, California 93106
The Hydrodynamics of Geochemical Mass Transport and Clastic Diagenesis: San Joaquin Basin, California

James R. Boles (University of California) (805-893-3719; Fax 805-893-2314; E-mail boles@magic.ucsb.edu) and Grant Garven (The Johns Hopkins University)
Objectives: The purpose of this study is to reconstruct the different hydrologic regimes in the San Joaquin basin and to model the importance of these regimes to porosity-reducing mineral reactions in the sediments.

Project Description: The project is to reconstruct the pore fluid history of the southern San Joaquin basin from the Miocene to the present and to compare the documented clastic diagenesis in the basin to the flow model. This hydrologic reconstruction will identify the relative importance of meteoric invasion ver- sus compaction-driven flow in the basin and constrain the potential effect of each hydrologic regime on welldocumented clastic diagenetic reactions in the basin. The modeling will also quantify the effects of tectonism along the basin margin, including basin bounding faults. Initially, the hydrologic reconstruction will be a 2-D model along an east-west transect where abundant subsurface data is available to constrain and compare to the hydrologic model.

Results: This project has only recently been initiated. 
GRANTEE:

GRANT:

TITLE:

PERSON IN CHARGE:
UNIVERSITY OF CALIFORNIA, SANTA BARBARA

Institute for Crustal Studies

Santa Barbara, California 93106-1100
DE-FG03-91ER14211

Physical and Experimental Studies of Magma Rheology, Sedimentary Basins, and Molecular Dynamics of Silicates
Objectives: Objectives are (1) construction of high viscosity rheometer and laboratory measurements on magma, (2) determination by MD simulations of the structure and properties of aluminosilicate melts and glasses, (3) numerical modeling of magmatic underplating and dynamics of granitic magma ascent, and (4) dynamics of thermohaline porous media convection.

Project Description: This collaborative project with D. A. Yuen at the University of Minnesota will improve our understanding of the thermal, chemical, dynamical, and mechanical state of the continental crust and subcrustal lithosphere with particular focus on the interactions between the various subsystems. The work plan includes (1) construction of new rheological apparatus and laboratory measurements on melts and magmatic suspensions, (2) determination of the thermodynamical and transport properties of molten silicates by MD simulations, (3) three-dimensional modeling of salt diapirs, including the effects of dehydration on salt rheology, (4) numerical modeling of magmatic underplating and the formation of granitic diapirs, (5) coupling between mantle convection with temperature-dependent and non-Newtonian rheology and mantlle diapirs on the thermal regime and subsidence curves of rift-related basins, (6) the dynamical influences of lithospheric phase transitions on the thermal-mechanical evolution of sedimentary basins, (7) the development of stress fields and criteria for faulting in the crust, and (8) numerical modeling of heat and solute transport driven by thermal and salinity heterogeneities in geothermal systems.
Results: Results cited below are for the UCSB part of this project. Additional results are given in the summary of activities by the University of Minnesota team led by $D$. A. Yuen. Molecular dynamics simulations on melts in the system $\mathrm{NaAlSiO}_{4}-\mathrm{SiO}_{4}$ at $3 \mathrm{GPa}$ and high temperatures have been completed. Results have been published in American Mineralogist. One citation is: "Molecular Dynamics Simulations of Liquids and Glasses in the System $\mathrm{NaAlSiO}_{4}-\mathrm{SiO}_{2}$ : Methodology and Melt Structures," American Mineralogist, vol. 80, pp. 417-431(1995). A second publication on this subject is Molecular Dynamics Simulations of Liquids and Glasses in the System $\mathrm{NaAlSiO}_{4}-\mathrm{SiO}_{2}$ : Physical Properties and Transport Mechanisms, American Minerologist, vol. 81, pp. 284-302 (1996). In a separate work, a model has been developed and applied to study the origin of compositional and phase heterogeneity in magma bodies undergoing simultaneous convection and phase change. Results are published in Simulations of Convection with Crystallization in the System $\mathrm{KAISi}_{2} \mathrm{O}_{6}-\mathrm{CaMg} \mathrm{Si}_{2} \mathrm{O}_{6}$ : Implications for Compositionally Zoned Magma Bodies, American Mineralogist, vol. 80, pp.1188-1207 (1995). A paper on anatexis driven by mafic magma underplating using this same approach is currently in preparation.

In additional work, the design, fabrication, and assembly of a new high-precision concentric cylinder rheometer with capability in the range $10^{-3}$ to $3 \mathrm{Nm}$ of torque and shear rates in the range $10^{-4}$ to $1 \mathrm{~s}^{-1}$ at $10^{5} \mathrm{~Pa}$ and temperatures to $1600^{\circ} \mathrm{C}$ is almost complete. All major subsystems have been procured and the final assembly is underway. We expect to be making measurements by early 1997 . 
GRANT:

TITLE:

PERSON IN CHARGE:

\section{DE-FG03-87ER13807}

The Seismology of Geothermal Regimes

K. Aki (213-740-5830; Fax 213-740-0011; E-mail aki@coda.usc.edu)
Objectives: Objectives include development of effective interpretation theory for the analysis of seismic data collected in geothermal areas characterized by strongly heterogeneous subsurface structure and by seismic sources involving interactions among gas, liquid, and solid.

Project Description: Seismic data from active and passive experiments in geothermal areas are extremely complicated because of the strongly heterogeneous earth's structure and seismic sources involving interactions among gas, liquid, and solid. To develop effective interpretation theory for analyzing the data, our current objectives are the following: (1) development of analysis methods for defining strongly heterogeneous zones using the localization of scattered seismic energy, (2) 3-D modeling of seismic source, path, and site effects on the observed spectra of seismic events in the active geothermal areas, and (3) exploration of effective inversion procedures for geometry and mechanical properties of subsurface structure using steady-state (frequency domain) data rather than conventional wave form (time domain) data. These problems are identified as targets of investigation with fruitful outcome in the near future.

In the past year, the P.I. divided his time between southern California and the island of Réunion in the Indian Ocean, where he had access to a wealth of seismological data on an active volcano gathered by the modern monitoring network maintained by the Institute of Physics of Globe in Paris. We found clear evidence for localization of scattered seismic energy in the deep magmatic system of the volcano. The seis- mic coda of local earthquakes show concentrated energy in the rift zones as late as 30 to 40 seconds after the origin time. This offers a very effective method for defining a fracture zone on a region scale, complementary to the high resolution study using trapped modes.

We identified several hundred long-period events with various frequencies and durations from the data collected within three episodes of eruption. We are applying a finite-element method to find the location, geometry, and physical properties of their source deterministically. The preliminary result suggests that their sources may be a horizontally lying crack at a few $\mathrm{km}$ depth under the summit area.

We have completed a systematic measurement of coda $\mathrm{Q}^{-1}$ using the enormous amount of digital data stored at the data center of the Southern California Earthquake Center for the period from 1987 to 1994. Remarkable features of coda $\mathrm{Q}^{-1}$ maps for difference frequencies and time windows are (1) high $Q$ region corresponding to the Peninsular Range where seismic velocity at mid-crust depth is high, gravity anomaly is high, and heat flow is low and (2) low Q regions corresponding to the epicentral areas of 1952 Kern County, 1992 Joshua Teee - Landers - Big Bear, and 1994 Northridge earthquakes. We found also that some negative $\mathrm{Q}^{-1}$ areas appear to lie in a zone trending NW to SE, subparallel to the San Andreas Fault and other strike-slip faults. Since the negative $\mathrm{Q}^{-1}$ implies that strongly scattered waves arrive in the later part of the time window, some erratic (specular?) reflections from the fault zone may be involved. 
GRANTEE:

GRANT:

TITLE:

PERSONS IN CHARGE:
CARNEGIE INSTITUTION OF WASHINGTON

Geophysical Laboratory

5251 Broad Branch Road, NW

Washington, DC 20015-1305
DE-FG02-93ER14400

Water-Rock Interaction in the Earth's Upper Mantle:
Application of Combined Stable Isotope and Infrared
Spectroscopic Analytical Techniques

D.R. Bell (202-686-2410; E-mail dbell@gl.ciw.edu), F.R. Boyd, and D. Rumble
Objectives: The objective is to use concentrations of light stable isotopes and trace elements, particularly $\mathrm{H}$, in mantle-derived rocks and minerals to advance understanding of the Earth's global water cycle.

Project Description: This project has evolved into three areas of investigation: (1) isotope analysis of mantle-derived $\mathrm{H}$ in the form of large amphibole crystals in basalt volcanoes in order to constrain better the degree of $\mathrm{D} / \mathrm{H}$ heterogeneity of mantle $\mathrm{H}$ and its tectonic correlation, (2) ${ }^{18} \mathrm{O} /{ }^{16} \mathrm{O}$ analysis of mantle-derived rocks on which trace $\mathrm{OH}$ and other geochemical measurements (including $\mathrm{Fe}^{3+} / \mathrm{Fe}$ ) have been made to evaluate the relative importance of hydrous fluids and bulk recycling in effecting $\mathrm{O}$-isotope and redox heterogeneity in the mantle, and (3) examination of trace $\mathrm{OH}$ and other element abundances in mantle minerals to understand controls on trace $\mathrm{H}$ incorporation and transport in the mantle. In addition, a comprehensive literature survey of $\mathrm{H}$ and trace element abundances in oceanic basalts has allowed a reappraisal of the distribution of $\mathrm{H}$ and it origin in various Earth reservoirs.

Results: $\mathrm{H}$-isotope analysis has concentrated on developing a sampling methodology for mantle $H$ that reduces, or explains, the scatter seen in present literature data sets. A study of 17 megacryst amphiboles from Dish Hill, California, revealed a uniform $\mathrm{H}$ content of $1.0 \mathrm{wt} \% \mathrm{H}_{2} \mathrm{O}$ and $\delta \mathrm{D}_{\text {SMow }}$ of $-46 \pm 7 \%$, with easily recognizable outliers, in contrast with previous studies reporting substantial heterogeneity. The study provides a basis for future sampling strategies and furthermore indicates a restricted and somewhat D-en- riched isotopic composition for this section of otherwise "normal" depleted mantle.

O-isotope work has concentrated predominantly on development by $D$. Rumble of a UV-laser technique for in situ $\mathrm{O}$-isotope analysis. This now yields precise determination of $\delta^{18} \mathrm{O}$ in refractory silicates and oxides. Some small but apparently systematic offsets between IR- and UV-laser techniques are observed, which are presently under evaluation. Present indications are of little correlation between $\delta^{18} \mathrm{O}$ and $\mathrm{OH}$ content of mantle minerals, even in highly isotopically anomalous garnets from a suite of eclogite xenoliths from kimberlite. These results suggest a greater importance for bulk recycling in affecting mantle $\delta^{18} \mathrm{O}$.

Strong correlation of $\mathrm{OH}$ with other trace element abundances have been found in a series of high-pressure garnets from the Colorado Plateau diatremes, which shed light on the substitution mechanism of $\mathrm{H}$ in garnet under certain conditions. This contrasts with results on olivine indicating a lack of minor-element-coupled substitutions. Olivine $\mathrm{OH}$ concentrations are broadly correlated with pressure of origin but do not indicate increased water activity with depth. Both petrologic and crystal chemical correlations between $\mathrm{H}$ and other elements are thus possible in nominally anhydrous minerals.

Coherence of water and other trace element abundances is also apparent in oceanic basalts, where literature data indicate a notable difference in $\mathrm{H}$ behavior in arc-related lavas compared with MORB and OIB, which may explain the present day distribution of $\mathrm{H}$ between hydrosphere and mantle. 
GRANTEE:

GRANT:

TITLE:

PERSONS IN CHARGE:
UNIVERSITY OF CHICAGO

Center for Advanced Radiation Sources

5640 S. Ellis Avenue

Chicago, Illinois 60637
DE-FG02-94ER14466

GeoCARS: A National Resource for Earth, Planetary, Soil, and Environmental Science Research at the Advanced Photon Source
Objectives: GeoCARS is a national consortium of earth scientists whose goal is to design, construct, and operate, as a national user facility, two synchrotron radiation beamlines (one sector) at the Advanced Photon Source, Argonne National Laboratory.

Project Description: The GeoCARS sector will include instrumentation for (1) absorption spectroscopy and anomalous scattering, (2) fluorescence microprobe analysis and microtomography, (3) powder and microcrystal diffraction, (4) high-pressure research with diamond anvil cells, and (5) high-pressure research with the large-volume press. The availability of these facilities, dedicated to earth science research, will allow extension of current research at synchrotron facilities to much lower concentration levels, low $\mathrm{Z}$ elements, low dimensionality materials (surfaces and interfaces), small volume samples, and transient phenomena. Major areas that will benefit include migration and remediation of toxic metals and radioisotopes in contaminated sediments, redox chemistry of transition metals at the root-soil interface and its role in agriculturally-relevant plant diseases, the chemical nature of hydrothermal fluids and evolution of hydrothermal systems, chemical reactions on mineral surfaces, petrogenesis of strategic elements, phase transitions in mantle minerals, and the properties of the Earth's core.

Results: The Preliminary Design Report for the GeoSoilEnviroCARS sector (an extensive document that describes the scientific scope, optics design, component design, cost and schedule estimates, and safety plans for the sector) was submitted to the Advanced Photon Source on December 12, 1995, and was approved on May 21, 1996. Construction of the eight radiation enclosures began in June 1996, and completion is scheduled for September 1996. First light into both the bending magnet and undulator beamline first optics enclosures will be realized in September 1996. Drafts of instrumentation design reports were produced by the five GeoSoilEnviroCARS design teams, and plans were developed for achieving final designs and initial experiments. Preliminary experiments will begin in December 1996. Very successful prototype testing of Kirkpatrick-Baez microfocusing mirrors was done at NSLS. 
GRANTEE:

GRANT:

TITLE:
UNIVERSITY OF CHICAGO

Center for Advanced Radiation Sources

5640 S. Ellis Avenue

Chicago, Illinois 60637

DE-FG02-92ER14244

Synchrotron X-Ray Microprobe and Microspectroscopy: Technical Development for Advanced Photon Source Research and Low Temperature Geochemistry Applications

PERSON IN CHARGE:

S. R. Sutton (312-702-9930; Fax 312-702-5454; E-mail

sutton@cars.uchicago.edu)

Objectives: The objectives are to develop and apply a synchrotron-based X-ray microprobe that can be used to determine the composition, structure, oxidation state, and bonding characteristics of earth materials with trace element sensitivity and micrometer spatial resolution.

Project Description: The project focuses on development and application of the X-ray fluorescence microprobe on beamline X26 at the National Synchrotron Light Source (NSLS), Brookhaven National Laboratory. Geochemical problems that are under investigation include the nature of hydrothermal fluid inclusions, toxic metal and radioisotope speciation in contaminated sediments, determinations of the chemical histories of contaminated sites through microanalytical studies of indigenous organisms, and redox chemistry of $\mathrm{Mn}$ at the root-soil interface and its role in agriculturally-relevant plant diseases. The goal is to extend this research at the Advanced Photon Source, the next generation of synchrotron radiation source at Argonne National Laboratory.

Results: The NSLS X-ray microprobe (XRM) is capable of (1) trace element analyses (1 ppm) with 5 micrometer spatial resolution and (2) X-ray absorption spectroscopy analyses with 100 micrometer spatial resolution and $100 \mathrm{ppm}$ sensitivity. Applications using the microprobe are conducted in large part as collaborations between University of Chicago personnel and other investigators, including geochemists, environmental scientists, and agronomists. Examples of research projects and collaborators include: Zonation of Fe oxidation state in amphiboles (J. Delaney et al.); Speciation of zinc in individual fluid inclusions (A. Anderson et al.); Toxic metal diffusion in sediments (T. Tokunaga et al.); In situ $\mathrm{U}_{4+} / \mathrm{U}_{6+}$ oxidation state determinations and mapping in contaminated soils (P. Bertsch et al.); Kinetic measurements of iron reduction in clay minerals (P. Nuessle et al.); and Role of manganese redox reactions in plant diseases (D. Schulze et al.). 
GRANTEE:

GRANT:

TITLE:

PERSON IN CHARGE:
UNIVERSITY OF CHICAGO

Department of the Geophysical Sciences

Chicago, Illinois 60637

\section{DE-FG02-94ER14478}

Experiments and Models for Chemical Diffusion in Silicate Melts

Frank M. Richter (312-702-8118; Fax 312-702-9505; E-mail richter@dionheinz.uchicago.edu)

Objectives: Objectives are to characterize and understand multicomponent chemical diffusion in silicate melts using laboratory experiments on molten $\mathrm{CaO}$ $\mathrm{Al}_{2} \mathrm{O}_{3}-\mathrm{SiO}_{2}, \mathrm{MgO}-\mathrm{Al}_{2} \mathrm{O}_{3}-\mathrm{SiO}_{2}$, and $\mathrm{MgO}-\mathrm{CaO}-\mathrm{Al}_{2} \mathrm{O}_{3}-$ $\mathrm{SiO}_{2}$ at $1500^{\circ} \mathrm{C}$ and $10 \mathrm{Kbar}$.

Project Description: Chemical diffusion can be characterized by a diffusion matrix whose elements are a set of linear coefficients relating the flux of each component to chemical gradients of all the independent components that make up the system. The first part of this project involves laboratory experiments from which the diffusion matrix is derived by inversion of chemical interdiffusion profiles. The chemical diffusion matrix so obtained is an empirical construct that provides a general and accurate representation of chemical fluxes, but it gives no insight into the underlying reasons for the often very complicated dependence of the flux of a given component on the various chemical gradients present.

The second part of this project involves using additional experiments together with theoretical models to identify the mechanisms responsible for the complex coupling among diffusing components of a silicate melt. There are at least two reasons for diffusive coupling. The first follows from diffusion being driven by gradients in chemical potential, not concentration gradients; thus, the more a system departs from ideality, the greater the diffusive coupling when fluxes are written in terms of concentration gradients. Thermodynamic coupling is theoretically straightforward but in practice is very difficult to measure. One set of new experiments will attempt to better resolve the chemi- cal activity-composition relations in molten $\mathrm{MgO}$ $\mathrm{Al}_{2} \mathrm{O}_{3}-\mathrm{SiO}_{2}$ using a recently developed method of equilibrating the molten silicate compositions with palladium metal under suitably reducing conditions. The second source of diffusive coupling arises from a volume constraint that involves the fact that components cannot migrate freely (without regard for fluxes in the other components), because, were they to do so, they would very likely result in more mass entering or leaving a fixed volume than is consistent with the molar volume of the mixture. The diffusive coupling due to the volume constraint is addressed by constructing different theoretical models for how the constraint is apportioned among the various components and then using existing molar volume data along with new component mobility (self-diffusion) measurements to produce model predictions of the chemical diffusion matrix, which are then compared to the actual diffusion matrix. The mobility data are derived from ion microprobe measurements of isotope exchange in otherwise isochemical diffusion couples.

Results: The diffusion matrix in molten $\mathrm{CaO}-$ $\mathrm{Al}_{2} \mathrm{O}_{3}-\mathrm{SiO}_{2}$ has been determined from relatively high silica contents $\left(25 \% \mathrm{CaO}, 15 \% \mathrm{Al}_{2} \mathrm{O}_{3}, 60 \% \mathrm{SiO}_{2}\right)$ to low silica content $\left(35 \% \mathrm{CaO}, 25 \% \mathrm{Al}_{2} \mathrm{O}_{3}, 45 \% \mathrm{SiO}_{2}\right)$ by simultaneously inverting chemical diffusion profiles that intersect these compositions from different directions in composition space. Multicomponent diffusion, and also double diffusive convection, in molten $\mathrm{MgO}-\mathrm{Al}_{2} \mathrm{O}_{3}-\mathrm{SiO}_{2}$ at $1550^{\circ} \mathrm{C}$ and $5 \mathrm{Kbar}$ were studied using diffusion couples formed around the composition of 22.5 (wt \%) $\mathrm{MgO}, 17.5 \% \mathrm{Al}_{2} \mathrm{O}_{3}$, and $60 \%$ 
$\mathrm{SiO}_{2}$. The diffusion matrix was obtained from the simultaneous least squares inversion of two stable chemical diffusion profiles, while double-diffusive fingering instabilities very similar to those reported earlier in $\mathrm{CaO}-\mathrm{Al}_{2} \mathrm{O}_{3}-\mathrm{SiO}_{2}$, were documented in other directions by detailed X-ray concentration mapping of the sectioned diffusion charges. The mobility (self-diffusion) of $\mathrm{Ca}, \mathrm{Al}, \mathrm{Si}$, and $\mathrm{O}$ was measured at 10 compositions in molten $\mathrm{CaO}-\mathrm{Al}_{2} \mathrm{O}_{3}-\mathrm{SiO}_{2}$, with a precision documented by replicate runs. This data set has been used to show the general inadequacy - at least for the system studied - of the Stokes-Einstein and the Eyring relationships between mobility and viscosity. Plots of mobility vs degree of polymerization or vs molar volume are piecewise linear but interrupted by an abrupt change in slope that we earlier interpreted as resulting from an abrupt change in melt structure; however, re- cent NMR measurements on some of our quenched glasses showed no change in the coordination of $\mathrm{Al}$ across the discontinuity in slope.

The theoretical model that best accounts for the measured diffusive behavior of chemical components in molten $\mathrm{CaO}-\mathrm{Al}_{2} \mathrm{O}_{3}-\mathrm{SiO}_{2}$ is one in which thermodynamic nonideality plays an important role (quantified by Pd-based activity-composition relations), and the volume constraint is satisfied by each component in proportion to the product of its concentration times its mobility. An important conclusion that follows from this model is that off-diagonal terms are negligible for the flux of a dilute component, and thus the activitycomposition relations for fast-diffusing dilute components can be derived directly from their diffusion profiles at appropriately chosen times. 
GRANTEE:

GRANT:

TITLE:

PERSONS IN CHARGE:
UNIVERSITY OF COLORADO

Department of Civil, Environmental and Architectural Engineering

Boulder, Colorado 80309-0428

\section{DE-FG03-96ER14590}

\section{Two-Phase Immiscible Fluid Flow in Fractured Rock: The Physics of Two-Phase Flow Processes in Single Fractures}

Objectives: The objective is to develop a quantitative understanding of the critical processes controlling two-phase flow and transport in fractures based on detailed physical experiments and high resolution numerical simulations. This understanding may subsequently be abstracted for use in conceptual models applied at large-scale to applied problems in petroleum extraction and the isolation of hazardous or radioactive waste.

Project Description: Under two-phase, immiscible fluid-flow conditions, phase-geometry within the fracture (i.e., the geometry saturated with each phase) ultimately controls the permeability to each phase, fluid pressure/saturation relations, and solute dispersion within each phase. Phase geometry is a function of both the aperture field and the two-phase flow processes themselves. Capillary, gravitational, and viscous forces in combination with boundary and initial conditions have all been demonstrated to play roles in the formation of fracture phase-geometry. Phase "fingering," separate from the single phase concept of flow channelization, occurs where any of these forces are dominant (capillary fingering, gravity-driven fingering, viscous fingering), emphasizing the importance of understanding the two-phase displacement processes themselves.

In this collaborative project between Sandia $\mathrm{Na}$ tional Laboratories and the University of Colorado, systematic physical experimentation is coupled with concurrent numerical simulation to explore the inter- play between capillary, gravitational, and viscous forces in the control of phase structure, and thus flow and transport in rough-walled fractures. Understanding of capillary, viscous, and gravity fingering is explored in order to identify mechanisms that may be used to damp or enhance fingered flow. In addition, a conceptual understanding is developed for the phase invasion processes controlling replacement of a fully entrapped, immobile phase as it dissolves into the flowing phase.

Results: This project was initiated in January 1996. Large-scale numerical simulators were developed for modeling flow in variable-aperture fractures. Systems with grid sizes of up to $2048 * 1024$ were simulated, using aperture fields measured at SNL. Attempts to match the measured fracture transmissivities with numerical formulations based on the Reynolds equations with allowance for expansion/contraction resulted in an overestimation by about $13 \%$. Work is in progress to examine alternative formulations of the flow equations that will lead to closer agreement between theoretical and experimental estimates. The flow simulator will be applied for estimating relative permeabilities under conditions of phase entrapment. This task will be pursued once the discrepancy between the saturated flow transmissivity estimate and the measured value is resolved.

A large-scale transport simulator has been developed for modeling solute transport in a variable aperture fracture in three dimensions (i.e., including the effect of the velocity profile across the aperture). $\mathrm{Nu}-$ 
merical simulations will be performed to examine the scaling of the dispersivity with flow velocity. The scaling implied by numerical simulations will be compared to experiments that will be carried out at SNL and to experiments reported by other researchers. The transport simulator was also designed to account for transport within the tortuous geometry of a single phase in a two-phase system.

We have also researched the issue of modeling interphase mass transfer, matrix diffusion and dissolu- tion of a trapped phase at a high resolution. We have identified appropriate approaches for modeling these phenomena. Matrix diffusion and interphase mass transfer can be modeled with a generalized particle-tracking approach accounting for discontinuities in diffusivities. For modeling slow dissolution of a trapped phase, an approach based on the "quasi-stationary state approximation" developed in the context of flow-reaction coupling appears promising. 
GRANTEE:

GRANT:

TITLE:

PERSON IN CHARGE:
UNIVERSITY OF COLORADO

Cooperative Institute for Research in Environmental Sciences

CB 216, Department of Geological Sciences

Boulder, Colorado 80309

DE-FG03-95ER14499

Interpretation of Geodetic Crustal Strains Using Massively Parallel Supercomputer Simulations of Nonlinear Dynamical Models

John B. Rundle (303-492-5642; Fax 303-492-1149; E-mail rundle@ cires.colorado.edu) and W. Klein (Department of Physics, Boston University)
Objectives: The underlying objective of this basic research is to understand the fundamental physical processes giving rise to the hazards and risks a variety of critical energy facilities face from several kinds of tectonic instabilities, notably earthquakes, volcanic eruptions, and landslides, in concert with the International Decade of Natural Disaster Reduction.

Project Description: A variety of nonlinear dynamical processes operate within the complex earth system and are observed to display the signatures of many of the same phenomena as, for example, neural networks, driven foams, and magnetic depinning in high temperature superconductors. In particular, scaling (fractal distributions), nonlinear thresholds, and spatial interactions are all features possessed by these systems. Signatures of these processes include the appearance of scaling (geometric and dynamical fractal distributions), global and local self-organization, intermittancy (transitions from "laminar" to "turbulent" behavior), chaos, and the emergence of coherent spacetime structures. The geodynamical effects observed in earthquake systems, particularly crustal straining, dynamical segmentation, and intermittent seismicity, are being modeled in massively parallel simulations in an effort to clarify the origins of these phenomena. Simulations and theoretical investigations are particularly aimed at quantifying the limits of predictability for disasters that occur within the earth system. We are currently developing both the simulation methods for earthquake models and the statistical mechanical analy- sis techniques needed to understand and interpret the results. From these simulations, we will then predict geodetic and other deformations associated with impending earthquakes to be tested against Global Positioning System, Synthetic Aperature Radar, and other field data.

Results: During this second year of the project, we have been led by physical considerations to examine mean field models for the dynamics of driven systems with thresholds. Such systems have been used to successfully model earthquakes, neural networks, driven foams, and magnetic depinning transitions in superconductors. In a variety of results, we found that (1) these systems have Boltzmann energy fluctuations, (2) a spatial-temporal coarse graining procedure can be defined that leads to a well defined Ito-Langevin equation for the mean field dynamics, and (3) a new class of models called "Traveling Density Wave" models can be constructed that have a Lyapunov functional and are governed by the same kind of Ito-Langevin equations. The significance of this work is that these scientifically and technologically important classes of systems can be understood using statistical field theoretic tools developed over the past few decades for analyzing equilibrium systems. Thus, we have shown that mean field threshold systems can be mapped into systems that have appealing and elegantly simple symmetries, scaling properties, and dynamical patterns. These systems are also subject to both first and second order "phase" transitions in the dynamical variables. 
GRANTEE:

GRANT:

TITLE:

PERSON IN CHARGE:

\section{UNIVERSITY OF COLORADO}

Cooperative Institute for Research in Environmental Sciences

Department of Geological Sciences

Boulder, Colorado 80309-216

\title{
DE-FG03-94ER14419
}

\section{Seismic Absorption and Modulus Measurements in Porous Rocks Under Fluid and Gas Flow-Physical and Chemical Effects: A Laboratory Study}

\author{
Hartmut Spetzler (303-492-6715; Fax 303-492-1149; E-mail \\ spetzler@colorado.edu)
}

Objectives: The effect of fluids on the complex modulus of porous rocks is being investigated. The aim of the studly is to provide a tool for monitoring changes in fluids near toxic and nuclear waste sites as well as aid in the detection and recovery of hydrocarbons.

Project Description: Fluids interact with rocks in various ways. Not only the physical properties of the rock matrix and of the fluid are important in the interaction but also the chemical properties of both. The complex moduli of partially saturated porous rocks have been measured. The results indicate a high sensitivity of the complex modulus to the chemical composition of the fluid and show a significant time dependence over at least 21 days. This complex behavior led to the design of experiments that make it possible to isolate and understand specific effects. Direct measurements of the complex moduli of partially saturated single cracks and measurements of the forces involved when a meniscus moves or is distorted yield the important physical parameters in support of the theoretical model studies. The modeling describes the energy absorbed when a single crack, partially filled with a fluid is sinusoidally deformed. All input parameters are measured quantities.
Results: The attenuation of seismic waves in porous, partially fluid saturated rocks depends on the pore geometry, the physical properties of the fluid, as well as the physicochemical interactions among the fluid, the gas, and the solid. The behaviors of the meniscus and the contact line, where solid, liquid, and gas meet, control a significant part of the attenuation. Akin to solid friction, there is a resistive static force that must be overcome before a contact line will move. Until this static force is overcome the meniscus deforms to accommodate displacement of fluid. Once the contact line moves, it offers a dynamic resistance to motion and thus absorbs energy. This dynamic resistance is velocity-dependent, offering increasing resistance with increasing speed.

The meniscus and contact line forces are measured in the laboratory and form the basis for a theoretical description of attenuation. Trace amounts of contaminants can collect on the surfaces and significantly alter the forces required to move the contact line. Depending on the geometry and the physical and physiochemical properties of the system, attenuation of seismic waves due to the contact line forces can be greater than that due to viscous dissipation, the bulk flow of the fluid. 


\section{GRANTEE:}

GRANT:

TITLE:

PERSONS IN CHARGE:

\section{UNIVERSITY OF COLORADO}

Department of Geological Sciences

Boulder, Colorado 80309

\section{DE-FG03-95ER14518}

\section{Theoretical and Experimental Studies of Hydrological Properties of Rock Fractures During Active Deformation}

Shemin Ge (303-492-8323; Fax 303-492-2606; E-mail ges@spot.colorado.edu), Hartmut Spetzler, and Ivan Getting

Objectives: Investigate the dependency of fracture permeability on the state of stress, roughness of fractures, porosity, fluid pressure, mineral dissolution, and precipitation.

Project Description: Hydrological studies in the upper part of the Earth's crust greatly depend on our understanding of the hydrologic parameters, such as hydraulic permeability. Fractures ranging from microcracks to large-scale faults are dominant features in rock formations. Considerable efforts have been expended on the mechanical properties of rock fractures. Understanding of the hydrologic parameters and their roles during hydromechanical processes, on the other hand, is still limited. This project uses a combined theoretical and experimental approach investigating the hydraulic properties of rock fractures. The project consists of three components: (1) analytical study, (2) laboratory experiment, and (3) numerical modeling. The analytical study provides theoretical guidance for understanding fracture permeability. The laboratory experiments provide first-hand data on the interaction between fluid flow and fracture development. The numerical modeling verified by the analytical study and the laboratory experiments serves as a predictive tool for situations that are beyond the capability of analytical tools and laboratory experiments.

Results: The characteristics of flow in a rough fracture were examined and fracture apertures were rede- fined uniquely. A new governing equation for incompressible laminar flow in rough fractures is derived. The equation is formulated in both local and global coordinates and explicitly incorporates two vectorial variables of fracture geometry: true aperture and tortuosity. The new equation reduces to the Reynolds equation when the variations in tortuosity and aperture are small. Application of the new equation to a rough fracture shows that the error in permeability estimation induced using the Reynolds equation can reach 10 percent. In a sinusoidal surface fracture, the new equation shows a significant improvement over the Reynolds equation method in both permeability and pressure calculations. An apparatus was designed and built for measuring fracture permeabilities. Experiments using smooth parallel plate fractures were conducted first to calibrate the apparatus. Good agreements between the experimental results and the theoretical calculations of fracture permeability are achieved. Experiments on rough fractures have been initiated. A sinusoidal surface fracture was manufactured and fluid flow experiments are in progress. Numerical studies are conducted using the Lattice Gas Automata (LGA) method. The permeability values predicted by the LGA model agree well with both theoretical and experimental results for parallel plate fractures. The numerical model is being extended to simulate fluid flow in sinusoidal surface fractures. 
GRANTEE:

GRANT:

TITLE:

PERSON IN CHARGE:
COLUMBIA UNIVERSITY

Lamont-Doherty Earth Observatory

Palisades, New York 10964-8000
DE-FG02-95ER14572

The Distribution in Space and Time of Wet Events in the Western North American Drylands

Wallace S. Broecker (914-365-8413; Fax 914-365-8155; E-mail broecker@1deo.columbia.edu)
Objectives: The primary objective of this research is to map out spatial and temporal distribution of Heinrich (H2, H1) and Younger Dryas wet events that were recorded in rock varnish in the drylands of western North America.

Results: During the first year of this project, a total of 337 rock varnish samples were collected from 54 different localities over the entire Great Basin and other regions of southwestern USA. The preliminary results obtained so far include: (1) the general lamination pattern previously established in Death Valley, CA, and the surrounding regions replicates in varnish from the entire Great Basin; (2) some changes in lamination patterns have been observed in varnish from the Sonoran desert (Lat. $33^{\circ} \mathrm{N}$ and south), which may re- flect regional variations in circulation patterns of the atmosphere; (3) at least three short-lived and slightly weak wet periods have been identified in Holocene varnish, which yields new evidence for reevaluation of the Holocene climate stability; (4) the levels of closedbasin lakes such as Summer Lake and Pyramid Lake in the Great Basin have fluctuated differently in the past 20,000 years in response to changes in climatic conditions; and (5) elemental mapping of rock varnish by ion microprobe reveals correlations between black layers in varnish and elemental concentrations of $\mathrm{Al}, \mathrm{Si}$, $\mathrm{Fe}, \mathrm{Mn}, \mathrm{Ba}$, and other trace elements, such as $\mathrm{P}, \mathrm{Cl}$, and $\mathrm{V}$, which may help understand the relationship between varnish formation and climate change. 
GRANTEE:

GRANT:

TITLE:

PERSONS IN CHARGE:
COLUMBIA UNIVERSITY

Lamont-Doherty Earth Observatory

Palisades, New York 10964

DE-FG02-86ER13287

\section{Energetics of Silicate Melts from Thermal Diffusion Studies}

D. Walker (914-365-8658; E-mail dwalker@ldeo.columbia.edu) and M. C. Johnson (914-365-8712; Fax 914-365-3183; E-mail rikitt@Ideo.columbia.edu)

Objectives: This research program characterizes mass transport by diffusion in geologic fluids in response to thermal, solubility, and/or chemical gradients to obtain quantitative information on the thermodynamic and kinetic properties of multicomponent systems. Equipment development for this research and many other community objectives is an integral part of the research.

Project Description: Thermal diffusion is the phenomenon of chemical migration in response to heat flow along a thermal gradient. The details of this response are conditioned by the thermochemical properties and constitution of the substance. Silicate liquids undergo substantial thermal diffusion (Soret differentiation), whereas the response in sulfide, carbonate, and aqueous fluids to an imposed temperature gradient is varied. The experimental observations of this differentiation are used to evaluate the form and quantitative values of solution parameters and to quantify ordinary diffusion coefficients, heats of transport, and activation energies of multicomponent liquids. The diffusion, solution, and element partition coefficients determined for these geological fluids form a data base for understanding magmatic crystallization behavior and for evaluating geothermal, ore deposit, and nuclear waste isolation potentials. Heating strategies for simultaneous high-pressure and high-temperature experiments as well as ambient pressure aqueous brines are developed.

Results: High-pressure and -temperature Soret diffusion experiments with carbonates, sulfides, and silicates were made possible through extensive technical advances in pressure media, gasketing configurations, and furnace materials for multi-anvil assemblies. Other multi-anvil labs will benefit from this development work. The development of new refractory semiconductors to fine-tune thermal structure has produced material that is robust against oxidation/reduction failure and will be of potential importance as fuel cell connector rod material. Experiments in brine/salt systems have demonstrated the potential utility of sulfate backfills in nuclear waste isolation applications. Pilot experiments at ISIS pulsed neutron source at the Rutherford Appleton Laboratory in the UK have demonstrated the feasibility of using epithermal neutron resonance pyrometry to calibrate the effect of pressure on thermocouple emf. In collaboration with colleagues at IBM, synthesis of novel precursors for high-temperature superconductors has been undertaken at high pressure. 
GRANTEE:

GRANT:

TITLE:
PERSONS IN CHARGE:

\author{
.
}

PERSONS IN CHARGE:

\author{
UNIVERSITY OF CONNECTICUT \\ Department of Marine Sciences \\ 1084 Shennecossett Road \\ Groton, Connecticut 06340-6097
}

DE-FG02-95ER14528
Rare Gas Studies of Fluids in the San Joaquin Basin: A Basin Scale Test of Hydrogeological Process Models

Thomas Torgersen (860-445-3441; Fax 860-445-3484) and

B. M. Kennedy (Lawrence Berkeley National Laboratory)
Objectives: This research project (with LBNL) will use isotopes of rare gases and their concentrations as in situ process tracers to investigate the source regions, release mechanisms, and time scales for fluid flow in the San Joaquin Basin. Specifically, this project will investigate the Elk Hills and Cymric oil fields west of Bakersfield, CA.

Project Description: The processes and time scales of fluid flow in sedimentary basins represent a fundamental question in the earth sciences with direct application to exploration and exploitation strategies for energy and mineral resources. Published studies on basin evolution and cementation history of the San Joaquin Basin suggest a simple (first cycle) sediment accumulation history and an episodic fluid flow history with currently extant fluids from three distinct sources: (1) meteoric waters, (2) diagenetically altered waters that have apparently undergone little transport in the system, and (3) significant cross-formation fluid flow from deeper in the system but of unknown specific origin.

This project will use rare gas isotope measurements and chemical analyses of fluids obtained from oil wells and water wells in the San Joaquin Basin to (1) define end member sources for these fluids and (2) use the dynamics of helium transport in the system to generate "helium model ages" (residence times) that have the capability of dating fluids on the geologic time and space scales. This study will provide first order constraints on the parameterization of fluid flow control- ling the evolution of gas/oil in this system. Such refinements provide a critical test of basin models and improvements in exploration/exploitation strategies.

Results: The separate field collection efforts coordinated with three different operators have produced a suite of approximately 25 samples, including waters and oils from the lower Miocene Carneros sandstone through the upper Miocene Etchegoin Formation. An additional set of gas samples has been obtained from the Pliocene Mya member of the San Joaquin Formation. These samples cover a depth range from $-10,000$ feet to 200 feet and spread over $13 \mathrm{~km}$, covering several pools.

Water samples are being analyzed for $\mathrm{Na}, \mathrm{K}, \mathrm{Ba}$, $\mathrm{Sr}, \mathrm{Ca}, \mathrm{Mg}$, and a suite of heavy metals, using plasma emission spectroscopy, and for $\mathrm{Cl}, \mathrm{Br}, \mathrm{F}$, and $\mathrm{SO}_{4}$, using ion chromatography. Preliminary examination of the analysis to date suggests that most water samples are a mixture of a deep-sourced brine with variable degrees of mixing with a less concentrated fluid. Subgroups are distinguished by reaction end members.

Oil samples were analyzed by gas chromatography/mass spectrometry and selected biomarker parameters, including C27:C28:C29 stearane ratios, $\mathrm{C} 27: \mathrm{C} 28: \mathrm{C} 29$ ring $\mathrm{C}$ monoaromatic stearane ratios, and pristane:phytane and phytane:C18 ratios. The results suggest a common depositional environment (in agreement with the geologic setting) for all the oils with some differences in maturity evident. Some of the shallow 
oils show differing degrees of biodegradation with some being highly degraded.

Gas samples are being analyzed for noble gas abundances and isotopic compositions in the RARGA laboratory at Lawrence Berkeley National Laboratory. Co-variations between the ${ }^{4} \mathrm{He} /{ }^{36} \mathrm{Ar},{ }^{132} \mathrm{Xe} /{ }^{36} \mathrm{Ar}$, and ${ }^{3} \mathrm{He} /{ }^{4} \mathrm{He}$ ratios indicate mixing of two components. One is ${ }^{4} \mathrm{He}$ and ${ }^{132} \mathrm{Xe}$ rich $\left({ }^{4} \mathrm{He} /{ }^{36} \mathrm{Ar}>4500\right.$ times the air ratio and ${ }^{132} \mathrm{Xe} /{ }^{36} \mathrm{Ar}>35$ times the air ratio) and a
${ }^{3} \mathrm{He} /{ }^{4} \mathrm{He}$ ratio $\left.<0.02 \mathrm{Ra}\right)$. The other component is most evident in the deeper and older formations and may have a ${ }^{3} \mathrm{He} /{ }^{4} \mathrm{He}$ ratio as high as $\sim 1 \mathrm{Ra}$, but the ${ }^{4} \mathrm{He} /{ }^{36} \mathrm{Ar}$ and ${ }^{132} \mathrm{Xe} /{ }^{36} \mathrm{Ar}$ ratios are low $(<1000$ and $<3.5$ times the air ratios). As the high ${ }^{3} \mathrm{He} /{ }^{4} \mathrm{He}$ ratio of the second component cannot be explained by atmospheric contamination, there is a mantle $\mathrm{He}$ component in the deeper portions of the Cymric and Elk Hills Fields. 
GRANTEE:

GRANT:

TITLE:

PERSONS IN CHARGE:
UNIVERSITY OF DELAWARE

Department of Chemistry and Biochemistry

Newark, Delaware 19716

\begin{abstract}
Development of an Experimental Database and Theories for Prediction of Thermodynamic Properties of Aqueous Electrolytes and Nonelectrolytes of Geochemical Significance at Supercritical Temperatures and Pressures
\end{abstract}

Objectives: The objective of this research is to measure heat capacities and volumes of key compounds of importance to predictions of geochemical phenomena at high temperatures and pressures. A second objective is to use the key compounds as a data base together with simulations to develop empirical and theoretical methods for predicting a wide variety of other compounds.

Project Description: Measurements of volumes and heat capacities of a wide variety of organic electrolytes and nonelectrolytes at temperatures from $25^{\circ}$ to $325^{\circ} \mathrm{C}$ will be made. This will allow the development of group additivity schemes to predict a very wide variety of organic species containing these functional groups. Previous measurements on $\mathrm{H}_{2} \mathrm{~S}, \mathrm{CO}_{2}, \mathrm{CH}_{4}$, $\mathrm{NH}_{3}$, and $\mathrm{H}_{3} \mathrm{BO}_{3}$ are being analyzed to find correlations that can predict other species. Molecular dynamics simulations of the chemical potential of aqueous methane, ethane, and propane at temperatures from $600^{\circ}$ to $1200^{\circ} \mathrm{C}$ and water densities from 0 to $1 \mathrm{gm} /$ $\mathrm{cm}^{3}$ have been made. Revisions of the equations of state for aqueous ions and nonelectrolytes to allow better predictions of properties at high temperatures and pressures will be developed.

Results: The experimental measurements on key compounds are almost complete and most of the results have been published or are in press. The volumes and heat capacities of aqueous boric acid from room temperature to $705 \mathrm{~K}$ have been published (Hnedkovsky et al., J. Chem. Thermodynamics 1995, 27, 801-814). Volumetric and heat capacity measurements on aqueous solutions of $\mathrm{CH}_{4}, \mathrm{CO}_{2}, \mathrm{H}_{2} \mathrm{~S}$, and $\mathrm{NH}_{3}$ from 298 to $705 \mathrm{~K}$ have also been published (Hnedkovsky et al., $J$. Chem. Thermodynamics 1996, 28, 125-142; Hnedkovsky and Wood, J. Chem. Thermodyn. 1996, in press). The volumetric properties of a wide variety of organic electrolytes and nonelectrolytes have been accepted for publication (Criss and Wood, J. Chem. Thermodyn. 1996, in press). This paper decomposes the results into functional group contributions so that predictions can be made for all organic compounds composed of $\mathrm{CH}_{3}, \mathrm{CH}_{2}, \mathrm{COOH}, \mathrm{CONH}_{2}, \mathrm{OH}, \mathrm{NH}_{2}$, $\mathrm{NH}_{3}^{+}$, and $\mathrm{COO}^{-}$at $28 \mathrm{MPa}$ and temperatures to $250^{\circ} \mathrm{C}$. It has been found that the functional additivity seems to be as accurate at $250^{\circ} \mathrm{C}$ as it is at room temperature. Measurements of the heat capacity of a wide variety of organic nonelectrolytes and electrolytes have been submitted for publication (Inglese and Wood, J. Chem. Thermodyn. 1996, in press; Inglese et al., J. Solution Chem. 1996, accepted; Inglese et al., J. Chem. Thermodyn. 1996b, submitted).

Predictions of the chemical potential of dilute aqueous solutions of methane, ethane, and propane at extremely high temperatures using molecular dynamic simulations have been accepted (Lin and Wood, J. Phys. Chem. 1996). In collaboration with Prof. John 
O'Connell, a new equation of state for correlating and predicting the volumetric properties of nonelectrolytes at infinite dilution in water has been accepted for pub- lication (O'Connell et al., Ind. and Eng. Chem. Res., 1996). Work on adapting this equation for electrolytes and functional groups is in progress. 
GRANTEE:

GRANT:

TITLE:

PERSONS IN CHARGE:
DESERT RESEARCH INSTITUTE

Water Resources Center

Reno, Nevada 89506
Multicomponent Convection in Porous Media and Fractures

Scott W. Tyler (702-673-7391; Fax 702-673-7397; E-mail scott@maxey.dri.edu), Robert J. Glass, and Harlan W. Stockman

(Sandia National Laboratories)
Objectives: Objectives are to understand the physical processes controlling multicomponent convection in natural porous and fractured media and to develop quantitative relationships between system parameters (permeability, porosity, and solute concentrations) and the magnitude of convective mass transport in subsurface hydrologic environments.

Project Description: Multicomponent convection is a transport phenomenon that can occur in fluid bodies and fluid-filled porous media that contain two or more components (heat, solutes, etc.) that influence the local fluid density. If two or more of the components individually influence local fluid density, differ in diffusivity, and have opposing individual density gradients, then the globally stable system can develop local buoyancy-driven instabilities in the form of thin fingers or larger convection cells. These instabilities may in turn dirive larger scale motion within the porous media or fluid body. Multicomponent (double-diffusive for two component systems) convection may contribute significantly to mass and heat transport in porous and fractured systems, leading to fluxes in excess of two orders of magnitude higher than would be predicted in an equivalent, density-stable system.

In this collaborative project between Sandia National Laboratories and the Desert Research Institute, we combine systematic physical experimentation with concurrent numerical simulation to explore multicomponent convection in porous media and fractures. Sandia National Laboratories' high resolution, full-field energy transmission techniques are used to study the onset and development of multicomponent convection in simulated porous media (Hele-Shaw cells), sands, and fracture analogs. Boundary and initial conditions, as well as the permeability field, are varied to evaluate the conditions under which multicomponent convection occurs in natural systems. Numerical modeling efforts focus on application of lattice gas automata techniques to consider two- and three-component systems.

Results: This project has only recently been initiated. We have analyzed 13 experiments that investigate the factors controlling the transition from stable diffusive transport to unstable multicomponent convection. Each experiment began by layering a sucrose solution over a sodium chloride solution in a Hele-Shaw cell such that the fluid was density stable, although double-diffusively unstable. The concentration of the sucrose solution was systematically varied between experiments to test the analytical theory predicting the stability boundary. With light transmission techniques, the sodium chloride concentration field was tracked using a nonreactive dye. Analysis of images taken throughout an experiment show mass conservation better than $2 \%$, in spite of the evolution of highly contorted concentration fields.

Experiments conducted to date suggest that for sufficiently large component Rayleigh numbers, system stability can be predicted without detailed knowledge of variability within the permeability or solute concentration field. If found to hold, this will be an important result, as uncertainty with respect to the permeability and solute concentration fields is often extreme within 
subsurface environments. The experiments also demonstrate that solute fluxes can be quantitatively determined and that these fluxes are well in excess of those predicted if the solutes are transported by diffusion alone. 
GRANTEE:

GRANT:

TITLE:

PERSON IN CHARGE:

\section{GEORGIA INSTITUTE OF TECHNOLOGY}

School of Earth and Atmospheric Sciences

Atlanta, Georgia 30332-0340

\title{
DE-FG05-95ER14517
}

\section{Biomineralization: Organic-Directed Controls on Carbonate Growth Structures and Kinetics Determined by In Situ Atomic Force Microscopy}

\author{
P. M. Dove (404-894-6043; Fax 404-894-5638; E-mail \\ dove@eas.gatech.edu)
}

Objectives: The objective is to determine the kinetics and mechanisms by which selected amino acids interact with calcite surfaces during crystal growth to govern the polymorph and surface structure that forms. The longer- term goal is to develop a mechanistic understanding of the physical basis for biomineralization and the larger role of organic compounds in governing carbonate precipitation and growth in natural and engineered Earth systems.

Project Description: Primary biominerals form exclusively through biologically mediated activities of marine and freshwater organisms. They result from organic-directed crystal nucleation and growth processes that act in concert to develop chemically and morphologically complex structures. When combined with a macromolecular matrix of proteins, polysaccharides, and lipids, these structures fulfill specific physiological functions, such as providing stiffness and strength to mineralized skeletal tissues. An understanding of organic-mineral surface interactions also has application to (1) avoidance strategies for cementation/ scaling in oil/gas fields, (2) the role of organics in the long-term behavior of carbonates in waste repositories, and (3) new biomaterial technologies in the synthesis of lightweight mineral composites.

Despite extensive investigations of mineral formation in diverse environments, the mechanistic roles of organic molecules in the formation of biominerals remain largely unknown. Previous studies have found that the matrix macromolecules involved in regulating biological crystal growth have an acidic character and often contain aspartic or glutamic acid-rich domains. In vitro studies suggest that these macromolecules possess certain inhibitory effects that modify the morphology of calcite during growth by specifically binding to certain crystal faces. The mechanistic explanation for this inhibitory effect has focused upon the orientation and interactions of side-chain carboxylates with calcite surfaces and their ability to create extended calcium-interacting domains. When adsorbed onto a solid substrate, these macromolecules induce the formation of unusual crystallographic faces such as the (0001). Site-specific interactions are believed to be a controlling factor in development of diverse biomineral morphologies, but fundamental relationships are presently unknown.

This project combines in situ atomic force microscopy (AFM) investigations with kinetic measurements and surface chemical modeling to investigate the rates and mechanisms by which amino acids may modify the crystallization and dissolution of calcium carbonate minerals. The investigation uses amino acids selected for their functional group chemistries to test specific hypotheses regarding controls of these compounds on growth and dissolution processes.

Results: Investigations to date have focused on the influence of aspartate on calcite growth and dissolution. Observations of calcite growth in $10^{-2}$ molal Asp at $\mathrm{IAP} / \mathrm{K}_{\mathrm{sp}} \approx 4$ show that step advancement on (1014) calcite surfaces is modified by the introduction of Asp 
and indicates that post-nucleation growth is dominated by nonspecific surface sorption. The observed complexity led to collaborations with the crystal physics group at LLNL. As a summer intern at LLNL, Georgia Tech Ph.D. student, Mr. Henry Teng, is combining LLNL's expertise in crystal growth theory with experimental data from Georgia Tech to address mechanisms of Asp-calcite interactions during growth (Teng et al., in prep.).

Other work has revealed the role of Asp in modifying surface reactivities on the calcite $\{1014\}$ face. Interactions of Asp with fragments of Iceland spar during dissolution using in situ Fluid Cell AFM showed that dissolution of the calcite $\{10 \overline{1} 4\}$ form in Asp solutions generates etch pits with a triangular morphology in contrast to the rhombohedral pits typically produced in water. With long-term exposure to Asp-bearing solutions, these pits evolve into etch hillocks of interconnected triangular pyramids. The component pyramid faces have Miller-Bravais indices of (0001), (1100), and
$(01 \overline{1} 0)$. These intersect the $(10 \overline{1} 4)$ face in the [010], [43 1 ], [501] directions (Teng and Dove in prep.).

Asp reacts preferentially with specific crystallographic directions by molecular recognition between Asp and mineral surface sites. The recognition process is constrained by combination(s) of electrostatic attraction, geometric, and stereochemical cooperation. Development of the basal face is governed by simple electrostatic attraction of Asp for the pure calcium layer of the (0001) to form >Ca-Asp complexes and hence to slow rates of $\mathrm{Ca}$ hydration and detachment from the lattice. Development of the prismatic faces is more complex. In addition to electrostatic attraction, geometrical and stereochemical matching of Asp functional groups with both $\mathrm{Ca}$ and $\mathrm{CO}_{3}$ sites is required (Teng and Dove, 1996). This constraint is fulfilled by only one type of site, leading to slower detachment of atoms from these sites and the development of prismatic faces. These findings may enable us to predict facespecific interactions of other amino groups found in proteins associated with biomineralizing systems. 
GRANTEE:

GRANT:

TITLE:

PERSONS IN CHARGE:

\section{INCORPORATED RESEARCH INSTITUTIONS FOR} SEISMOLOGY (IRIS)

Arlington, Virginia 22209

\author{
DE-FG05-95ER14545
}

Acquisition of Equipment for High Resolution Seismic Imaging

David Simpson and James Fowler (703-524-6222;

Fax 703-527-7256)
Objectives: The objective is to purchase two high resolution seismic reflection systems to be used by the research community.

Project Description: The goal of this project is to purchase two portable 60-channel reflection recording systems that will provide instrumentation for very shallow to very deep seismic reflection investigations of the Earth's crust. The multichannel instruments will complement the current PASSCAL inventory of REF TEK recorders and will greatly expand the amount of instrumentation available for active source seismic investigations carried out by university groups and government labs. DOE funding is for hardware costs only. As part of its NSF-funded core PASSCAL program, IRIS will service and maintain the equipment at its Stanford Instrument Center. In addition, IRIS will carry out the modification and developments necessary to fully integrate these instruments with the existing PASSCAL instruments in field operations and data analysis.
Results: The first 60-channel unit was delivered by Geometrics in November 1995 along with

- 90 high frequency $(40 \mathrm{~Hz})$ geophones

- cdp cables for shallow reflection work

- 75 strings of low frequency $(4.5 \mathrm{~Hz})$ geophones

- cdp cables for deep reflection profiling

- roll-along switch

- permanent shipping cases for all of the above The equipment was used on its first experiment in January 1996 . There were four other experiments during the first six months of 1996. To date, all experiments have utilized only the high frequency components of the system; however, there are experiments scheduled for next year that will utilize the low frequency components as well.

A second complete system was ordered during early June 1996, and it will be available for use by late fall.

In addition, the IRIS PASSCAL program is conducting demonstrations and providing a training program so that interested investigators in the university community can learn to use the equipment. 
GRANTEE:

GRANT:

TITLE:

PERSON IN CHARGE:
INDIANA UNIVERSITY

Department of Chemistry

Bloomington, Indiana 47405

DE-FG02-91ER14175

Mechano-Chemical Self-Organization and Nonlinear Dynamics in Sedimentary Basins

P. Ortoleva (812-855-2717; Fax 812-855-8300; E-mail

ortoleva@indiana.edu)
Objectives: A sedimentary basin is viewed as a nonequilibrium reaction-transport-mechanical system. As a result, phenomena, such as reaction front fingering, stylolites, diagenetic bedding, and episodic fluid release from overpressured domains, are put in the unified framework of instability and nonlinear dynamics, and implications for petroleum are drawn.

Project Description: These phenomena are modeled and simulated numerically. Rate laws for stressmediated reactions and the dependence of rock rheology, permeability, and dispersion on texture, mineralogy, and fracture parameters are set forth. A quantitative model is constructed based on equations of conservation of mass, force balance, and incremental stress rheology. The models are simulated numerically, when small-scale features (such as stylolites, differentiated layering, or fractures) affect the basin scale dynamics, and, conversely, homogenization techniques are used to make the calculations practical. Parallel numerical algorithms are also developed and implemented. Emphasis is placed on basin simulations in three spatial dimensions.

Results: Dramatic new findings on the grain and basin scale have advanced the understanding of the evolution of a sedimentary basin. Recent observations by others on the indenture of mica flakes into quartz grains in a basin had been interpreted to imply that there must be an alternative explanation to pressure solution. According to these authors, a mica flake breaks at less than 10 bars, supposedly too small a stress to promote a pressure solution-mediated indenture. We have shown that the higher surface charge on mica and the low stress across the flake edge/quartz contact permits a thick water layer in the contact. The small diffusion path in the flake-quartz grain contact and the thick water film there allow for a surprisingly fast rate of water film diffusion/mediated pressure solution that can easily account for the observed indenture rate.

Next, it was shown that kilometer- to basin-scale compartments sequestering fluids and their abnormal pressures can form spontaneously. The mechanism involves the coupled, nonlinear dynamics of the kinetics of hydrofracturing and compaction during epochs of rapid burial. Heretofore, it was generally believed that these phenomena required variations in rock properties dictated (templated) by sedimentary bedding. We show that these features can organize themselves and, in addition, undergo complex (chaotic) spatiotemporal fluid flow. 
GRANTEE:

GRANT:

TITLE:

PERSONS IN CHARGE:
THE JOHNS HOPKINS UNIVERSITY

Department of Earth and Planetary Sciences

Baltimore, Maryland 21218

\section{DE-FG02-96ER14619}

The Hydrodynamics of Geochemical Mass Transport and Clastic Diagenesis: San Joaquin Basin, California

Grant Garven (410-516-8689; Fax 410-516-7933; E-mail garven@indigo.eps.jhu.edu) and James R. Boles (UC-Santa Barbara) (805-893-3719; Fax 805 893-2314; E-mail boles@magic.geol.ucsb.edu)

Objectives: Deep groundwater migration plays an important role in many geologic processes, including diagenesis in sedimentary basins, that directly affects other processes, such as overpressuring, oil migration, and sediment-hosted ore mineralization during burial, because of the control on permeability and porosity. The principal objective is to quantify the hydrogeologic regimes for clastic diagenesis, using the San Joaquin Basin of California to establish geologic constraints for mathematical modeling at the basin and formation scale.

Project Description: Few hydrogeologic models have been developed or applied to field data sets that rigorously couple geochemical processes or test conceptual models for diagenesis beyond abstract formation-scale numerical simulations or core-scale laboratory studies. The approach used here is to develop coupled hydrodynamic-geochemical models with computer simulations constrained by geochemical and hydrologic observations for the San Joaquin Basin of California, an ancient forearc system.

This project entails the compilation and general mapping of pore pressure and permeability data for the main aquifers in the basin to build a clearer picture of flow patterns as they exist today at the regional scale. More detailed hydrogeologic maps will be compiled for the eastern margin of the basin to assess the effects of framing faults near the Sierras. The principal task, however, is to quantify the paleohydrology and thermal history of the San Joaquin Basin with a new finiteelement code for simulating fluid migration and pressure changes during sedimentation, uplift, and erosion. Once the hydrogeologic history has been explored in a hydrodynamic sense, we will conduct reactive flow simulations to assess mechanisms for diagenesis and chemical mass transport in the clastic wedge. The merits of different diagenetic fluid flow hypotheses, such as compaction dewatering, episodic pulses, meteoric invasion, and cross-formational flow will be tested with the coupled hydrogeologic models through a sensitivity analysis.

Results: This project has only recently been initiated. Geochemical and hydrologic data sets have been assembled and the co-PIs have met once in California to discuss project strategy. A new finite-element-based code for modeling two-dimensional fluid flow and heat transport is under development with verification against earlier publications. Preliminary transient simulations have been made to quantify the compaction flow history during marine-terrestrial sedimentation and subsequent uplift with the onset of topography-driven flow over the past few million years of basin emergence. 
GRANTEE:

GRANT:

TITLE:

PERSON IN CHARGE:
THE JOHNS HOPKINS UNIVERSITY

Department of Earth and Planetary Sciences

Baltimore, Maryland 21218

DE-FG02-96ER14616

\section{Predictive Single-Site Protonation and Cation Adsorption Modeling}

Dimitri A. Sverjensky (410-516-8568; Fax 410-516-7933; E-mail: dimitri@eve.eps.jhu.edu)
Objectives: The overall goal of this research is to develop a predictive model of adsorption processes at the mineral-water interface that can be applied to a fundamental understanding of the role of adsorption in geochemical processes, such as weathering, diagenesis, the chemical evolution of shallow and deep groundwaters and ore-forming fluids, and the fate of contaminants in groundwaters.

Project Description: The research is aimed at generating a comprehensive, internally consistent, quantitative description of proton and cation adsorption on oxides and silicates using an extended triplelayer model. The model will be developed to integrate the available experimental information on proton and cation adsorption based on internally consistent assumptions. By so doing, it will considerably facilitate the comparison of experimental data from different investigators. In addition, the model will permit predictions of surface speciation to supplement the lack of experimental adsorption data for many systems of geochemical interest. In addition, it will provide a ba- sis for extending applications of the concept of surface complexation to oxide and silicate dissolution kinetics. The proposed extended triple-layer model will include (1) internally consistent assumptions and methods of estimating site densities and capacitances, (2) explicit recognition of ion solvation, (3) explicit recognition of proton attraction-repulsion, (4) inclusion of the extended Debye-Huckel model for aqueous ionic activity coefficients, and (5) inclusion of a geochemical thermodynamic data file for aqueous species and minerals.

Results: This project has only recently been initiated. Current research involves the development of a new computer code for evaluating simultaneous aqueous and surface speciation over a wide range of minerals and solution compositions of geochemical interest by using this data for surface protonation and adsorption of cations. A new method for estimating surface site densities has been developed based on considerations of surface crystal structure and experimental measurements of site densities. 
GRANTEE:

GRANT:

TITLE:

PERSONS IN CHARGE:
THE JOHNS HOPKINS UNIVERSITY

Department of Earth and Planetary Sciences

34th and Charles Street

Baltimore, Maryland 21218

\title{
DE-FG02-96ER14074
}

\section{Reactions and Transport of Toxic Metals in Rock-Forming Silicates at $25^{\circ} \mathrm{C}$}

\author{
D.R. Veblen (410-516-8487; Fax 410-516-7933; E-mail \\ dveblen@jhu.edu) and E.S. Ilton (610-758-5834; \\ Fax 610-758-3677; E-mail esi2@lehigh.edu)
}

Objectives: Objectives are to determine grain boundary structures and their relationship to fluid transport properties of rocks, provide constraints on conditions that control the rates of sorption and coupled sorption-reduction of environmentally sensitive elements to distinct crystallographic surfaces of silicate minerals in near-surface aqueous systems, and develop XPS into a quantitative method for determining Fe(II)/ $\mathrm{Fe}$ (III) in hydrous silicates.

Project Description: $\mathrm{Cr}(\mathrm{VI}), \mathrm{Cr}(\mathrm{III}), \mathrm{Se}(\mathrm{VI})$, $\mathrm{Cd}(\mathrm{II})$, and $\mathrm{Co}$ (II)-bearing solutions will be reacted with ferrous silicates, such as biotite, amphibole, and pyroxene. The surfaces and interior portions of the silicates will be examined with high-resolution transmission electron microscopy (HRTEM), analytical electron microscopy (AEM), scanning electron microscopy (SEM), and X-ray photoelectron spectroscopy (XPS). These techniques will help to determine the oxidation state, form, and relative concentration of the sorbate. HRTEM and computer simulations will be used to gain a greater understanding of the structure of silicate grain boundaries and the relationships between grain-boundary structure and transport properties. XPS is being calibrated to quantitatively determine $\mathrm{Fe}(\mathrm{III}) /$ $\mathrm{Fe}(\mathrm{II})$ in the near-surface of silicates. An outgrowth of this work is a project to develop XPS into a microbeam technique for determining $\mathrm{Fe}(\mathrm{III}) / \mathrm{Fe}$ (II) in minerals in thin sections. Such a method would replace unwieldy bulk analytical techniques and aid geoscien- tists in fields as diverse as petrology and environmental geochemistry.

Results: Computer simulations indicate that the images of semicoherent pyroxene-amphibole boundaries show the positions of individual silicate tetrahedral chains and octahedral strips. The revealed structure varies along the interfaces but in general is atomically tight with no discrete dislocations. In contrast, images of alkali and plagioclase feldspar grain boundaries with pyroxene, oxides, and quartz are incoherent, and the structures of dislocation-like features are being analyzed using computer simulations. XPS of biotite edges indicated that the rate and absolute amount of $\mathrm{Cr}(\mathrm{VI})$ sorption-reduction increased with increasing $\mathrm{NaCl}, \mathrm{LiCl}$, and $\mathrm{Na}_{2} \mathrm{SO}_{4}$ concentrations, where the relative effect for a given ionic strength is $\mathrm{NaCl}>\mathrm{LiCl}>\mathrm{Na}_{2} \mathrm{SO}_{4}$. No sorption-reduction occurs in solutions with $\mathrm{RbCl}$ or $\mathrm{CsCl}$. In the interlayer region of biotite, both lithium and sodium are hydrated whereas rubidium and cesium form inner-sphere bonds. The experiments indicate that it is the exchange of hydrated cations for potassium in the interlayer region, not the ionic strength or anion, that enhances the reaction. Sulfate appears to partially counter the effect of $\mathrm{Na}^{+}$more than chloride, presumably by competing effectively with chromate for sorption sites. The data show that $\mathrm{Na}^{+}$exchanges more readily with interlayer potassium than $\mathrm{Li}^{+}$. Uncertainties for the XPS $\mathrm{Fe}(\mathrm{II}) / \mathrm{Fe}$ (III) calibration and in situ analyses have been rigorously determined. A self-mod- 
eling curve technique, involving target transformation factor analysis, yielded peak shape parameters that compare favorably with those originally derived by least squares fitting. A needle search method yielded a peak separation for $\mathrm{Fe}(\mathrm{II})$ and $\mathrm{Fe}(\mathrm{III})$ similar to one originally estimated by the separation of minima in the second derivative of $\mathrm{Fe} 3 \mathrm{p}$ spectra. 
GRANTEE:

\author{
LEHIGH UNIVERSITY \\ Department of Earth and Environmental Sciences \\ 31 Williams Drive \\ Bethlehem, Pennsylvania 18015
}

\begin{abstract}
GRANT:
TITLE:

PERSONS IN CHARGE:

DE-FG02-93ER14373

Surface and Solution-Interface Geochemistry of Lead Sulfide and Lead Selenide Minerals

Carl O. Moses (610-758-4907; Fax 610-758-3677; Internet com0@lehigh.edu) and Eugene S. Ilton (610-758-5834; Internet

esi2@lehigh.edu)
\end{abstract}

Objectives: This project is an investigation of the aqueous reactivity of sulfide minerals and their selenide analogues (end member and solid-solution compositions). The specific goal is a comprehensive and integrated understanding of reactivity based on fundamental high-vacuum surface chemistry and the rates of aqueous exchange and dissolution reactions. The present focus is on $\mathrm{PbS}$ and $\mathrm{PbSe}$.

Project Description: Sulfide minerals play important roles in the distribution and mobility of metals, sulfur, and selenium in the hydrosphere. Their instability in oxic environments can make them a source of their components to the environment, while their stability in anoxic environments can make them a sink for such components. The research approach here integrates information from mass transfer experiments in aqueous solution with information from surface chemistry studies utilizing high-resolution X-ray photoelectron spectroscopy (XPS) and field-emission scanning electron microscopy. Research goals include characterizing surface stoichiometry, determining the depth of surface-chemical alterations during gas- or solutionphase exposures, identifying changes in surface morphology during exposures, determining the scope of environmental controls on exchange and release rates, establishing reaction mechanisms for exchange and dissolution, and determining the range of mineral-solution interface properties that are environmentally relevant. The PbS-PbSe system was selected for this investigation because its crystal chemistry and electronic structure are well-understood, the solid solution is complete and ideal, and mass transfer processes at their solution interfaces, which have implications for environmental quality, are incompletely understood.

Results: Freshly synthesized high-purity $\mathrm{PbS}$ was retrieved from evacuated synthesis tubes under anoxic conditions, pressed into graphite sheet, and mounted in specially constructed apparatus for controlled exposure to high-purity gases. This method of sample preparation provides a surface with very little adventitious $\mathrm{C}$ or $\mathrm{O}$ and no evidence of other contamination. Experiments included exposure to $\mathrm{CO}_{2}, \mathrm{H}_{2} \mathrm{O}_{(v)}, \mathrm{O}_{2}$, $\mathrm{CO}_{2}+\mathrm{H}_{2} \mathrm{O}_{(v)}, \mathrm{O}_{2}+\mathrm{H}_{2} \mathrm{O}_{(\mathrm{v})}$, and $\mathrm{O}_{2}+\mathrm{CO}_{2} . \mathrm{CO}_{2}$ alone and $\mathrm{H}_{2} \mathrm{O}_{(v)}$ alone do not react with or even adsorb appreciably to the PbS surface. In the initial stages of oxidation of $\mathrm{PbS}$ in $\mathrm{O}_{2}$ with or without admixed gases, no new XPS peaks were observed for sulfur, but new peaks were observed for oxygen at 529-530 eV binding energy $(\mathrm{BE})$. The lead peaks were broadened on the high $\mathrm{BE}$ side due to the emergence of a new feature. These observations are compatible with the formation of $\mathrm{PbO}$, but they could also be due to oxygen adsorbed on $\mathrm{PbS}$ or taking sulfur positions in the PbS structure near the surface. For longer exposure times, two new $S 2 p_{3 / 2}$ peaks of similar strength are found at 167.8 and 161.8 $\mathrm{eV}$, a new oxygen peak emerges at $531.3 \mathrm{eV}$, in addition to the oxide-type peak found at $529.4 \mathrm{eV}$, and a $\mathrm{Pb}_{4} \mathrm{f}_{7 / 2}$ peak at $138.3 \mathrm{eV}$ can be separated by spectral 
subtraction procedures. The relative $\mathrm{BE}$ positions of the sulfur and oxygen peaks are in good agreement ( \pm $<0.1 \mathrm{eV}$ ) with the lead thiosulfate reference spectra. The relative $\mathrm{Pb}_{4 \mathrm{f}} \mathrm{BE}$ is $0.2 \mathrm{eV}$ lower than found for bulk lead thiosulfate, but this is attributable to contributions from lead atoms in the oxide-type component. Following the nomenclature used for similar cases in the literature, the oxidation product would be designated a single-phase basic salt, but the data may better be interpreted as indicating a multiphase mixture of lead oxide and lead thiosulfate. Sulfur peaks at these positions have previously been interpreted as sulfate or basic sulfate and polysulfide. The agreement in relative $\mathrm{BE}$ positions, however, warrants the interpretation of the BEs as corresponding to the central and ligand sulfur atoms of the thiosulfate ion. The identification of the $\mathrm{PbS}_{2} \mathrm{O}_{3}$ product is an important result, confirming the intermediate role of thiosulfate in the conversion of sulfide sulfur to sulfate. Sulfate was not identified on the surface after a one-week exposure to oxygen.

The formation of the thiosulfate component was greater in the $\mathrm{O}_{2}+\mathrm{H}_{2} \mathrm{O}_{\text {(v) }}$ experiment than in $\mathrm{O}_{2}$ alone, although the ratio of $\mathrm{PbO}: \mathrm{PbS}_{2} \mathrm{O}_{3}$ formation was approximately the same in both cases. This finding suggests a synergistic role for $\mathrm{H}_{2} \mathrm{O}_{(v)}$ in the oxidation process, but the presence of $\mathrm{H}_{2} \mathrm{O}_{(v)}$ apparently does not favor the oxidation route to thiosulfate over that to oxide.

In the $\mathrm{O}_{2}+\mathrm{CO}_{2}$ experiment, $\mathrm{PbCO}_{3}$ was observed to form along with the $\mathrm{PbO}$ and $\mathrm{PbS}_{2} \mathrm{O}_{3}$ expected from the presence of $\mathrm{O}_{2}$. The sample used for the $\mathrm{O}_{2}$ exposure (surface altered to $\mathrm{PbO}+\mathrm{PbS}_{2} \mathrm{O}_{3}$ ) was exposed to pure $\mathrm{CO}_{2}$, yielding a surface that also had a $\mathrm{PbCO}_{3}$ component. Because $\mathrm{CO}_{2}$ alone will not react with the $\mathrm{PbS}$ surface, the formation of $\mathrm{PbO}$ (i.e., reaction with $\mathrm{O}_{2}$ ) is evidently a prerequisite for the formation of $\mathrm{PbCO}_{3}$. Another important finding was the shift in $\mathrm{Pb}$ and $\mathrm{S}$ $\mathrm{BEs}$ upon reaction with $\mathrm{CO}_{2}$. It was previously established that initial reaction of a pristine $\mathrm{PbS}$ surface with $\mathrm{O}_{2}$ led to band bending at the surface as the initially ntype $\mathrm{PbS}$ became p-type (BEs shift to lower values). When the $\mathrm{PbS}$ surface with $\mathrm{PbO}+\mathrm{PbS}_{2} \mathrm{O}_{3}$ was reacted with $\mathrm{CO}_{2}$, the $\mathrm{Pb}$ and $\mathrm{S} \mathrm{BEs}$ shifted upward, which is compatible with band pending from p-type back towards n-type.

In subaqueous experiments, measurements of zeta potential indicate a $\mathrm{pH}_{\mathrm{zpc}}$ for $\mathrm{PbS}$ of 2.3 to 2.4. The $\mathrm{pH}_{\mathrm{zpc}}$ is not altered by surface oxidation, but zeta potentials measured under oxic conditions are consistently lower than those measured under anoxic conditions. This finding suggests that surface alteration occurring during oxidation yields products with a greater density of surface charge than the unaltered surface. The $\mathrm{pH}_{z p c}$ of the $\mathrm{PbSe}$ surface is $<2.2$. The difference in $\mathrm{pH}_{z \mathrm{pc}}$ is attributable to the greater acidity of selenide $\left(\mathrm{pK}_{\mathrm{al}}\right.$ for $\mathrm{H}_{2} \mathrm{~S}$ is $\sim 6.9$, while $\mathrm{pK}_{\mathrm{al}}$ for $\mathrm{H}_{2} \mathrm{Se}$ is $\sim 3.9$ ). $\mathrm{Zn}^{2+}$ in solution raises the zeta potential of the $\mathrm{PbS}$ surface but does not alter the zeta potential of $\mathrm{PbSe}$. 
GRANTEE:

GRANT:

TITLE:

PERSON IN CHARGE:
UNIVERSITY OF MARYLAND

Department of Chemistry and Biochemistry

College Park, Maryland 20742

DE-FG02-94ER14467

Theoretical Studies of the Adsorption of Gold Complexes and Flotation Collectors onto Sulfide Mineral Surfaces

\author{
J. A. Tossell (301-405-1868; Fax 301-314-9121; E-mail \\ tossell@chem.umd.edu)
}

Objectives: This study began by utilizing computational quantum chemistry to study the structures, stabilities, and spectral properties of heavy metal sulfide species, such as $\mathrm{As}(\mathrm{SH})_{3}, \mathrm{Sb}(\mathrm{SH})_{3}$, and $\mathrm{Au}(\mathrm{SH})_{2}{ }^{-1}$, both in aqueous solution and adsorbed on mineral surfaces and the interaction of flotation collector molecules with sulfide mineral surfaces. We have also evaluated the properties of As hydroxides to compare with recent data and with our results for the corresponding sulfides. Studies are in progress on the $\mathrm{Hg}$ sulfides and on the complexes of P oxysulfide collectors with Au sulfides. Recently, we have begun to examine aluminosilicate cage structures with single and double 4-ring geometries with the goal of synthesizing new materials with new chemical reactivity.

Project Description: To understand the mechanism of formation of gold deposits one must understand both the dissolution and precipitation of gold sulfide minerals and the adsorption of gold-bearing species onto other mineral surfaces. To effectively concentrate gold deposits of low grade one must utilize sulfide-bearing flotation collector molecules that selectively bond to the surface of the gold minerals. In both cases a complete understanding requires knowledge of the structures and properties of both gold sulfide compounds and mineral surfaces in contact with water. In the first year of this project we calculated the structures, energetics, and spectral properties of gold bisulfide, gold bichloride, and other complexes in aqueous solution and adsorbed on simple models for arsenic and antimony sulfide surfaces We also studied the geo- metric and electronic structures of a number of As and $\mathrm{Sb}$ sulfide minerals that possess a number of different structural forms, many of which are essentially molecular in nature (e.g., $\mathrm{As}_{4} \mathrm{~S}_{4}$, in the minerals realgar and pararealgar).

Results: In the first year of the project the main focus was on calculating the structures, stabilities, and properties of various metal sulfide species in solution and of the arsenic and antimony sulfide minerals and their surfaces. First $\mathrm{Au}(\mathrm{I})$ and $\mathrm{Au}(\mathrm{III})$ species in solutions containing sulfide and chloride, such as $\mathrm{Au}(\mathrm{SH})_{2}^{-1}$ and $\mathrm{AuCl}_{4}{ }^{-1}$, were studied. The calculations were tested by comparison with structural data from crystals and aqueous solutions and with available Raman and visible/UV spectra in solution. A parameterized form of the Born-Mayer approach was used to evaluate the solvent stabilization of the ions. The results supported the presence of $\mathrm{Au}(\mathrm{OH})\left(\mathrm{H}_{2} \mathrm{O}\right)$ in aqueous solution in the absence of chloride and sulfide, where the above formula gives the molecular composition of the central metal atom and its first coordination sphere. The $\mathrm{Au}(\mathrm{SH})(\mathrm{OH})^{-1}$ complex was calculated to be stable at high $\mathrm{pH}$, rather than the $\mathrm{Au}_{2} \mathrm{~S}_{2}{ }^{-2}$ species previously assumed. Calculated bond distances and vibrational frequencies for the $\mathrm{AuCl}_{\mathrm{x}}(\mathrm{OH})_{4-\mathrm{x}}{ }^{-1}$ series matched well against EXAFS and Raman data, and the replacement of $\mathrm{Cl}^{-}$by $\mathrm{OH}^{-}$was calculated to be exothermic. $\mathrm{Au}(\mathrm{SH})$ forms a bond to the bridging $\mathrm{S}$ of a $\mathrm{Sb}_{2} \mathrm{~S}(\mathrm{SH})_{4}$ surface model but bonds even more strongly to the terminal $S$ of the hydrolyzed surface. In collaboration with G. Helz (Univ. of Maryland) and D. J. 
Vaughan (Univ. of Manchester) structures and spectra were calculated for a number of As sulfide species in aqueous solution. The $\mathrm{pH}$-dependent Raman spectra and solution EXAFS have been interpreted in terms of $\mathrm{AsS}(\mathrm{SH})_{2}^{-1}$ and $\mathrm{AsS}_{2}(\mathrm{SH})^{-2}$ species, rather than the oligomers often assumed. The arsenic and antimony sulfides that can form molecular minerals, such as $\mathrm{As}_{4} \mathrm{~S}_{3}$ (dimorphite) and $\mathrm{As}_{4} \mathrm{~S}_{4}$ (realgar and pararealgar), were also studied. Calculated structures and vibrational spectra were in good agreement with experiment, with the two different isomeric forms of the $\mathrm{As}_{4} \mathrm{~S}_{4}$ molecule (present in realgar and pararealgar) calculated to differ in energy by almost $3 \mathrm{kcal} / \mathrm{mol}$.

In the second year of this project, we have extended our studies on metal sulfides to the complexes of $\mathrm{Hg}$, using the same relativistic effective core potential Hartree-Fock techniques as in our study of $\mathrm{Au}$ complexes. Our studies have so far indicated that small oligomeric $\mathrm{Hg}$ sulfide clusters are stable, as observed by Paquette and Helz (UMCP) and have structures very much like those of bulk crystalline materials. For example, calculated bond distances and angles in $\mathrm{Hg}_{3} \mathrm{~S}_{2}(\mathrm{SH})_{2}$ are very much like those in cinnabar. $\mathrm{Hg}$ NMR shieldings are also reproduced well by our (allelectron) calculations yet show considerable sensitivity to the presence of water. This suggests that NMR shieldings, if properly interpreted, can give very useful information on hydration and speciation of $\mathrm{Hg}$. We have also examined As hydroxides, which have been recently studied by Raman spectroscopy. Since the As hydroxides are much more soluble than the sulfides, it is possible to prepare concentrated solutions that contain significant concentrations of oligomeric species. Our calculations accurately reproduce the properties of the $\mathrm{As}_{4} \mathrm{O}_{6}$ molecule occurring in arsenolite and indicate that additional features observed in $\mathrm{As}_{2} \mathrm{O}_{3}$ glass and in concentrated aqueous As solutions arise from so-called "3-ring" species, like $\mathrm{As}_{3} \mathrm{O}_{3}(\mathrm{OH})_{3}$.

We have also improved our procedures for describing the structure and vibrational spectra of anions in solution, using polarizable continuum and supermolecule (e.g. , $\mathrm{AsO}_{2}(\mathrm{OH}) \ldots 4 \mathrm{H}_{2} \mathrm{O}^{-1}$ molecule) approaches. In addition to more accurate spectral predictions, these changes allow more accurate calculation of ion hydration energies and acid dissociation constants for compounds like $\mathrm{As}(\mathrm{OH})_{3}$.

We have also initiated a new project in some respects an extension of our 1993 study on Al,Si energetics in aluminosilicate 4-rings. Our goal, however, is not just to explain Al,Si energetics using a molecular approach but to design new stable materials with Al$\mathrm{O}-\mathrm{Al}$ (and other underbonded $\mathrm{O}$ ) linkages and to evaluate their properties computationally. Our first completed study is on so-called $\mathrm{T}_{8}$ molecules, (e.g., $\mathrm{Si}_{8} \mathrm{O}_{12} \mathrm{H}_{8}$ ) and on their complexes with counterions like $\mathrm{H}^{+}$and $\mathrm{Na}^{+}$. We have established that the lowest energy structure of $\mathrm{Si}_{6} \mathrm{~A}_{12} \mathrm{O}_{12} \mathrm{H}_{10}$, which should be stable in superacid solution, has an $\mathrm{Al}-\mathrm{O}-\mathrm{Al}$ linkage.

Publications: (1) Oligomerization in As(III) sulfide solutions: Theoretical constraints and spectroscopic evidence, G. R. Helz, J. A. Tossell, J. M. Charnock, R. A. D. Pattrick, D. J. Vaughan and C. D. Garner, Geochimica et Cosmochimica Acta, 59, 4591-4604 (1995); (2) The speciation of gold in aqueous solution: A theoretical study, J. A. Tossell, Geochimica et Cosmochimica Acta, 60, 17-29 (1996); (3) Theoretical studies on As and Sb sulfide molecules, J. A. Tossell, Mineral Spectroscopy: A Tribute to Roger G. Burns, Geochemical Society Special Publ., in press (1996); (4) Theoretical studies of $\mathrm{Si}$ and $\mathrm{Al}$ distributions in molecules and minerals with eight tetrahedrally coordinated atoms (T8) in double four-ring (D4R) geometries: Octasilasesquioxanes, gismondite and zeolite A, J. A. Tossell, Journal of Physical Chemistry, in press (1996); (5) Aluminosilicate and borosilicate single 4rings: Effects of counterions and water on structure, stability and spectra, J. A. Tossell and G. Saghi-Szabo, Geochimica et Cosmochimica Acta, submitted (1996). 
GRANTEE:

GRANT:

TITLE:

PERSONS IN CHARGE:
MASSACHUSETTS INSTITUTE OF TECHNOLOGY

Department of Earth, Atmospheric, and Planetary Sciences

77 Massachusetts Avenue

Cambridge, Massachusetts 02139

DE-FG02-94ER14431

\section{A High-Precision MT Study of the Mid and Lower Crustal San Andreas Fault Zone}

Theodore Madden (MIT) (617-253-6854; Fax 617-253-6385;

E-mail trm@halley.mit.edu) and Randall Mackie (Department of

Geological Sciences, Indiana University, Bloomington, Indiana 47405;

812-855-36121; Fax 812-855-7899; E-mail randy@indiana.edu)

Objectives: The objective is to study the variations in the electrical conductivity of the mid and lower crustal parts of the San Andreas Fault system in central California using magnetotelluric measurements.

Project Description: The relative and absolute weakness of the San Andreas Fault can be explained if the slip zone of the fault contains excess fluids with high fluid pressures relative to the rest of the fault zone and adjacent crust. Fluids in the fault zone have also been invoked to explain the behavior of the creeping section of the fault zone, and they may also play an important role in the earthquake cycle of the locked section of the fault. It has been suggested that any fluids in the fault zone may come from the lower crust, and, if this is the case, then high-conductivity lower crustal channels created by the pore fluid paths should be resolvable using high-quality magnetotelluric measurements. This project will involve making magnetotelluric measurements across the Carizzo Plains section of the fault in the first year, and the
Mojave section of the fault in the second year, and is associated with the San Andreas Deep Drilling Project.

Results: During the past year, very high-quality MT measurements were made along two profiles perpendicular to the San Andreas Fault along the Mojave section of the fault, going from the San Gabriel Mountains north of Los Angeles into the Mojave Desert. At each site along these profiles, EMI equipment was used to collect remote-reference data, which spanned the frequency range from $250-0.003 \mathrm{~Hz}$. The use of a far remote reference site ( $>100 \mathrm{~km}$ away) allowed us to obtain very good estimates of the MT impedances, even at sites nearer to Los Angeles. Initial inversions of the data indicate that the San Andreas Fault is more conductive than surrounding crust, and the resulting conductivity section correlates well with the results of the seismic LARSE tomography experiment. Future work involves detailed analysis of the data for the effect of local distorters and continued inversions to refine the conductivity images and resolution of the data. 
GRANTEE:

GRANT:

TITLE:

PERSON IN CHARGE:
MASSACHUSETTS INSTITUTE OF TECHNOLOGY

Department of Earth, Atmospheric, and Planetary Sciences

Cambridge, Massachusetts 02139

DE-FG02-93ER14322

Electroseismic Characterization of Lithology and Fluid Type in the Shallow Subsurface

M. Nafi Toksoz (617-253-7852; Fax 617-253-6385; E-mail

nafi@erl.mit.edu)

Objectives: The objective of this project is to study the electrokinetic coupling between seismic and electric fields in the earth. We test the electroseismic method to remotely characterize lithology and pore fluid compositions. The goal is to employ the electroseismic method to detect fractures, their orientation and permeability.

Project Description: The purpose of this work is to study the electroseismic method to remotely characterize permeability of a fracture zone, pore fluid compositions, and contrasts. The project is divided into three phases. The first phase is solving electroseismic equations in 3-D using the finite difference method. The focus of the modeling studies will be to (1) understand and model electroseismic signals generated in fractures and (2) model electroseismic effects in and around a borehole. In the second phase electroseismic measurements are performed on layered and borehole models to verify the theory and to help design field experiments. Emphasis will be on the detectability of permeable/fractured zones and fluid chemistry contrasts. In the third phase, electroseismic data is acquired in surface geometry and in borehole geometry. Specific electroseismic field data processing needs to be developed. Emphasis will again be on the detectability of permeable/fractured zones and fluid chemistry contrasts.

Results: Equations controlling the coupled electromagnetics and acoustics of porous media were derived. Uniqueness, statements of energy conservation, and reciprocity in an anisotropic, heterogeneous porous medium were derived. Representation integrals for wavefields were derived requiring nine Green's tensors. Both plane wave and point source responses were obtained in isotropic, homogeneous full space. Boundary conditions at all interface types were derived. An electroseismic field vector formalism was developed. This formalism was solved numerically to determine full-waveform electroseismic point source responses in stratified media. We developed a boundary element technique to study seismic sources in a borehole and receivers either at the surface or embedded in the medium.

The forward models were compared to laboratory data collected in the M.I.T. Earth Resources Laboratory's seismic physical tank. The laboratory measurements on fluid saturated sandstones confirm that electroseismic signals are electrokinetic in origin and sensitive to both fluid chemistry and rock lithology. $\mathrm{P}$ and $\mathrm{S}$ wave transducers generate measurable converted electric signals at contrasts in medium properties. The conversions are predicted numerically. Electroseismic field data were acquired and interpreted. The data show electroseismic conversions that are predicted by the theoretical model. The amplitude behavior of the predicted electroseismic conversions versus source-antenna distance match the field measurements. 
GRANTEE:

GRANT:

TITLE:

PERSONS IN CHARGE:

\author{
MASSACHUSETTS INSTITUTE OF TECHNOLOGY \\ Department of Earth, Atmospheric, and Planetary Sciences \\ Cambridge, Massachusetts 02139
}

DE-FG02-86ER13636

In Situ Permeability Determination Using Borehole and Seismic Logging Data

M. Nafi Toksoz (617-253-7852; Fax 617-253-6385; E-mail

nafi@erl.mit.edu) and C.H. Arthur Cheng (617-253-7206;

Fax 617-253-6385; E-mail cheng@erl.mit.edu)

Objectives: The objective of this project is to identify, locate, and characterize in situ fractures using downhole and surface seismic methods. The goal is to estimate the permeability of these fractures from the way they interact with seismic waves.

Project Description: The purpose of this work is to study methods of determining in situ permeability or hydraullic conductivity of a fracture or fracture zone using full waveform and shear wave acoustic logging, vertical seismic profiling, and other downhole, crosshole, and seismic imaging techniques. In addition, methods to determine the orientation and extent of natural and man-made fractures are studied. The behavior of full waveform and shear wave logs in a fractured medium is studied using numerical models, laboratory scale model experiments, and actual field data. The method of locating a hydrofrac using microearthquake arrival time is being improved by relative and absolute location techniques. The aim is to characterize and image in situ fractures for the purpose of hydrocarbon production from naturally or artificially fractured reservoirs, nuclear waste disposal planning, and geothermal energy recovery.

Results: In the past year, our effort in the characterization of fractures from acoustic logging has been focused on shear wave logging using dipole sonic logging tools. We have found that the commonly used four-component rotation of cross-dipole logging data gives a robust and accurate estimate of the directions of the principal axes of the formation shear wave anisotropy; however, because of cross-coupling in nonideal situations in the field and the dispersive nature of the flexural waves, determining the amount of shear wave velocity anisotropy can be unstable and processingdependent. A more stable velocity estimation scheme needs to be developed.

We have also investigated the sensitivity of Stoneley wave velocity and attenuation to a gas-saturated formation. It is determined that in a gas-saturated formation the Stoneley wave is sensitive to formation permeability as low as a millidarcy or lower, because of the low viscosity and density of gas.

We have continued our analysis on the passive monitoring of hydraulic fracture data, in particular, the ARCO data set that incorporates two independent cemented geophone strings. We are able to observe fracture growth with time, and it is hopeful that further analysis of this data set will allow us to better understand the hydraulic fracturing process. 


\section{GRANTEE:}

\section{GRANT:}

TITLE:

\section{PERSONS IN CHARGE:}

UNIVERSITY OF MICHIGAN

Department of Geological Sciences

1006 C. C. Little Building

Ann Arbor, Michigan 48109-1063
DE-FG02-94ER14412

\section{Applications of ICP Magnetic Sector Multicollector Mass Spectrometry to Basic Energy Research}

Alexander N. Halliday (313-764-1482; Fax 313-763-4690; E-mail anh@umich.edu) and Chris M. Hall

Objectives: Objectives are to accurately determine the ages of, and source of components in, hydrothermal mineralization and diagenesis in order to evaluate the mechanisms responsible for the formation of economic base metal and hydrocarbon accumulations, to understand the controls on the chemistry of the oceans with particular reference to hafnium, and to determine the mechanisms of entrapment of pollutants in sediments.

Project Description: This research project will develop the new technique of ICP multicollector mass spectrometry and apply the methods to a variety of problems in low temperature geochemistry. These will include new methods of dating sulfides, such as long-lived isotopic chronometers $\left({ }^{115} \mathrm{In}-{ }^{115} \mathrm{Sn}\right.$ ), and higher sensitivity applications of established geochronometers, such as Lu-Hf dating of phosphates. Laser ablation in situ isotopic measurements should be possible for dating and determining the origins of components in low temperature overgrowths and fine-grained diagenetic minerals, such as U-Pb measurements of zircon, anatase, and sphene, and $\mathrm{Sr}$ isotopic measurements in carbonates and feldspars. High sensitivity Hf isotopic studies of seawater and metalliferous sediments will be used to evaluate the Hf isotope geochemistry of the oceans. Precise isotope dilution measurements of transition metals and platinum group elements in dust, seawater, and sediments will be used to evaluate the controls on the chemistry of the oceans and the mechanisms of entrapment of pollutants in sediments.

Results: The production version of the multiple collector ICPMS has been commissioned, a 30-cm electrostatic energy filter added, and techniques for measuring ${ }^{230} \mathrm{Th}$ abundances established. A new NdYAG laser, frequency-quadrupled to operate in the uv, has been used for high-precision in situ isotopic measurements of $\mathrm{Sr}$ and $\mathrm{Pb}$ isotopic compositions. Accurate and reproducible $\mathrm{U} / \mathrm{Pb}$ ratios can be determined using this laser, and precise U-Pb dating of accessory minerals is being attempted. We have also determined $\mathrm{Pb}$ isotopic compositions as a function of age in traverses through Mn crusts. A hydrothermal Hf signal, correlated with $\mathrm{Pb}$ isotopic composition, is recorded in many of these and can be used to test theories for the role of hydrothermal contributions to the oceans through time. Precise isotopic measurements of $W$ have permitted improved constraints on the age of the Earth's core. New techniques for the measurement of $\mathrm{Ru}, \mathrm{Pd}$, $\mathrm{Ag}, \mathrm{Cd}, \mathrm{Te}, \mathrm{Re}, \mathrm{Ir}$, and $\mathrm{Pt}$ have been developed to complement our techniques for $\mathrm{In}, \mathrm{Sn}, \mathrm{W}$, and $\mathrm{Pb}$. We are currently developing methods for measuring $\mathrm{Tl}$. These will provide the groundwork for very accurate measurements of chalcophile and siderophile element abundances in rocks and fluids. 
GRANTEE:

GRANT:

TITLE:

PERSONS IN CHARGE:
UNIVERSITY OF MICHIGAN

Department of Geological Sciences

Ann Arbor, Michigan 48109-1063

\section{DE-FG02-96ER14615}

\section{Combined Noble Gas and Stable Isotope Constraints on Nitrogen Gas Sources Within Sedimentary Basins}

Chris J. Ballentine (313-764-1435; Fax 313-763-4690;

E-mail chrisjb@umich.edu), Alexander N. Halliday, and Barbara Sherwood-Lollar (University of Toronto)

Objectives: Objectives are to combine the information provided by both noble gas and stable isotope systematics in order to constrain the origin of nitrogen gas sources, transport behavior, and mass balance within sedimentary basin systems.

Project Description: Nitrogen is one of the major non-hydrocarbon gases found in natural gas reservoirs. Many regions in which the gas fields have a high nitrogen content also show a relationship between the concentration of nitrogen and crustal-radiogenic helium. The crustal He will be associated with crustal ${ }^{40} \mathrm{Ar}$ and ${ }^{21} \mathrm{Ne}$. Noble gases derived from other sources such as the air dissolved in groundwater and magmatic sources can be quantified from the noble gas isotopic composition. Combined with the distinct elemental abundance patterns, it is possible to resolve the extent of crustal, mantle and atmosphere-derived noble gas involvement in these systems.
The Kansas/Texas Hugoton/Panhandle giant gas field has perhaps the best documented $\mathrm{He} / \mathrm{N}_{2}$ relationship of any system. The first phase of this program focuses on samples from these and neighboring fields that preserve a regional $\mathrm{He} / \mathrm{N}_{2}$ ratio. The noble gas and stable isotope composition of these samples will be compared with those samples that show excess nitrogen. This will enable us to identify any regional nitrogen gas isotopic end members; quantify the extent of their contribution to the sedimentary fluid regime; constrain the conditions for deep nitrogen release and transport; and, by comparison with samples that show rare gas abundance fractionation, identify the mechanism of fractionation (i.e., mass-dependent transport fractionation, solubility/phase fractionation) and assess its impact on the stable isotope systematics.

Results: This project has only recently been initiated. 
GRANTEE:

GRANT:

TITLE:

PERSON IN CHARGE:
UNIVERSITY OF MINNESOTA, TWIN CITIES

Department of Geology and Geophysics

Minneapolis, Minnesota 55455

DE-FG03-91ER14212
Physical and Experimental Studies of Magma Rheology, Sedimentary Basins, and Molecular Dynamics of Silicates

David A. Yuen (612-624-1868; Fax 612-624-8861;

E-mail davey@krissy.msi.umn.edu)
Objectives: Objectives are (1) numerical modeling of dynamics of sedimentary basins and lithospheric processes, (2) mixing processes in thermal convection, (3) numerical modeling of magmatic underplating and dynamics of plume ascent, and (4) determination by molecular dynamics (MD) simulations of the structure and properties of melts and thermal convection of multicomponent substances.

Project Description: This collaborative project with F. J. Spera at the U. of California, Santa Barbara, will improve our understanding of the thermal, chemical, dynamical, and mechanical states of the continental crust and the subcrustal lithosphere with particular focus on the interactions among the various subsystems. The work plan includes (1) determination of the structure and property of melts and thermal convection of multicomponents by MD simulations, (2) mixing processes of convection in temperature-dependent Newtonian and non-Newtonian convection and visualization of complex structures, (3) numerical modeling of magmatic underplating and lithospheric thinning, (4) dynamical effects of lithospheric phase transitions on the thermal-mechanical evolution of sedimentary basins, (5) development of stress fields and criteria for faulting in the crust, and (6) numerical modeling of heat and mass transport driven by thermal and chemical heterogeneities.

Results: Results cited below are for the U. of MN part of this project. Additional results can be found in the summary of activities by the Univ. of California team led by F. J. Spera. MD simulations of $10^{5}$ to $10^{6}$ particles describing macroscopic flows have been completed. Results have been published in Molecular Simulations. We have also developed a new technique for studying mixing dynamics by integrating the partial differential equation governing the temporal evolution of material interfaces. Very high resolution, up to 3000 x 3000 grid points, has been achieved, and the results have been visualized using 4 million pixels. One paper has appeared in Geophys. Res. Lett. We have also developed a theory based on fractals to study the timedependent dynamics of mixing. Fractal analysis has been conducted on the large data set generated by our efficient numerical scheme. We have also developed a line technique for studying mixing processes in which $10^{4}$ to $10^{5}$ particles are linked together in a line. With 10 to 20 lines we can achieve a very high resolution as all of the wrinkles along a line, severely deformed by the velocity field, can be accurately mapped out. The feedback mechanism between temperature-dependent and non-Newtonian rheology has been studied in both 2- and 3-D geometries. Two papers have come out in Geophysical Research Letters and one in Physics Earth Planetary Interior. Two-dimensional wavelet techniques based on collocation formalism have been developed, allowing for extremely high numerical resolution and large viscosity contrasts. We have confirmed the stress amplification mechanism for a thin lithosphere ( $2 \%$ of the layer) with a viscosity contrast of $10^{8}$. Quasi-analytical solutions have been developed to study the effects of multiple phase transitions in the lithosphere and the time-history of the subsidence for various conditions. 
GRANTEE:

GRANT:

TITLE:

PERSON IN CHARGE:
NATIONAL ACADEMY OF SCIENCES/NATIONAL RESEARCH COUNCIL

Board on Earth Sciences and Resources

Washington, DC 20418

\author{
Board on Earth Sciences and Resources, Committee on \\ Seismology, U.S. Geodynamics Committee
}

Objectives: The Board on Earth Sciences and Resources coordinates the National Research Council's advice to the federal government on solid-earth science issues related to research, education, the environment, geologic hazards, resource utilization, and economic development.

Project Description: The Board provides information and advice to the government through committees of volunteer geoscientists drawn from academia, industry, and government. The primary purpose of these committees is to respond to requests from the Executive Branch, Congress, and federal agencies for information or advice on specific issues before the government. The committees also serve as a forum for discussions and exchange of information among government, university, and industry scientists and policy makers. The Board strives to provide accurate and timely advice that can be used for wise decision making by preparing reports and bringing scientists and policy makers together at workshops, symposia, and forums. The Board also coordinates activities of various U.S. National Committees, including those for the International Union of Geodesy and Geophysics, the International Union of Geological Sciences, the International Geographical Union, the International Union for Quaternary Research, and the U.S. National Committee for Rock Mechanics.

The major committees of the Board and their areas of oversight include the Committee on Seismology (seismology related to research, hazards, and verifica- tion), U.S. Geodynamics Committee (solid-earth science issues, research and applications of geodetic data), Committee on Geophysical and Environmental Data (national and international data policies and services), Committee on Earth Resources (national energy and mineral resource issues), and Mapping Science Committee (spatial data handling and analysis issues).

Additional ad hoc committees and panels are formed to address topics that fall outside the purview of these committees. Current ad hoc activities include "Seeing" into the Earth -- Non-Invasive Characterization of the Shallow Subsurface for Environmental and Engineering Applications, Rediscovering Geography, Research Programs of the U.S. Bureau of Mines, and Science of Earthquakes.

Results: The Committee on Seismology issued its report, "Seismological Research Requirements for a Comprehensive Test Ban Monitoring System" (November 1995), to advise the Advanced Research Projects Agency on the design of an International Monitoring System to support the verification of a Comprehensive Test Ban Treaty (CTBT). The recommendations of this report have played an important role in establishing the data access policies and instrument design for the CTBT monitoring system. At the request of the Department of Defense, the committee has established a subsequent panel to assess the basic research requirements for CTBT monitoring. This activity is a significant broadening of the previous study, incorporating a review of the disciplines of hydroacoustic, infrasound, and ra- 
dionuclide transport as well as seismology. In July 1996, the committee published its report "High Performance Computing in Seismology," based on the proceedings of a workshop help at the San Diego Supercomputer Center.

The U.S. Geodynamics Committee has two ongoing panel studies. The first is assessing the multidisciplinary research opportunities on the origin and evolution of sedimentary basins. This research will lead to a better understanding of important but poorly understood geodynamic processes, such as sea level change, crustal uplift, and mantle convection, and it will improve the ability to predict the distribution and extent of hydrocarbon, water, and certain mineral resources. The report of this panel will be published in the fall of 1996. The committee has also established a panel to assess the utility of secular gravity data for studies of dynamic Earth problems associated with geodynamics, natural hazards, and global change. In May 1996, the committee convened a workshop on Synthetic Aperture Radar Interferometry. A summary of this meeting was published in the August 30 issue of Science magazine.

The Committee on Earth Resources published three reports in the past year. At the request of the Office of
Fossil Energy of the Department of Energy (DOE), the committee established a panel to review DOE's Reservoir Class Field Demonstration Program. Its final report, "Maintaining Oil Production from Marginal Fields: A Review of the Department of Energy's Reservoir Class Program," was published in April 1996. On June 11, the chairman presented the report to the Congressional Oil and Gas Forum, a bipartisan coalition of senators and representatives interested in issues involving the U.S. oil and gas industry. At the request of the U.S. Geological Survey (USGS), the committee established a panel to provide a critical scientific evaluation of the agency's Mineral Resource Surveys Program plan. The report, "Mineral Resources and Society: A Review of the U.S. Geological Survey's Mineral Resource Surveys Program Plan," was delivered to the USGS on April 20.- In February 1996, the committee issued a brief report on "Mineral Resources and Sustainability: Challenges for Earth Scientists." This report, which is based on a workshop convened by the committee, examines the concept of sustainability as it pertains to mineral resources and mining and suggests how earth scientists can contribute more effectively toward the goals of sustainability as it applies to resource depletion and environmental concerns. 
GRANTEE:

GRANT:

TITLE:

PERSONS IN CHARGE:
UNIVERSITY OF NEW MEXICO

Department of Earth and Planetary Sciences

Albuquerque, New Mexico 87131-1116

\section{The Crystal Chemistry and Structural Analysis of Uranium Oxide Hydrates}

Mark L. Miller (505-277-9447; Fax 505-277-8843; E-mail

mlm@unm.edu) and Rodney C. Ewing (505-277-4163;

Fax 505-277-0090; E-mail rewing@unm.edu)

Objectives: Objectives are to determine the crystal-chemical and crystal structural systematics of the corrosion products of uraninite and uranium dioxide. These are commonly identified actinide phases in oxidizing environments (e.g., the corrosion of spent nuclear fuel).

Project Description: All known uranyl oxides are sheet structures, with the uranium occurring in a nearly hexagonal array within a sheet. The nearly linear uranyl groups are oriented approximately perpendicular to the sheet oxygens and hydroxyls that coordinate the uraniums.

This project includes the determination of unknown UOH crystal structure phases. The structural descriptions will be used to expand the data base of described crystal structures; to develop a hierarchy of crystal structures for this group of materials, including a systematic quantitative description of the UOH phases; and, ultimately, to create a structural model for the estimation of thermodynamic quantities. In this second year of funding the breadth of this project has been expanded to include all inorganic phases in which the uranyl ion plays a significant structural role.

Results: During the last year, a data base, containing the crystal structures of all inorganic phases for which the structures have been described, has been completed. Analysis of the crystal structures of these phases has led to the development of a structural hierarchy of inorganic phases in which hexavalent uranium plays a significant structural role. The hierarchy is based on the polymerization of cations of higher bond valance. Structures are grouped into those containing isolated uranyl polyhedra, finite clusters of uranyl polyhedra, infinite chains, sheets, and frameworks of uranyl polyhedra. Comparison of the crystal chemistry of the uranyl ion in the phases of the data base with the crystal structures and crystal chemistry of phases containing transuranic elements indicates that many of the known corrosion products are likely to incorporate pentavalent $\mathrm{Np}$ and $\mathrm{Pu}$ as well as tetravalent $\mathrm{Pu}$. Fission products such as $\mathrm{Sr}$ may be incorporated into the interlayers of the known corrosion products. Of the 180 phases for which the crystal structures are known, 106 phases have structures that are best described as sheets of polyhedra containing hexavalent uranium, including all uranyl oxide hydrates (the only phase known to be important to the corrosion of SNF that is not a sheet structure is soddyite, a framework). The crystal structures of these phases are classified on the basis of their sheet anion topologies of which we have identified 29. We are currently completing the classification of these sheet anion topologies. The crystal structures of the two most important SNF corrosion products have been determined: schoepite and ianthinite (although the ianthinite is only preliminary at this time). These phases are the first to form as a result of oxidative corrosion of SNF. Furthermore, crystal chemical considerations indicate that these phases are likely to incorporate pentavalent $\mathrm{Np}$ and $\mathrm{Pu}$ and possibly tetravalent $\mathrm{Pu}$ as impurity cations substituting for uranium. 
GRANTEE:

GRANT:

TITLE:

PERSONS IN CHARGE:
NEW MEXICO INSTITUTE OF MINING AND TECHNOLOGY

Socorro, New Mexico 87801

DE-FG03-96ER14589

John L. Wilson (505-835-5308; Fax 505-835-6436; E-mail

jwilson@nmt.edu) and Vincent C. Tidwell (Sandia National

Laboratories)

Objectives: The basic objective of this research program is to enhance fundamental understanding of the processes and media characteristics that govern permeability upscaling. Specifically, we will address the following questions:

- Does permeability upscale in a predictable and quantifiable manner?

- What characteristics of the geologic medium influence upscaling behavior?

- What are the appropriate measures of permeability upscaling (i.e., first two statistical moments, fractal dimension, other)?

Project Description: Laboratory investigation of permeability upscaling is accomplished through the use of a specially adapted mini-permeameter that we have termed the multi-support permeameter (MSP). The MSP allows rapid, precise, nondestructive measurement of gas permeability over a range of discrete sample supports (i.e., sample volumes). Measurements are made at different sample supports by simply varying the size of the permeameter tip seal. In this way, measurements spanning five orders of magnitude on a per volume basis are made subject to consistent boundary conditions and flow geometry. Experiments progress by collecting thousands of measurements on multiple faces of meter-scale blocks of rock with each of five different tip seals $(0.31,0.62,1.27,2.54$, and $5.08 \mathrm{~cm}$ ID) plus a single large-scale $(15.24 \mathrm{~cm}$ ID) measurement designed to integrate over the entire sampling domain. This process is repeated on multiple rock samples, each of which is carefully selected according to its depositional and diagenetic history. The acquired data is used to evaluate the performance of theoretical upscaling models, to bound their application with re- spect to limiting assumptions, and to explore alternative measures and models of upscaling behavior.

Results: In this project's first year, efforts have focused on evaluation of the MSP. Modifications to tip seal design have been made to achieve improved control over tip seal geometry under compression. Evaluation of seal quality as a function of compression time and pressure has also been accomplished. In addition, effects of gas slippage, head loss, nonsteady-state flow, and non-Darcy flow on permeability calculations have been assessed. A series of experiments were then performed on synthetic, "homogeneous" plaster and mortar blocks to demonstrate that measurements made at different sample supports are free from bias induced by the measurement technique. A suite of exhaustive measurements was also collected from natural rock samples to demonstrate that measurement error is low and consistent across the different tip seals.

Upon completion of the system evaluation, extensive upscaling data were collected from two fluvial sandstones, a 0.3 by 0.3 by $0.3 \mathrm{~m}$ block of Berea Sandstone $(14,000$ permeability measurements) and a 1.0 by 1.0 by $1.0 \mathrm{~m}$ block of Massillon Sandstone (75,000 permeability measurements). It should be noted that such 3-D, spatially exhaustive, multi-support data sets do not exist elsewhere. Reduction of this data has revealed strong trends in the mean, variance, and correlation length scale as a function of sample support. Considering the care that has been taken to insure consistency in the multi-support measurements, we are convinced that the measured trends are not simply artifacts of the sampling program but are diagnostic of permeability upscaling. Analysis of this data and comparison to theoretical upscaling models is ongoing. 
GRANTEE:

GRANT:

TITLE:
THE CITY COLLEGE OF THE CITY UNIVERSITY OF NEW YORK

Benjamin Levich Institute and Department of Physics

New York, New York 10031

DE-FG02-93ER14327

Nonlinear Transport and Collective Processes in Heterogeneous Media

PERSON IN CHARGE:

Joel Koplik (212-650-8162; Fax 212-650-6835; E-mail

koplik@sci.ccny.cuny.edu)

Objectives: We propose to seek a better understanding of fundamental physical laws that govern several important nonlinear and collective transport processes in heterogeneous media: dispersion, filtration, rapid flow, and inelastic clustering.

Project Description: Four topics will be considered. First, previous work on hydrodynamic dispersion in two-dimensional porous media flows involving multipole distributions of sources and sinks will be extended to three dimensions. Particular attention will be paid to systems with macroscopic disorder, such as fractures. Next, we will consider flow through porous media in the high Reynolds number regime, where nonlinear effects become important. We will use numerical simulations and multiple scale expansions to elucidate the origins of the Forchheimer equation, whose relevance has been experimentally established. Third, we will investigate basic aspects of filtration, in particular the plugging of a porous matrix by deposition and trapping of suspended particles. These removed particles gradually plug the porous medium, giving rise to feedback between transport and filtration efficiency. Finally, we propose to investigate the dynamics and clustering phenomena of inelastic gases. The steady response in small gradients will be used to help provide insights about the clustering phenomenon observed in the transient cooling of the gas.

Results: Initial progress on the four topics listed above is as follows: (1) The shape and characteristic decay laws for the transit-time distribution of a passive tracer in homogeneous 3-D systems have been found. (2) Our numerical simulations verify the Forchheimer equation, and the scaling of fluctuations with porosity and Reynolds number are being determined. (3) A simple model resembling directed percolation has been developed and applied to filtration, and more sophisticated simulation methods allowing for particle interactions and realistic microscopic junction dynamics are being tested. (4) Initial exploratory numerical work has observed similar clustering phenomena to those reported in the literature. 
GRANTEE:

GRANT:

TITLE:

PERSON IN CHARGE:
STATE UNIVERSITY OF NEW YORK AT STONY BROOK

Department of Applied Mathematics and Statistics

Stony Brook, New York 11794-3600
DE-FG02-92ER14261

Medial Axis Analysis of Porous Media

W. B. Lindquist (516-632-8361; Fax 516-632-8491; E-mail lindquis@ams.sunysb.edu)
Objectives: The goal of this work is to investigate the utility of medial surface and medial axis transforms in characterizing the geometry of void and grain microstructure from three-dimensional microtomographic images of rock.

Project Description: High resolution (1 to $5 \mathrm{mi}-$ crons), computed-microtomographic, three-dimensional images of rock samples are segmented to provide specific grain/pore identification for each voxel in the image. Appropriate transforms are then applied to the segmented, digitized images to produce either medial surface (co-dimension one) or medial axis (co-dimension two) representations of the void (or grain) structure. The geometric properties of the medial surface/ axis are then investigated statistically to develop predictive stochastic distributions characteristic of real, three-dimensional porous media geometry.
Results: A computer package, 3 DMA, written in $\mathrm{C}$, has been developed that takes as input three-dimensional tomographic images and, under user menu control, performs a variety of stochastic and geometric analyses of the image. Major analyses include segmentation of the object, construction of medial surface/axis of either void or grain phase, and computations of pore size distribution, distribution of connected volumes, and geometric tortuosity of shortest pathways through the medial axis. Currently computation of two point correlation functions is being implemented. Progress during this last year has been in (1) improving the quality of the segmentation and medial axis transform algorithms, (2) accessing and analyzing rock samples of larger image size, and (3) porting our code to other investigators. To avoid memory limitations, analysis of larger image sizes has required parallelization of the computational routines using domain decomposition techniques. 
GRANTEE:

GRANT:

TITLE:

PERSONS IN CHARGE:

\author{
STATE UNIVERSITY OF NEW YORK AT STONY BROOK \\ Department of Earth and Space Sciences \\ Stony Brook, New York 11794-2100
}

\section{DE-FG02-94ER14455}

\author{
Micromechanics of Failure in Brittle Geomaterials
}
Teng-fong Wong (516-632-8212; Fax 516-632-8240; E-mail wong@seism1.ess.sunysb.edu) and Joanne T. Fredrich (Sandia National Laboratory)

Objectives: The objectives of this project are to provide a fundamental understanding of the effects of pore geometry and cementation, damage state, and load path on the deformation and failure mode of brittle porous and nonporous geologic materials by measurement of mechanical behavior under high pressure and deviatoric stress, quantitative microstructural characterization of pristine and deformed samples, and theoretical analysis.

Project Description: Knowledge of the failure behavior of rocks is important for several energy-related applications, including reservoir engineering, oil and gas exploration and production, underground disposal of nuclear waste, and drilling technology. The experimental investigation will provide a detailed understanding of the micromechanical processes associated with the brittle failure of geomaterials and includes triaxial compression and extension tests following various load paths. Tests are conducted to various stages of failure and include measurement of strain and acoustic emission. The micromechanical failure process is further elucidated and characterized quantitatively using light microscopy, laser scanning confocal microscopy, and scanning electron microscopy. Work focuses on porous carbonate and siliciclastic rocks, although related experiments are also being performed on lowporosity crystalline rocks in order to study completely the effect of certain parameters. The results of the laboratory tests and microstructural studies are used to guide analyses using fracture mechanics and continuum plasticity theories.

Results: (1) One result is the completion of triaxial compression experiments on five sandstones (with po- rosities ranging from $11 \%$ to $35 \%$ ) and detailed characterization of the failure envelopes in both the brittle fracture and cataclastic flow regimes. The failure stresses have respectively positive and negative dependences on effective pressure in the two different regimes. The yield stress in the cataclastic flow regime decreases with increasing porosity and grain size. A micromechanical model (incorporating the effects of normal loading and shear slip on the stress field and fracture mechanics of Hertzian contacts) captures the key attributes of the experimental observations. The compactive yield stresses map out a failure envelope that is approximately elliptical in agreement with the critical state and cap models. This envelope was used to estimate the porosity reduction. Theoretical prediction (based on associated flow rule of classical plasticity theory) and experimental data on compactive strains are in reasonable agreement. (2) A series of triaxial extension experiments were conducted on the same sandstones. Data on shear-enhanced compaction and the compactive yield stress coincide with the triaxial compression data in the stress space, with the implication that the yield envelope is not sensitively dependent on the loading path. (3) Quantitative characterization of the damage accumulated in the Berea sandstone in the brittle fracture and cataclastic flow regimes was conducted. The data provide quantitative constraints on the micromechanical modeling of failure and network modeling of permeability evolution. (4) Preliminary experiments were conducted on failure of porous carbonates. Some of the deformed sample was prepared for quantitative characterization of damage. 
GRANTEE:

GRANT:

TITLE:

PERSONS IN CHARGE:
STATE UNIVERSITY OF NEW YORK AT STONY BROOK

Research Foundation of The State University of New York for

and in conjunction with the Office of Research Services

Stony Brook, New York 11794-3366
High Precision Radiometric Dating of Sedimentary Materials

G. N. Hanson (515-632-8210; Fax 516-632-8240; E-mail ghanson@ccmail.sunysb.edu) and W. J. Meyers
Objectives: The objective is to develop field, petrographic, and geochemical criteria to allow high precision $\mathrm{U}-\mathrm{Pb}$ dating of calcretes or caliches enriched in uranium at paleo-exposure surfaces within rapidly deposited sequences of carbonate and clastic rocks

Project Description: The ultimate goal is to obtain radiometric ages with uncertainties of three million years or less for times of sedimentation. Such uncertainties would be much less than those for most epoch or period boundaries within the Paleozoic or early Mesozoic. U-enriched caliches will be selected from soils developed in rapidly deposited sequences. It is essential that the duration of soil development be less than the analytical uncertainties. We have begun our studies on caliches in the Mesozoic rocks of the Hartford Basin, Connecticut, and the upper Paleozoic rocks of the Sacramento Mountains, New Mexico. These studies should also lead to a better understanding of the geochemistry of paleosols, including the processes responsible for U-enrichment. They should also provide additional criteria for recognizing erosion surfaces.
Results: The early results of our dating are very encouraging. The first test was the dating of massive micritic calcite from a sample of caliche near the base of the Triassic New Haven Arkose (Norian), Hartford Basin, Connecticut. Multiple aliquots of a 100-gram sample were dated independently by Mr. Wang and Ms. Rasbury, using different chemistries, different size aliquots, and different isotopically enriched spikes. The two separate U-Pb isochron ages are $212 \pm 2(2 \sigma) \mathrm{Ma}$ and $212.4+3.4(2 \sigma)$ Ma for Mr. Wang and Ms. Rasbury, respectively. These ages are in good agreement with the $208 \pm 16$ ( $2 \sigma) \mathrm{Ma}$ age for the Triassic-Jurassic boundary and the $223 \pm 18(2 \sigma)$ Ma age for the Carnian-Norian boundary given by Harland et al., 1990.

Early dating results for paleo-caliche below the Pennsylvanian-Permian boundary in the Holder Formation, New Mexico, and above the boundary in the UNOCAL core in Texas give U-Pb isochron ages of $291 \pm 15(2 \sigma)$ Ma and $298 \pm 1.3(2 \sigma) \mathrm{Ma}$, respectively. These are in good agreement with the $290 \pm 20(2 \sigma)$ Ma age for the Pennsylvanian-Permian boundary given by Harland et al., 1990. 
GRANTEE:

PERSON IN CHARGE:
GRANT:

TITLE:
NORTHWESTERN UNIVERSITY

Department of Civil Engineering

Evanston, Illinois 60208-3109
DE-FG02-93ER14344

Shear Strain Localization and Fracture Evolution in Rocks

J.W. Rudnicki (847-491-3411; Fax 847-491-4011; E-mail

jwrudn@nwu.edu)
Objectives: To obtain an improved understanding of the occurrence, development, and evolution of zones of shear localization (faults) in rocks and their relation to the macroscopic constitutive description, especially that governing multiaxial response, and microscale mechanisms of deformation.

Project Description: Because of the significance of fractures to energy production, waste disposal, and mineral technologies, prediction of their causative stresses, location, orientation, thickness, and spacing is important. This project examines the applicability of a theory of localization that describes faulting as an instability of the constitutive description of homogeneous deformation. Because the predictions depend strongly on the constitutive parameters governing abrupt changes in the pattern of deformation, theoretical work is being done to develop a more realistic constitutive model based on the growth and interaction of microcracks and resulting increase in overall compliance of the solid. This constitutive relation is calibrated by comparison with axisymmetric compression tests and then used to predict the response in more complex experiments (compression-torsion) with abrupt changes in the pattern of loading. Comparison of numerical studies with experiments addresses the effects of realistic geometries and boundary conditions.
Results: Abrupt changes in the pattern of deformation, such as occur in localization and in the combined compression versus torsion tests (Olsson, Mech. Mat., 1995), cause unloading of open cracks in some orientations. Consequently, the response to abrupt changes in the pattern of deformation depends strongly on the unloading response. A phenomenological description of unloading and reloading has been implemented in a microcrack model. Implementation is guided by understanding gained from laboratory observations and from a detailed study of the unloading response predicted by a model in which opening and extension of tensile wing cracks is driven by sliding on an oblique crack with Coulomb friction (Jeyakumaran and Rudnicki, GRL, 1995). Comparison of the predictions with observations suggests that there is rapid partial rehealing of small microcracks or some other source of resistance to crack reopening.

Experimental results on simulated fault gouge (e.g., Marone and Kilgore, Nature, 1993) have suggested that the deformation response of the fault depends on processes of shear localization within the gouge. A simple theoretical model suggests that the development of localized deformation in hydraulically isolated fault zones is strongly affected by coupling between internal fluid flow and slight variations in porosity. 
GRANT:

TITLE:

PERSON IN CHARGE:
DE-F602-93ER14391

\section{Energy Partitioning of Seismic Waves in Fractured Rocks}

Laura J. Pyrak-Nolte (219-631-8377; Fax 219-631-9236; E-mail

pyrak-nolte @nd.edu)
Objectives: The primary objectives of the proposed research are to investigate through numerical and laboratory investigations: (1) partitioning of seismic energy between body waves, guided waves, and scattered waves produced by sources of finite size that are transmitted, reflected, and channeled along single and multiple fractures, (2) techniques for exciting these waves, (3) effects of spatial variations in the mechanical properties along the fracture on seismic wave propagation, and (4) effects of a finite fracture on seismic waves.

Project Description: Rock masses contain fractures and discontinuities on all length scales that affect the mechanical stability of a rock mass and the flow of fluids through a rock mass. A goal of site characterization for waste isolation or mineral exploration is to detect and characterize the hydraulic and mechanical properties of fractures using seismic techniques. Seismic data are often difficult to interpret because of wave conversions that occur at interfaces. Converted wave modes can arise when seismic waves are propagated through a fractured rock mass and these waves inhibit direct interpretation of the received signals. Because the existence of interface waves has not previously been taken into account in seismic data interpretation, it is important to understand how non-welded interfaces, such as fractures and joints, give rise to interface waves. In this research project, the partitioning of seismic wave energy into body waves and interface waves caused by fractures (non-welded contacts) is studied through laboratory experiments and numerical analysis.
Results: The specific results for the third year of this project include (1) experiment evidence of compressional-mode interface wave that co-propagates with the bulk compressional wave, (2) generation of Rayleigh-mode interface waves for sources at oblique angles of incidence to the fracture, and (3) determination of the effect of asperity spacing on Bragg scattering and on the limits of applicability of the displacement discontinuity theory for interface waves. The compressional-mode interface wave propagating along a fracture was observed in a fracture in limestone. This compressional-mode interface wave is localized to the region surrounding the fracture and has particle motions containing both transverse and longitudinal displacements. As stress across the fracture increases, the wave energy shifts to higher frequencies and to earlier arrival times and is accompanied by a decrease in the transverse displacement and an increase in the longitudinal displacement of the particle motion.

Previously, interface waves were generated by straddling the fracture with seismic transducers. The ability to generate interface waves for off-fracture placement of the source was confirmed through measurements of particle motion of the interface waves and the behavior of the waves under stress. For off-fracture generation, interface waves were only observed when the shear wave was incident at or greater than the critical angle for shear-wave to compressional-wave conversion. 
GRANTEE:

GRANT:

TITLE:

PERSONS IN CHARGE:
UNIVERSITY OF OKLAHOMA

School of Geology and Geophysics

Norman, Oklahoma 73019
DE-FG05-913414209

A Study of Hydrocarbon Migration Events: Development and Application of New Methods for Constraining the Time of Migration and an Assessment of Rock-Fluid Interactions

\author{
R. D. Elmore (405-325-3253; Fax 405-325-3140; E-mail \\ delmore@uoknor.edu) and M. H. Engel
}

Objectives: The objective of the research is to test and refine a paleomagnetic method for dating hydrocarbon migration and maturation of organic matter. The specific objectives include field tests of the dating method and laboratory simulation experiments to better constrain the mechanisms for the precipitation of authigenic magnetite under a variety of geologic conditions.

Project Description: Investigations of fluid migration are commonly hindered by a lack of temporal control. There is little doubt that the ability to constrain the time of oil migration would be of significant benefit for exploration. The paleomagnetic dating method is based on a genetic connection between hydrocarbons/organic matter and precipitation of authigenic magnetite. Isolation of the magnetization carried by the magnetite and comparison of the corresponding pole position to the apparent polar wander path allow the timing of diagenetic events to be determined. The research involves paleomagnetic field tests of the method and laboratory simulation studies to constrain appropriate chemical and physical conditions for magnetite authigenesis.

Results: Field and laboratory studies completed this past year provide further evidence for chemical remanent magnetizations (CRMs) in sedimentary rocks that resulted from fluid migration and from maturation of organic-rich sediments. For example, paleomagnetic and rock magnetic analyses of bitumen-impregnated limestones from the Kimmeridgian-Portlandian
Asphaltkalk deposits of the Hils Syncline near Holzen (northern Germany) contain a late Cretaceous/early Tertiary age CRM that resides in magnetite. A paleomagnetic fold test indicates that the CRM was acquired after folding. The stable CRM was not observed in nonbitumen-impregnated limestones from the same localities, indicating a connection between hydrocarbon migration and the precipitation of authigenic magnetite. The age of the CRM is consistent with that suggested for petroleum generation (late Cretaceous) in this region. A second case study consisted of Mississippian age limestones in southern Indiana that contain hydrocarbons seeping from large stylolites. The stylolites are conduits for hydrocarbon migration. The limestones contain a modern magnetization and a southeasterly and shallow Late Paleozoic CRM, both residing in magnetite. Magnetic intensity of the modern component decreases away from the stylolites and is interpreted to result from recent hydrocarbon migration. The occurrence and intensity of the Late Paleozoic CRM are independent of the stylolites. Finally, we have completed a study of organic-rich, Jurassic age limestones (Blue Lias) that occur in a fault zone along the southern margin of the Bristol Channel Basin at Kilve, West Somerset, England. The Bristol Channel Basin is one of several fault-bounded sedimentary basins in the Celtic Sea/Irish Sea region in which the timing of deformation, maturation of organic matter, and hydrocarbon migration is uncertain. Deformation at Kilve consists of numerous normal faults 
and associated folds. Fluid flow within the fault zone is indicated by widespread calcite veining associated with the faults. The veins contain hydrocarbons. The veins and limestones both contain a northerly and down component that resides in magnetite. This magnetization is a CRM that was acquired when the vein calcite precipitated. A revised pole position suggests remanence acquisition in the late Cretaceous/early Tertiary. Fold tests on several folds associated with the faults suggest the presence of a pervasive CRM in the limestones that is synfolding. The timing of alteration in the limestones, however, is difficult to determine because of rotations on the faults and the problem with determining paleohorizontal. Preliminary analyses of the same limestones on the northern margin of the Bristol Channel Basin near Penarth (Wales) indicate the presence of hydrocarbons and a magnetization (CRM) similar to that in the rocks on the southern margin of the basin.

This past year our test for a relationship between maturation of organic matter and magnetite authigenesis focused on limestones adjacent to a dike on the Isle of Skye, Scotland. Paleomagnetic results indicate a southerly and negative magnetization in a 0.9 -meter-thick Tertiary dike and in the organic-rich limestones within a meter of the dike. With increasing distance from the dike, the limestone does not contain a stable magnetization. The dike emplacement has clearly caused a magnetization in the surrounding limestone. Immediately adjacent to the dike, the magnetization has high maximum unblocking temperatures and is thermochemical in origin. These unblocking temperatures decrease to approximately $300^{\circ} \mathrm{C}$ at $110 \mathrm{~cm}$. Magnetic susceptibility and NRM intensities are higher around the dike compared to background levels away from the dike. This suggests the addition of magnetite, perhaps by chemical processes. The magnetic susceptibility decreases to background levels within the first $20 \mathrm{~cm}$ away from the dike but then increases near $25 \mathrm{~cm}$ and stays above background out to $110 \mathrm{~cm}$. Interestingly, it has been reported (Bishop and Abbot, 1993, Geochim. Cosmochim. Acta 57, 3661-3668) that the oil generation window begins at a distance of about $25 \mathrm{~cm}$ from the dike. These preliminary results suggest a possible connection between the magnetization and the maturation of hydrocarbons adjacent to the dike. We are currently performing rock magnetic measurements and conducting petrographic studies to determine whether a CRM is present in the $25-110 \mathrm{~cm}$ interval. 
GRANTIEE:

GRANT:

TITLE:

PERSON IN CHARGE:
OREGON STATE UNIVERSITY

College of Oceanic and Atmospheric Sciences

Ocean Administration Building 104

Corvallis, Oregon 97331

DE-FG03-96ER14595

Multi-Station Magnetotellurics

Gary D. Egbert (503-737-2947; Fax 503-737-2064; E-mail

egbert@oce. orst.edu)
Objectives: The principal objective of this project is to develop and test new methods for collecting and processing remote reference magnetotelluric data in areas with significant cultural noise, with special emphasis on the "dead band" (approximately $0.1-10.0 \mathrm{~Hz}$ ) where signal levels are low and noise levels are high.

Project Description: The project has three aspects: (1) In the first year, data were collected in a series of three station MT arrays that span conditions from very noisy (just south of San Jose, CA) to very remote sites. Our emphasis was on collecting a large volume of dead band data at a small number of sites. Multiple remote sites at varying distances and in various combinations of noisy and quiet were included to allow us to characterize spatial and temporal properties of signal and noise and to test different approaches to remote reference data acquisition. (2) New approaches to remote reference data processing are being developed. We are adapting multivariate and robust statistical methods to the special problems of MT data processing in the dead band. (3) Using the multistation MT (MSMT) data from our experiment and other compilations of remote reference MT data, we are testing and comparing various strategies for collecting and processing remote reference MT data.
Results: Efforts over the past year have focused on making the multiple station processing program (MULTMT) useful for routine MT data processing. Initial documentation for MULTMT has been prepared, the user interface has been improved, and formats of output files have been standardized so that commonly available plotting packages can be used for displaying results. A preliminary set of programs and documentation has been made available to interested MT researchers via MTNet (http://www.cg.NRCan.gc.ca/mtnet/ mtnet.html). A manuscript describing the new processing methods has been submitted for publication.

We are also continuing efforts to test and further develop multiple station processing methods. Efforts in this direction have included collaborative work with H.F. Morrison and students at U.C. Berkeley, applying multivariate processing methods to data from two experiments: a natural source induced polarization (IP) array experiment conducted at Battle Mt., Nevada, and an ongoing electromagnetic earthquake precursor monitoring experiment being conducted at two sites on the San Andreas Fault in California. We are also extending previously developed methods, in particular focusing on improving error estimates and on more rigorous statistical tests for the presence of coherent noise in MT array data. 
GRANTEE:

GRANT:

TITLE:

PERSONS IN CHARGE:
PENNSYLVANIA STATE UNIVERSITY

College of Earth and Mineral Sciences

University Park, Pennsylvania 16802
DE-FG02-95ER14547

\section{Dissolution Rates and Surface Chemistry of Feldspar Glass and Crystal}

\author{
Susan L. Brantley (814-863-1739; Fax 814-863-7823; E-mail \\ brantley @essc.psu.edu) and Carlo G. Pantano (814-863-2071; \\ Fax 814-865-0016; E-mail pantano@ems.psu.edu)
}

Objectives: This project aims to develop dissolution/surface hydration models for feldspar that can be used to relate laboratory data to geoenvironmental field systems.

Project Description: The key issue in relating experimental feldspar dissolution rates to dissolution of feldspar in soils, aquifers, and watersheds concerns the nature of the surface. In this program, the flow conditions, form of the feldspar, and solution composition in laboratory experiments are being varied and correlated with direct measurement of the dissolution rate and the surface layer characteristics. These relationships will provide a road map that can be used to evaluate the more complex dissolution behavior of minerals in the natural environment. The hypothesis is that the surface is the link. This requires the ability to characterize surfaces of naturally weathered minerals with a precision and reliability that can be used to back-calculate how those surfaces formed. Thus, the laboratory samples include glassy and crystalline feldspars in both granular and bulk forms. The dissolution rates are measured in static and in flow at neutral to basic $\mathrm{pH}$ as a function of dissolved aluminum. The surface analytical methods rely on XPS and depth-profiling methods that can be applied to both laboratory and natural specimens. The ability to distinguish leaching and surface adsorption/precipitation is critical. These findings will provide the basis for interpretation of the surface analyses of natural feldspars so that the factors controlling dissolution in the field can be determined.
Results: In the first year of the project, the following tasks were completed: design of the flow-through dissolution experiments, establishment of a protocol for surface analysis of feldspars, and initial comparison of natural and laboratory-dissolved feldspars.

The completed static experiments were designed to investigate dissolution of feldspar under conditions of near neutral $\mathrm{pH}$ and close to equilibrium. These experiments were run at $\mathrm{pH} 7.3$ to 8.3 with albite and potassium feldspar. The crystals were allowed to dissolve for up to 2200 hours. After 1700 hours of dissolution, a few samples were removed and were analyzed using X-ray photoelectron spectroscopy to determine $\mathrm{Al} / \mathrm{Si}$ and $\mathrm{Na} / \mathrm{Si}$ ratios of the surface layers. For all experiments, solution chemistry gave no indication of ongoing dissolution (the rate was too small to be measured because of the small surface area/water volume ratio of the experiment). In addition, no evidence for dissolution was observed under SEM; however, XPS analysis of the investigated surfaces showed a clear change in the $\mathrm{Na} / \mathrm{Si}$ and $\mathrm{Al} / \mathrm{Si}$ surface ratios. The observed decrease in the $\mathrm{Na} / \mathrm{Si}$ ratio of the surface may be related to either $\mathrm{Na}$ leaching or to Si precipitation on the albite surface. Similarly, the decrease in $\mathrm{Al} / \mathrm{Si}$ ratio of the near equilibrium experiment could be related to either aluminum leaching or Si precipitation. Because the atomic percent $\mathrm{Si}$ in the sample dissolved in solution with $37.1 \mathrm{ppm}$ Si was increased above that of the unleached starting crystal, the preliminary conclusion is that a $\mathrm{Si}$ back-reaction has occurred. Such a back-reaction may 
explain the observed decrease in $\mathrm{Al} / \mathrm{Si}$ ratio; however, some $\mathrm{Al}$ and $\mathrm{Na}$ leaching must also have occurred to explain the observed ratios.

In contrast, polished samples of Quebec albite that were buried $15 \mathrm{~cm}$ deep in a Pennsylvania soil show an opposite trend: increasing Al/Si ratio. An increasing $\mathrm{Al} / \mathrm{Si}$ ratio was also found on the Norwegian moraine feldspar samples. It appears that natural samples mani- fest either (1) increased Al surface content or (2) decreased Si content. XPS analysis of Cape Cod feldspars shows a similarly high $\mathrm{Al} / \mathrm{Si}$ ratio on the surface. Further investigation of this consistent discrepancy between naturally dissolved feldspars (high $\mathrm{Al} / \mathrm{Si}$ surface ratio) and laboratory-dissolved feldspars (low $\mathrm{Al} / \mathrm{Si}$ surface ratio) is necessary in order to better understand controls on natural feldspar weathering. 
GRANTEE:

GRANT:

TITLE:

PERSONS IN CHARGE:
PENNSYLVANIA STATE UNIVERSITY

Ore Deposits Research Section

University Park, Pennsylvania 16802

DE-FG02-96ER14634

\section{Zeolite Thermodynamics and Kinetics}

H. L. Barnes (814-865-7573; Fax 814-863-2001; E-mail

barnes@geosc.psu.edu) and Rick T. Wilkin (814-865-3565; Fax

814-863-2001; E-mail rwilkin@ geosc.psu.edu)

Objectives: The goal of this project is to obtain data from hydrothermal experiments pertaining to the basic thermochemical properties and kinetic factors that govern dissolution and crystallization of zeolite phases, especially clinoptilolite, mordenite, and analcime. These data are needed to understand chemical and physical processes that occur in shallow crustal environments during the low-grade metamorphism of volcanic and sedimentary rocks.

Project Description: The project includes both closed- and open-system experimental investigations on high-purity natural zeolites. Closed-system experiments involve measuring zeolite solubilities at temperatures to about $300^{\circ} \mathrm{C}$ and pressures to about $0.20 \mathrm{kbar}$. Reversible solubility measurements are made on analcime and cation-exchanged varieties of clinoptilolite and mordenite so that thermodynamic data are acquired for $\mathrm{Na}-, \mathrm{K}-\mathrm{Ca}$-, and $\mathrm{Mg}$-end-member compositions with a fixed water content and Si/Al ratio. The solubil- ity measurements provide a basis for relating measurements of dissolution and precipitation reaction rates to measured or specified departures from metastable equilibrium conditions. Kinetics of congruent zeolite-water reactions are tracked using a hydrothermal flow-through system. The flow-through system is advantageous because reaction rates can be measured under conditions of fixed fluid composition, flow rate, temperature, and pressure. In addition to providing basic thermodynamic and kinetic parameters, the experimental data permit kinetic evaluations of zeolite transformations, for example, clinoptilolite-analcimealbite. Although the mechanisms of zeolite transformations remain equivocal, such reaction paths define the transition from zeolite to greenschist metamorphic regimes and are characterized by the release of water and silica and large, negative molar volume changes.

Results: This project has only recently been initiated. 
GRANTEE:

GRANT:

TITLE:

PERSON IN CHARGE:
PRINCETON UNIVERSITY

Department of Geological and Geophysical Sciences

Princeton, New Jersey 08544

DE-FG02-85ER13437

Thermodynamics of Minerals Stable Near the Earth's Surface

A. Navrotsky (609-258-4674; Fax 609-258-1274; E-mail

alex@geo.princeton.edu)
Objectives: The goals of the project are to increase both the data base and the fundamental understanding of the thermodynamics of volatile-bearing mineral phases (arnphiboles, micas, clays, zeolites, carbonates) important to surficial, sedimentary, and shallow crustal processes.

Project Description: Using high temperature solution calorimetry, this research determines the enthalpies of formation of hydrous minerals and carbonates. Systematics in energetics of ionic substitutions are sought in order to predict the thermodynamics of complex multicomponent minerals. Mixing properties of mica, amphibole, clay, zeolite, and carbonate solid solutions are also studied.

Results: Carbonates: Study of a largely disordered series of synthetic ankerites $(\mathrm{Mg}, \mathrm{Fe}) \mathrm{Ca}\left(\mathrm{CO}_{3}\right)_{2}$ and of more ordered natural samples confirm significant differences in enthalpy between the two groups of materials. These are consistent with an enthalpy of disordering of $\mathrm{MgCa}\left(\mathrm{CO}_{3}\right)_{2}$ of $20-25 \mathrm{~kJ} / \mathrm{mol}$ and an enthalpy of disordering of $\mathrm{FeCa}\left(\mathrm{CO}_{3}\right)_{2}$ of about $10 \mathrm{~kJ} / \mathrm{mol}$. The rather large enthalpy of disordering of dolomite is supported both by the systematics of solid solution energetics derived by Davies and Navrotsky (1982) and by a calorimetric study of a metastable apparently totally disordered $\mathrm{CaMg}\left(\mathrm{CO}_{3}\right)_{2}$ sample made from aqueous solution. The latter sample is energetically less stable than a mixture of huntite $\mathrm{CaMg}_{3}\left(\mathrm{CO}_{3}\right)_{4}$ and $\mathrm{Ca}$-rich dolomite to which it decomposes on heating. The system $\mathrm{SrCO}_{3}-\mathrm{CaCO}_{3}$ has been studied by calorimetry.

Zeolites: Work on the Ca-zeolites (laumontite, leonhardite, yugawaralite, warakite) and their ion-exchanged forms has been published. The energetics of ion exchange and hydration in other zeolites, including chabazites, is under investigation. The energetics of the $\mathrm{Si}=\mathrm{Al}+\mathrm{Na}$ substitution is similar in faujasites and aluminosilicate glasses.

Clays: A calorimetric study of kaolinite, dickite, smectites, and illites has commenced. 
GRANTEE:

GRANT:

TITLE:

PERSON IN CHARGE:
PURDUE UNIVERSITY

Department of Earth and Atmospheric Sciences

West Lafayette, Indiana 47907

DE-FG02-93ER14365

Rupturing and Ground Deformation During the 28 June 1992 Landers, California, Earthquake

Arvid M. Johnson (317-494-3259; E-mail

gotesson@omni.cc.purdue.edu)

Objectives: This project has the overall objective of understanding the form and significance of surface rupture produced by earthquake sequences. Specific objectives are to describe fracturing, strains, and other manifestations of broad belts of ground rupture during earthquake sequences (Loma Prieta, Landers, and Northridge); to mechanically analyze those structures, where appropriate; and to relate the observations and analyses to earthquake processes. The specific project funded here is our research on the Landers earthquake.

Project Description: Our project has been to document, via detailed maps, the ground rupture and deformation in earthquake areas and to relate them to the broader processes of earthquake sequences. At Landers in 1992-1994, we mapped about $10 \mathrm{~km}$ of rupture zones along three faults at scales of 1:400 or more detailed, including rupture belts associated with growth of a tectonic ridge, Tortoise Hill ridge, along the Emerson fault zone and rupture belts along the Kickapoo and Homestead Valley fault zones. In 1995 we used photogrammetry, precision land surveying, and leveling to determine deformations at different scales in the vicinity of the rupture zones and across the tectonic ridge. We resurveyed a network of 46 benchmarks of horizontal control points established during the 1970s by Southern California Edison that extended across the Emerson fault zone. The network includes a grid of benchmarks set every $1 / 4$ mile and is supplemented by 30 wing points set for elevation control. We also used photogrammetry to survey a ladder of quadrilaterals across Tortoise Hill ridge. The surveys show, for the first time, details of the determination of horizontal strains and differential vertical displacements over a broad area across a fault zone and within the fault zone and included a growing ridge.

In the 1994 Northridge earthquake sequence, we were presented with a different opportunity to study ground deformation during an earthquake. Since the Northridge earthquake sequence occurred in a highlydeveloped metropolitan area, land survey data and therefore detailed deformation data are available that do not exist in the more rural settings in 1989 at Loma Prieta and in 1992 at Landers. In 1995 and 1996, we have been analyzing hundreds of City of Los Angeles survey records on relative positions of street-intersection monuments in parts of the San Fernando Valley so that we could describe the strains and identify areas or belts of elevated strains. We have been relating the survey data to damage to streets, sidewalks, sewers, and houses.

Results: Our results have been more exciting than we could have predicted. Our mapping and analysis of ground rupture in the epicentral area of the Loma Prieta earthquake sequence and our analysis of strains and changes in uplift of ground at Northridge have together documented, for the first time, that many faults or shear zones with different kinematic signatures move coactively with the fault responsible for the main shock during an earthquake sequence and cause much of the damage to man-made structures during an earthquake. At Landers we have rediscovered a phenomenon ap- 
parently described earlier only by G.K. Gilbert in the 1906 earthquake, that intense ground rupture along the main earthquake-fault that intersects the ground surface occurs across a broad zone, 50 to $200 \mathrm{~m}$ wide. Any structures within this zone can be severely damaged. At Landers we have documented, for the first time, actual growth of a tectonic ridge. Although such growth was suspected based on previous studies, nobody had observed it. Our detailed surveys at Landers documented growth of a ridge by one meter as the fault zone slipped three meters. Furthermore, we obtained new insight into the origin of ridges along strike-slip fault zones. Tortoise Hill ridge is along a relatively straight segment of the Emerson fault zone, so it cannot be a result of a left-step or bend on a right-lateral fault zone (or vice versa), which is the current explanation for such phenomena. We suggest that Tortoise Hill ridge, like analogous ridges that occur in landslides, grew as a result of localized dilation of material within a belt of shear zones along the Emerson fault zone.
We suspect that many earthquakes occur because the seismogenic structure, within which the main shock occurs, is growing rapidly, as happened for example for the anticline at Kettleman Hills. The most far-reaching result of our research is that, at Northridge, we have identified a specific seismogenic structure; it is a heart structure, consisting of a basin and a high on either side. The highs are the Santa Monica Mountains on one side and the Santa Susana Mountains on the other, and the basin is the San Fernando Valley. Movement along a limb of the dish fault responsible for the heart structure produced the main shock and coactive movement along many smaller faults within this structure and was apparently responsible for much of the damage during the Northridge earthquake sequence.

This year we have written drafts of two papers on Tortoise Hill ridge and two on coactive faults at Northridge, which are in review as U.S. Geological Survey open-file reports. We will publish shorter versions in referred journals. 
GRANTEE:

GRANT:

TITLE:

PERSON IN CHARGE:
RENSSELAER POLYTECHNIC INSTITUTE

Department of Earth and Environmental Sciences

Troy, New York 12180-3590

DE-FG02-95ER144532

Transport Phenomena in Fluid-Bearing Rocks

E. B. Watson (518-276 8838; Fax 518-276-8627;

E-mailwatsoe@ @rpi.edu)

Objectives: The objective of this project is to shed light on chemical transport in the Earth through (1) development and implementation of a technique for measuring mineral solubilities and diffusivities of dissolved mineral components in aqueous fluids at extreme P-T conditions (up to $3 \mathrm{GPa}$ and $1200^{\circ} \mathrm{C}$ ) and (2) characterization of the grain-scale permeability of fluid-bearing rocks under conditions of chemical and mechanical equilibrium.

Project Description: Deep in the Earth, fluid-assisted geochemical transport is controlled mainly by: 1) the solubilities of rock components in the fluid of interest, 2) diffusion characteristics of the dissolved solutes, and 3) the permeability of the rock to fluid flow. (Under circumstances where $P_{\text {fluid }}>>P_{\text {total }}$ and an open fracture system is not sustainable, the permeability of interest is that dictated by the equilibrium microstructure of the rock.) All three of these properties are poorly constrained. Solubility data are scarce at pressures in excess of $1 \mathrm{GPa}$, and information concerning solute diffusion and rock permeability is virtually nonexistent. The Rensselaer project involves the development and implementation of techniques to characterize these key properties.

The principal methodology for the solubility and diffusion measurements is experimentation at high pressures $(0.5-3.0 \mathrm{GPa})$ and temperatures $\left(500^{\circ}-900^{\circ} \mathrm{C}\right)$ in a conventional solid-media, piston-cylinder apparatus, using noble-metal capsules (or cells) developed for the purpose. In the permeability study, the piston-cylinder apparatus is used to fabricate metal-jacketed "rock" samples exhibiting near-equilibrium microstructure in the presence of aqueous fluid. After recovery from the piston-cylinder apparatus, the samples are mounted for permeability characterization at room conditions using conventional gas-flow techniques.

Results: During the past year, the investigation of silica solubility and diffusion in $\mathrm{H}_{2} \mathrm{O}$ at $0.5-1.5 \mathrm{GPa}$ and $530^{\circ}-880^{\circ} \mathrm{C}$ was brought to completion. At $1.0 \mathrm{GPa}$, the diffusivity is given (in $\mathrm{m}^{2} / \mathrm{s}$ ) by

$$
D_{\mathrm{SiO}_{2}}=\left(4.58 \times 10^{-5}\right) \exp (-6684 / \mathrm{T})
$$

corresponding to an activation energy of $55.6 \mathrm{~kJ} / \mathrm{mole}$. This equation is consistent with diffusion behavior predicted on the basis of the Stokes-Einstein equation, which relates the diffusivity to the size of the diffusant and the viscosity of the diffusion medium. Interestingly, the equation above specifies aqueous $\mathrm{SiO}_{2}$ diffusivities that approach the rate of heat transport in rocks, suggesting that diffusion in fluid-bearing rocks is a highly effective means of geochemical transport even in the absence of fluid advection.

Several additional findings resulted from completion of this part of the project: (1) the solubility data for $\mathrm{SiO}_{2}$ in $\mathrm{H}_{2} \mathrm{O}$ obtained in the present study are in substantial agreement with previously-published values, (2) the effect of pressure on diffusion of aqueous $\mathrm{SiO}_{2}$ is relatively small in the $0.5-1.5 \mathrm{GPa}$ range, with $\mathrm{D}_{\mathrm{SiO} 2}$ decreasing by no more than $0.5 \log$ units over a 1-GPa increase in pressure, and (3) Soret (thermal diffusion) effects are immeasurably small in silica-saturated $\mathrm{H}_{2} \mathrm{O}$ at $1 \mathrm{GPa}$ with a temperature gradient of $\sim 10 \% \mathrm{~mm}$. 
An investigation of the solubility of $\mathrm{CaF}_{2}$ in water at $1 \mathrm{GPa}$ and $500^{\circ}-900^{\circ} \mathrm{C}$ was undertaken during the past year as a prelude to diffusion experiments like those completed for $\mathrm{SiO}_{2}$. The goal is to see whether diffusion in $\mathrm{H}_{2} \mathrm{O}$ of simple ions like $\mathrm{Ca}^{2+}$ and $\mathrm{F}^{-}$is still faster than $\mathrm{SiO}_{2}$, which presumably diffuses as a relatively large anionic complex $\left(\mathrm{Si}[\mathrm{OH}]_{4}\right)$. Exploratory runs involving solubility and transport of $\mathrm{TiO}_{2}, \mathrm{ZrSiO}_{4}$, clinopyroxene, and basaltic glass components were also made.

The grain-scale permeability side of the project was initiated by synthesis (at $1 \mathrm{GPa}$ and $850^{\circ} \mathrm{C}$ ) of a series of porous $\mathrm{CaCO}_{3}$ rocks (i.e., marbles) characterized by near-equilibrium microstructure and a grain size of
$100+$ microns. Water present during the syntheses resulted in interconnected, fluid-filled porosities $(\phi)$ ranging from $\sim 1 \%$ to $13 \%$. The Ni-jacketed cylindrical samples were recovered from the high-pressure apparatus and sawn open at both ends, allowing their permeabilities to be characterized by the transient-pulse, gas-flow technique. The resulting permeabilities vary in proportion to $\phi^{3}$.

A series of porous synthetic quartzites has also been synthesized; in these samples, the fluid geometry is characterized by a lower dihedral angle than that for the $\mathrm{CaCO}_{3}$ system. Porosity measurements on these samples are in progress. 


\section{GRANTEE:}

GRANT:

TITLE:

\section{RICE UNIVERSITY}

Geology and Geophysics

Houston, Texas 77251-1892
PERSON IN CHARGE:

Objectives: It is proposed that the light hydrocarbons in petroleum, including natural gas, are formed catalytically through the condensation of $n$-alkenes and hydrogen in fine-grained carbonaceous sedimentary rocks. The transition metals are suggested as the catalytic agents. The objective of this research is to test this hypothesis and to explore the catalytic properties of transition metals under realistic geologic conditions.

Project Description: Various natural sources of transition metals, including the asphaltene fraction of petroleum and source rocks, are being analyzed for catalytic activity. Pure transition metal complexes (metal porphyrins, acetylacetonates, oxides, and sulfides) are also under study. Reactions are being conducted in gas manifold systems under steady-state and batch reactor conditions and products analyzed by high-resolution gas chromatography.

Results: Petroleum source rocks are catalytic in the conversion of hydrogen and olefins into natural gas, marking the first time that natural gas has been generated in the laboratory under mild conditions (Mango et al., Nature, 368, 535, 1994). The evidence supports transition metals as the active agents (Mango, Ad. Org. Geochem., in review). Various metal compounds in the pure state show the same levels of catalytic activity as sedimentary rocks, and the products are identical. The metal oxides (V, $\mathrm{Co}, \mathrm{Fe}$, and $\mathrm{Ni})$ are particularly active and remarkably robust. Activity is unaffected by typical poisons, like air, water, $\mathrm{CO}$, or $\mathrm{CO}_{2}$, and kinetic studies suggest high levels of catalytic activity at all stages of catagenesis. Nickel oxide promotes the formation of $\mathrm{n}$-alkanes in addition to natural gas (NG), demonstrating the full range of the hypothetical catalytic process:

$$
\begin{aligned}
& \text { [NiO*] } \\
& \mathrm{n}-\mathrm{C}_{\mathrm{x}}=+\mathrm{H}_{2} \rightarrow \mathrm{NG}+\mathrm{n}-\mathrm{C}_{5}+\mathrm{n}-\mathrm{C}_{6}+\ldots \mathrm{n}-\mathrm{C}_{\mathrm{x}-1}
\end{aligned}
$$

The cyclohexanes and cyclopentanes are a challenge in any theory on the origin of light hydrocarbons. They are major components of oil, yet their origin has remained obscure. Unlike the higher polycyclic biomarkers, they are without biological parents and it is unlikely they could be degradation products. It was suggested that they might be catalytic products, formed from kerogen-derived dienes (Mango, Geochim. Cosmochim. Acta., 56, 553, 1992). Our results with $\mathrm{NiO}$ support this view. Under the same conditions giving natural gas, $\mathrm{NiO}$ promotes the cyclization of dienes to cyclohexanes and cyclopentanes. For example, 1,6 heptadiene gives methylcyclohexane and the various isomers of dimethylcyclopentane seen in petroleum:

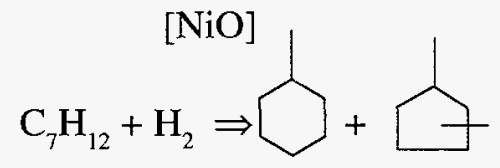

We have now demonstrated the primary tenets of the original hypothesis, namely that the light hydrocarbons in petroleum - n-alkanes, iso-alkanes, cycloalkanes, and natural gas - can be formed through the catalytic action of transition metals in sedimentary rocks. These results support the view that transition 
metal catalysis is probably a major pathway through which oil and gas is formed in the earth. This catalytic process is, to our knowledge, largely unprecedented, and attention is now directed to its scope and mechanistic details. 
GRANTEE:

GRANT:

TITLE:

PERSONS IN CHARGE:
STANFORD UNIVERSITY

Department of Geological and Environmental Sciences

Stanford, California 94305-2115

\section{Cation Chemisorption at Oxide Surfaces and Oxide-Water Interfaces: X-Ray Spectroscopic Studies and Modeling}

Gordon E. Brown, Jr., and George A. Parks (415-723-9168;

Fax 415-725-0979; E-mail gordon@ pangea.stanford. edu)
Objectives: This project concerns chemical interactions between metal ions in aqueous solution and oxide surfaces representative of those found in the Earth's crust. These "sorption" reactions partition the metal between fluid and solid phases and must be understood at a molecular level to develop quantitative geochemical understanding of mineral surfaces and the macroscopic models required to predict the fate of contaminants in the environment. Our objectives are to (1) characterize sorption reactions by determining composition, molecular-scale structure, and bonding of the surface complexes produced using direct sorption measurements and synchrotron-based X-ray absorption fine structure (XAFS), X-ray photoelectron (XPS), and UV/ Vis/IR spectroscopies, (2) investigate how these properties are affected by the solid surface and aqueous phase composition, and (3) develop molecular-level and macroscopic models of sorption processes.

Project Description and Results: (1) GrazingIncidence XAFS Studies of $\mathrm{Co}(I I)$ and $\mathrm{Pb}(I I)$ Sorption Complexes on Single Crystal $\alpha-\mathrm{Al}_{2} \mathrm{O}_{3}$ : Using an apparatus we developed for fluorescence XAFS of adsorbates on wet single crystal surfaces in grazing-incidence geometry, we examined sorption complexes of $\mathrm{Co}$ (II) and $\mathrm{Pb}$ (II) on $\alpha-\mathrm{Al}_{2} \mathrm{O}_{3}(0001)$ and (1-102) surfaces and of $\mathrm{Co}$ (II) on $\mathrm{TiO}_{2}$ (rutile) (110) and (001) surfaces. As an example of our results, we found that $\mathrm{Pb}$ (II) forms outer-sphere (OS) complexes on $\alpha-\mathrm{Al}_{2} \mathrm{O}_{3}(0001)$ but inner-sphere (IS) complexes on $\alpha-\mathrm{Al}_{2} \mathrm{O}_{3}$ (1-102). In contrast, $\mathrm{Co}$ (II) forms about equal concentrations of IS complexes on both surfaces of $\alpha-\mathrm{Al}_{2} \mathrm{O}_{3}$, adsorbing dominantly to tridentate sites on the (0001) surface and dominantly to tetradentate sites on the (1-102) surface. These differences are explained using a bond-valence model that accounts for structural differences on the alumina surfaces and differences in coordination chemistry of $\mathrm{Co}$ (II) and $\mathrm{Pb}$ (II) in solution. These results provide the first direct structural evidence that different surfaces of an oxide can adsorb cations in different modes.

(2) Fluorescence-yield XAFS Studies of Pb(II) and $\mathrm{Co}$ (II) Sorption Complexes on Powdered $\alpha-\mathrm{Al}_{2} \mathrm{O}_{3}$ and Iron Oxides: We have used XAFS to study $\mathrm{Co}$ (II) and $\mathrm{Pb}$ (II) sorbed onto high surface area $\alpha-\mathrm{Al}_{2} \mathrm{O}_{3}$ and iron oxides. On $\alpha-\mathrm{Al}_{2} \mathrm{O}_{3}, \mathrm{~Pb}$ (II) sorbs preferentially to edges of $\mathrm{Al}(\mathrm{O}, \mathrm{OH})_{6}$ octahedra as mononuclear bidentate IS complexes at pH 6-7 and sorption densities $(\Gamma)$ of 0.5 to $5.2 \mu \mathrm{moles} / \mathrm{m}^{2}$. Pb(II) sorbs on goethite and hematite as mononuclear bidentate complexes to edges of $\mathrm{FeO}_{6}$ octahedra. Our bond-valence model and XAFS results suggest that $\mathrm{Pb}$ (II) sorbs primarily at unprotonated surface sites. Hydrolysis of $\mathrm{Pb}$ (II) appears to be the primary source of proton release during $\mathrm{Pb}$ (II) sorption. Absence of dimeric $\mathrm{Pb}$ (II) complexes on iron oxides and their presence on $\alpha-\mathrm{Al}_{2} \mathrm{O}_{3}$ may be related to differences in $\mathrm{Al}(\mathrm{O}, \mathrm{OH})_{6}$ and $\mathrm{FeO}_{6}$ octahedral edgelengths and bond-valence sums at the surface oxygens to which $\mathrm{Pb}$ (II) bonds. XAFS study of aqueous $\mathrm{Co}$ (II) sorption on alumina powders $(\mathrm{pH} 8, \Gamma=0.28-23$. $1 \mu \mathrm{moles} / \mathrm{m}^{2} ;[\mathrm{Co}]_{\mathrm{T}}=100 \mu \mathrm{M}-12.6 \mathrm{mM}$ ) provides strong evidence for a new type of mixed $\mathrm{Co}-\mathrm{Al}$ hydroxide precipitate at Co $\Gamma \geq 3 \mu$ moles $/ \mathrm{m}^{2}$. Under these 
solution conditions, the Co concentration is below the solubility of solid $\mathrm{Co}(\mathrm{OH})_{2}$. The co-precipitates are less soluble than either $\mathrm{Al}(\mathrm{OH})_{3}$ or $\mathrm{Co}(\mathrm{OH})_{2}$ and apparently form when $\mathrm{Al}$ dissolves from $\mathrm{Al}_{2} \mathrm{O}_{3}$.

(3) Copper(II) and 2,2'-bipyridine Co-adsorption on Oxide Surfaces: We have used XAFS and other methods to determine how 2,2'-bipyridine (bipy) influences sorption of $\mathrm{Cu}(\mathrm{II})$ on amorphous $\mathrm{SiO}_{2}$ and $\gamma-\mathrm{Al}_{2} \mathrm{O}_{3}$. Cu sorbs as IS complexes on both oxides. Complexes are multinuclear, possibly dimeric, and monodentate on am- $\mathrm{SiO}_{2}$ but monomeric and probably monodentate on alumina. Under the conditions studied, bipy inhibits $\mathrm{Cu}(\mathrm{II})$ sorption on $\gamma-\mathrm{Al}_{2} \mathrm{O}_{3}$. On am- $\mathrm{SiO}_{2}$, bipy enhances $\mathrm{Cu}(\mathrm{II})$ sorption when $\Gamma \leq 0.05 \mu \mathrm{M} / \mathrm{m}^{2}$, but inhibits sorption when $\Gamma \geq 0.7 \mu \mathrm{M} / \mathrm{m}^{2}$. With solution Cu:bipy of $1: 2$, Cu:bipy in the sorption complex was $1: 1$ on $\gamma-\mathrm{Al}_{2} \mathrm{O}_{3}$ but $1: 2$ on am- $\mathrm{SiO}_{2}$, indicating that one bipy dissociates from the complex during sorption on $\gamma-\mathrm{Al}_{2} \mathrm{O}_{3}$. FTIR showed that all sorbed bipy was bound to $\mathrm{Cu}$ on both solids. Comparison of EXAFS and XANES spectra of the $\mathrm{Cu} /$ bipy $_{2} / \gamma-\mathrm{Al}_{2} \mathrm{O}_{3}$ sample with spectra from the $\mathrm{Cu}$ (bipy), and $\mathrm{Cu}$ (bipy), solutions indicates that the surface species on $\gamma-\mathrm{Al}_{2} \mathrm{O}_{3}$ is predominantly $\mathrm{Cu}(\text { bipy) })_{1}$, in agreement with the Cu:bipy ratio derived from uptake data. XAFS analysis suggests IS binding of $\mathrm{Cu}$. Comparison of the EXAFS of $\mathrm{Cu}(\mathrm{II}) / \mathrm{bipy}_{2} / \mathrm{am}-\mathrm{SiO}_{2}$ with those of crystalline $\mathrm{Cu}$ (bipy) ${ }_{2}$ compounds shows that the surface species is $\mathrm{Cu}$ (bipy) ${ }_{2}$.

(4) Macroscopic Sorption Modeling: Using a surface complexation, electrical triple layer sorption model (SCM-TLM) in the speciation codes HYDRAQL and
FITEQL, we have found that the structural and compositional information derived from XAFS constrains the selection of sorption reactions. For sorption of $\mathrm{Co}$ (II) on $\gamma-\mathrm{Al}_{2} \mathrm{O}_{3}$, many sorption reactions are capable of simulating uptake data alone. In this system, as for $\mathrm{Co}(\mathrm{II})$ on $\alpha-\mathrm{Al}_{2} \mathrm{O}_{3}$, XAFS-derived near-neighbor $\mathrm{Co}$ stoichiometry requires multinuclear surface complexes, however, and thus rules out strictly mononuclear models. Our recent observation of mixed $(\mathrm{Co}, \mathrm{Al})$ hydroxide precipitates in undersaturated solutions reinforces assumptions that precipitation is an important sorption reaction. A small set of inner-sphere, bidentate, mononuclear sorption reactions, dimeric and monomeric multinuclear complexes, and $\mathrm{Co}(\mathrm{OH})_{2}$ precipitation approximate uptake and XAFS data well.

(5) Other XAFS Studies of Metal-Ion Sorption Complexes: U(VI) sorbed onto kaolinite was studied using XAFS spectroscopy to develop a molecular-level understanding of sorption of U(VI) by clays in soils and sediments. A parallel XAFS study of $U$ in crystalline solids demonstrated the accuracy of structural information derived from U XAFS, including the second coordination shell around U. Sorption complexes on kaolinite contained the uranyl moiety bonded in IS mode, surrounded by five equatorial oxygens. At $\mathrm{pH}$ 6-7 in air, mononuclear U species dominate. At pH 77.5 in air, small multinuclear $U$ complexes dominate, with numbers of $\mathrm{U}$ atoms similar to those of dominant species in the corresponding aqueous solution. With $\mathrm{CO}_{2}$ absent and $\mathrm{pH} 7-8$, multinuclear complexes also dominate. 
GRANTEE:

GRANT:

TITLE:

PERSONS IN CHARGE:
STANFORD UNIVERSITY

Department of Geological and Environmental Sciences

Stanford, California 94305-2115

\section{Development of Fracture Networks and Clusters: Their Role in Channelized Flow in Reservoirs and Aquifers}

Objectives: The objectives of this project are to describe and document the geometry of opening-mode fracture networks and clusters in sedimentary rock, understand the mechanics of their development in relationship to faults and folds, and develop a sound methodology for prediction of spatial variations of permeability in fractured aquifers and reservoirs using an integrated program of field mapping, laboratory simulation, and theoretical analysis.

Project Description: The principal elements of the project are to (1) investigate the variations in orientation and distribution of fracture sets near normal faults and characterize their geometric and fluid flow properties, (2) investigate the mechanisms of fracture clustering and construct conceptual and mechanical models for the impact of fracture clusters on the development of faults and folds in sedimentary rocks, (3) design and carry out laboratory experiments using a brittle-coating technique to investigate the development of fracture networks in folded layered materials, (4) design and carry out laboratory experiments on three-dimensional fracture propagation in blocks of PMMA under mixed-mode loading to understand the relationships between loading and complex fracture geometries, and (5) develop a computer code for predicting the connectivity and spatial density of fractures in a reservoir or aquifer using wellbore data.
Fracture Clusters in the Perturbed Stress Field Near Normal Faults

Results: Over the past year, we focused on the characterization of joints that form approximately orthogonal to normal faults. Classic Andersonian theory invokes a stress regime that produces joints parallel to the strike of faults; however, this theory fails to incorporate the influence of the fault on the stress field. As a fault grows, the surrounding stress field is perturbed so that joints may form with orientations different from Andersonian predictions.

At Arches National Park, Utah, field evidence, such as joint densities and age relationships, supports the hypothesis that joint growth was driven by the stresses induced by faulting. The joints are nearly perpendicular to the faults and are steeply dipping. The spacing of the joints is on the order of the thickness of the unit in which they are contained (Moab Member of the Entrada Formation), and the joints frequently occur as clusters of several closely-spaced joints.

Using a boundary element method computer program and principles of linear elastic fracture mechanics, the stress perturbation around a normal fault does indeed predict joint growth at high angles to faults in the vicinity of the fault tips, where stress concentrations are highest. Three-dimensional rendering of the stress field provides an informative demonstration of the spatial variation in the stress field and associated joints around normal faults. 
Fault Development from Localized Shearing of Joint Zones

Results: Faults with offsets ranging from $\sim 1 \mathrm{~cm}$ to $\sim 150 \mathrm{~m}$ were mapped in the Valley of Fire State Park, southern Nevada. These maps include the geometric and physical attributes of the associated fractures and provide a large data base for conceptual models of faults and fractures in sandstone and their hydraulic properties. Fracture localization, produced by shearing of preexisting joint zones, results in faults with a highly damaged and fragmented core. The maps enable identification of fragmentation mechanisms and characteristic fracture geometries associated with accumulated slip. Fragmentation occurs at irregularities in the trace of joints subjected to shear, at sheared joint intersections, and in the span between overlapping echelon sheared joint segments.

Two classes of faults produced from sheared joint zones have been identified. One type is associated with right stepping joint zones sheared in a left sense or left stepping joints sheared in a right sense. In these cases fragmentation occurs by failure of intervening rock in compression. The other fault type is associated with right stepping joint zones sheared in a right sense or left stepping joints sheared in a left sense. Fragmentation in these cases is produced by tensile failure of rock spans between sheared joints.

\section{Numerical Modeling of Multilayered Flexures with Fractures}

Results: Two mechanisms that produce joint clusters in folds are bending and bedding plane slip. Therefore, fractures are likely to be associated spatially with regions of greater curvature and with larger slip gradients on bedding plane faults. Bedding planes were mapped through the thickness of the aeolian Navajo Formation of East Kaibab Monocline, Utah, and the occurrence of joints related to bedding plane slip and fold curvature were documented. Slip along bedding planes, as evidenced by joint clusters oblique to bedding, develops in the center of the formation. Joints perpendicular to bedding and parallel to the fold axis form near the synclinal hinge.
Numerical experiments used the boundary element method to examine bending of a layer flexed to match the Navajo Formation at Hackberry Canyon. Both uniform and observed distributions of frictional layers were modeled. The numerical models include inelastic frictional slip and the development of opening-mode fractures from points of stress concentration. Slip along horizontal frictional interfaces develops in the center of the layer and opening-mode fractures related to curvature form within the anticlinal and synclinal hinges of the fold. Thus, the first-order numerical results match field observations.

The same numerical code was used to investigate frictional bedding plane slip in the initial stages of faultrelated folding. Results show how fold shape depends on dip of the underlying fault; asymmetric anticlines are produced under contraction boundary conditions and asymmetric synclines are produced under extension. At depths as shallow as $1 \mathrm{~km}$ there is no significant difference between fold amplitudes in the hanging wall and the footwall. The presence of frictional bedding planes near fault tips encourages development of fault flats from fault ramps.

\section{Fracture Characterization and Prediction from Borehole Data}

Results: A computer code, Pred2/3D, for predicting ("rebuilding") subsurface fracture networks using borehole image data provides $2 \mathrm{D}$ and $3 \mathrm{D}$ relative fracture spatial density, connectivity, and prediction uncertainty maps in the range from tens to hundreds of feet from the wellbore. The underlying physical basis for the prediction comes from laboratory and numerical modeling of the evolution of fracture sets. Reservoir engineers can use the information provided by this computer program to find the best drilling direction, predict the effectiveness of a new well, or assess the future value of an aged well.

The code has been tested using $2 \mathrm{D}$ data from experimentally produced fracture networks in a layered brittle material and 3D data from two Mobil horizontal boreholes, two Arco horizontal boreholes in chalk, one North Sea horizontal borehole in chalk, and some USGS testing wells in the Mirror Lake area of central New Hampshire. 
GRANTEE:

GRANT:

TITLE:

PERSONS IN CHARGE:
STANFORD UNIVERSITY

Department of Geological and Environmental Sciences

Stanford, California 94305-2115

Experimental Investigation of Kinetics and Rheology During Diagenesis

J. G. Liou (415-723-2716; Fax 415-725-2199; E-mail

liou@pangea.stanford.edu) and B. R. Hacker (415-725-0045; Fax

415-725-2199; E-mail hacker@pangea.stanford.edu)

Objectives: Objectives are to determine the dehydration rate of laumontite and its effect on the frictional rheology of laumontite.

Project Description: Two processes of enormous economic consequence occur within the upper to middle crust: (1) the formation, migration, entrapment, and degradation of hydrocarbons and (2) hazardous seismicity. Substantial scientific evidence suggests that both these processes are influenced by devolatilization reactions during diagenesis; however, surprisingly few laboratory studies have been conducted on materials actively undergoing low-grade metamorphism or diagenesis. Because of this, there exists no suitable basis for understanding the rates at which devolatilization occurs and what effects this process has on deformation at shallow to moderate depths in the crust.

We are conducting a coordinated deformation and kinetic study of an important devolatilization reaction, the breakdown of laumontite. Laumontite is a common zeolite whose equilibrium phase relations and room-temperature frictional behavior are well understood. Besides serving as a model system for more complicated rocks, laumontite is an important mineral in its own right, particularly for hydrocarbon fields in sandstones and for fault zones in the crust. Hydrostatic experiments are being conducted to investigate the kinetics and mechanism of laumontite dehydration, and triaxial deformation experiments will enable characterization of the effect of differential stress on the reaction and the effect of synkinematic dehydration on the mechanical behavior of rock. We anticipate results of significant import for hydrocarbon exploration and recovery and for understanding the strength and seismic potential of crustal fault zones.

Results: We have determined the rate and mechanism of the laumontite $Æ$ wairakite $+\mathrm{H}_{2} \mathrm{O}$ reaction in experiments as long as three months at $\mathrm{P}_{\mathrm{H} 2 \mathrm{O}}=100 \mathrm{MPa}$ and temperatures of $350^{\circ}-450^{\circ} \mathrm{C}$. At $350^{\circ}-400^{\circ} \mathrm{C}$, nucleation occurred on the smallest laumontite fragments in the starting material. Growth proceeded by the dissolution of large laumontite grains, transport within the fluid, and reprecipitation of euhedralsubhedral wairakite. At $425^{\circ}$ and $450^{\circ} \mathrm{C}$, each sample contains two product phases, wairakite and an unidentified plagioclase-like phase. The plagioclase-like silicate is stabilized by the uptake of $\mathrm{Na}$ and formed early as $\sim 10 \mu \mathrm{m}$-wide skeletal grains along laumontite grain boundaries. The wairakite grains subsequently nucleated and grew into large laumontite grains.

Nucleation rates varied from $>10^{7}$ wairakite grains per square meter of laumontite surface per second at $425^{\circ} \mathrm{C}$ to $>10^{8} \mathrm{~m}^{-2} \mathrm{~s}^{-1}$ at $450^{\circ} \mathrm{C}$; at lower temperatures the volumetric nucleation rate is $>10^{11}-10^{12} \mathrm{~m}^{-3} \mathrm{~s}^{-1}$. Growth rates varied from $1.5 \times 10^{-11} \mathrm{~m} / \mathrm{s}$ at $350^{\circ} \mathrm{C}$ to $2.1 \times 10^{-10} \mathrm{~m} / \mathrm{s}$ at $450^{\circ} \mathrm{C}$; the low-temperature data can be fit with an apparent activation energy of $72 \pm$ $13 \mathrm{~kJ} /$ mole and a pre-exponential "interface jump distance" of $\sim 1 \times 10^{-18} \mathrm{~m}$. These rates are comparable to those predicted by Walther and Wood to characterize interface-controlled reactions in silicates under $\mathrm{H}_{2} \mathrm{O}$ - 
saturated conditions. Extrapolation of our data indicates that the rate-limiting step in the transformation of laumontite to wairakite under natural conditions cannot be interface-controlled growth under $\mathrm{H}_{2} \mathrm{O}$-saturated conditions and must instead be nucleation rate, heating rate, rate of fluid transport, or fluid activity. We have completed nine friction experiments on laumontite powder at temperatures of $23^{\circ}, 350^{\circ}$, and $400^{\circ} \mathrm{C}$. Sliding rates have been varied between 0.01 and $1.0 \mu \mathrm{m} / \mathrm{sec}$ at a controlled $\mathrm{H}_{2} \mathrm{O}$ pressure of $100 \mathrm{MPa}$ and a fixed effective pressure of $100 \mathrm{MPa}$. All experiments so far are baseline measurements of the variations in laumontite friction with increasing temperature in the absence of transformation. At room temperature the strength of the laumontite gouge follows Byerlee's law, as expected, but at $350^{\circ}-425^{\circ} \mathrm{C}$ the coefficient of friction is the highest ever measured for a silicate, $\mu=0.95 \not{E}>1$. All samples strain harden, so the steady-state value may be higher. Pressure-stepping tests reveal that the strength is sensitive to confining pressure, suggesting that the deformation is dominantly brittle. This is confirmed by microscopic observation of the samples, which contain Riedel shears spaced $300-400 \mu \mathrm{m}$ apart and are made up of submicron-sized particles. Transmission-electron microscopy in progress is designed to reveal the deformation/transformation mechanism responsible for this unusual mechanical behavior.

\section{Published Abstracts}

Jové, C.F., and Hacker, B.R., 1994, Kinetics of laumontite breakdown during diagenesis: preliminary results. Eos, Transactions American Geophysical Union, v. 75, p. 703 .

Hacker, B.R., Blanpied, M.L., Lockner, D.A., and Jové, C.F., 1995, Dehydration and friction: laumontite Æ wairakite $+\mathrm{H}_{2} \mathrm{O}$. Geological Society of America Abstracts with Programs, v. 27.

Jové, C.F., and Hacker, B.R., 1995, Experimental diagenesis of laumontite breakdown. Geological Society of America Abstracts with Programs, v. 27. 
GRANTEE:

GRANT:

TITLE:

PERSON IN CHARGE:
STANFORD UNIVERSITY

Geophysics Department

Stanford, California 94305-2215

DE-FG03-95ER14535/A000

\section{Crosshole Seismic Attenuation Tomography and Attenuation Logging in Boreholes}

Jerry M. Harris (415-723-0496; Fax 415-725-2032; E-mail harris@pangea.stanford.edu)
Objectives: The objectives of this research are to (1) develop methods of attenuation estimation for crosswell seismic and sonic log data and (2) interpret the attenuation estimates, along with velocity data, for in situ reservoir properties.

Project Description: Attenuation imaging is possible using the frequency-shift dispersion method, where the downshift in the centroid frequency of a seismic wavelet is used as projection data in tomographic inversion. This is analogous to using travel time for velocity imaging. Frequency shift data are less sensitive to effects that severely contaminate amplitudes which might otherwise be used to estimate attenuation. If attenuation is caused by friction between pore fluids and the pore walls, then attenuation measurements may be useful as indirect measurements of fluid permeability. Travel time tomography algorithms will be adapted to invert the frequency-shift data for local attenuation, and, finally, the attenuation images will be interpreted, cooperatively with other data, for in situ permeability near and between boreholes. The project makes extensive use of synthetic modeling of waves in viscoelastic and poroelastic media and real field data from the crosshole and sonic logging geometries.

Results: A model that relates the integrated attenuation and the frequency shifts has been found. For a constant-Q model and a signal spectrum that can be fit to a Gaussian distribution, the integrated attenuation equals the frequency-shift divided by the variance of the radiated spectrum. To verify this model, synthetic tests were needed. Since the frequency shift method uses information on dispersion, purely numerical modeling methods (e.g., finite differences) could not be used. We developed a semi-analytical modeling method and the corresponding computer codes to simulate the complete viscoelastic wave field in radially layered media. This forward modeling method is efficient and accurate and has no grid dispersion. Complete crosshole seismic surveys are simulated and used for synthetic attenuation tomography. Inversion results reveal that the frequency shift method is capable of imaging the attenuation distribution. Initial tests on field data also show that the attenuation tomograms exhibit good correlation with the geological structures.

We also investigated the effects of scattering from thin layers on the frequency shifts. We found that geometrical spreading caused by refraction around complicated boreholes is highly frequency-dependent (i.e., dispersive) at high logging frequencies. The apparent spreading factor $\left(1 / \mathrm{z}^{\mathrm{P}}\right.$ with $\mathrm{p}<1, \mathrm{p}=1$, or $\mathrm{p}>1$ for damaged, simple, and flushed boreholes, respectively) alters the frequency shifts in a way that significantly affects the estimation of intrinsic attenuation from the logging geometry. 
GRANTEE:

PERSON IN CHARGE:
GRANT:

TITLE:
STANFORD UNIVERSITY

Geophysics Department

Stanford, California 94305-2215
DE-FG03-90ER14152

Induced Seismicity

P. Segall (415-725-7241; Fax 415-725-7344; E-mail

segall@pangea.stanford.edu)
Objectives: The objective of this project is to develop a fundamental understanding of seismicity associated with energy production.

Project Description: Earthquakes are known to be associated with oil, gas, and geothermal energy production. The goals of the project are to develop physical models that predict when seismicity is likely to occur and to determine to what extent these earthquakes can be used to infer conditions within energy reservoirs. Early work focused on earthquakes induced by oil and gas extraction, which we were able to demonstrate are caused by poroelastic stressing.

Our present work is focused on two problems: (1) earthquakes within geothermal fields, such as The Geysers in northern California and (2) fundamental physics of earthquake nucleation, including effects of dilatancy, rate and state-dependent friction, and shear heating. The former has involved modeling thermoelastic and poroelastic effects of geothermal production and water reinjection, as well as Global Positioning System (GPS) measurements of deformation within and around The Geysers. The latter has involved the development of constitutive laws for dilatancy based on laboratory data and theoretical and numerical analyses of the stability of frictional sliding under conditions appropriate for crustal faulting.

Results: We have developed a simple model of the stresses induced by the injection of cold water into a highly permeable fault zone within a geothermal reservoir. Pore pressures within the fault zone depend on the mass flow rate of injected fluid, duration of injection, and product of permeability and fault zone thick- ness (kh). Maximum pore pressures are on the order of 2 to $3 \mathrm{MPa}$ above ambient for injection rates of $10 \mathrm{~kg} / \mathrm{s}$, $\mathrm{kh}=1011 \mathrm{~m}^{3}$ (typical values for The Geysers) and injection times of 10 years or less. Advective cooling of rock adjacent to the fault zone induces thermoelastic stresses. The thermoelastic reduction in compressive stress normal to the fault zone is expected to weaken the fault against frictional sliding. For a temperature contrast between the injected water and initial rock temperatures of $200^{\circ} \mathrm{C}$ (appropriate for The Geysers), the maximum reduction in effective normal stress across the fracture is on the order of $10 \mathrm{~s}$ of MPa. The thermal stress decreases with increasing distance from the borehole, eventually becoming negative (compressive). The result that thermoelastic stresses dominate pore pressure changes is true even when rapid volume changes due to heating and boiling of the injectate are taken into account.

Observations of surface subsidence and horizontal strain can help constrain the distribution of strains within the reservoir due to changes in temperature and pore-pressure. In 1994 and 1995, 40 geodetic monuments within The Geysers geothermal field were reoccupied with GPS receivers. Precision is sub-centimeter in the horizontal coordinates and $1-2 \mathrm{~cm}$ in the vertical. Displacements between 1994 and 1995 are significant at the $95 \%$ confidence level and indicate subsidence within the reservoir as well as significant horizontal deformation.

We have developed constitutive laws for dilatant fault gouges that include rate-dependent effects. Using these results together with laboratory-derived fric- 
tion laws, we determine conditions under which dilatant faults can exhibit stick-slip instabilities. Under isothermal conditions, dilatancy is stabilizing while pore-fluid exchange with the surrounding rocks is de- stabilizing. For adiabatic conditions a shear heating instability competes with frictional weakening to cause stick-slip instability. For the shear heating instability both dilatancy and pore-fluid exchange are stabilizing. 
GRANTEE:

GRANT:

TITLE:

PERSON IN CHARGE:
STANFORD UNIVERSITY

Geophysics Department

Stanford, California 94305-2215
DE-FG03-86ER13601.A004

Porous Reservoir Rocks with Fluids:

Acoustic and Reservoir Transport Properties

Amos Nur (415-723-9526; Fax 415-723-1188;

E-mail nur@pangea.stanford.edu)
Objectives: The objectives of the research are to (1) relate seismic characteristics of hydrocarbon reservoirs and groundwater aquifers to rock, soil, and porefluid properties and (2) apply the results to the design and interpretation of in situ seismic measurements to obtain subsurface fluid saturation, flow description, and flow monitoring. The research program involves laboratory measurements, theoretical modeling, and in situ field studies. It spans several projects.

\section{Effect of Gas in the Pore Space}

Project Description: Conduct a high resolution shallow seismic refraction and reflection experiment with repeated profiling of every 20 minutes to 1.5 hour to investigate the seismic response of water table excursions (and the air-saturated layer above the water table) in beach sand due to ocean tide.

Results: It has been found that a low velocity layer exists right above the fully saturated sand layer and right below the near-surface dry sand. This low velocity layer is caused by the relatively high density of the almost saturated sand, where only small amounts of gas are present, and its low compressibility, which is close to that of the dry sand. Thus, small gas bubbles trapped in the flooded sand strongly affect the system's seismic response. The history of water level variation is a key control of the seismic response. The results can be used to map water table from which both subsurface flow patterns and relative permeability can ultimately be obtained.

\section{Effect of Liquid in the Pore Space}

Project Description: Investigate the seismic and sonic effects of the topology of fluid distribution in porous rocks, as applied to various processes of pore fluid replacement during drilling, well completion, hydrocarbon recovery, and also geological fluid migration.

Results: Whereas Gassmann's equation can be used for perfectly homogeneous rock systems, even slight lithologic inhomogeneity (e.g., clay content spatial variation) may lead to significant saturation inhomogeneity (or patchiness) where Gassmann's equation is not directly applicable. When saturation is patchy, newly derived modified equations have to be used to predict saturation from seismic and to calculate rockframe properties from well logs. Accounting for saturation inhomogeneity is especially important in the interpretation of repeated surface and crosswell seismic data and sonic well logs for monitoring fluid recovery in two or three phase reservoirs.

\section{Effect of Solids in the Pore Space}

Project Description: Investigate the sensitivity of seismic velocities to the amount and location of the solid phase (such as diagenetic cement or gas hydrates) in the pore space.

Results: In diagenesis of typical sandstones and carbonates, cement first precipitates at grain contacts so that the stiffness and hence velocity increase rap- 
idly with even small decrease in porosity. Permeability, on the other hand, is not very sensitive to filling the grain contacts (at high porosity) and shows only small decrease with decreasing porosity. In the reverse situation, where a solid phase is placed in larger pores and away from the grain contacts, the opposite is true; the velocity is only weakly affected by the decreasing porosity but permeability decreases rapidly. This latter situation appears to be the case in the formation of gas hydrates under Earth's ocean floor and is likely to be responsible for the trapping of large pools of free methane under impermeable hydrated layers associated with bottom simulating reflectors. 
GRANTEE:

\author{
GRANT:
}

TITLE:

PERSONS IN CHARGE:
TEMPLE UNIVERSITY

\author{
Department of Chemistry
}

Philadelphia, Pennsylvania

\title{
DE-FG03-ER
}

The Surface Chemistry of Pyrite: An Interdisciplinary Approach

\author{
Daniel R. Strongin (215-204-7119; Fax 215-204-1532) and \\ Martin A. A. Schoonen (Department of Earth and Space Sciences, \\ SUNY, Stony Brook; 516-344-3124; E-mail \\ schoonen@sbmpo4.ess.sunysb.edu)
}

Objectives: A research program has been initiated to study the surface reactivity of pyrite, the most abundant metal sulfide on Earth. A unique aspect of this research program is that it integrates experimental observations made using low-temperature aqueous techniques and modern surface science probes. Lowtemperature aqueous techniques, such as electrophoresis, provide insight into the overall acid-base behavior, charge development, and sorption onto the surface. Modern surface probes, such as high resolution electron loss spectroscopy, photoelectron spectroscopy, low energy electron diffraction, and temperature programmed desorption, provide molecular level information on the geometric and electronic structure of both the chemisorbed molecule and adsorbing surface. With these probes it is possible, for example, to determine the nature of surface groups that are responsible for the acid-base reactions and charge development observed in electrophoresis experiments.

Project Description: In the first stage of this project, the focus will be on understanding the charge development on pyrite and the interaction of its surface with water. Electrophoresis will be used to determine the charge development of pyrite in solutions with known concentrations of inorganic and organic species. Modern surface science probes will be used to interrogate the molecular structure and thermal chemistry of adsorbed species on pyrite. These surface science studies encompass two types of experimental studies. The objective of the first type of surface science study is to investigate the reactivity of an atomically clean "as grown" surface of pyrite, in the ultra high vacuum (UHV) environment, toward a variety of molecular reactants. Naturally occurring samples of pyrite will be cleaned using a technique developed in our research group (Chaturvedi et al., 1996, Am. Min. 81, 261-264). This cleaning technique allows us to study the reactivity of atomically clean cubic and octahedral surfaces of pyrite and avoids the more extensive structural and chemical changes associated with cleaving, cutting, and polishing samples. The interaction of the clean surfaces with selected molecules (e.g., $\mathrm{H}_{2} \mathrm{O}, \mathrm{H}_{2} \mathrm{~S}, \mathrm{CH}_{3} \mathrm{OH}$ ) will be investigated in UHV using the array of electron spectroscopic and thermal desorption techniques. The goal of these experiments will be to develop an atomic level view of the structure and reaction chemistry of the chemisorbed species and pyrite surface. The second type of study investigates the surface of pyrite after exposure to solutions of known composition. These experiments provide us with a bridge between the electrophoresis experiments and the UHV studies. To conduct this type of experiment, a transfer cell has been designed that allows exposure of a well-defined pyrite crystal to a solution at room temperature and pressure, followed by transfer of the sample into the UHV environment for analysis with surface science probes. With this transfer cell it is possible to investigate the change in surface composition as a function of solution composition. Our choice of solution compositions for these studies will be guided by the results of the electrophoresis experiments. 
Results: The combined results of this interdisciplinary study will provide a detailed picture of the type of functional groups at the pyrite surface, its charge development, the acid-base behavior, and the reactivity of these surfaces. Because of the ubiquity of pyrite in the natural environment and its importance in industrial applications, the results of this research will be of interest to geochemists, environmental chemists, and material scientists. 
GRANTEE:

GRANT:

TITLE:

PERSONS IN CHARGE:

\author{
UNIVERSITY OF TENNESSEE \\ Institute for Rare Isotope Measurements \\ 10521 Research Drive, \#300 \\ Knoxville, Tennessee 37932
}

DE-FG05-95ER14497

\title{
Development of Laser-Based Resonance Ionization Techniques for ${ }^{81} \mathrm{Kr}$ and ${ }^{85} \mathrm{Kr}$ in the Geosciences, II
}

\author{
N. Thonnard (423-974-9700; Fax 423-974-8289; E-mail \\ nthonnar@utk.edu), T.C. Labotka, and L.D. McKay
}

Objectives: Objectives are to (1) bring into operation a new analytical methodology for ${ }^{81} \mathrm{Kr}$ and ${ }^{85} \mathrm{Kr}$, (2) identify performance limitations and implement improvements in reproducibility, accuracy, throughput, and sample size, and (3) initiate research in the geosciences.

Project Description: The ${ }^{81} \mathrm{Kr}$ and ${ }^{85} \mathrm{Kr}$ noble gas radioisotopes, with abundances and concentrations of $10^{-12}$ and $10^{-22}$ in modern water, could contribute to our understanding of processes in the environment, including dating of polar ice and very old groundwater, ocean circulation, and modern water flow patterns. Cosmogenic ${ }^{81} \mathrm{Kr}\left(2.1 \times 10^{5}\right.$ year half-life $)$ can date events in the 50,000- to 1,000,000-year time period, while anthropogenic ${ }^{85} \mathrm{Kr}$ (10.8-year half-life) is useful in tracing events during the last 50 years. Neither isotope is accessible by accelerator mass spectrometry. A few measurements of ${ }^{85} \mathrm{Kr}$ from 200 -liter water samples, using decay counting, have been demonstrated. The only ${ }^{81} \mathrm{Kr}$ measurements from natural samples to date are a handful of results from old groundwater and polar ice, using the laser-based analytical technique under development here. The chemical inertness of the noble gases can simplify interpretation of results. When fully operational, this technique should permit ${ }^{85} \mathrm{Kr}$ measurements using only 1 - to 5-liter samples and ${ }^{81} \mathrm{Kr}$ measurements from 10- to 20-liter samples. The technique presently consists of a multi-step process starting with (1) degassing of the sample, (2) separating $\mathrm{Kr}$ from the remainder of the gas, (3) a first isotopic enrichment, reducing interfering isotopes by $10^{5}$, (4) a second isotopic enrichment of $10^{3}$, and (5) detecting the rare krypton isotope in a time-of-flight mass spectrometer utilizing resonance ionization. As there are only a few thousand analyte atoms in the sample, the sensitivity, element selectivity, and immunity to interferences of resonance ionization are required. A detection limit of $100{ }^{85} \mathrm{Kr}$ atoms had been demonstrated earlier in the final mass spectrometer. Required still is characterization of the efficiency, accuracy, and blank level of each step; stabilization and automation of operating parameters in steps (1), (2), and (3); complete redesign of step (4); and improvement to the laser and data acquisition systems in step (5).

Results: Most of the effort this past year has been to steps (3), (4), and (5). The first enrichment system (3) uses a 15-inch velocity filter and plasma ion source in a closed, gas recirculating system. The ion-source controller has been rebuilt, a Hall-Effect probe installed, an isotope dilution calibration system designed, and the ion path completely realigned. These changes should significantly enhance accuracy, stability, reliability, and safety. Gold coating of the rods in the quadrupole-based second enrichment system (4) and redesign of the collector and detection hardware should breathe a little more life into this obsolescent system until the design of the magnetic sector-based replacement is finished. The resonance ionization time-of-flight mass spectrometer (5) has a significantly improved data acquisition system, a completely new sample introduction system, and enhanced vacuum system. 
GRANTEE:

GRANT:

PERSONS IN CHARGE:
TITLE:

IN CHARGE:
TEXAS A\&M UNIVERSITY

Center for Tectonophysics

Department of Geology and Geophysics

College Station, Texas 77843-3115
DE-FG05-87ER13711

\section{Mechanical Properties and Modeling of Seal-Forming Lithologies}

A.K. Kronenberg, J.E. Russell, and N.L. Carter (409-845-0132;

Fax 409-845-3002; E-mail a.kronenberg@tamu.edu)
Objectives: This research addresses the mechanical properties of two weak sedimentary lithologies, shale and rock salt, that deform under gravitational and tectonic loads and examines the roles of these lithologies in the development of structural traps and unconventional oil and gas reservoirs.

Project Description: The shapes and physical properties of a wide range of structural traps and barriers to mobile hydrocarbons are governed by the mechanical properties of shale or those of salt and by the loading histories to which they have been subjected. Concurrent experimental and modeling studies are underway to determine the fracture and flow properties of these two lithologies, to determine physicallybased constitutive relationships that can be applied to geologically relevant conditions, and to make predictions concerning the development and timing of structural traps relative to known depositional histories.

Results: Significant progress has been made during this year towards characterizing the mechanical and transport properties of Wilcox shale saturated with fluids of varying chemistry and towards simulating the evolution of salt structures by modeling the deformation of rock salt and overlying sediments with nonlinear, experimentally constrained rheologies.

Our investigations of shale deformation have been extended from strain rates of $10^{-8} \mathrm{~s}^{-1}$ to $10^{-3} \mathrm{~s}^{-1}$ to include time scales that represent drained and effectively undrained conditions as determined from experimen- tally determined hydraulic diffusivities and calculations of internal pore pressures. Having established these time scales, we have determined and are currently refining effective stress laws for permeability and failure strength of shale. We have examined the effects of fluid chemistry on permeability using $\mathrm{NaCl}, \mathrm{KCl}$, and $\mathrm{CaCl}_{2}$ brines and distilled water, and we have further explored the effects of water as a pore fluid and as adsorbed layers at clay surfaces, on mechanical properties. Permeability measured at increasing and decreasing effective pressures suggest substantial changes in pore geometries that are inelastic as effective pressure is increased while recoverable poro-elastic effects are observed as effective pressure is decreased.

Our numerical studies of salt structure development have led to insights into the initiation, evolution, and timing of complex salt structures of the northern continental shelf of the Gulf of Mexico, as well as the sensitivities of salt structure development to subsurface conditions, viscosity contrasts between salt bodies and overlying sediments, and degrees of nonlinearity in rheology. These model studies have been accompanied by studies of deformation microstructures of natural salt structures of the Gulf of Mexico using cores recovered from actively deforming allochthonous salt nappes. Equivalent stress levels within these structures, as determined from stress-dependent microstructures, offer important constraints for the models and the rheologies on which our models are based. 
GRANTEE:

GRANT:

TITLE:
UNIVERSITY OF TEXAS

Department of Geological Sciences

Austin, Texas 78712

DE-FG05-92ER14278

\section{Energy Flux and Hydrogeology of Thermal Anomalies in the Gulf of Mexico Sedimentary Basin - South Texas Example}

\section{PERSON IN CHARGE:}

Objectives: The objectives of this study were to (1) evaluate if observed heat flow anomalies in the south Texas portion of the Gulf of Mexico sedimentary basin (if reconfirmed by extensive data analysis) can be accounted for by conduction alone or if convection is a significant process, (2) determine if the present potential field is amenable to convection hypotheses, and (3) develop fluid and heat flux histories compatible with both compiled and newly collected data.

Project Description: In order to test hypotheses posed to address the above objectives, we compiled an extensive data base of fluid pressures $(>25,000$ data points at depths of up to 5 kilometers [over 16,000 feet]), water chemistries ( $>2000$ data points), and formation temperatures ( $>5500$ data points) from a variety of private and public sources; installed a G.I.S. to analyze these data; analyzed selected drill cores and cuttings for their mineralogical, thermal conductivity, radiogenic heat production, and porosity/bulk density data. We culled spurious pressure and temperature data, corrected temperature and pressure data to infer predevelopment conditions, calculated buoyancy gradients, and implemented mathematical and numerical models to simulate the study area's temperatures and pressures and to infer the importance of the various processes.
Results: Analysis of the data reconfirmed the thermal anomalies discerned from the previous, much smaller data bases. New data on fault zone locations centered the anomalies along the deepest-seated Wilcox Faults. The pressure data revealed that petroleum production has created significant depressurization that extends well beyond the immediate petroleum reservoirs. The water chemistry data revealed zones of higher salinity coincident with Wilcox and Frio fault zones. Several areas have significant buoyancy gradients. This creates conditions conducive to free convection that was confirmed using the SUTRA computer model. The thermal property data revealed several interesting trends. First, radiogenic heat production in the Gulf of Mexico Basin is significant and should be accounted for in simulation models, but this production is not responsible for the thermal anomalies. Secondly, sandstone thermal conductivities correlate well with quartz content and porosity; a new empirical equation for Gulf Coast sandstone thermal conductivities was developed. Shale cuttings indicated significant shrinkage so that laboratory measurements of shale thermal conductivity, porosity, and bulk density are suspect. Our models indicate that forced convection (advection) is a significant factor in geological-time, regional-scale heat transport and that both free and forced convection are significant in salinity transport. 
GRANTEE:

GRANT:

TITLE:

PERSONS IN CHARGE:
UNIVERSITY OF TEXAS

Bureau of Economic Geology

University Station, Box X

Austin, Texas 78713-8924

\section{DE-FG03-95ER14504}

\section{A Robust Economic Technique for Crosswell Seismic Profiling}

Bob A. Hardage (512-471-1534; Fax 512-471-0140; E-mail hardageb@begv.beg.utexas.edu) and James L. Simmons, Jr. (E-mailssimmonsj@begv.beg.utexas.edu)

Objectives: This project is investigating techniques by which crosswell velocity tomograms can be constructed from seismic wavefields generated by a surface-positioned source and recorded by downhole sensors in two or more in-line receiver wells and is verifying if this type of source-receiver geometry produces travel-time tomograms of sufficient accuracy to be used in reservoir characterization and monitoring.

Project Description: Crosswell velocity tomograms can be helpful in reservoir characterization and monitoring, yet crosswell applications cannot be attempted in highly attenuating rocks or between widely separated wells because of the limited energy output of present downhole seismic sources. In concept, crosswell data can be acquired in these no-data situations by using a robust surface-based energy source and then measuring the travel times required for these surface-generated wavefields to travel between downhole sensors positioned at different depths in two in-line receiver wells. If this combination of surface energy source and twin receiver wells allows ray paths to be recorded over an adequate angular aperture and also provides a travel-time accuracy that is adequate for velocity inversion, then crosswell applications can be implemented in reservoirs having almost any well spacing and any type of interwell lithology. The purposes of this research are to determine how to best record this type of crosswell data and then to verify if the data satisfy the numerical requirements for creating travel-time tomograms that can be used in reservoir evaluations.
Results: Crosswell data were recorded between two receiver wells that penetrated low-velocity, weakly consolidated Pleistocene rocks in South Texas. The downhole sensors in each well were a six-level hydrophone array with $10-\mathrm{ft}$ spacings between adjacent hydrophone elements. The surface energy source was a Bolt land air gun stationed at four offset positions that were in-line with the two receiver wells. The downhole data were recorded at vertical increments of $10 \mathrm{ft}$ over a depth aperture of 1500 to $2500 \mathrm{ft}$ in each receiver well.

This work was done in an active oil field so that the typical background seismic noise of pumping wells, nearby workover activity, and continuous vehicular traffic associated with a producing reservoir would be superimposed on the downhole data. This environment was desired so a determination could be made if production activity has to be reduced in order to record crosswell data of adequate quality when using this type of source-receiver geometry. It is particularly important to know how these types of cultural noises affect free-hanging hydrophones, because a hydrophone array can be moved to a new downhole recording level quicker than a wall-clamped receiver array can, thus allowing crosswell data to be recorded in less time and at less cost.

An eikonal technique has been used to reproduce the P-wave arrival times observed in these data and to construct an interwell P-wave tomogram. The interwell velocity distribution resulting from this eikonal computation agrees with the velocity control that is available at the twin-well site. 
GRANTEE:
TITLE:

PERSONS IN CHARGE:
UNIVERSITY OF TEXAS AT DALLAS

Center for Lithospheric Studies

P.O. Box 830688 (FA31)

Richardson, Texas 75083-0688

\section{GRANT: $\quad$ DE-FG03-96ER14596}

\section{Sedimentological and Geophysical Studies of Clastic Reservoir Analogs: Methods, Applications, and Developments of Ground- Penetrating Radar for Determination of Reservoir Geometries in Near-Surface Settings}

George A. McMechan (214-883-2419; Fax 214-883-2829; E-mail mcmec @utdallas.edu) and Kristian Soegaard (214-883- 2415; Fax 214-883-2537; E-mail soegaard@utdallas.edu)
Objectives: Ground-penetrating radar is evaluated for constructing 3-D models of sandstone hydrocarbon reservoirs from near-surface analogs. Constraints include detailed sedimentologic mapping of outcrops and lab and petrophysical analyses of plug and core samples.

Project Description: Existing reservoir models are based on only 2-D outcrop studies; their 3-D apsects are inferred from correlation between well data and so are inadequately constrained for reservoir simulations. Field study sites are in the Cretaceous Ferron Sandstone in Utah. Detailed sedimentary facies maps of cliff faces will define the geometry and distribution of reservoir flow units, barriers, and baffles at the outcrop. High resolution 3-D ground-penetrating radar (GPR) images will extend these reservoir characteristics into 3-D, thereby enabling development of realistic 3-D reservoir models. Models will use geometrical information from the mapping and the GPR data, petrophysical data from surface and cliff-face outcrops, lab analyses of outcrop and core samples, and petrography.

Results: Several field sites have been identified in the Ferron Sandstone in Central Utah. Previously acquired 3-D GPR data sets are being processed at
ARCO; the results will be incorporated into this project. An extensive new data set has been collected from fluvial deposits at one site at Coyote Basin, covering a $40 \mathrm{~m} \times 16.5 \mathrm{~m}$ surface area to a depth of 30 meters. The fluvial sandstone is composed of a channel complex in the upper 12 meters of a section that overlies floodplain mudstone, coal, and crevasse splay deposits. Three 3-D GPR data volumes were acquired at frequencies of 50,100, and $200 \mathrm{MHz}$. The surface geology has been mapped and shows fractures and sedimentary features, such as cross beds. A facies map has been created of the adjacent vertical cliff face. Five stratigraphic sections, gamma-ray profiles, and photographs were made at the cliff face, extending through the upper fluvial sandstone; one section extends to a depth of 30 meters, well into the underlying floodplain deposits. Approximately 700 core plugs have been extracted from the cliff face for determination of permeability. Paleo- current data have been obtained at four localities in the vicinity of the GPR survey site. Four 14-meter wells have been cored within the GPR data cube; stratigraphic sections have been logged from the core. Thus, most of the raw data for characterization of this site are now in hand. 
GRANTEE:

GRANT:

TITLE:

PERSON IN CHARGE:
U.S. DEPARTMENT OF ENERGY CORE AND SAMPLE REPOSITORY

c/o RUST Geotech Inc.

P. O. Box 14000

Grand Junction, Colorado 81502-5504
None (B\&R KC040101)

\section{U.S. Department of Energy, Core and Sample Repository}

Larry M. Fukui (970-248-6172; Fax 970-248-6040; Internet gjcore@gjpomail.doegjpo.com)
Objectives/Project Description: The DOE Core and Sample Repository provides the scientific community with ready access to geologic samples and information, ensures proper preservation and storage of samples and data, maintains records of sample requests, and promotes the use of sample inventory and data by qualified investigators.
Results: The DOE Core and Sample Repository has distributed over 4000 samples selected from the more than 13,900 meters $(45,000$ feet) of drill core to about 90 investigators in the USA and foreign countries.

Please note that all of the core will be moved to the University of Utah Earth Science and Resources Institute in Salt Lake City by the end of Fiscal Year 1997. 
GRANTEE:
GRANT:

TITLE:

PERSON IN CHARGE:
UNIVERSITY OF UTAH

Earth Sciences and Resources Institute

Department of Civil and Environmental Engineering

Salt Lake City, Utah 84112
DE-FG02-90ER14133
Assessing the Role of Active and Ancient Geothermal Processes
in Oil-Reservoir Evolution in the Basin and Range Province

Jeffrey B. Hulen (801-581-8794; Fax 801-585-3540; E-mail

jhulen@esrilan.esri.utah.edu)
Objectives: The project is structured around investigation of the premise that active and ancient moderate-temperature hydrothermal systems, by various means, have been instrumental in the generation, migration, and entrapment of oil in the Basin and Range province of the western United States.

Project Description: The eastern Basin and Range encompasses several shallow and hot $(<2 \mathrm{~km}$; up to $130^{\circ} \mathrm{C}$ ) oil fields (for example Blackburn and Grant Canyon/Bacon Flat) that geologically resemble the Carlin-type, Paleozoic sediment-hosted gold deposits occurring in the same region-in particular those of the southern Alligator Ridge mining district about midway between the towns of Elko and Ely, Nevada. We are investigating the distinct possibility that at least some of these gold deposits are the exhumed and oxidized, paleogeothermal analogues of the modern, exploited geothermal oil fields. Our approach is multidisciplinary, involving (1) detailed geologic mapping, (2) logging of drill cuttings and cores, with emphasis on alteration, porosity characteristics, vein mineralization and paragenesis, and hydrocarbon type and distribution, (3) three-dimensional stratigraphic/ structural analysis to allow reconstruction of fluid-flow paths used by both thermal waters and hydrocarbons, (4) fluid-inclusion microthermometry, to ascertain the compositions and temperatures of these fluids at different times during the duration of the hydrothermal system, (5) whole-rock and vein-mineral geochemistry, (6) hydrogeochemistry of oil-field vs. regional waters, and (7) stable-isotopic systematics of thermal waters and vein and alteration minerals.

Results: During the past year, we have mapped several small, new open-pit gold mines in the southern Alligator Ridge district, adding new details to the stratigraphic/structural and hydrothermal picture previously established for this area. All the new mines penetrate the same oil-bearing, altered, and mineralized Paleozoic sedimentary sequence encountered in prior excavations. The oil, freely-flowing and in fluid inclusions, occurs within and around both low- and high-grade gold ore bodies. From detailed petrographic and fluid-inclusion work coupled with field relationships, the oil appears to have been introduced in the same hydrothermal system responsible for the precious-metal mineralization. The temperature of mineralization apparently did not exceed $130^{\circ} \mathrm{C}$. This surprising finding is confirmed not only by pressure-corrected, fluidinclusion homogenization temperatures but also by temperature-dependent biomarker transformation preserved by hydrocarbons in oil-rich fluid inclusions. There is a distinct depletion in ${ }^{18} \mathrm{O} /{ }^{16} \mathrm{O}$ of the oil-bearing ore bodies' wall rocks relative to their unaltered and unmineralized counterparts. Two deep oil wells completed in the immediate area penetrated neither intrusive rocks nor sedimentary rocks hydrothermally altered at high temperatures. One of these wells, just a mile from the ore bodies, bored through the hydrocarbon source rocks, which at this location and depth were shown by Rock-Eval pyrolysis to be near peak oil-gen- 
eration capacity. It now appears highly likely that the gold-depositing hydrothermal system was directly responsible here for the generation, migration, and entrapment of oil; however, we still do not know to what extent, if any, the oil actually contributed to the mineralization process. In other words, the formation of this particular fossil oil reservoir may well have been just a beneficial side effect of the ore-forming hydrothermal event. By contrast, at another oil-rich gold deposit, Gold Point near Ely, we have determined that hydrocarbons were crucial to mineralization, most likely providing highly adsorptive substrates for electrum precipitation.

In huge Railroad Valley, about $25 \mathrm{~km}$ southwest of Gold Point and the site of most of Nevada's oil production, our study of oil-well drill-stem-test temperatures has indicated that the western side of this fault-bounded valley is probably a major regional hydrologic downflow zone, whereas the eastern side, along which the hottest oil fields occur, is a region of localized geo- thermal upflow of the same waters. These geothermal plumes have fostered the maturation of hydrocarbon source rocks as well as the migration and entrapment of the newly generated oils. A pilot study of the regional hydrocarbon-sealing mechanism in this valley has indicated that volcanic-ash-rich beds at the base of the valley-fill sequence have been widely altered to montmorillonite, thereby inhibiting the escape of oils structurally entrapped in underlying Tertiary ignimbrites and brecciated Paleozoic dolomites. At Kyle Hot Springs, near Winnemucca in western Nevada, an active, moderate-temperature geothermal system has generated paraffin-rich heavy crude oils from hypersaline-lacustrine Tertiary source rocks, which are otherwise well below the favorable oil-generation "window." The Kyle system, in a more energetic early phase, also precipitated hydrocarbon- and gold-bearing siliceous sinter, bolstering the geothermal/oil/gold connection we have been documenting in the eastern part of the state. 
GRANTEE:

GRANT:

TITLE:

PERSON IN CHARGE:
UNIVERSITY OF UTAH

Department of Geology and Geophysics

717 Browning Building

Salt Lake City, Utah 84112

DE-FG03-93ER14313

High Resolution Imaging of Electrical Conductivity Using Low Frequency Electromagnetic Fields

Dr. Alan C. Tripp (801-462-2112 or 801-581-4664;

Fax 801-581-7065; E-mail actripp@mines.utah.edu)

Objectives: The project seeks to determine means of increasing the resolution of low frequency electromagnetic techniques by means of an optimal use of a priori information.

Project Description: The research concentrates on extending to inductive sources a theory of focussing DC sources investigated under previous funding. This theory couples a priori information to data weights to give optimal resolution of a perturbation on a prespecified conductivity structure. This approach is viable in cases where something is known about back- ground geo-electric structure, and resolution of perturbations about this structure is very important.

In the DC case, optimization variables include the electrode distribution and the source weighting. In extending the theory to the inductive source, optimization variables besides these include frequencies, loop sizes, and source phasing. The theory will be applied to feasibility studies for enhanced oil recovery and energy-related environmental monitoring.

Results: Work on extending the focussing theory to the inductive case has only been recently initiated. 


\section{GRANTEE:}

\author{
GRANT:
}

TITLE:

PERSONS IN CHARGE:
UTAH STATE UNIVERSITY

Logan, Utah 84321
DE-FG03-95ER14526 A000

Kevin Hestir (Utah State University; Department of Mathematics and Statistics) (801-797-2826; Fax 801-797-1822),

James P. Evans (Utah State University); Stephen Martel (University of Hawaii, Honolulu, HI 96844), and Jane C. S. Long and Janet Jacobsen (Lawrence Berkeley National Laboratory, Berkeley, California 94720)

Objectives: The project is designed to examine the three-dimensional hydrogeologic structure of fault zones by field mapping, mechanical modeling, and probabilistic modeling. The results of these efforts will be used in developing inverse techniques for determining fault zone hydrologic behavior from well test data.

Project Description: We are examining the threedimensional permeability structure of faults in crystalline rocks and integrating these results into fluid flow models, developing mechanical models for the nucleation and growth of faults in three dimensions, and using these mechanical models in developing and testing the numerical models of fluid flow. Goals of the project are to

(1) Establish the geometry and permeability structure of small faults by geologic mapping and examinations of both hydrothermal mineral deposits and hydrothermally altered rock along the faults.

(2) Develop a three-dimensional, numerical-mechanical technique to model fracture growth. The results of the model will be compared to the natural faults we investigate. We also will conduct parameter studies to help predict how different states of stress and different material properties affect the distribution and linkage (i.e., organization) of permeable and impermeable features along faults.

(3) Develop stochastic models, based on field data and our mechanical models, for fault development. These models will represent how permeable features and impermeable features are likely to be organized along faults. This work will form the foundation of a stochastic model for examining the hydrology of faults.

(4) Compare the long-term permeability structure of faults, as revealed by geologic evidence, with the short-term permeability structure revealed by well tests.

(5) Implement and develop software for visualizing in three-dimensions both field data on fault structure and hydrologic models of fracture flow systems.

This research integrates field work with deterministic and stochastic modeling to gain insight into how the three-dimensional permeability structure of a fault develops through time. This work will lead to an increased understanding of fault zones from geologic, geomechanical, and hydrologic points of view and to the development of a methodology for building physically realistic stochastic models for fault zone hydrology.

Results: Detailed maps of the fault zone in the Bear Creek region of the Sierra Nevada, California, have been made and visualized in three dimensions. Thin sections have been prepared from nearly all of the rock samples collected last summer in the Bear Creek region. Nearly all the samples collected for the purpose of dating the fault zones show significant amounts of fracture-bound white mica; this indicates that the samples can yield dates for the timing of fracturing and faulting. The thin sections collected for mineralogical and geochemical analyses have also been 
examined; they indicate episodic precipitation of hydrothermal minerals in the faults.

One stage of two-dimensional analytical modeling has nearly been completed that bears on the mechanics of fracturing near the ends of the faults. The results so far mark a distinct improvement in our ability to account for the orientation of fault-related fractures as observed in the field, appear to place constraints on forthcoming three-dimensional mechanical modeling, and also suggest how the most essential aspects of fracturing might be accounted for in a simple but realistic manner in the stochastic modeling.

A manuscript describing a two-dimensional stochastic fracture hydrology model is awaiting final com- ments from the coauthors and will be submitted this fall to the Journal of Geophysical Research. Two preliminary three-dimensional stochastic models for fault zones have been constructed. These models incorporate fault zone structures suggested by the mechanical and field results of the project. The first stochastic model will be used with field maps to estimate the likely size and density of fracture components in the mapped fault zone. The second model will be used to study the hydrology of fault zones, including an inverse modeling with pressure data from a similar fault zone at the Finnsjon site in Sweden. 
GRANTEE:

GRANT:

TITLE:

PERSON IN CHARGE:
VIRGINIA POLYTECHNIC INSTITUTE AND STATE UNIVERSITY

Fluids Research Laboratory

Department of Geological Sciences

Blacksburg, Virginia 24061

DE-FG05-89ER14065

\section{Geochemical Studies of Fluid Systems}

R. J. Bodnar (703-231-7455; Fax 703-231-3386;

E-mail bubbles@vt.edu)

Objectives: The objective of this project is to experimentally determine the pressure-volume-temperature-composition (PVTX) relationships of $\mathrm{H}_{2} \mathrm{O}-\mathrm{CO}_{2}-\mathrm{NaCl}$ mixtures over the complete range of PTX conditions encountered in crustal energy, resource, and waste-related environments. These data are used to develop equations of state to predict the behavior of these fluids in crustal rocks.

Project Description: Volumetric (PVT) data provide the fundamental information needed to understand the physical and chemical behavior of fluids in energy, resource, and waste-related environments. Further, these data represent the basis for developing empirical or theoretical equations of state to predict the thermodynamic properties of fluids over crustal PTX conditions. In this study the PVTX properties of $\mathrm{H}_{2} \mathrm{O}-\mathrm{CO}_{2}-\mathrm{NaCl}$ are being experimentally determined using the synthetic fluid inclusion technique. With this technique, fluids of known composition are trapped as inclusions by healing fractures in quartz at known temperatures and pressures. Phase relations and P-T locations of isochores in the $\mathrm{H}_{2} \mathrm{O}-\mathrm{CO}_{2}-\mathrm{NaCl}$ system are obtained by observing the temperatures and modes of homogenization of the synthetic fluid inclusions during subsequent heating and cooling experiments in a fluid inclusion stage mounted on a petrographic microscope.

Results: The location of the solvus and isochores for an $\mathrm{H}_{2} \mathrm{O}-\mathrm{CO}_{2}-\mathrm{NaCl}$ solution having a composition of $20 \mathrm{wt} . \% \mathrm{NaCl}$ and $10 \mathrm{~mol} \% \mathrm{CO}_{2}$ (both relative to $\mathrm{H}_{2} \mathrm{O}$ ) were determined over the range $350^{\circ}-580^{\circ} \mathrm{C}$ and up to $5 \mathrm{~kb}$. These data significantly extend the range of PTX conditions over which data are available for this geologically important fluid system. The results confirm the earlier suggestion that the solvus displays a pressure minimum in P-T space with a very steep slope at temperatures below the minimum and a very shallow slope at temperatures above the minimum.

A technique has been developed for determining compositions of synthetic $\mathrm{H}_{2} \mathrm{O}-\mathrm{CO}_{2}$ inclusions, based on laser Raman microprobe (LRM) analysis. With the technique, inclusions are analyzed at $350^{\circ} \mathrm{C}$ using LRM, and the intensities are related to composition through a simple polynomial equation. The technique is valid for $\mathrm{CO}_{2} /\left(\mathrm{H}_{2} \mathrm{O}-\mathrm{CO}_{2}\right)$ ranging from $0-1$ and is relatively insensitive to inclusion density variations.

The Hydrothermal Diamond-Anvil Cell (HDAC) has been developed as a pressurized fluid inclusion stage. The HDAC permits analysis of fluid inclusions that develop high internal pressures during conventional microthermometry. Previously, data could not be obtained from such inclusions because they decrepitated (exploded) before the homogenization temperature was reached as the internal pressure exceeded the tensile strength of the host mineral. This development permits PVT data for $\mathrm{H}_{2} \mathrm{O}-\mathrm{CO}_{2}-\mathrm{NaCl}$ to be obtained over a much wider range of PTX conditions than possible previously. 


\section{GRANTEE:}

GRANT:

TITLE:

PERSONS IN CHARGE:
WASHINGTON UNIVERSITY

Department of Earth and Planetary Sciences

St. Louis, Missouri 63130
Development of an Experimental Database and Theories for
Prediction of Thermodynamic Properties of Aqueous Electrolytes
and Nonelectrolytes of Geochemical Significance at Supercritical
Temperatures and Pressures

Everett L. Shock (314-726-4258; Fax 314-935-7361;

E-mail shock@zonvark.wustl.edu) and R. H. Wood (302-831-2941;

Fax 302-831-6335; E-mail rwood@brahms.udel.edu)
Objectives: The objectives of this research are to combine new experimental measurements on heat capacities and volumes of key compounds with theoretical equations of state to generate predictions of thermodynamic data that allow quantitative models of geochemical processes at high temperatures and pressures.

Project Description: This project is part of an ongoing collaboration between Prof. Everett Shock of Washington University and Prof. Robert Wood of the University of Delaware in which we are (1) making substantial improvements in theoretical equations of state for aqueous nonelectrolytes and electrolytes, based largely on data collected during previous DOE-funded research, (2) pursuing novel applications of these equations of state to the study of high temperature/pressure geochemical processes, involving aqueous fluids, and (3) building predictive methods for organic solutes, using functional group contributions that allow estimates of thermodynamic properties at high temperatures and pressures. The experimental work is conducted at the University of Delaware. Geochemical applications of the data and development of predictive methods is done at Washington University. Efforts to improve the equations of state for nonelectrolytes and the functional group contributions are shared between the two labs, because this task in particular requires close collaboration between the two principal investigators.

Results: Progress in developing new equations of state has been presented at national meetings (ACS and GSA) by Mitch Schulte, the graduate student who is conducting this research as part of his $\mathrm{PhD}$ thesis. The new equations are considerably more accurate than the revised Helgeson-Kirkham-Flowers (HKF) equations for nonelectrolytes, and the results are being prepared for publication. The equations and estimation procedures have been tested against data recently obtained by Schulte in the lab of Prof. Vladimir Majer at the Université Blaise Pascal in Clermont-Ferrand, France. As a consequence, new methods for making predictions for organic solutes are also near completion. Dr. Jan Amend has been hired as a post-doc to pursue theoretical developments closer to the critical point of $\mathrm{H}_{2} \mathrm{O}$ and to expand on the functional group estimation procedure. Usefulness of the revised-HKF equations for inorganic ions, electrolytes, and complexes has expanded. Revised data and parameters for aqueous ions and hydroxide complexes are in press at Geochimica et Cosmochimica Acta (Shock et al., 1996). Exploration continues on methods to use the revised-HKF approach at pressures $>5 \mathrm{~kb}$. 
GRANTEE:

GRANT:

TITLE:

PERSONS IN CHARGE:

\section{UNIVERSITY OF WASHINGTON}

Geophysics Program

Seattle, Washington 98195

DE-FG06-92ER14231

Two- and Three-Dimensional Magnetotelluric and Controlled Source Electromagnetic Inversion

John Booker and Martyn Unsworth (206-543-4980; E-mail unsworth@geophys.washington.edu)
Objectives: The objective is to develop efficient techniques for high resolution imaging of multidimensional electrical structure of the Earth's subsurface.

Project Description: Because the electromagnetic inverse problem for natural sources is generally multidimensional, most imaging algorithms saturate available computer power before the complete data set can be addressed. We have developed an algorithm called the rapid relaxation inversion (RRI) to directly invert large multidimensional magnetotelluric (MT) data sets. This method is orders of magnitude faster than competing methods. The key to its efficiency is that an improvement in the structure directly beneath an MT site can be calculated from a one-dimensional (1-D) inverse problem if one has information about the multidimensional fields as a function of depth beneath the site. The capability of RRI for two-dimensional (2-D) structure is being enhanced, and it is being extended to fully three-dimensional (3-D) structure. In addition, related holographic electromagnetic imaging techniques are being investigated and RRI is being extended to handle data generated by controlled source techniques.

Results: In the past year, RRI has been extended to invert data generated by controlled sources. This has been achieved by interfacing the RRI algorithm and a finite element algorithm that model the EM fields of the transmitter in 3-D. The inversion has been successfully tested on synthetic and field data. In each case the inversion was able to generate a subsurface resistivity model that reproduced the data. The inversion of synthetic data produced a model containing the important features present in the model used to generate the data. In the case of the field data, the model agreed well with independent estimates of subsurface structure, such as well-log information. The approximations used in the original RRI appear to work well for the controlled source electromagnetic signals. Progress has also been made on two algorithms used to obtain accurate MT data from field data. In the first, an alternative formulation of the Groom-Bailey tensor decomposition method is used to remove the effect of shallow structure and to determine the regional 2-D strike direction. In the second algorithm, rho-plus, data is evaluated for consistency with a 1-D subsurface resistivity structure, and the apparent resistivity and phase are checked for mutual consistency. These algorithms have been found to be very useful in evaluating a number of MT data sets and in providing responses that can be analyzed with a 2-D inversion. 
GRANTEE:

GRANT:

TITLE:

PERSON IN CHARGE:
UNIVERSITY OF WISCONSIN

Department of Geology and Geophysics

Madison, Wisconsin 53706

DE-FG02-93ER14328

HRTEM Investigations of Interactions Between Minerals, Fluids, and Lithobiontic Communities During Natural Weathering

Jillian F. Banfield (608-262-0915; Fax 608-262-0693;

E-mail jill@geology.wisc.edu)

Objectives: HRTEM evidence strongly suggests that rates and mechanisms of reactions at interfaces between organisms and minerals differ from those occurring at surfaces, reacting in the absence of biological influences. Our current objective is to explore in detail the probable mechanisms and quantitatively determine the resulting chemistry and distribution of clay minerals.

Project Description: The project has been designed to explore, at high resolution, interfaces between communities of microorganisms and mineral surfaces. Lichen colonization of rock surfaces provides an ideal and well-defined microcosm for the study of microbemineral interactions. Our work focuses exclusively on characterization of intact interfaces with a variety of chemical and structural techniques, including highresolution transmission electron microscopy, analytical electron microscopy (AEM), polarized light microscopy, and confocal microscopy. Research is being conducted on samples of syenite from the Stettin complex in central Wisconsin colonized by the crustose lichens Porpidia albocaerulescens and Rhizocarpon grande and on Saint Peters sandstone in western Dane County, Wisconsin, colonized by Rinodina tephraspis.

Results: Results from interfaces among organic polymers, clays and feldspars, pyroxenes, and amphi- boles verify that smectites grow on and within organic films. Quantitative AEM data suggest that postcrystallization modification of clay compositions occurs by interaction with fluids whose chemistry is less impacted by proximity to primary mineral surfaces. For example, smectites formed by biologically mediated weathering of ferrohastingsite are initially nontronitic. More evolved clay aggregates have substantial interlayer $\mathrm{K}$ and $\mathrm{Ca}$ and are slightly aluminous, indicating cation exchange with solutions and overgrowth by aluminumbearing 2:1 layers.

Confocal microscopy has revealed a complex consortium of microorganisms associated with quartz grains colonized by Rinodina tephraspis. In addition to the mycobiont and phycobiont, cyanobacteria, tentatively identified as Nostoc sp. and Gloeocapsa sp., are present. These genera, capable of nitrogen fixation, may play a critical role in the microbial community.

Experiments using the $\mathrm{pH}$-sensitive, ratiometric SNARF 1 fluorescent dye indicate only small gradients in $\left[\mathrm{H}^{+}\right]$at mineral-organic interfaces. Consequently, work initiated recently involves experiments to extract proteins from extracellular polymers to test the hypothesis that minerals are dissolved by specific enzymes secreted from fungal/algal/bacterial cells (e.g., "mineralases," analogous to cellulases and chitinases). 
GRANTEE:

GRANT:

TITLE:

PERSON IN CHARGE:

\section{UNIVERSITY OF WISCONSIN}

Department of Geology and Geophysics

Madison, Wisconsin 53706

DE-FG02-93ER14389

Microanalysis of Stable Isotope Ratios in Geothermal Systems: Long Valley and Skye

John W. Valley (608-263-5659; Fax 608-262-0693; E-mail valley@geology.wisc.edu)

Objectives: This project has developed and applied new geochemical techniques to decipher the complex effects of superimposed hydrothermal events in modern and fossil geothermal systems. At the Long Valley caldera, these results provide insight into the nature of magma chambers at depth, the size of the modern geothermal resource, and the volcanic hazards. On the Isle of Skye, Scotland, samples of granite from beneath an ancient, deeply eroded caldera provide new insights for active systems.

Project Description: This study focuses on samples from the Long Valley Exploratory Well and related rocks from the Mt. Morrison roof pendant, and the Isle of Skye. New techniques allow analysis of stable isotope ratios in ultra-small samples, and the oxygen isotope ratio can now be contoured across single crystals. This study is the first application of this technology to hydrothermally altered rocks. Mineral zonation patterns provide new insights into the process of water/rock interaction: mechanisms of exchange, timing, degree of equilibration, variability of fluid fluxes, and fluid sources. Enhanced understanding of these processes is essential for improving computer models of fluid flow through hot rocks. The goals of this study continue to be enhanced as we refine new techniques of ion microprobe and laser analysis of oxygen isotope ratio.

Results: Advances have been made to improve the accuracy of laser probe analysis, and ion microprobe analysis is finally possible for silicate minerals. During the past year ion probe precision for $\sigma^{18} \mathrm{O}$ in silicate minerals has been improved from \pm 1.0 to $\pm 0.4 \%$, permitting many new studies. Ion probe analysis of hydrothermally altered quartz from Skye granites shows that fluid flow and isotopic exchange is heterogeneous, anisotropic, crack controlled, and not equilibrated. Laser analysis of zircons proves that some granite magmas on Skye were low in $\sigma^{18} \mathrm{O}$ before crystallization, and thus the hydrothermal system was more localized than some previous studies have thought. At least five generations of quartz veins cut basement quartzites in LVEW drill core from beneath Long Valley. Combined ion probe and laser analysis demonstrates an early high temperature origin for the earliest four, and only the latest generation involved meteoric water. In contrast, laser analysis of micro domains in the overlying volcanic rocks in LVEW documents an inverted thermal gradient resulting from vigorous, postBishop tuff hydrothermal convection. 
GRANTEE:

GRANT:

TITLE:

PERSON IN CHARGE:
UNIVERSITY OF WISCONSIN

Department of Geology and Geophysics

Madison, Wisconsin 53706

DE-FG-02-91ER14194

\section{Poroelasticity of Rock}

Herbert F. Wang (608-262-5932; Fax 608-262-0693; E-mail wang@geology.wisc.edu)

Objectives: The primary objective is to develop theory for, and obtain laboratory measurements of, poroelastic parameters to predict rock mass behavior under quasistatic conditions (Darcy flow).

Project Description: The scientific problem is to understand the fluid response of a rock mass to stress and vice versa. The quasistatic poroelastic constants are important for characterizing such coupled phenomena as subsidence due to large amounts of fluid extraction from reservoirs and fluid pressure response to the stress field generated by an earthquake. The project methodology includes laboratory measurement of poroelastic coefficients and theoretical development of the constitutive equations for the poroelastic response of a fractured, porous rock.

Results: A theory of the poroelastic response of fractured, porous rock developed in collaboration with
James Berryman at LLNL was applied to a fractured Berea sandstone to show that a change in pore pressure within matrix blocks produces about $10 \%$ of the volume change due to an equal but opposite change in confining pressure, whereas the same change in pore pressure within fractures is about $90 \%$ as effective. The theory was also applied to solve analytically the problem of one-dimensional consolidation of a double-porosity medium. Sudden application of a vertical load builds up fracture pressures above matrix pressures, which leads to a time-dependent increase in the matrix pressure. The transient pulse technique for permeability measurements was analyzed numerically, using a full poroelastic formulation to show that the storage coefficient obtained from laboratory experiments is that for constant stress, which is $50 \%$ greater than that for uniaxial stress conditions. 
GRANTEE:

GRANT NO.:

TITLE:

PERSON IN CHARGE:

\section{UNIVERSITY OF WISCONSIN}

Department of Geology and Geophysics

1215 West Dayton Street

Madison, Wisconsin 53706
DE-FG02-94ER14439

Testing the Correlation Between Seismic Stratigraphy, Diagenesis, and Physical Rock Properties: Evaluation of Fluid Flow During Early and Late Diagenesis

Jean M. Bahr (608-262-5513; Fax 608-262-0693; E-mail jmbahr@geology.wisc.edu)
Objectives: This project, conducted in collaboration with G. Eberli and P. Swart of the University of Miami, was designed to test the conceptual models of diagenesis developed by those researchers with numerical modeling of fluid flow through the Great Bahama Bank.

Project Description: The finite difference code HST3D was used to simulate fluid flow, heat transport, and solute transport through the Great Bahama Bank. Simulations focussed on a 2-D profile for which the major hydrologic units and properties were chosen, based on available seismic and core data provided by the Miami collaborators. The model was used to evaluate the relative importance of mechanisms that have been proposed to drive fluid circulation in carbonate banks, including reflux of dense water from the shallow bank, circulation associated with freshwater recharge over an island, cross-bank flow driven by differences in sea level across the bank, and thermal convection generated by the natural geothermal flux.

Results: Simulations conducted in fiscal year 1996 included ones in which density variations due to salin- ity contrasts were accounted for in addition to density variations resulting from temperature variations. Sensitivity analyses of these models incorporating solute transport generally confirmed conclusions developed from previous simulations that included only heat and fluid transport. Evaporative reflux and freshwater recharge have local effects on salinity and flow directions, but the bank scale circulation patterns and steady state-temperature distributions are relatively insensitive to these processes. For the range of parameters and boundary conditions investigated, geothermal flux is the dominant driving force for bank scale fluid circulation. Simulated temperatures vary significantly across the bank with regions of high temperature occurring in zones of upflow in the interior. Of particular interest are the relatively high temperatures that developed within the Straits of Andros deposits for a number of hypothetical permeability distributions. This suggests a potential mechanism for accelerated hydrocarbon maturation if good source rocks are present in these deposits. 
Woods Hole, Massachusetts 02543

GRANT:

TITLE:

PERSON IN CHARGE:
DE-FG02-94ER14435

Robust, Controlled Leverage Magnetotelluric Data Analysis

Alan D. Chave (508-289-2833; Fax 508-457-2150; E-mail

alan@faraday.whoi.edu)
Objectives: Objectives are to develop an improved understanding of the causes of bias and variability in magnetotelluric response function estimates, particularly in the presence of source field problems and cultural noise, to develop new processing methods that will eliminate these problems, and to apply tensor decompositions for galvanic distortion to the response functions in an automatic fashion.

Project Description: Over the past decade, a collaboration with D. J. Thomson of AT\&T Bell Laboratories has resulted in major improvements to magnetotelluric data processing methodology, including robust remote reference algorithms that eliminate outliers in the electric field and extension of the jackknife to obtain nonparametric estimates of confidence limits; however, these methods do fail under some circumstances. This research will focus on further advances that will be driven by analysis of diverse types of data, including those of interest in industry. The major problems to be addressed include

1. Investigating the efficacy of multiple remote references

2. Designing algorithms that control the influence of extreme data in the magnetic as well as the electric field (which conventional robust algorithms cannot do)

3. Testing the hypothesis that statistically-based data sorting can remove many of the confounding influences that sometimes affect magnetotelluric data

4. Testing the importance of magnetic field galvanic distortion in a variety of data
Results: A robust, controlled-leverage algorithm has been developed that automatically removes the influence of outlying electric field data (as for conventional robust methods) and also controls the leverage effects of unusual magnetic field data. The latter is accomplished by weighting, based on the size of the diagonal elements of the hat matrix, and has necessitated the derivation of the statistical distribution of this quantity for Gaussian data that has evidently not been done previously. The algorithm has been extended to allow multiple instead of single remote references. This involves computing the projection of the local magnetic field from all of the remote sites and reduces to the conventional remote reference method when only a single reference site is available. In addition, the projection operation is performed robustly, opening up a new way of removing cultural noise in the local magnetic field if the remote site is not affected by it. The multiple remote reference, robust, controlled-leverage algorithm with jackknife error estimates has been programmed and is being tested with a variety of data to refine the approach. This has occupied most of the effort over the past year. A manuscript describing these results is in the final stages of preparation, needing only the addition of several suitable examples to reach completion.

An X-windows graphical user interface to the robust, controlled-leverage code is nearly completed and is also undergoing testing. This interface greatly simplifies setting up and executing runs and in particular facilitates viewing graphical output from a run. One 
of the data sets used for testing was collected in northern Saskatchewan and is strongly influenced by auroral effects. Like cultural noise, the aurora affects both the electric and magnetic fields and hence poses serious analysis problems. The robust, controlled-leverage method has effectively eliminated its influence in an automatic manner. Such a result could previously be achieved only by tedious culling of the nighttime data. This result was presented at the Workshop on Electromagnetic Induction in Onuma, Japan, in summer 1996 and is currently being written up for publication. 
GRANTEE:

GRANT:

TITLE:

PERSON IN CHARGE:
WOODS HOLE OCEANOGRAPHIC INSTITUTION

Department of Marine Chemistry and Geochemistry

Woods Hole, Massachusetts 02543

DE-FG02-92ER14232

\begin{abstract}
Geochemical Incorporation of Sulfur into Organic Matter: Role of Sulfur in the Formation and Diagenesis of Macromolecular Organic Matter in Sediments
\end{abstract}

Timothy I. Eglinton (508-289-2627; Fax 508-457-2164; E-mail teglinton@whoi.edu)

Objectives: The overall goal of this study is to improve our understanding of the role of sulfur in organic matter (OM) diagenesis. Two specific objectives are outlined: (1) development and evaluation of structural models quantitatively describing organicallybound sulfur (OBS) in sediments and (2) application of these models for assessment of sulfur incorporation into organic matter as a preservation (kerogen formation) mechanism and for elucidation of diagenetic pathways for OBS.

Project Description: In marine sediments, sulfur is intimately involved in organic matter diagenesis. Several recent studies suggest an important role for sulfur in the formation of macromolecular organic matter in sediments. The experimental and theoretical approach is based on the premise that OBS can be represented as model structures that differ in S-linkage type (intermolecular linkages vs intramolecular bonds), as well as the number of linkages per molecule and the number of $\mathrm{S}$ atoms in each linkage. These models are important for accurate prediction of organic carbon burial efficiency in sediments and delineation of temperature-time requirements for petroleum generation. $\mathrm{X}$-ray absorption spectroscopy (XANES) is used for determination of S-speciation. Chemical degradation experiments provide information on linkage type, the sites of S-attachment, the number of linkages involved, and the molecular structures of the S-containing molecules. Analytical pyrolysis is used to derive structural information and to estimate organic S content. S-iso- topic measurements yield information on the timing of diagenetic $S$ incorporation. These analyses are performed on fractions isolated from sedimentary OM according to approximate molecular size and/or solubility. The Peru margin and Miocene Monterey Fm, $\mathrm{CA}$, are the primary study areas because of their high sedimentary organic carbon and sulfur contents and equivalence in terms of (paleo)depositional environment.

Results: Structural characterization of sulfur-containing macromolecules. In a collaboration with Dr. Colin Snape (Univ. of Strathclyde, Scotland), we have been comparing high pressure temperature-programmed reduction (TPR) with other geochemical methods (XANES, analytical pyrolysis) in terms of their ability to provide compositional information on sedimentary organic sulfur. In TPR the sample is progressively heated under hydrogen pressure, and resulting S-containing products that evolve are reduced to $\mathrm{H}_{2} \mathrm{~S}$. Under these conditions conversion of all forms of organic sulfur to $\mathrm{H}_{2} \mathrm{~S}$ approaches $100 \%$, and the thermal evolution profile of the $\mathrm{H}_{2} \mathrm{~S}$ (measured mass spectrometrically) is indicative of the sulfur speciation. TPR has an advantage over XANES in that it is able to quantitatively distinguish mono-, di-, and poly-sulfides.

We compared assessments of sulfur speciation based on TPR and XANES for a suite of Peru margin and Monterey Formation kerogens. TPR indicated that di/polysulphides account for virtually all the reduced sulfur in samples collected from surficial Peru sedi- 
ments. In contrast, mono-sulfides have been found to be the dominant sulfur form in deeper Peru sediment samples (>50 m) and the Monterey kerogen. This new information is highly complementary to XANES and helps to shed further light on the mode of sulfur linking in sedimentary organic matter. In a parallel study, we are using XANES and analytical pyrolysis, coupled with sulfur isotopic measurements (see below), to examine the organic sulfur speciation in a series of Peru sediment samples separated by a field-flow fractionation (SPLITT) method on the basis of particle size/ density. Ten size fractions were obtained, ranging from $>250 \mathrm{~mm}$ to $<1 \mathrm{~mm}$. Our results showed a striking correlation between particle size and sulfur speciation. Reduced organic sulfur forms, comprising mainly organic polysulfides and sulfides, were associated smallest size fraction. With increasing particle size, reduced forms of sulfur decreased in abundance with a concomitant increase in oxidized forms of sulfur, including sulfonates and sulfate esters. More detailed compositional studies are in progress towards understanding the significance of these results.

Sulfur isotopic studies. We are studying variations in sulfur isotopic composition $\left(\delta^{34} \mathrm{~S}\right)$ of OBS within discrete sedimentary phases. The impetus for this aspect of our research is to better define the mode and timing of sulfur addition to sedimentary organic matter (and hence predict its distribution in sediments). Previous isotopic studies have only distinguished crude sub-fractions of sedimentary sulfur. Most importantly, the organic phases studied do not allow for discrimination of "diagenetic" vs "biogenic" sulfur, and this has frustrated attempts to pinpoint the timing of OBS formation with respect to other [inorganic] sulfur sinks.

We are attempting to overcome this limitation through $\delta^{34} S$ determinations on well-defined sub-frac- tions within sedimentary organic matter. Specifically, we are endeavoring to "tease apart" variations in isotopic composition in the following three ways: (1) SPLITT fractionation, (2) gel permeation chromatography (GPC), and (3) preparative capillary gas chromatography (PCGC).

In the first approach, $\delta^{34} S$ values for pyrite sulfur from the SPLITT-separated Peru sediment samples described above show an interesting trend. Values vary by almost $10 \%$ (from $-36 \%$ o to $-27 \%$ ), with the most depleted values occurring in the $38-15 \mu \mathrm{m}$ size fraction and most enriched values in the $>250 \mu \mathrm{m}$ fraction. This implies that pyrite formation occurs initially in the $38-15 \mu \mathrm{m}$ fraction as a result of iron reacting with ${ }^{34} \mathrm{~S}$-depleted $\mathrm{H}_{2} \mathrm{~S}$ from bacterial reduction of sulfate in surficial pore waters. In the second approach we are investigating $\delta^{34} S$ variations in different molecular size fractions (isolated by GPC) from a Peru sediment sample. Here, we are working on the premise that early diagenetic sulfur addition may give rise to cross-linked macromolecules that would likely be different in molecular size and sulfur isotopic composition from biogenically-derived organosulfur compounds. Our final approach is designed to provide a definitive answer concerning the sulfur isotopic composition of diagenetically derived OBS. We are attempting the direct measurement of sulfur isotopic compositions of individual organic sulfur compounds isolated by PCGC. For these purposes we isolated a suite of $\mathrm{C}_{20}$ isoprenoid thiophenes and a steroidal thiophene from a Monterey shale sample. These compounds were chosen because they have an unequivocally diagenetic origin. Using the PCGC approach, we isolated $>100 \mu \mathrm{g}$ of each target compound (equivalent to $0.5 \mu \mathrm{M} \mathrm{S}$ ) in high purity. We are currently awaiting sulfur isotopic determinations on these samples. 
GRANTEE:

GRANT:

TITLE:

PERSON IN CHARGE:
WOODS HOLE OCEANOGRAPHIC INSTITUTION

Department of Marine Chemistry and Geochemistry

Woods Hole, Massachusetts 02543

DE-FG02-89ER13466

\title{
Organic Geochemistry of Outer Continental Margins and Deep Water Sediments
}

\author{
J. K. Whelan (508-289-2819; Fax 508-457-2164; E-mail \\ jwhelan@whoi.edu)
}

Objectives: The objective of this program is to develop a better understanding of processes of hydrocarbon generation and migration in coastal and offshore sedimentary basins as an aid in predicting favorable exploration areas for oil and gas.

Project Description: Our current research focuses on utilization of organic compounds in elucidating mechanisms, rates, and consequences of subsurface fluid flow processes. Our group at Woods Hole, in collaboration with the Geochemical and Environmental Research Group (GERG) at Texas A\&M, has been the principal organic geochemical arm of the Global Basin Research Network (GBRN) since its formation in 1989. The GBRN is a distributed network of scientists working to understand the coupled physical and chemical processes that control fluid movement in sedimentary basins.

Results: During the past several years, organic geochemical evidence has led to a very surprising conclusion - that vertical oil and gas injection from deeper intervals into shallower producing reservoirs may be a continuing process in some parts of the Gulf of Mexico, particularly at the shelf edge and in deeper water slope sediments that are currently an area of active exploration. The organic geochemical data show that oil and gas are being injected vertically from deeper reservoirs or sources $(20,000$ to $25,000 \mathrm{ft})$ into some Pleistocene oil and gas reservoirs of Eugene Island Block 330 in the offshore Louisiana Gulf Coast at the present time.

Research this year has focused on gaining further proof for the concept of continuous reservoir replen- ishment, which we believe is pervasive in deeper water continental slope areas to the south of EI-330. Our focus has been on detailed spatial and temporal variations in fluid compositions in the EI-330 Field where "dynamic fluid injection" was first suggested. We have shown conclusively that variations in reservoir oil compositions over periods of a year to several years are real and are not being caused by sampling, storage, or analytical artifacts. Temporal changes in reservoir oil and gas compositions, which are the distinguishing characteristic of dynamic fluid flow processes, were unexpected and therefore not previously examined. We have used statistical and graphical treatment of the detailed compositions of fluids collected over an eightyear period at EI-330 to show that temporal variability of EI-330 oils and gases over time scales as short as a year are occurring; however, the process is spotty at EI-330 for different reservoirs. Temporal changes in oil compositions are not occurring in South Marsh Island 128 reservoirs just to the north. Extensive previous research by the GERG strongly suggests that dynamic injection both into reservoirs and directly to the sea floor is pervasive along the continental slope to the south of EI-330, where active subsidence as well as oil and gas generation are presently occurring. The chemical characteristics of the EI-330 oils also show that the newly injected oil is coming from much deeper intervals and is not derived from localized migration among producing reservoirs. These results are consistent with the generation-migration scenario we proposed last year: biomarkers show that oils in different 
reservoirs of the EI-330 field are related to one another and to a deeper source rock of Jurassic-early Cretaceous age. These oils are envisioned to have been initially generated from marine source rocks and trapped under salt. With further burial, this marine source/reservoir was carried down as a sealed system. At the present time, oil cracking to gas has progressed far enough to cause pressure buildup and rapid migration of oil dissolved in gas upward through geopressure. The resulting release of pressure causes a fractionation with progressively lighter oil fractions filling progressively shallower reservoirs.

This work strongly supports a dynamic fluid injection model for migration of oil and gas into EI-330 reservoirs and areas to the south. The short-term (years) time scale and continuous nature of oil and gas migration from depth in fields such as EI-330 suggest that oil and gas fluid flow in this area may need to be treated mathematically as a "steady state" rather than as a finite fixed resource. Furthermore, these findings lead us to consider that similar processes may be occurring worldwide beneath other active oil- and gas-generating areas, such as the North Sea, as well as beneath actively subsiding oil- and gas-generating basins, including most of the major river deltas of the world. If so, we may need to reconsider how we think about oil and gas reserves in these areas. Similar dynamic fluid flow processes may account for a significant fraction of the 94\%-96\% of oil and gas that is being continuously generated and expelled worldwide but that is never trapped. Part of our research this year has been in considering experimental means to test where and at what rate these hydrocarbons are moving upward and are being discharged through the seafloor into the world's oceans. Seeping oil and gas, after suitable biological alteration in the water column, could be forming a significant fraction of the ubiquitous "old" dissolved organic carbon (DOC) in the deep oceans. The source of this "old" DOC, which constitutes one of the earth's largest exchangeable carbon reservoirs, is currently a major unsolved oceanographic mystery. 
GRANTEE:

GRANT:

TITLE:

PERSONS IN CHARGE:
UNIVERSITY OF WYOMING

Department of Geology and Geophysics

Laramie, Wyoming 82071-3006

\section{DE-FG03-96SF14623/A000}

\section{Mineral Dissolution and Precipitation Kinetics: A Combined Atomic-Scale and Macro-Scale Investigation}

Carrick M. Eggleston (307-766-6769; Fax 307-766-6679; E-mail carrick@uwyo.edu) and Kevin G. Knauss (510-422-1372;

Fax 510-422-0209; E-mail knauss@s19.es.llnl.gov)

Objectives: Our objectives are to build and test a contact atomic force microscope (AFM) capable of operation at up to $150^{\circ} \mathrm{C}$ and $6 \mathrm{~atm}$ pressure; to apply this AFM to direct, in situ, and real-time observation of step dynamics during dissolution and growth of oxide and silicate minerals at elevated temperature and pressure; and to use rate and stoichiometric data from parallel macroscopic dissolution and growth experiments to interpret mineral rates, using a combined microscopic Burton-Cabrera-Frank and macroscopic surface-complexation model.

Project Description: This project combines atomic-scale and macroscale approaches to the study of mineral-fluid interaction in order to significantly improve our understanding of, and ability to predict the course of, mineral dissolution and precipitation processes. We are building a high temperature flowthrough fluid cell for the AFM. This will allow atomicscale kinetic experiments under geologically relevant conditions for important oxide and aluminosilicate min- erals. Identical conditions will be investigated, using macroscopic wet-chemical rate experiments, including conditions both near and far from equilibrium. We will measure rates of dissolution and precipitation, determine activation energies, measure rates of step motion across surfaces (including anisotropy), and investigate step-step interactions that affect rate. We will then be able to address many still open questions concerning the exact forms for rate laws near and far from equilibrium, the microscopic interpretation of these rate laws in terms of dissolution and precipitation mechanisms operating under various conditions, and the question of what exactly the "active area of interaction" and "active sites" are on mineral surfaces.

Results: This project was only recently initiated. We are still in the design stages for the proposed high temperature and pressure AFM. Several important design modifications have been made so that we can use existing commercial control electronics, software, and, in some cases, hardware. 
GRANTEE:
GRANT:

TITLE:

PERSON IN CHARGE:
YALE UNIVERSITY

Department of Geology and Geophysics

New Haven, Connecticut 06520-8109
DE-FG02-95ER14522

\section{A Field Experiment on Plants and Weathering}

Robert A. Berner (203-432-3183; Fax 203-432-3134;

E-mail berner@milne.geology.yale.edu)
Objectives: A major control on atmospheric $\mathrm{CO}_{2}$ over long geological time scales is the chemical weathering of silicate minerals, and an important factor in this weathering is the role played by higher plants. Our objective is to determine the quantitative effect of trees and other vascular plants in accelerating silicate weathering rate by performing controlled experiments under natural field conditions.

Project Description: Dissolved element concentrations in throughfall and drain waters for small (60 $\mathrm{m}^{2}$ ) vegetated and unvegetated plots are presently being determined as part of an ongoing ecological experiment at the Hubbard Brook Experimental Forest Station in New Hampshire. Three plots are being investigated: one that was planted with red pine in 1983 , one planted with two species of grass also in 1983, and a control containing only mosses and lichens and kept free of higher plants over the same period. All plots are lined with an impermeable plastic so that all water passing through the plots can be collected at an outlet pipe. By correcting for measured rain, snowmelt, and dry deposition inputs, as well as evapotranspiration (by normalizing to $\mathrm{Cl}$ ), we can determine relative release rates of dissolved species in drainage from each plot. Flow rates are determined at the site, and we are analyzing waters collected over the past 12 years and now being collected weekly for $\mathrm{Na}^{+}, \mathrm{K}^{+}, \mathrm{Ca}^{++}, \mathrm{Mg}^{++}$, $\mathrm{SO}_{4}^{--}, \mathrm{NO}_{3}^{-}, \mathrm{Cl}^{-}, \mathrm{HCO}_{3}^{-}, \mathrm{F}, \mathrm{H}_{4} \mathrm{SiO}_{4}$, and $\mathrm{pH}$. These water chemical results, when combined with data on storage in growing biomass and soil (from our results and those of other workers), will allow us eventually to obtain overall element release rates from primary minerals via chemical weathering.

Results: We have processed over 10,000 of our chemical analyses of the drainage waters from the Hubbard Brook plots, covering the period 1983-June 1996 in order to look for trends. One major discovery is that the fixation of $\mathrm{CO}_{2}$ as $\mathrm{HCO}_{3}^{-}$is accelerated under the trees during the winter and early spring. We hypothesize that this is due to the protection from sulfuric and nitric acid precipitation during the winter by a snow cover and the consequent buildup of alkalinity due to continued silicate weathering by organic and carbonic acids. This "old" water is then gradually flushed out in the spring, neutralized, and replaced by acidic snowmelt. We have also discovered a simple linear relation between dissolved $\mathrm{Ca}^{++}$and $\mathrm{Mg}^{++}$for the drainage waters from all three sandboxes, which we interpret as ion exchange equilibrium on clay minerals. Additional work has shown that biogenic uptake by both the red pines and grasses exceeds loss of silica in drainage and that total silica release from weathering is accelerated by trees and grasses relative to the bare plot. 
GRANTEE:

GRANT:

TITLE:

PERSONS IN CHARGE:
YALE UNIVERSITY

Department of Geology and Geophysics

New Haven, Connecticut 06511 results and to develop new techniques along four directions: (1) theoretical modeling of coupled fluid flowchemical reactions, (2) experimental and theoretical studies of water-rock reactions, (3) collection and interpretation of stable isotopic data from fluid flow systems at the regional scale; vein scale, and mineral grain scale in several geological environments, and (4) geochemical field-based studies of transport and reaction in environments, ranging from soils to sedimentary basins to high-grade metamorphic rocks.

Project Description: The main thrust of the theoretical modeling of coupled fluid flow and chemical reactions, involving kinetics, has been to understand the differences between equilibrium, steady-state, and non-steady-state behavior of the chemical evolution of open fluid-rock systems. These differences have not been fully appreciated in previous models. The computer codes developed in this project numerically treat multicomponent, finite-rate reactions combined with advective and dispersive transport in one, two, and three dimensions and incorporate isotopic exchange as well as heat and mass transfer. The codes also model flow and reaction along both fractures and porous media simultaneously. Experimental work has focused on obtaining the kinetic rate laws of pertinent silicatewater reactions. Theoretical studies have used ab initio quantum mechanical techniques to obtain the kinetics and mechanisms of silicate surface reactions.

Stable isotope studies have focused on new sampling strategies and techniques. These strategies and techniques provide data sets that can be input into transport and reaction models to determine the length and time scales relevant to fluid transport in a wide variety of geologic settings. These settings include (1) the Wepawaug metamorphic schist, (2) the Irish base-metal sediment hosted ore system, (3) the Olympics accretionary wedge, and (4) the Dalradian metamorphic complex in Scotland. Geochemical field-based studies are being carried out in the Pijiguaos bauxite deposit in Venezuela and in each of the stable isotope study areas. The field data, geochemical data, isotopic data, and experimental and theoretical rate data are used as input to or constraints on the numerical models.

Results: In the last year, we have made remarkable progress in our modeling of kinetically controlled quartz dissolution and precipitation in a two-dimensional heterogeneous permeable medium. Simulations include short-term convection, long-term convection, and forced flux injection. Implementation of a new spectral transform technique for solving Darcy's law with significant spatial variation in permeability has allowed us to model features never visualized in convective systems before. These include (1) oscillatory thermal boundaries, leading to quartz zonation down to the smallest observable scale, (2) saturation state reversals in much of the domain, (3) fluid velocities that change by up to an order of magnitude over the course of an oscillatory cycle, (4) enhanced fluid disequilibrium in rapidly advecting high permeability zones, (5) shifting locations of rapid flow zones due to dissolution and precipitation, and (6) regions of undersatu- 
rated upwelling fluid moving down temperature and regions of oversaturated downwelling fluid moving up temperature, both cases opposing the conventional wisdom based on equilibrium (Bolton, Lasaga, and Rye, 1996a).

We have completed the formulation and code development of the multimineralic flow/reaction system for albite, quartz, gibbsite, kaolinite, and paragonite. This code will allow us to examine more complex feedbacks in a nonisothermal heterogeneous porous medium (Bolton, Lasaga, and Rye, 1996d).

The experimental work pioneered in our laboratories continues to produce important results on kinetic rate laws of silicate-water reactions. Recent experiments with smectite, anorthite, and the zeolites analcime and clinoptilolite have confirmed the nontrivial dependence of dissolution rate on DGR. The effects of $\mathrm{pH}$ and $\mathrm{Al}$ inhibition are also being studied in more detail. The development of new column experiments (see below) constitutes an important step in conducting laboratory kinetics experiments that more closely reproduce natural systems. The excellent agreement between model and experimental results provided a valuable test of the form of the rate law used to describe mineral dissolution. Similar approaches are currently being used in combination with experimental work related to the dissolution of kaolinite and the effect of oxalate in the dissolution of gibbsite.

Phase shift interferometry (PSI) is a relatively new surface technique that provides $\sim 1 \mathrm{~nm}$ height resolution with a lateral resolution on the order of $\sim 1 \mu \mathrm{m}$. The most basic PSI design involves a Michelson interferometer, but the reference mirror is moved mechanically in steps of $1 / 8$ of the wavelength of the light source. Therefore, three phase-shifted interferograms are recorded and used to calculate the phase map of the surface, which is related to the surface topography.

A new in situ near-atomic scale hydrothermal system based on PSI is being built at Yale and will be the first of its kind. The equipment will open up a whole new area of information on the dynamics of features, such as steps, etch pits, and spirals on the surfaces of many of the important silicates and aluminosilicates. Because the kinetics of many of these minerals are very slow at $25^{\circ} \mathrm{C}$, the equipment will be used to study the rates and mechanisms of mineral dissolution/precipi- tation under hydrothermal conditions up to $350^{\circ} \mathrm{C}$ and 300 bars.

In the Wepawaug Schist, the application of the experimental data to the kinetics of isotopic exchange of water with quartz and the model results has already shown that fluid flow was transient in cracks (now preserved as veins). Not only was the flow transient, the isotopic composition of the fluid oscillated between values that were istopically lighter and heavier than the surrounding host rocks.

Oxygen isotopic zonation in garnets as well as isotopic, modal, and chemical profiles for individual minerals in wall rocks next to veins show that each fluid recorded in the veins infiltrated and reacted with the wall rocks. Garnets are istopically zoned with the cores being isotopically lighter than the rims. Staurolite and kyanite throughout the profile formed late and are isotopically heavy. Quartz, biotite, and muscovite have intermediate isotopic compositions, and plagioclase is isotopically light. These results make it clear that we can no longer consider metamorphic rocks to be "closed or semi-closed" systems. Regional metamorphic rocks are, in many cases, metasomatic in origin. We can never go back to looking at whole rocks or single minerals, and we can never go back to looking at a single locality; however, the rocks do preserve some of the fluid flow history, and we can unravel that history.

Over the last two years, we have collaborated with the Central University of Venezuela and the Venezuelan bauxite mining company, Bauxilum, to obtain data on the huge lateritic bauxite deposit in the "Los Pijiguaos" region, located in the NW edge of the Guiana Shield. To characterize weathering properly, we need accurate modal data as well as chemical data. This fact required us to develop an entirely new technique to obtain accurate modal analyses of samples that contained both gibbsite $\left(\mathrm{Al}(\mathrm{OH})_{3}\right)$ and kaolinite $\left(\mathrm{Al}_{2} \mathrm{Si}_{2} \mathrm{O}_{5}(\mathrm{OH})_{4}\right)$. Accurate modal analyses of many bauxite samples were obtained using standard image analysis techniques on back scattered electron (BSE) images on the electron microprobe/SEM system. Simulations, using our coupled reaction flow models, in both one and two dimensions, have shown that long time scales (several millions of years) are required to produce the observed weathering profiles and that the pres- 
ence of a transition zone with both gibbsite and kaolinite is only predicted if kinetic rate laws are used.

Comparison with the one-dimensional model requires that mechanical denudation has been active during the formation of the bauxite to explain the limited thicknesses of the weathering profiles in the field. In the two-dimensional modeling, the characteristics of the flow field are such that the most intense weathering and the maximum thicknesses of the weathering profiles are developed close to the vertical cliffs that limit the extension of the plateau on which the Los Pijiguaos bauxite is found (most lateritic bauxites formed on plateaus are limited by steep slopes). In the field, weathering profiles become thinner upon approaching these steep slopes because physical erosion is most intense.

Papers: Bolton, E.W., K.A. Maesch and I M. Lilly, 1995, A wavelet analysis of Plio Pleistocene climate indicators: A new view of periodicity evolution, Geophysical Research Letters, 22, 2753-2756; Ganor, J., Mogollon, J.L., Lasaga, A.C., 1995, The effect of pH on kaolinite dissolution rates and on activation energy, Geochim. Cosmochim. Acta, 59, pp. 1037-1052; Lasaga, A.C. and Rye, D.M., 1993, Fluid flow and chemical reaction kinetics in metamorphic systems, Amer. Jour. Sci., 293, 361-404; Lasaga, A.C., Soler,
J.M., Ganor, J., Burch, T.E., Nagy, K.L., 1994, Chemical weathering rate laws and global geochemical cycles, Geochim. Cosmochim. Acta, 58, 2361-2386; Nagy, K.L. and Lasaga, A.C., 1993, Simultaneous precipitation kinetics of kaolinite and gibbsite at $80^{\circ} \mathrm{C}$ and $\mathrm{pH} 3$, Geochim. Cosmochim. Acta, 57, 4329-4335; Steefel, C.1. and Lasaga, A.C., 1992, Putting transport into Water-Rock Interaction Models, Geology, 20, 680-684; Steefel, C. I. and Lasaga, A.C., 1994, A coupled model for transport of multiple chemical species and kinetic precipitation/dissolution reactions with application to reactive flow in single phase hydrothermal systems, Amer. Jour. Sci., 294, 529-592; Tanaka, N., Rye, D.M., Xiao, Y., and Lasaga, A.C., 1994, Use of stable sulfur isotope systematics for evaluating oxidation reaction pathways and in-cloud-scavenging of sulfur dioxide in the atmosphere, Geophys. Res. Letters, 21, 1519-1522; Xiao, Y., and Lasaga, A. C., 1994, Ab initio quantum mechanical studies of the kinetics and mechanisms of silicate dissolution: $\mathrm{H}^{+}\left(\mathrm{H}_{3} \mathrm{O}^{+}\right)$catalysis, Geochim. Cosmochim. Acta, Vol. 58, No. 24, pp. 5379-5400; Xiao, Y., and Lasaga, A. C., 1994, Application of ab initio quantum mechanical potential surfaces to mineral physics calculations, Mineralogical Magazine, Vol. 58A, pp. 992-993. 


\section{TOPICAL INDEX}

\section{GEOPHYSICS AND EARTH DYNAMICS}

Large-Scale Earth Dynamics

$12,56,108,109,124$

Evolution of Geologic Structures

Properties of Earth Materials $4,6,9,10,12,13,16,23,24,27,29,30,35,48,51,53,54,55,56,65$, $82,84,91,118,119,126,127,129,130,132,151,156,161,173,176$ Rock Mechanics, Fracture, and Fluid Flow $4,7,9,10,13,14,19,20,21,22,23,29,51,52,53,57$, $58,65,69,93,96,97,104,119,120,130,132,133$, $141,143,149,151,154,156,161,169,176$

Underground Imaging $3,8,10,11,18,33,34,87,108,118,120$, $133,136,156,163,164,173,178$

\section{GEOCHEMISTRY}

Thermochemical Properties of Geological Materials $25,26,27,28,36,37,40,41,44,47,48,49,54$, $55,72,75,77,78,80,90,98,99,114,116$, $122,137,139,140,162,180,184$

Rock-Fluid Interactions $3,4,12,14,15,28,43,45,47,48,49,55,67,68,70,72,80,88,89,90,96,102$, $106,122,134,137,139,143,147,158,166,171,172,174,182,184,185,186$

Organic Chemistry $4,6,31,55,68,102,106,134,145,166,172,174,180,182,185$

Geochemical Transport $12,15,16,25,26,27,42,48,54,67,70,73,75,80,82,84,85,89,90,91,99$, $100,102,110,112,116,121,122,131,143,160,166,171,172,175,186$

\section{ENERGY RESOURCE RECOGNITION, EVALUATION, AND UTILIZATION}

Resource Definition and Utilization $8,18,24,29,30,34,35,87,98,100,120,124,136,154,166,168$ Reservoir Dynamics and Modeling Properties and Dynamics of Magma $18,20,31,33,40,41,56,64,109,122,128,149,154,164$

Continental Scientific Drilling $77,86,91,123,175$ $120,153,165$

\section{HYDROGEOLOGY}

Fluid Transport Dynamics and Modeling $10,14,18,20,21,22,52,57,58,97,104,111$, $123,127,128,132,133,143,156,162,177$

Thermochemical Properites of Energy Materials $13,56,100,171$

Perturbations of Fluid Flow $19,57,58,93,104,169$

\section{SOLAR-TERRESTRIAL INTERACTIONS}

Magnetospheric Physics $38,39,63$

Upper Atmosphere Chemistry and Physics 39

Solar Radiation and Solar Physics 63 


\section{SCIENTIFIC INDEX}

${ }^{40} \mathrm{Ar}{ }^{39} \mathrm{Ar} 82$

Activity coefficients 25,111

Adsorption 3, 14, 48, 49, 55, 56, 81, 111, 116, 137,148

Anisotropy 11, 29, 39, 47, 48, 52, 120, 184

Aqueous electrolytes $16,102,172$

Aqueous geochemistry 41

Aqueous nonelectrolytes 172

Aqueous solutions 41, 44, 47, 81, 102, 116

Atomic force microscopy 3, 47, 56, 106

Atomic structure 3

Attenuation 36, 52, 96, 120, 153

Berthierine 68

Biomineralization 106

Biotite 46, 70, 112, 187

Born 8

Brittle fracture 130

Caliche 131

Calorimetry $78,79,140$

Capillary fingering 57,93

Capillary pressure 10

Carbon $5,13,14,24,35,43,44,46,65,66,72$, $75,180,183$

Carbonate minerals 47, 54, 78, 106

Carbonates $37,42,46,54,78,79,99,106,121$, $130,140,156$

Carbonyls 5

Cataclastic flow 130

Cation adsorption 111

Cementation 9, 20, 51, 67, 100, 106, 130

Chamosite: 68

Chemical diffusion $77,91,92$

Chemical potential $77,91,102$

Chemical remanent magnetization 134

Chemical weathering 185,188

Chemisorption 48,147

Chromium 15

Clays $13,41,55,67,140,148$

Climate $13,37,55,98,188$

Climate change 98

$\mathrm{CO}_{2} 12,14,35,40,41,43,44,46,47,65,70,72$, $78,102,114,115,145,148,171,185$
Colloids 73

Compressive fracture 7

Computer simulations $38,63,69,95,110,112$

Convection $63,86,91,104,123,125,162,175$, 177,186

Crystal chemistry 114,126

Crystal growth 106,107

Dating $12,21,28,36,37,38,100,121,131,134$, 160,169

Devolatilization 151

Diagenesis $5,6,13,37,42,43,55,67,68,85$, $110,111,121,151,152,156,177,180,186$

Diffusion $12,15,25,27,45,46,48,54,63,70$, $71,73,77,82,84,90,91,92,94,99,105$, $109,143,144$

Diffusion coefficients $25,27,54,73,77,84,99$

Diffusivity $46,70,104,143$

Dissolution $3,14,27,28,29,41,42,43,45,47$, $48,49,55,56,58,75,78,80,81,84,94,97$, $106,107,111,114,116,137,139,151,184$, $186,187,188$

Dissolution kinetics 111

DMO 33

DOC 183

Double-diffusive fingering 92

Earth resources $119,124,125$

Earthquake $29,36,69,87,95,118,120,136$, $141,142,154,176$

Earthquake models 69,95

Electrical conductivity $8,24,35,65,118$

Electromagnetic inversion 8,173

Energy transport 38

Enstatite 54, 55

Environment 3, 5, 8, 11, 15, 17, 19, 21, 26, 36, $38,39,44,45,47,49,68,70,73,89,90,93$, $95,100,104,105,106,112,114,124,125$, $126,137,139,143,147,149,151,158,159$, $160,163,166,168,171,180,182,186$

Equation of state 16,103

Fault zones 11, 15, 132, 141, 142, 151, 162, 169, 170

Faulting 12, 53, 86, 123, 132, 149, 154, 170 
Feldspar 41, 46, 70, 71, 82, 83, 112, 121, 137, 138,174

Ferron Sandstone 164

Fluid $3,4,9,10,11,12,13,14,15,20,21,24$, $26,27,28,29,40,41,42,43,45,46,52,57$, $58,65,66,67,70,71,72,84,85,90,93,96$, $97,100,104,107,109,110,112,118,119$, $122,132,134,135,139,143,144,147,149$, $151,152,153,154,155,156,161,162,166$, $169,171,175,176,177,182,183,184,186$, 187,188

Fluid flow 4, 10, 20, 21, 52, 57, 67, 93, 97, 100, $109,110,132,135,143,149,169,175,177$, $182,183,186,187,188$

Fluid inclusions 41, 43, 90, 166, 171

Forchheimer equation 128

Fracture $7,9,10,11,16,23,24,29,35,51,52$, $53,57,58,65,87,93,97,104,109,119,120$, $130,132,133,143,149,150,154,161,169$, 170,176

Fracture evolution 53,132

Fracture growth 9, 120, 169

Fracture localization 150

Fracture mechanics $51,130,149$

Fractured reservoirs 120

Fractured rock 10, 15, 52, 57, 93, 133

Friction $7,9,14,96,132,150,151,152,153$, 154,155

Galvanic distortion 178

Garnet 12, 24, 26, 27, 75, 84, 88, 187

Gas $6,11,12,13,14,15,20,21,26,27,29,31$, $33,37,40,42,43,51,56,57,58,59,64,65$, $70,77,84,87,96,97,100,101,104,106$, $114,120,122,125,127,128,130,143,144$, $145,146,154,156,157,160,161,181,182$, 183

Geochemical transport 3,143

Geochemistry 3, 5, 13, 17, 25, 36, 40, 41, 47, 54, $67,72,90,112,114,121,131,166,180,182$

Geochronology 36, 37

Geodesy 124

Geothermal 11, 16, 40, 41, 42, 43, 45, 46, 70, 77, $86,87,99,120,154,166,167,175,177$

Geothermal energy 70, 120, 154

Glass 9, 28, 57, 72, 93, 104, 117, 137, 144

Gold 116, 117, 160, 166, 167
Gravity $34,57,58,87,93,125$

Gravity fingering 58,93

Ground deformation 141

Growth kinetics 3, 55

Gulf of Mexico 67, 161, 162, 182

Heat capacity 102

Hermoelasticity 29

Heterogeneity 9, 23, 49, 86, 88

High field strength elements 26

High resolution $36,47,51,57,58,87,93,94$, $104,108,123,129,156,158,164,168,173$, 174

High temperature $16,29,35,43,44,69,86,95$, $102,140,166,172,175,177,184$

Hydrocarbon reservoirs 156,164

Hydrocarbons 40, 70, 96, 134, 135, 145, 151, $161,166,167,183$

Hydrogeology 162,169

Hydrology 169,170

Hydrothermal $27,40,41,46,70,71,75,84,89$, $90,121,139,166,167,169,170,171,175$, 187,188

Hydrothermal systems 75, 89, 166, 188

Hydroxyl 72

Hysteresis 10, 36, 78

Illite/smectite 68

Imaging $8,11,18,19,34,42,51,52,55,108$, $120,153,168,173$

Induced Seismicity 154

Inelastic gases 128

Instability $33,38,39,53,63,109,114,132,155$

Interface waves 133

Inversion $8,11,87,91,92,118,153,163,173$

Ion microprobe $26,27,42,43,46,54,70,77,84$, $91,98,175$

Iron oxides $35,42,44,147$

Isotopes $13,14,20,27,41,42,43,54,67,72$, $73,84,88,89,100,160$

Kinetics 3, 5, 13, 28, 55, 72, 81, 106, 109, 111, $139,151,152,184,186,187,188$

Lattice gas automata 97, 104

Laumontite $140,151,152$

Long Valley Caldera 12, 175

Low temperature geochemistry 90,121

Magma $12,34,65,72,77,86,87,99,122,123$, 175 
Magmatic systems 72

Magnetic reconnection 63

Magnetic storms 39

Magnetite authigenesis 134, 135

Magnetosphere 38, 39

Magnetospheric substorms 39,63

Magnetotellurics 136

Mantle $11,14,15,21,24,26,27,34,35,72,86$, $88,89,101,122,125$

Mass spectrometry $13,14,21,26,37,42,73$, $100,121,160$

Micro-XANES 15,16

Microanalysis 175

Micromechanics 51, 130

Microstructure 9, 23, 36, 51, 68, 70, 129, 143, 144,161

Migration $17,33,42,47,67,70,77,89,99,110$, $134,151,156,166,167,182,183$

Mineral growth $3,45,46,55$

Mineral surfaces $3,29,47,54,55,65,80,89$, $116,147,174,184$

Mineral-fluid interface 3

Mineralization 106, 110, 121, 166, 167

Mini-permeameter 56, 127

Molecular dynamics 48, 49, 86, 102, 123

Molecular simulation 123

Multicomponent convection 104

Nitrogen 75, 122, 174

Noble gases $12,37,122,160$

Nonlinear dynamics 109

Nonlinear elasticity 35

Oil migration 110,134

Organic sulfur $5,6,180,181$

Organically-bound sulfur 180

Oxidation state $73,90,112$

Oxidation-reduction 3

Oxides $35,42,44,49,70,88,111,112,126,145$, 147,148

Oxygen isotopes 42,72

Paleohydrology 110

Particle Acceleration 39

Permeability 4, 29, 40, 41, 42, 45, 56, 57, 93, 97, $104,109,110,119,120,127,130,143,144$, $149,153,154,156,157,161,164,169,176$, 177,186
Petroleum 4, 5, 33, 53, 57, 64, 75, 93, 109, 134, $145,162,180$

Phase dissolution 58

Plasma instabilities 38

Pore geometry 96,130

Poroelasticity 29, 176

Porous media 86, 104, 119, 128, 129, 186

Precipitation 3, 28, 29, 41, 42, 44, 55, 67, 68, 97, $106,116,134,137,139,148,151,167,170$, $184,185,186,187,188$

Pressure solution 109

Pyrite $42,158,159,181$

Pyrolysis 166, 180, 181

Q-domain 8, 19

Quartz 3, 24, 28, 41, 46, 54, 55, 67, 70, 71, 109, $112,144,162,171,174,175,186,187$

Radiogenic heat production 162

Radioisotopes 89, 160

Radiometric dating 131

Rare gases 20,100

Reactive fluid flow 186

Reduction 3, 4, 15, 34, 39, 42, 43, 57, 69, 75, 90, $95,99,112,127,130,154,180,181$

Reflection 11,34, 108, 156

Refraction 34, 153, 156

Relative permeability 18,156

Reservoir characterization $8,29,163$

Resonance $14,36,52,81,99,160$

Rheology 86, 109, 123, 151, 161

Rivers $17,73,89$

Robust methods 178

Rock fracture 23, 97

Rock mechanics 124

Rock physics 30

Rock salt 161

Rock-fluid interactions 134

Rupture belt 141

San Andreas Fault 14, 87, 118, 136

San Joaquin Basin 20, 21, 85, 100, 110

Saturation $10,28,47,56,57,93,156,186$

Scanning loops 10

Sedimentary basins $17,20,40,42,43,45,46$, $67,75,86,100,109,110,122,123,125,134$, 182,186

Sedimentary rocks 42, 134, 139, 145, 149, 166 
Sediments $5,6,13,15,67,85,89,90,121,134$, $148,161,180,181,182$

Seismic absorption 96

Seismic anisotropy 31

Seismic reflection 11, 108

Seismology $11,87,108,124,125$

Selenium 13, 15, 114

Self-diffusion $54,71,73,77,91,92$

Self-organization $69,95,109$

Shale $161,162,181$

Shear localization $23,52,132$

Shear strain localization 53, 132

Silicate glass 72,140

Silicate melts $26,72,73,86,91,99$

SIMS 67,70

Solar flares 39,63

Solar prominences 63

Solubility $41,44,45,77,78,99,122,139,143$, $144,148,180$

Solution properties 25

Sonic logging 120,153

Sorption 45, 49, 55, 107, 112, 147, 148, 158

Space plasmas 38

Spectroscopy $5,6,13,14,21,35,65,72,89,90$, $100,112,114,117,137,148,158,180$

Stable isotopes $41,42,43,54,88$

Stochastic models 169,170

Substorms 39, 63

Sulfide minerals $42,114,116$

Sulfonates $5,6,181$

Surface analysis 137

Surface chemistry $47,80,114,137,158$

Surface complex 50,111, 147, 148

Surface protonation 111

Surface reactivity 48,158

Surface speciation $45,49,111$

Synchrotron radiation $3,89,90$

Synchrotron radiation beamlines 89

Teleseisms 34

TEM 8, 19, 68, 70, 71

Temperature-programmed reduction 180

Thermal conductivity 162

Thermal diffusion $77,99,143$

Thermochemical properties 77, 99, 139

Thermochronometry 82

Thermodynamics $13,25,140$
Thiosulfate 5,115

Transmission electron microscopy 54, 112, 174

Transport 3, 10, 12, 15, 16, 17, 21, 25, 26, 27, $38,40,44,45,46,48,52,57,58,67,70,71$, $73,75,77,84,85,86,88,93,94,99,100$, $104,109,110,112,122,123,125,128,143$, $144,151,152,156,161,162,177,186,188$

Two-phase flow 52, 57, 58, 93

Upscaling 56, 57, 127

Uranium 18, 26, 27, 36, 84, 126, 131

Uranium Oxide 126

Valles Caldera 34

Velocity tomogram 163

Viscous fingering 57,93

Volcanic 12, 28, 34, 37, 69, 72, 95, 139, 167, 175

Volcanoes 72,88

Water $3,12,14,15,16,21,24,25,26,27,42$, $43,44,46,47,48,49,50,65,70,71,72,75$, $77,78,80,81,84,88,100,102,103,104$, $107,109,111,116,117,125,137,139,144$, $145,147,154,156,158,160,161,162,175$, $177,182,183,185,186,187,188$

Water chemistry 162

Wave propagation $10,36,133$

Wavefield $8,19,33,119,163$

Waves $10,11,33,36,87,96,120,133,153$

Weathering $28,45,55,111,138,174,185,187$, 188

Western North America 98

Wet events 98

X-ray absorption spectroscopy $6,90,180$

$\mathrm{X}$-ray photoelectron spectroscopy $35,65,112$, 114,137

$\mathrm{X}$-ray scattering 3

XANES spectroscopy 5,6

XPS 35, 112, 114, 137, 138, 147

Zeolites 139, 140, 187

Zeta potential 115 


\section{INDEX OF TECHNICAL CONTRIBUTOR}

CONTRIBUTOR

Akasofu, S.-I.

Aki, K.

Amonette, J.E.

Anovitz, L.M.

Appleton, B.R.

Aydin, A.

Baer, D.R.

Bahr, J.M.

Baldridge, W.S

Ballentine, C.J.

Banfield, J.F.

Barnes, H.L.

Becker, A.

Bedzyk, M.J.

Bell, D.R.

Benezeth, P.

Benson, S.M.

Berge, P.A

Berner, R.A.

Berryman, J.G.

Birn, J.

Blair, S.C

Bleistein, N.

Blencoe, J.G.

Bodnar, R.J.

Boles, J.R.

Booker, J.

Bourcier, W.L

Boyd, F.R.

Brady, P.V.

Brantley, S.L

Broecker, W.S.

\section{ORGANIZATION}

University of Alaska 63

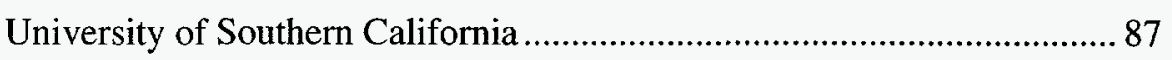

Pacific Northwest National Laboratory .............................................. 47

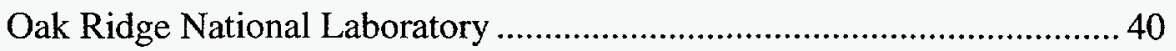

Oak Ridge National Laboratory .............................................................. 40

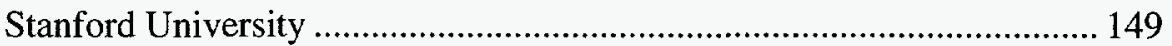

Pacific Northwest National Laboratory …............................................. 47

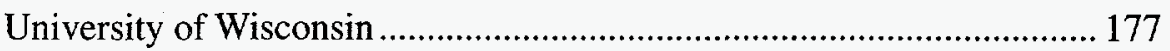

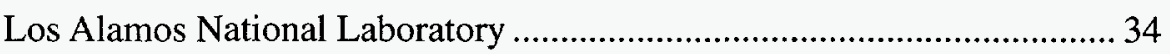

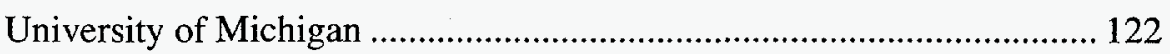

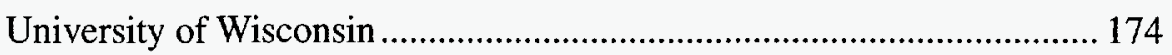

Pennsylvania State University ........................................................... 139

Lawrence Berkeley National Laboratory ............................................. 8

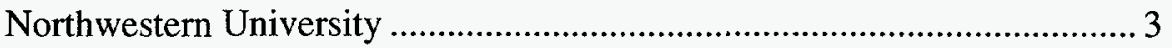

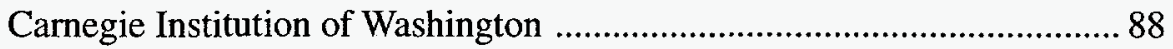

Oak Ridge National Laboratory 41,44

Lawrence Berkeley National Laboratory $8,12,16,19$

Lawrence Livermore National Laboratory ...................................... 29, 30

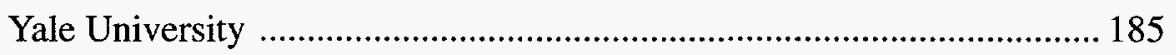

Lawrence Livermore National Laboratory ...................................29, 30

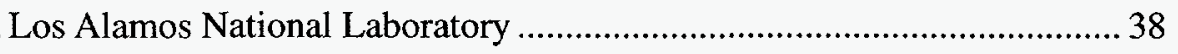

Lawrence Livermore National Laboratory ................................................ 23

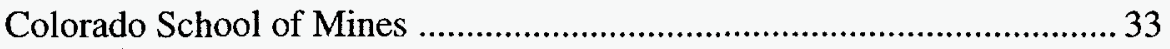

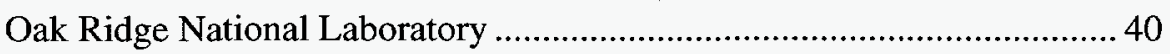

Virginia Polytechnic Institute and State University ............................... 171

University of California, Santa Barbara ..................................... 85, 110

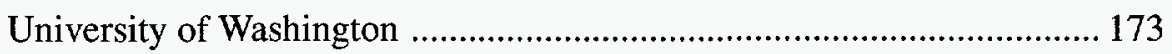

Lawrence Livermore National Laboratory ............................................... 28

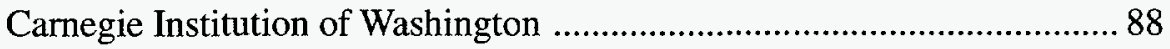

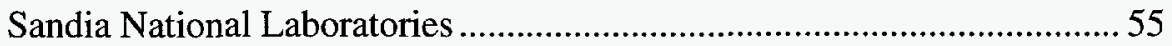

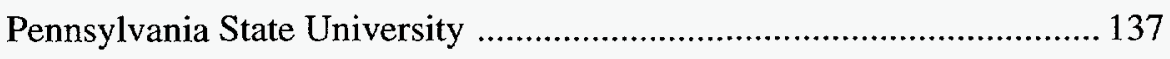

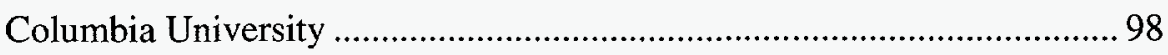


Brown, S.R.

Sandia National Laboratories.

Burnham, A.K.

.. Lawrence Livermore National Laboratory ............................................. 31

Buseck, P.R. Arizona State University 68

Carroll, S.A.

Lawrence Livermore National Laboratory 28

Carter, N.L.

Texas A\&M University 161

Casey, W.H.

University of California, Davis $78,79,80,81$

Chave, A.D.

Woods Hole Oceanographic Institution 178

Cheney, M.A. Rutgers University 13

Cheng, C.H.A.

Massachusetts Institute of Technology 37,120

Chiarello, R.P.

Northwestern University 3

Cole, D.R.

Oak Ridge National Laboratory . $41,42,43,45$

Cook, N.G.W.

Lawrence Berkeley National Laboratory $9,10,18,52$

Cygan, R.T. Sandia National Laboratories . 54,55

Davin, E.M. American Geological Institute 64

DePaolo, D.J.

Lawrence Berkeley National Laboratory 12

Dove, P.M.

Georgia Institute of Technology 106

Duba, A.G.

. Lawrence Livermore National Laboratory $24,35,65$

Egbert, G.D. Oregon State University 136

Eggleston, C.M. University of Wyoming. $28, \quad 184$

Eglinton, T.I. Woods Hole Oceanographic Institution 6,180

Elata, D. Lawrence Livermore National Laboratory 29,30

Elmore, R.D.

University of Oklahoma 134

Engel, M.H.

University of Oklahoma 134

Epstein, J,

Idaho National Engineering Laboratory 7

Epstein, S. California Institute of Technology 72

Evans, J.P. Utah State University $19, \quad 169$

Ewing, R.C. University of New Mexico 126

Farver, J.R. Brown University . 70

Fehler, M.

Los Alamos National Laboratory 33,34

Felmy, A.R. Pacific Northwest National Laboratory 47,49

Fisler, D.K. Sandia National Laboratories 54

Fowler, J. Incorporated Research Institutions of Seismology (IRIS) 108

Fredrich, J.T. Sandia National Laboratories

$.51,130$

Fukui, L.M.

U.S. Department of Energy Core and Sample Repository 165

Garven, G. The John Hopkins University 85,110 
Gary, S.P.

Los Alamos National Laboratory

$\mathrm{Ge}, \mathrm{S}$.

University of Colorado

Getting, I.

University of Colorado

Glass, R.J.

Sandia National Laboratories

$57,58,93,104$

Goldstein, S.J

Los Alamos National Laboratory 36

Guyer, R.A.

. University of Massachusetts .35

Hacker, B.R.

Stanford University 151

Hall, C.M.

University of Michigan

Halliday, A.N.

University of Michigan

Hanson, G.N.

State University of New York at Stony Brook

Hardage, B.A.

The University of Texas

Harris, J.M.

Stanford University

153

Harrison, T.M.

University of California, Los Angeles

Helgeson, H.C.

University of California, Berkeley 75

Hervig, R.L. Arizona State University 67

Hess, A.C.

Pacific Northwest National Laboratory .48

Hestir, K

Utah State University

$19, \quad 169$

Holcomb, D.J.

Sandia National Laboratories

.53

Horita, J.

Oak Ridge National Laboratory 41,43

Hulen, J.B.

University of Utah

Ilton, E.S

Lehigh University

$112, \quad 114$

Jacobsen, J.

Lawrence Berkeley National Laboratory

19,169

Janecky, D

Los Alamos National Laboratory

36

Johnson, A.M.

Purdue University 141

Johnson, L.R.

Lawrence Berkeley National Laboratory

11

Johnson, M.C.

Columbia University .99

Johnson, P.A.

Los Alamos National Laboratory 35

Johnson, T.M.

Lawrence Berkeley National Laboratory

.21

Jones, K.W.

Brookhaven National Laboratory

Kennedy, B.M.

Lawrence Berkeley National Laboratory

$12,14,20,100$

Klein, W.

Boston University

69,95

Knauss, K.G.

Lawrence Livermore National Laboratory

28,184

Koplik, J.

The City College of the City University of New York 128

Kronenberg, A.K. Texas A\&M University 161

Labotka, T.C. University of Tennessee 160

LaFemina, J.P.

Pacific Northwest National Laboratory 
Larner, $\mathrm{K}$ Colorado School of Mines 30

Lasaga, A.C.

Yale University

Lee, K.H.

Lawrence Berkeley National Laboratory

8,18

Lee, L.C.

University of Alaska 63

Lesher, C.E.

University of California, Davis .77

Lindquist, W.B.

State University of New York at Stony Brook

4,129

Liou, J.G.

Stanford University 151

Long, J.C.S.

Lawrence Berkeley National Laboratory

19, 169

Mackie, $R$.

Indiana University 118

Madden, $\mathrm{T}$.

Massachusetts Institute of Technology 118

Majer, E.L.

Lawrence Berkeley National Laboratory 11

Mango, F.D.

Rice University 145

Manowitz, B.

Brookhaven National Laboratory 5,6

Martel, S. University of Hawaii 19, 169

Mathez, E.A.

American Museum of Natural History $24,35,65$

McCarthy, M.I.

Pacific Northwest National Laboratory .48

McEvilly, T.V

Lawrence Berkeley National Laboratory 11

McKay, L.D.

University of Tennessee 160

McKeegan, K.D.

University of California, Los Angeles .

$.27,84$

McMechan, G.A.

The University of Texas at Dallas 164

Mesmer, R.E.

Oak Ridge National Laboratory .44

Meyers, W.J.

State University of New York at Stony Brook 131

Miller, D.G.

Lawrence Livermore National Laboratory 25

Miller, M.L.

University of New Mexico 126

Morrison, H.F.

Lawrence Berkeley National Laboratory 8

Moses, C.O. Lehigh University 114

Muir, F. Stanford University 30

Murrell, M.T.

Los Alamos National Laboratory 36

Myer, L.R.

. Lawrence Berkeley National Laboratory $9,10,18,23,52$

Nagy, K.L. . Sandia National Laboratories . .55

Navrotsky, A.

Princeton University 140

Nicholl, M.J.

Oklahoma State University $.57,93$

Nihei, K.T.

Lawrence Berkeley National Laboratory

9,10

Nur, A. Stanford University 156

Olsson, W.A.

Sandia National Laboratories. .53

Ortoleva, P. Indiana University 109 
Pantano, C.G.

Pennsylvania State University 137

Parks, G.A. Stanford University . 147

Phillips, B. University of California, Davis . .80

Pitzer, K.S. Lawrence Berkeley National Laboratory 16

Pollard, D.D. Stanford University 149

Poths, J.

Los Alamos National Laboratory 37

Pyrak-Nolte, L.J. University of Notre Dame

Rajaram, $\mathrm{H}$. University of Colorado, Boulder

.57, 93

Rard, J.A.

Lawrence Livermore National Laboratory .25

Reeves, G.D. Los Alamos National Laboratory 39

Richter, F.M. The University of Chicago .91

Riciputi, L.R. Oak Ridge National Laboratory $42, \quad 45$

Ripperdan, R.L. Oak Ridge National Laboratory .42

Rivers, M.L. The University of Chicago 89

Rock, P.A.

University of California, Davis . .78

Rudnicki, J.W.

Northwestern University 132

Rumble, D. Carnegie Institution of Washington .88

Rundle, J.B. University of Colorado 69,95

Russell, J.E. Texas A\&M University 161

Rustad, J.R. Pacific Northwest National Laboratory 49

Rye, D.M. Yale University 186

Ryerson, F.J.

Lawrence Livermore National Laboratory $23,25,26,27,29,84$

Schiffries, C.M. National Academy of Sciences/National Research Council 124

Schoonen, M.A.A. State University of New York at Stony Brook 158

Segall, $\mathrm{P}$. Stanford University 154

Seitz, J.C. Oak Ridge National Laboratory 40

Shankland, T.J. Los Alamos National Laboratory $24,35,65$

Sharp, Jr., J.M. The University of Texas 162

Shaw, H.F. Lawrence Livermore National Laboratory 26

Sherwood-Lollar, B. University of Toronto 122

Shock, E.L. Washington University 102,172

Simmons, Jr., J.L. The University of Texas 163

Simpson, D. Incorporated Research Institutions of Seismology (IRIS) 108

Soegaard, K. The University of Texas at Dallas . 164

Sorensen, L.B. University of Washington 3

Spera, F.J.

University of California, Santa Barbara. 86 
Spetzler, $H$.

University of Colorado

96, 97

Sposito, G.

Lawrence Berkeley National Laboratory 13

Steffler, E.

Idaho National Engineering Laboratory 7

Stockman, H.W.

Sandia National Laboratories 58,104

Stolper, E.

California Institute of Technology .72

Strongin, D.R

Temple University .158

Sturchio, N.C.

. Argonne National Laboratory 3

Sutton, S.R.

The University of Chicago

89,90

Sverjensky, D.A.

The John Hopkins University 111

Thonnard, N.

University of Tennessee 160

Tidwell, V.C.

Sandia National Laboratories 56, 127

Toksoz, M.N.

Massachusetts Institute of Technology $33,119,120$

Tokunaga, T.K.

Lawrence Berkeley National Laboratory

Torgersen, $\mathrm{T}$.

The University of Connecticut

20,100

Tossell, J.A.

University of Maryland 116

Tripp, A.C.

University of Utah 168

Tsang, C.-F.

Lawrence Berkeley National Laboratory 16

Tsvankin, I.

Colorado School of Mines 30

Tyler, S.W. . Desert Research Institute 58,104

Unsworth, $M$. University of Washington 173

Vairavamurthy, M.A.

Brookhaven National Laboratory 5,6

Valley, J.W.

University of Wisconsin 175

Veblen, D.R.

. The John Hopkins University

Walck, M.C

Sandia National Laboratories $.51,54,56$

Columbia University 99

Walker, D.

. Lawrence Berkeley National Laboratory .22

Wan, J.

University of Wisconsin 176

Wang, H.F.

California Institute of Technology

Watson, E.B.

Rensselaer Polytechnic Institute 143

Wawersik, W.R.

Sandia National Laboratories

.53

Wesolowski, D.J.

Oak Ridge National Laboratory

$41,43,44$

Westrich, H.R.

Sandia National Laboratories

54,55

Woods Hole Oceanographic Institution 182

Pennsylvania State University

Arizona State University

New Mexico Institute of Mining and Technology

56,127 
Wong, T.-F.

State University of New York at Stony Brook

51,130

Wood, R.H.

University of Delaware

$102, \quad 172$

Wu, R.-S.

University of California, Santa Cruz

$\mathrm{Xu}, \mathrm{H}$. Arizona State University 68

Yang, G. Lawrence Berkeley National Laboratory $10,18,52$

Yuen, D.A. . University of Minnesota, Twin Cities 123

Yund, R.A. Brown University 


\section{GEOSCIENCES RESEARCH PROGRAM \\ Division of Engineering and Geosciences \\ Office of Basic Energy Sciences \\ Office of Energy Research \\ U.S. Department of Energy}

\begin{tabular}{|c|c|c|c|c|c|}
\hline ON-SITE INSTITUTION & FY 92 & FY 93 & FY 94 & FY 95 & FY 96 \\
\hline Argonne National Laboratory & 440 & 540 & 533 & 655 & 600 \\
\hline Brookhaven National Laboratory & 213 & 384 & 363 & 460 & 528 \\
\hline Idaho National Laboratory & 35 & 50 & 121 & 119 & 65 \\
\hline Los Alamos National Laboratory & 2730 & 2622 & 1881 & 2241 & 1960 \\
\hline Lawrence Berkeley National Laboratory & 2225 & 2340 & 2253 & 1875 & 2197 \\
\hline Lawrence Livermore National Laboratory & 2288 & 2025 & 1743 & 1921 & 1940 \\
\hline Oak Ridge National Laboratory & 1209 & 1041 & 1163 & 1140 & 1251 \\
\hline Pacific Northwest Laboratory & 780 & 975 & 664 & 665 & 684 \\
\hline Sandia National Laboratory & 2098 & 1987 & 1545 & 1345 & 1616 \\
\hline Westinghouse Hanford Laboratory & 46 & 45 & -- & - & -- \\
\hline Grand Junction Project Office & -- & 87 & 87 & -- & -- \\
\hline & ----- & ------ & -.--- & --.--- & -.--- \\
\hline total, on-site & 12064 & 12096 & 10353 & 10442 & 10865 \\
\hline total, off-site & 7114 & 7250 & 8477 & 7937 & 8815 \\
\hline total, operating & 19178 & 19346 & 18830 & 18379 & 19680 \\
\hline total, equipment & 1302 & 1270 & 1262 & 1141 & 1258 \\
\hline Total GEOSCIENCES & $\underline{20480}$ & $\underline{20616}$ & $\underline{20092}$ & $\underline{19520}$ & 20938 \\
\hline \multicolumn{6}{|l|}{ OFF-SITE INSTITUTION } \\
\hline U/Alaska (Lee) & 125 & 151 & -- & 49 & 98 \\
\hline U/Alaska (Eichelberger) & 149 & 120 & 112 & -- & -- \\
\hline Am. Geolog. Inst. (Davin) & -- & -- & 36 & 40 & 42 \\
\hline AM. Muus. NY (Mathez) & 49 & 39 & 37 & 72 & 69 \\
\hline Arizona St. (Buseck) & -- & -- & -- & 126 & 132 \\
\hline Arizona St. (Hervig) & -- & -- & 62 & 86 & 59 \\
\hline Boston Univ. (Klein) & -- & -- & -- & 71 & 74 \\
\hline Brown U (Yund) & 141 & 146 & 302 & -- & 152 \\
\hline Cal Tech (Clayton) & -- & 139 & 142 & 55 & -- \\
\hline Cal Tech. (Stolper) & 90 & 150 & 153 & 123 & 140 \\
\hline Cal Tech. (Wasserburg) & 345 & 370 & 388 & 400 & 400 \\
\hline Calif, Univ. of Berk (Caramichael) & 109 & 105 & -- & -- & -- \\
\hline Calif, Univ. of Berk (Helgeson) & 140 & 150 & 349 & -- & 185 \\
\hline Calif, Univ. of Berk (Morrison) & 68 & -- & -- & -- & -- \\
\hline Calif. Univ. of Davis (Casey) & -- & -- & -- & -- & 110 \\
\hline Calif, Univ. of Davis (Lesher) & 65 & 65 & 66 & 75 & -- \\
\hline Calif, Univ. of Davis (Rock) & 83 & 77 & 78 & -- & 151 \\
\hline Calif, Univ. of LA (Harrison) & 57 & -- & 100 & 105 & 111 \\
\hline Calif, Univ. of LA (McKeegan) & -- & 40 & 85 & -- & 44 \\
\hline Calif. Univ. of SB (Boles) & -- & -- & -- & -- & 20 \\
\hline
\end{tabular}




\section{GEOSCIENCES RESEARCH PROGRAM \\ Division of Engineering and Geosciences \\ Office of Basic Energy Sciences \\ Office of Energy Research \\ U.S. Department of Energy}

\begin{tabular}{|c|c|c|c|c|c|}
\hline OFF-SITE INSTITUTION & FY 92 & FY 93 & FY 94 & FY 95 & FY 96 \\
\hline Calif. Univ. of SB (Spera) & -- & 43 & -- & 82 & 75 \\
\hline Chicago, Univ. of (Richter) & -- & -- & 247 & -- & -- \\
\hline Chicago, Univ. of (Rivers) & -- & -- & 458 & -- & 341 \\
\hline Chicago, Univ. of (Smith/Sutton) & 105 & 126 & 127 & 138 & 159 \\
\hline Colo, Univ. of (Ge) & -- & - & -- & 179 & 13 \\
\hline Colo, Univ. of (Rajaram) & -- & 79 & & & \\
\hline Colo, Univ. of (Rundle) & -- & -- & -- & 109 & 114 \\
\hline Colo, Univ. of (Smyth) & 93 & 81 & 10 & -- & -- \\
\hline Colo, Univ. of (Spetzler) & 64 & 57 & 145 & 126 & 132 \\
\hline Colo Sch Mines (Larner) & -- & -- & 97 & -- & -- \\
\hline Columbia Univ. (Broecker) & -- & -- & -- & 131 & 137 \\
\hline Columbia Univ. (Walker) & 77 & 110 & 103 & 113 & -- \\
\hline Conn. Univ. of (Torgersen) & 110 & 31 & 19 & 76 & 65 \\
\hline Delaware, Univ. of (Wood) & 176 & -- & 90 & 108 & 109 \\
\hline Desert Res. Inst. (Tyler) & -- & -- & -- & -- & 80 \\
\hline DOSECC (Friedman) & 71 & -- & -- & -- & -- \\
\hline Florida, So. Univ of (Compton) & 122 & -- & 56 & -- & -- \\
\hline Florida St., Univ. of (SCC) & -- & 99 & 214 & -- & -- \\
\hline Geophys. Lab, CIW (Bell) & -- & 92 & 89 & 92 & -- \\
\hline Georgia Tech (Dove) & -- & -- & -- & 91 & 91 \\
\hline Hawaii, Univ. of (Martel) & -- & -- & -- & 81 & 79 \\
\hline Headquarters Services & 5 & 5 & 1 & -- & -- \\
\hline I.R.I.S. (Simpson) & -- & -- & -- & 211 & 211 \\
\hline Indiana, Univ. of (Ortoleva) & 85 & 63 & -- & 100 & 102 \\
\hline John Hopkins Univ. (Garven) & -- & -- & -- & -- & 67 \\
\hline John Hopkins Univ. (Sverjenski) & -- & -- & -- & -- & 118 \\
\hline John Hopkins Univ. (Veblen) & 134 & 138 & -- & 156 & 156 \\
\hline JPL, IAU Coloq (Tobiska) & -- & 3 & -- & -- & -- \\
\hline Lehigh Univ. (Ilton) & -- & -- & -- & 44 & 44 \\
\hline Lehigh Univ. (Moses) & -- & 223 & -- & -- & 123 \\
\hline Maryland, Univ. of (Tossell) & -- & -- & 35 & -- & 28 \\
\hline Miami, Univ. of (Eberli) & 127 & 155 & 169 & 155 & -- \\
\hline Michigan, Univ. of (Ballentine) & -- & -- & -- & -- & 69 \\
\hline Michigan, Univ. of (Halliday) & -- & -- & 147 & 172 & 207 \\
\hline Min. Soc. Amer (Gutherie) & -- & 5 & -- & -- & -- \\
\hline Minn. Univ of (Yuen) & -- & 47 & -- & 82 & 78 \\
\hline MIT (Madden) & -- & -- & 70 & 74 & -- \\
\hline MIT (Toksoz) & 372 & 342 & 374 & 367 & -- \\
\hline NASA (Blankston) & -- & -- & 100 & -- & 113 \\
\hline NAS/NRC (Benson/Crowley) & -- & -- & 10 & -- & -- \\
\hline NAS/NRC (Hart/Long/Burke) & -- & 100 & -- & -- & -- \\
\hline NAS/NRC (Phillips) & -- & -- & 121 & -- & -- \\
\hline
\end{tabular}


GEOSCIENCES RESEARCH PROGRAM

Division of Engineering and Geosciences

Office of Basic Energy Sciences

Office of Energy Research

U.S. Department of Energy

\begin{tabular}{|c|c|c|c|c|c|}
\hline OFF-SITE INSTITUTION & FY 92 & FY 93 & FY 94 & FY 95 & FY 96 \\
\hline NAS/NRC (Price) & -- & -- & 100 & 100 & 100 \\
\hline Nevada, Univ. of (Karlin) & 48 & -- & -. & -- & .- \\
\hline New Mexico Inst. Min. Tech. (Wilson) & -- & -- & .. & -- & 30 \\
\hline New Mexico, Univ. of (Crossey) & 43 & 43 & -- & -- & -- \\
\hline New Mexico, Univ. of (Miller) & -- & -- & -- & 100 & 100 \\
\hline NY, City Univ. of CC (Koplik) & -- & 125 & 121 & 125 & 98 \\
\hline NY, City Univ. of Q (C. Schreiber) & 126 & 92 & -- & -. & - \\
\hline NY, State Univ. of SB (Hanson) & 128 & - & 121 & 126 & 131 \\
\hline NY, State Univ. of SB (Lindquist) & 21 & 22 & 22 & 33 & 33 \\
\hline NY, State Univ. of SB (Schoonen) & -- & -- & -- & -- & 48 \\
\hline NY, State Univ. of SB (Wong) & -- & -- & 69 & 70 & 71 \\
\hline Northwestern Univ. (Devaney) & -- & 145 & -- & - & - \\
\hline Northwestern Univ. (Rudnicki) & -- & 75 & 72 & 85 & -- \\
\hline Notre Dame Univ (Pyrak-Nolte) & - & 61 & 61 & 65 & 78 \\
\hline Ohio St. Univ (Adler) & 59 & 62 & 161 & -- & 43 \\
\hline Okla, Univ. of (Elmore) & 112 & 247 & -- & 112 & 158 \\
\hline Oregon St. Univ (Egbert) & 111 & -- & -- & -- & 41 \\
\hline Penn St. Univ (Arthur) & 129 & 134 & -- & -- & -. \\
\hline Penn St. Univ. (Barnes) & -- & -- & -- & -- & 81 \\
\hline Penn St. Univ. (Brantley) & - & -- & -- & 115 & 117 \\
\hline Penn St. Univ. (Brantley) conf. & -- & -- & -- & -- & 10 \\
\hline Princeton Univ (Navrotsky) & 130 & 198 & 145 & 150 & 150 \\
\hline Purdue Univ. (Fritz) & 47 & -- & -- & -- & -- \\
\hline Purdue Univ. of (Johnson) & -- & 170 & -- & -- & -- \\
\hline Renesselaer Polytech. Inst. (Watson) & -- & -- & 144 & 140 & 146 \\
\hline Rice Univ. (Mango) & 127 & 100 & 97 & 136 & 105 \\
\hline Rust Geotech, Inc. (Fukui) & -- & - & -- & 87 & 87 \\
\hline San Diego St. Univ. (Jiracek) & 10 & -- & -- & -- & -- \\
\hline Santa Fe Inst. (Rundle) & -- & -- & 11 & -- & -- \\
\hline Calif. Univ. of So (Aki) & 160 & 160 & 155 & -- & 112 \\
\hline Stanford Univ. (Brown) & -- & 241 & 204 & 210 & -- \\
\hline Stanford Univ. (Ernst) & 158 & -- & -- & -- & -- \\
\hline Stanford Univ. (Harris) & -- & -- & -- & 115 & 120 \\
\hline Stanford Univ. (Liou) & -- & 160 & -- & 80 & - \\
\hline Stanford Univ. (Nur) & 176 & -- & 173 & 185 & 193 \\
\hline Standard Univ. (Pollard) & 159 & -- & 210 & 224 & 232 \\
\hline Stanford Univ. (Segall) & 70 & 87 & 83 & 83 & -- \\
\hline Stanford Univ. (Zoback) & -- & -- & 72 & 38 & -- \\
\hline Temple Univ. (Strongin) & -- & -. & -- & -- & 76 \\
\hline Tennessee Univ. of (Thonnard) & -- & -- & -- & 100 & 82 \\
\hline Texas, Univ. of (Hardage) & -- & -- & -- & 170 & 175 \\
\hline Texas, Univ of (Land) & 100 & 104 & 104 & -- & -- \\
\hline
\end{tabular}




\section{GEOSCIENCES RESEARCH PROGRAM \\ Division of Engineering and Geosciences \\ Office of Basic Energy Sciences \\ Office of Energy Research \\ U.S. Department of Energy}

\begin{tabular}{|c|c|c|c|c|c|}
\hline OFF-SITE INSTITUTION & FY 92 & FY 93 & FY 94 & FY 95 & FY 96 \\
\hline Texas, Univ of (Nelson) & -- & -- & 5 & - & $\ldots$ \\
\hline Texas, Univ of (Sharp) & 98 & -- & 48 & -- & - \\
\hline Texas, Univ of Dallas (McMechan) & -- & -- & -- & - & 164 \\
\hline Texas, Univ of Dallas (Mitterer) & 114 & 0 & 0 & - & - \\
\hline Texas, A\&M Univ. (Kronenberg) & 149 & 155 & 156 & 167 & - \\
\hline Tulsa, Univ. of (Barker) & 205 & -- & -- & -- & - \\
\hline USGS (Bredehoeft) & -- & 29 & 30 & - & -- \\
\hline USGS (Dean) & 99 & -- & -- & -- & -- \\
\hline USGS (Kharaka) & 18 & -- & -- & -- & - \\
\hline USGS (Russ) & 56 & -- & 126 & -- & - \\
\hline Utah, Univ. of (Hulen) & -- & 204 & -- & -- & - \\
\hline Utah, Univ. of (Tripp) & -- & 57 & 59 & 64 & 55 \\
\hline Utah, Univ of (Wannamaker) & 75 & -- & -. & -- & - \\
\hline Utah St. (Hestir) & -- & -- & -- & 99 & 160 \\
\hline VPI \& SU (Bodnar) & 127 & 129 & 133 & 104 & 100 \\
\hline VPI \& SU (Sinha) & 63 & 28 & -- & -- & -- \\
\hline Washington, Univ. of (Booker) & 101 & 104 & 247 & -- & 116 \\
\hline Washington St. Univ.-R (Reidel) & 48 & 49 & 5 & -- & -- \\
\hline Washington Univ, St. Louis (Shock) & 46 & -- & 24 & 53 & 75 \\
\hline Wisconsin, Univ of (Bahr) & -- & -- & 46 & 49 & -- \\
\hline Wisconsin, Univ of (Banfield) & -- & 76 & 98 & -- & 104 \\
\hline Wisconsin, Univ of (Haimson) & -- & 10 & 10 & -- & -- \\
\hline Wisconsin, Univ. of (Valley) & -- & 144 & 142 & 149 & -- \\
\hline Wisconsin, Univ of (Wang) & 99 & 105 & -- & 60 & - \\
\hline WHOI (Chave) & -- & -- & 91 & 91 & 55 \\
\hline WHOI (Eglinton) & 99 & 82 & 275 & -- & 135 \\
\hline WHOI (Whelan) & 199 & 180 & 180 & 191 & 195 \\
\hline Wyoming, Univ. of (Eggleston) & -- & -- & -- & -- & 81 \\
\hline Yale Univ. (Berner) & -- & -- & -- & 78 & 91 \\
\hline Yale Univ. (Lasaga) & 113 & 385 & -- & 207 & 290 \\
\hline Other & -- & 5 & 85 & 87 & 90 \\
\hline OFF-SITE TOTALS & 7114 & 7250 & 8477 & 7937 & 8815 \\
\hline
\end{tabular}

